\title{
Visualização da evolução temporal de coleções de artigos científicos
}



SERVIÇO DE PÓS-GRADUAÇÃO DO ICMC-USP

Data de Depósito:

Assinatura:

\title{
Visualização da evolução temporal de coleções de artigos científicos
}

\author{
Aretha Barbosa Alencar
}

Orientadora: Profa. Dra. Maria Cristina Ferreira de Oliveira

Tese apresentada ao Instituto de Ciências Matemáticas e de Computação - ICMC-USP, como parte dos requisitos para obtenção do título de Doutor em Ciências - Ciências de Computação e Matemática Computacional. VERSÃO REVISADA

USP - São Carlos

Março de 2013 
Ficha catalográfica elaborada pela Biblioteca Prof. Achille Bassi e Seção Técnica de Informática, ICMC/USP, com os dados fornecidos pelo(a) autor(a)

Alencar, Aretha Barbosa

Visualização da evolução temporal de coleções de artigos científicos / Aretha Barbosa Alencar; orientadora Maria Cristina Ferreira de Oliveira. -São Carlos, 2013. $159 \mathrm{p}$.

Tese (Doutorado - Programa de Pós-Graduação em Ciências de Computação e Matemática Computacional) -Instituto de Ciências Matemáticas e de Computação, Universidade de São Paulo, 2013.

1. projeção multidimensional dinâmica. 2. evolução temporal de tópicos. 3. extração de tópicos. I. Oliveira, Maria Cristina Ferreira de, orient. II. Título. 
Dedico esta tese aos meus amores: meus pais, Silmar e Maria; minha irmã, Silmara; e ao amor da minha vida, Marco Aurélio. 



\section{Agradecimentos}

À Deus por todas as horas em que esteve presente, mesmo eu nem sempre estando ciente.

À Prof a . Maria Cristina F. de Oliveira, pela excelente orientação fornecida, pelo incentivo, apoio e parceria na realização desta tese. Uma das melhores orientadores que alguém pode ter.

À Profa . Katy Börner, que me recebeu na Universidade de Indiana em Bloomington, Estados Unidos, para meu estágio de doutorado junto ao seu centro de pesquisa Cyberinfrastructure for Network Science Center (CNS). Também gostaria de agradecer a todos os funcionários e alunos do CNS pelo seu apoio.

Ao Prof. Fernando V. Paulovich pelas orientações adicionais, disponibilidade e constante incentivo em minha pesquisa. Também gostaria de agradecer aos demais professores do grupo de pesquisa de Visualização, Imagens e Computação Gráfica (VICG), que evoluiu a largos passos nos últimos anos. Agradeço também à todos os alunos do laboratório.

Aos meus pais, Silmar e Maria, pelo grande exemplo e apoio constante ao longo desses anos de estudo. Agradeço também a minha irmã Silmara que sempre me apoiou e torceu por $\operatorname{mim}$.

À todos os amigos que fiz aqui em São Carlos, que estiveram presentes em uma das fases mais importantes da minha vida e tornaram minha vida mais feliz.

À todos os funcionários do Instituto de Ciências Matemáticas e Computação (ICMC) pela competência e suporte em todas as etapas. Em especial, as funcionárias da Secretaria de Pós-Graduação, sempre prestativas.

À Fundação de Amparo à Pesquisa do Estado de São Paulo (FAPESP) pela concessão da bolsa de doutorado (processo 2008/00848-1) e pelo apoio financeiro para a realização desta pesquisa. Agradeço também a Coordenação de Aperfeiçoamento de Pessoal de Nível Superior (CAPES) pela concessão da bolsa de doutorado sanduíche (processo 1271-10-5) que me permitiu realizar um estágio com orientação da Prof ${ }^{a}$. Katy Börner.

Por último, mas não menos importante, ao meu noivo Marco Aurélio, que conheci durante nossos anos de estudo no ICMC, que sempre me apoiou em todos os momentos difíceis e felizes, e, com certeza, é um amor pra vida toda. 


\section{Sumário}

1 Introdução 1

1.1 Motivação . . . . . . . . . . . . . . . . . . . . . . . . . . . 2

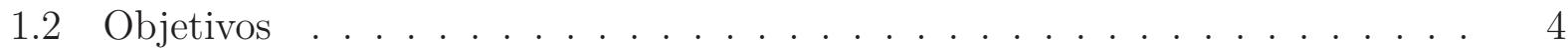

1.3 Terminologia . . . . . . . . . . . . . . . . . . 5

1.4 Organização do Texto . . . . . . . . . . . . . . . . . 5

2 Pré-Processamento e Representação de Coleções de Documentos $\quad 7$

2.1 Pré-processamento: Extração e Limpeza de Termos . . . . . . . . . . . . . . 8

2.1.1 Tokenização . . . . . . . . . . . . . . . . . . 8

2.1.2 Remoção de Stopwords . . . . . . . . . . . . . . . . . 9 9

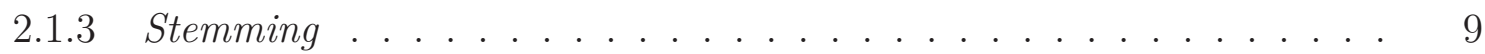

2.1.4 Lei de Zipf e Corte de Luhn . . . . . . . . . . . . . . . . 10

2.2 Representações de Coleções de Documentos . . . . . . . . . . . . . . . . . . 10

2.2.1 Modelo Vetorial . . . . . . . . . . . . . . . . . . . . . . . 11

2.2.2 Representação Probabilística: Latent Dirichlet Allocation (LDA) . . . 13

2.2 .3 Outras Representações . . . . . . . . . . . . . . . . 17

2.3 Métricas de Dissimilaridade entre Documentos . . . . . . . . . . . . . . . . 18

2.4 Considerações Finais . . . . . . . . . . . . . . . . . . . . . . 21

3 Visualização de Documentos e Mineração de Tópicos 23

3.1 Visualização de Documentos . . . . . . . . . . . . . . . . . . 24

3.1.1 Visualização de Coleções de Documentos . . . . . . . . . . . . . . 27

3.1.2 Visualização Temporal de Coleções de Documentos . . . . . . . . . . 36

3.1.3 Projeções Multidimensionais Dinâmicas . . . . . . . . . . . . . . . . . 41

3.2 Mineração de Tópicos . . . . . . . . . . . . . . . . . . . . . . . . . 51

3.2.1 Abordagens para detecção da evolução temporal de tópicos . . . . . . . 52 
4 Time-based Least Square Projection (T-LSP) e Mapa Dinâmico de Documentos

4.1 Time-based Least Square Projection (T-LSP) . . . . . . . . . . . . . . . . . 63

4.1 .1 Modelo Vetorial Estendido . . . . . . . . . . . . . . . . 66

4.1 .2 Animação e Elementos Visuais . . . . . . . . . . . . . . . . . 67

4.1.3 Avaliação Numérica da Técnica T-LSP . . . . . . . . . . . . . . . 70

4.1.4 Complexidade Computacional . . . . . . . . . . . . . 72

4.1.5 Comparação da T-LSP com a LSP . . . . . . . . . . . . . . . 73

4.2 Técnicas de Extração de Tópicos . . . . . . . . . . . . . . . . . 74

4.2.1 Extração de Tópicos baseada em PCA . . . . . . . . . . . . . . 74

4.2 .2 Extração de Tópicos baseada em LDA . . . . . . . . . . . . . . 77

4.2.3 Comparação entre Técnicas de Extração de Tópicos . . . . . . . . . . 80

4.2 .4 Topic Clouds . . . . . . . . . . . . . . . . . . 84

4.3 Detecção da Evolução Temporal de Tópicos baseada na T-LSP . . . . . . . . 85

4.3.1 Algoritmo de Agrupamento: DBSCAN . . . . . . . . . . . . 86

4.3.2 Rastreamento das Transições Temporais entre Grupos: MONIC . . . 90

4.3.3 Representação Visual das Transições Temporais . . . . . . . . . . . . 93

4.4 Considerações Finais . . . . . . . . . . . . . . . . . . . . . . . . . . . . . 97

5 Arcabouço Visual e Estudos de Caso $\quad 99$

5.1 Arcabouço Visual: Ferramenta Science View . . . . . . . . . . . . . . . . . . 99

5.1 .1 Funcionalidades . . . . . . . . . . . . . . . 100

5.1 .2 Coleta de Artigos Científicos . . . . . . . . . . . . . . . . . 102

5.1.3 Estrutura do Banco de Dados . . . . . . . . . . . . . . 103

5.2 Estudos de Caso . . . . . . . . . . . . . . . . . . . . 104

5.2.1 Trajetória de Pesquisa: Albert-László Barabási . . . . . . . . . . . . 105

5.2.2 Evolução de uma Área de Pesquisa: IEEE Transactions on Knowledge and Data Engineering . . . . . . . . . . . . . . . . . . 112

5.2.3 Evolução de uma Área de Pesquisa: Layer-by-layer (LbL) . . . . . . . . 124

5.3 Tempos de Processamento . . . . . . . . . . . . . . . . . . 129

5.4 Estudo comparativo entre técnicas para construção de mapas de documentos dinâmicos baseados em projeções multidimensionais dinâmicas . . . . . . . . 130

5.5 Considerações Finais . . . . . . . . . . . . . . . . . . . . . 133 
6 Conclusões $\quad 137$

6.1 Contribuições . . . . . . . . . . . . . . . . . . . . . 137

6.2 Limitações . . . . . . . . . . . . . . . . . . . . . . . . . . 139

6.3 Trabalhos Futuros . . . . . . . . . . . . . . . . . 140

6.4 Artigos Publicados . . . . . . . . . . . . . . . . . . . . . 141

Referências $\quad 142$

$\begin{array}{lr}\text { A Algoritmo MONIC } & 155\end{array}$

$\begin{array}{ll}\text { B Animação de Polígonos } & 157\end{array}$ 


\section{Lista de figuras}

2.1 A curva de Zipf e os cortes de Luhn. . . . . . . . . . . . . . . . . 10

2.2 Modelo de tópicos: (a) Processo generativo; (b) Problema da inferência estatística dos tópicos que geraram uma coleção de documentos. . . . . . . . 14

2.3 Visão de um modelo de tópicos por meio de fatoração de matrizes. . . . . . . 15

2.4 Distribuição probabilística de tópicos para um documento segundo um modelo LDA estimado com $T=100 \ldots \ldots \ldots \ldots \ldots \ldots \ldots \ldots$

3.1 Tag clouds para o discurso de posse do presidente norte-americano Barack

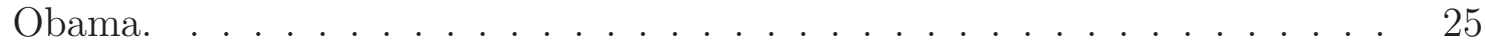

3.2 Técnicas Word Tree e Phrase Not. . . . . . . . . . . . . . . . 26

3.3 Mapas de documentos para a coleção da artigos científicos CBR-ILP-IR-SON gerados com as técnicas Force Scheme (FS) e Sammon's Mapping (SM). . . .

3.4 Mapas de documentos para a coleção da artigos científicos CBR-ILP-IR-SON gerados com as técnicas Hierarchical Point Placement (HiPP) e Neighbor Joining $(\mathrm{NJ}) . \ldots \ldots \ldots \ldots \ldots \ldots \ldots \ldots \ldots \ldots \ldots \ldots$

3.5 Mapa de documentos para a coleção da artigos científicos CBR-ILP-IR-SON gerado com a técnica ProjCloud. . . . . . . . . . . . . . . . 32

3.6 LSP - Relações de vizinhança, pontos de controle e matriz $A$ do sistema linear. 35

3.7 LSP- mapas de documentos para a coleção da artigos científicos CBR-ILP-IR-

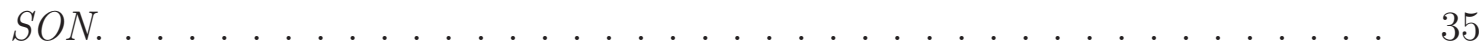

3.8 ThemeRiver: metáfora de um rio para indicar mudanças temáticas relativas a frequência ocorridas ao longo do tempo em uma coleção de documentos referentes à crise cubana-americana em 1960 . . . . . . . . . . . . . . 37

3.9 TIARA: sumário visual criado para 10.000 e-mails em 2008. . . . . . . . . 38

3.10 TextFlow: fluxo de tópicos para parte dos artigos publicados na conferência IEEE Information Visualization (Info Vis) de 2001 até 2010 . . . . . . . . . 
3.11 CiteSpace II: Rede híbrida composta por termos de uma frente de pesquisa, artigos de uma base intelectual e seus relacionamentos ao longo do tempo para uma coleção de artigos sobre terrorismo publicados entre 1990 a 2003 . . . . .

3.12 Streamit: Coleção de 1.000 projetos de pesquisa do NSF IIS que foram coletados

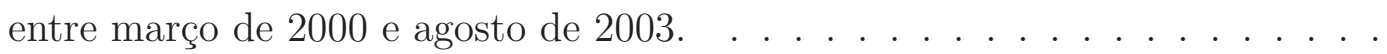

3.13 TextPool: relacionamentos de coocorrência entre os termos salientes de uma coleção de notícias abrangendo um período de 6 horas em 5 de abril de 2004 .

3.14 Visone: grafo dinâmico da coleção de artigos publicados por Michel Callon entre 1975 e 2010 - somente os últimos 4 intervalos de tempo. . . . . . . . .

3.15 incBoard: Visualização incremental de uma coleção de 675 artigos de quatro áreas de pesquisa diferentes: CBR, ILP, IR e SON. . . . . . . . . . . . .

3.16 Tópico dinâmico extraído para a coleção de 140.000 artigos publicados pela revista Science entre 1880 até 2002 . . . . . . . . . . . . . . . .

4.1 Esquema retroativo adotado pela técnica T-LSP. . . . . . . . . . . .

4.2 Animação da sequência de projeções obtida com a técnica T-LSP para a coleção de artigos publicados por Alessandro Vespignani. . . . . . . . . . . .

4.3 Stress estático e stress dinâmico para a projeção dinâmica da coleção de artigos publicados por Alessandro Vespignani mostrada na Figura 4.2b. . . . . . . .

4.4 Comparação da LSP com a T-LSP para coleção de artigos publicados por Alessandro Vespignani: (a), (b) e (c) projeções obtidas com a técnica LSP para os anos 2010, 2011 e 2012, respectivamente; (d), (e) e (f) projeções obtidas com a técnica T-LSP para os anos 2010, 2011 e 2012, respectivamente. . . .

4.5 Tópicos extraídos para o ano de 2012 da projeção dinâmica criada usando-se a T-LSP para o conjunto de artigos publicados por Alessandro Vespignani (mesma projeção da Figura 4.4f). . . . . . . . . . . . . . . .

4.5 Tópicos extraídos para o ano de 2012 da projeção dinâmica criada usando-se a T-LSP para o conjunto de artigos publicados por Alessandro Vespignani (mesma projeção da Figura 4.4f) (cont.). . . . . . . . . . . . . .

4.6 Topic cloud de tópicos extraídos por PCA com parâmetros min_topics $=0,35$ e min_terms $=0,7 \ldots \ldots \ldots \ldots \ldots$. . . . . . . . . . . . . . . . .

4.7 Noção de vizinhança e tipos de ponto no contexto do algoritmo DBSCAN. 87

4.8 Agrupamentos gerados pelo DBSCAN quando aplicado a projeção do ano 2012 da sequência de projeções apresentada na Figura 4.2b com três conjuntos diferentes de valores para os parâmetros $\varepsilon$ e MinPts. . . . . . . . . . . . 89

4.9 Diferença entre fecho convexo e Bubble Set. . . . . . . . . . . . . . . . . . 90

4.10 Representação visual da sobrevivência de um grupo. . . . . . . . . . . . . . . 94 
4.11 Representação visual da junção de dois grupos. . . . . . . . . . . . . . . . 95

4.12 Representação visual da subdivisão de um grupo. . . . . . . . . . . . . . . . 95

4.13 Representação visual do surgimento de um grupo no canto inferior esquerdo. 96

4.14 Representação visual do desaparecimento de um grupo seguido pelo surgimento de outro. . . . . . . . . . . . . . . . . . . . . . 96

5.1 ScienceView: (Centro) Projeção dinâmica obtida com a técnica T-LSP para conjuntos de artigos científicos publicados por Alessandro Vespignani. . . . 101

5.2 Busca pelos artigos do autor Eugene Garfield no portal Web of Science. . . . 102

5.3 Modelo relacional do banco de dados da ferramenta ScienceView. . . . . . . . 104

5.4 Número de artigos publicados por ano pelo pesquisador Albert-László Barabási.105

5.5 Sequência de projeções obtida com a técnica T-LSP para a coleção de artigos publicados por Albert-László Barabási. Grupos encontrados para cada projeção da sequência também são exibidos (áreas em cinza) . . . . . . . . . . 106

5.6 Subintervalo entre 2002-2004 do mapa dinâmico de artigos publicados por Albert-László Barabási. . . . . . . . . . . . . . . . . . . . . . . . . . 108

5.7 Subintervalo entre 2010-2012 do mapa dinâmico de artigos publicados por Albert-László Barabási. . . . . . . . . . . . . . . . . . . . . . . . . . . . . . . 111

5.8 Stress estático e stress dinâmico para a projeção dinâmica dos artigos publicados por László Barabási ,mostrada na Figura 5.5a. . . . . . . . . . . . 112

5.9 Número de artigos publicados pelo periódico TKDE. . . . . . . . . . . . . 113

5.10 Sequência de projeções obtida com a técnica T-LSP para a coleção de artigos publicados no periódico TKDE. . . . . . . . . . . . . . . . . 114

5.11 Subintervalo entre 1998-1999 do mapa dinâmico de artigos publicados no periódico TKDE. . . . . . . . . . . . . . . . . . . . . 117

5.12 Subintervalo entre 2002-2003 do mapa dinâmico de artigos publicados no periódico TKDE. . . . . . . . . . . . . . . . . . . . 119

5.13 Subintervalo entre 2002-2003 do mapa dinâmico de artigos publicados no periódico TKDE (cont.).

5.14 Stress estático e stress dinâmico para a projeção dinâmica da coleção de artigos publicados no periódico TKDE. . . . . . . . . . . . . . . . . . 121

5.15 Número de artigos publicados para a coleção Layer-by-layer (LbL). . . . . . 124

5.16 Sequência de projeções obtida com a técnica T-LSP para a coleção LbL. . . . 125

5.17 Stress estático e stress dinâmico para a projeção dinâmica da coleção de artigos $\mathrm{LbL} \ldots \ldots \ldots \ldots \ldots \ldots \ldots \ldots \ldots$ 
B.1 Animação para transformar polígono Pol $_{t}$ em Pol $_{t+1}$ para indicar a sobrevivência de um grupo. . . . . . . . . . . . . . . . . . . . . . . . . . . . . . . . 159 


\section{Lista de tabelas}

2.1 Representação vetorial para uma coleção de documentos. . . . . . . . . . . . . . 11

4.1 Modelo vetorial estendido. . . . . . . . . . . . . . . . . . . . . . 67

4.2 Exemplo de matrizes de saída do LDA para $T$ tópicos e $N$ documentos com

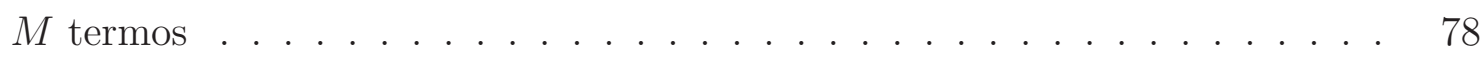

5.1 Transições entre grupos para o subintervalo entre 2002-2004 do mapa dinâmico de artigos publicados por Albert-László Barabási. . . . . . . . . . . . . . . . 109

5.2 Transições entre grupos para o subintervalo entre 2010-2012 do mapa dinâmico de artigos publicados por Albert-László Barabási. . . . . . . . . . . . . . . . 110

5.3 Transições entre grupos para o subintervalo entre 1998-1999 do mapa dinâmico de artigos publicados no periódico TKDE. . . . . . . . . . . . . 116

5.4 Transições entre grupos para o subintervalo entre 2002-2003 do mapa dinâmico de artigos publicados no periódico TKDE. . . . . . . . . . . . . . . . . . . 121

5.5 Estado final do mapa de documentos dinâmico para artigos publicados no periódico TKDE até 2012 . . . . . . . . . . . . . . . . . . 122

5.7 Tempos de processamento. . . . . . . . . . . . . . . . . . . . . 129

5.8 Comparativo entre Técnicas para Construção de Mapas Dinâmicos baseados em Projeções Multidimensionais Dinâmicas. . . . . . . . . . . . . . . . . 135 


\section{Lista de Algoritmos}




\section{Lista de acrônimos}

\begin{tabular}{|c|c|}
\hline tf & terms frequency ...................................... 11 \\
\hline tf-idf & term frequency inverse document frequency .................... 11 \\
\hline CBR & Case-Based Reasoning........ \\
\hline CNetS & Center for Complex Networks and Systems Research...............68 \\
\hline CNS & Cyberinfrastructure for Network Science Center................. vii \\
\hline DBSCAN & Density Based Spatial Clustering of Applications with Noise .........86 \\
\hline DOI & Digital Object Identifier.. \\
\hline EM & Expectation Maximization.... \\
\hline FDP & Force-Directed Placement. . \\
\hline FS & Force Scheme.... \\
\hline HiPP & Hierarchical Point Placement. \\
\hline ILP & Inductive Logic Programming. \\
\hline incBoard & Incremental Board ........... \\
\hline incSpace & Incremental Space............ \\
\hline IR & Information Retrieval .... \\
\hline JS & Jensen-Shannon.............. \\
\hline KL & Kullback Leibler............. \\
\hline k-NN & 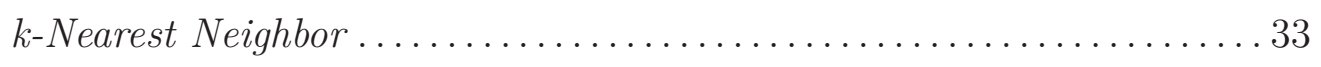 \\
\hline LbL & Layer-by-layer ... \\
\hline LDA & Latent Dirichlet Allocation .................... \\
\hline LDC & Linguistic Data Consortium .................................... 53 \\
\hline LEV & Log-Eigenvalue ....................................... 75 \\
\hline LSP & Least Square Projection. . \\
\hline
\end{tabular}


MDS

NCD

NCDs

NJ

NSF IIS

PCA

PFNet

PLMP

PLN

SON

SM

TDT

T-LSP

TKDE
Multidimensional Scaling

Normalized Compression Distance.

Scaled NCD

Neighbor Joining xiii

US National Science Foundation Information and Intelligence Systems Principal Component Analysis... 63

Pathfinder Network Scaling. 40

Part-Linear Multidimensional Projection 43

Processamento de Linguagem Natural .................... 8

Sonification . 28

Sammon's Mapping. xiii

Topic Detection and Tracking ... 53

Time-based Least Square Projection 62

IEEE Transactions on Knowledge and Data Engineering... 104 


\title{
Resumo
}

\author{
ALENCAR, A. B. Visualização da evolução temporal de coleções de artigos \\ científicos. 2012. $159 \mathrm{f}$. Tese (Doutorado) - Instituto de Ciências Matemáticas e de \\ Computação, Universidade de São Paulo, São Carlos, SP, 2012.
}

Artigos científicos são o principal mecanismo que pesquisadores usam para reportar suas descobertas científicas, e uma coleção de artigos em uma área de pesquisa pode revelar muito sobre sua evolução ao longo do tempo, como a emergência de novos tópicos e a evolução dos mesmos quanto ao seu conteúdo. No entanto, dada uma ampla coleção de artigos é geralmente muito difícil extrair informações importantes que possam ajudar leitores a interpretar globalmente, navegar e então eventualmente focar em itens relevantes para sua tarefa. Mapas de documentos baseados em conteúdo são representações visuais criadas para avaliar a similaridade entre documentos, e têm se mostrado úteis em auxiliar tarefas exploratórias neste cenário. Documentos são representados por marcadores visuais projetados em um espaço bidimensional de forma que documentos com conteúdo similar permaneçam próximos. Apesar de estes mapas permitirem a identificação visual de grupos de documentos relacionados e de fronteiras entre esses grupos, eles não transmitem explicitamente a evolução temporal de uma coleção. Nesta tese, propomos e validamos um mapa de documentos dinâmico interativo para coleções de artigos científicos capaz de evidenciar o comportamento temporal para apoiar tarefas de análise, preservando ao mesmo tempo a acurácia local do mapa e o contexto do usuário. As mudanças nas relações de similaridade, evidenciadas ao longo do tempo nesse mapa, oferecem suporte para detecção da evolução temporal dos tópicos. Essa evolução é caracterizada por meio de eventos de transição entre grupos, como a emergência de novos grupos e tópicos em momentos específicos e a especialização de um grupo, e pela detecção de mudanças no vocabulário dos tópicos, utilizando técnicas que extraem os termos mais relevantes (tópicos) em cada grupo, em diferentes momentos.

Palavras-chave: projeção multidimensional dinâmica, evolução temporal de tópicos, extração de tópicos. 


\title{
Abstract
}

\author{
ALENCAR, A. B. Visualization of the temporal evolution of scientific articles \\ collections. 2012. 159 f. Thesis (Doctoral) - Instituto de Ciências Matemáticas e de \\ Computação, Universidade de São Paulo, São Carlos, SP, 2012.
}

Scientific articles are the major mechanism used by researchers to report their scientific results, and a collection of articles in a research area can reveal a lot about its evolution over time, such as the emergence of new topics and changes in topic vocabulary. However, given a broad collection of articles it is usually very difficult to extract important information that can help readers to globally interpret, navigate and then eventually focus on subjects relevant to their task. Document maps based on content are visual representations created to convey the similarity between documents, and have proven to be useful in helping users conducting exploratory tasks in this scenario. Documents are represented by graphical markers projected onto a two-dimensional space so that documents similar in content remain close. Although these maps allow visual identification of groups of related documents and boundaries between these groups, they do not explicitly convey the temporal evolution of a collection. In this thesis, we propose and validate a dynamic document map for collections of scientific articles capable of showing the temporal behavior to support analysis tasks, while simultaneously preserving the local accuracy of the map and the user global context. Changes in the similarity relationships, evidenced over time in this map, support the detection of the temporal evolution of topics. This evolution is characterized by transition events between groups such as the emergence of new groups and topics at specific moments and the specialization of a group, as well by detecting changes in the vocabulary of topics, using techniques that extract the most relevant terms (topics) in each group, at different times.

Keywords: dynamic multidimensional projection, temporal evolution of topics, topic extraction. 


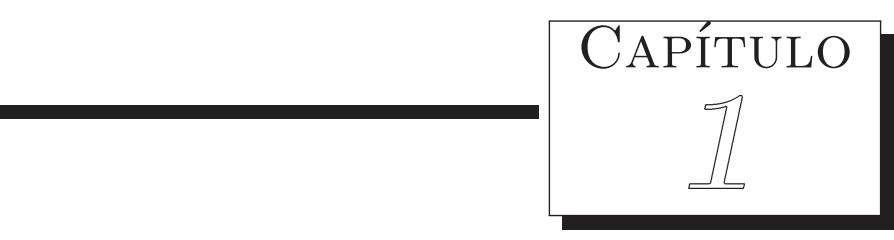

\section{Introdução}

A sobrecarga de informação é um fenômeno bem conhecido atualmente. Devido aos avanços no poder de processamento dos computadores e na capacidade de armazenamento de dados nas últimas décadas, diferentes tipos de dados são gerados e registrados em velocidades impressionantes. Esses dados são coletados por serem fontes potenciais de informações valiosas, provendo uma vantagem competitiva para quem deter tal informação. No entanto, nossa habilidade de gerar e armazenar dados aumenta a uma taxa mais rápida do que nossa capacidade de analisá-los, e se nenhuma informação for extraída, o armazenamento terá sido inútil (Keim, 2002; Keim et al., 2008).

Para favorecer o acesso à informação é preciso ampliar a capacidade cognitiva do ser humano em processos de exploração de dados. Esta é justamente a proposta da Visualização de Informação (Card et al., 1999; Chen, 2006b; Spence, 2007), disciplina que surgiu a partir da disponibilidade de interfaces gráficas mais eficientes com recursos de interação adequados. A Visualização de Informação busca criar modelos gráficos e representações visuais, com o objetivo de explorar a sofisticada capacidade visual do ser humano para facilitar a exploração e aquisição de informações úteis contidas nos dados (Oliveira; Levkowitz, 2003). A Visualização tem o seu potencial maximizado quando acoplada a estratégias analíticas, oriundas da Mineração de Dados (Fayyad et al., 1996), voltada ao processo de extração de conhecimento útil e previamente desconhecido em dados, por meio da aplicação de algoritmos que extraem modelos e padrões representativos. A integração de algoritmos de mineração e visualização permite associar a capacidade computacional com o conhecimento e capacidade de perceber padrões do ser humano. Já a disciplina Análise Visual (Visual Analytics) (Thomas; Cook, 2006) evoluiu a partir da Visualização de Informação e da Mineração de Dados, combinando 
essas duas disciplinas e reforçando a interação humana no processo analítico.

A literatura científica disponível também cresce em um ritmo rápido, com novos resultados, métodos e tecnologias sendo publicados constantemente. Esta natureza altamente dinâmica da ciência impõe desafios a pesquisadores que buscam acompanhar a evolução de uma certa disciplina ou área de pesquisa. Algumas técnicas e ferramentas de visualização têm sido propostas especificamente para apoiar a análise exploratória de coleções de artigos científicos (Herr II et al., 2008; SCI² TEAM, 2009; Gove et al., 2011). A maioria baseia-se na análise de redes - em que unidades como autores, instituições, países, palavras, artigos e meios de publicação são representados como vértices e suas relações como arestas de uma rede complexa - e permite a descoberta de padrões interessantes quanto aos relacionamentos ocultos em uma coleção de artigos científicos. Neste trabalho, nós focamos no aspecto semântico de uma coleção de artigos científicos, ou seja, no conteúdo dos artigos, e não em redes de autoria ou de citação, proporcionando assim uma visão complementar a essas abordagens baseadas em redes.

Coleções de artigos científicos podem ser consideradas como representativas de uma determinada área de pesquisa ou da trajetória acadêmica de um pesquisador em particular e apresentam, naturalmente, uma evolução temporal de seus tópicos, cuja compreensão é determinante para entender o seu comportamento. A compreensão da evolução dos tópicos em coleções grandes de artigos é importante para muitas pessoas, como acadêmicos e funcionários de agências de pesquisa. Primeiro, essa compreensão pode ajudá-los a se manter cientes dos tópicos novos, dos que atraem muita atenção dos pesquisadores, e das relações entre esses tópicos ao longo do tempo. Segundo, analistas podem obter uma visão global dos tópicos atuais, auxiliando-os em tarefas como avaliar um cenário e tomar ações baseadas nessa avaliação. No entanto, analisar como e porquê os tópicos evoluem ao longo do tempo não é uma tarefa trivial.

Assim, é útil propor representações visuais capazes de detectar e evidenciar mudanças no comportamento dessas coleções ao longo do tempo. A componente temporal da informação é muitas vezes negligenciada em ferramentas de visualização exploratória, apesar de desempenhar um papel tão crucial que, em muitos casos, pode determinar a falha ou sucesso de um processo de análise. Como agravante, coleções de artigos variantes no tempo tipicamente se apresentam em grandes volumes e alta dimensionalidade, esta determinada pelo número de atributos de sua representação. Tal cenário introduz diversos desafios para a criação de soluções de visualização efetivas.

\subsection{Motivação}

Técnicas de projeção multidimensional têm sido empregadas para gerar representações visuais globais de conjuntos de dados de alta dimensionalidade que podem ser embutidos em espaços métricos, ou para os quais uma matriz de distâncias entre as instâncias pode ser 
calculada (Paulovich, 2008). Essas técnicas mapeiam dados de alta dimensionalidade em um espaço de baixa dimensionalidade, tipicamente 2D, buscando preservar, na medida do possível, as relações de (dis)similaridade entre as instâncias. Já foi demonstrado que estas técnicas são capazes de gerar mapas de documentos adequados para visualização e exploração dos temas do conteúdo da coleção (Paulovich et al., 2008; Pinho et al., 2010; Paulovich et al., 2008; Pnnl, 2008). Devido a favorecerem a percepção de similaridade e dissimilaridade de conteúdo entre documentos, esses mapas permitem identificar grupos de documentos altamente relacionados (abordando tópicos similares) e fronteiras entre grupos.

No entanto, considerando uma coleção de artigos científicos indexada temporalmente como artigos de uma conferência anual, ou artigos publicados por um pesquisador ao longo de um determinado período - o espaço tópico não é estático, já que tópicos ascendem e decaem, de acordo com o interesse científico. Apesar da componente temporal ter um papel crucial em muitos tipos de dados, inclusive em textos, muitas técnicas de projeções multidimensionais existentes não a consideram explicitamente em seu processo de mapeamento. Existem algumas técnicas de projeção multidimensional dinâmicas (Alsakran et al., 2012; Wong, 2012; Pinho et al., 2010; Joia et al., 2011; Paulovich et al., 2010; Leydesdorff; Schank, 2008; Albrecht-buehler et al., 2005), cuja saída geralmente é uma sequência de layouts indexados temporalmente que captura as mudanças nas relações de similaridade ao longo do tempo. Essa sequência pode ser animada para evidenciar as mudanças entre momentos sucessivos, tais como a adição de novas instâncias ou a alteração da posição de instâncias previamente existentes.

Uma característica importante de projeções multidimensionais dinâmicas é que elas sempre buscam obedecer duas propriedades principais conflitantes, um conceito importado da disciplina que aborda o desenho de grafos dinâmicos (Frishman; Tal, 2008):

- Manutenção da acurácia local - A projeção relativa a cada período de tempo deve representar corretamente a estrutura inerente aos dados nesse período. Em outras palavras, em cada momento a projeção dinâmica deve buscar os mesmos objetivos de uma projeção convencional, i.e., representar bem as estruturas globais e as vizinhanças locais dos dados.

- Manutenção da coerência espacial global - É esperado que instâncias de dados que têm conteúdo similar e foram posicionadas em uma certa região da projeção no instante de tempo $t$ mantenham-se aproximadamente na mesma região da projeção no instante de tempo subsequente $t+1$. Este comportamento favorece a preservação do "mapa mental" do usuário: apesar das modificações, os layouts devem se manter consistentes ao longo da sequência de mapas de forma a evitar confusão do usuário. O termo "mapa mental" refere-se à estrutura cognitiva que um usuário cria internamente ao observar o layout de uma representação visual (Diehl; Görg, 2002).

O sucesso ou falha de uma projeção multidimensional dinâmica será determinado pelo grau de equilíbrio entre essas duas propriedades conflitantes. Outra questão é que nem 
todas as projeções dinâmicas são aplicáveis diretamente, ou indicadas, para coleções de documentos (Paulovich et al., 2010; Joia et al., 2011). Mesmo aquelas aplicáveis muitas vezes falham na manutenção de uma das propriedades citadas anteriormente ou apresentam outras limitações.

Quando analisamos uma coleção de artigos, eventos que caracterizam a evolução temporal dos tópicos, tais como: a emergência de novos tópicos em instantes de tempo específicos; a especialização de um tópico, quando parte dos artigos deste tópico tornam-se heterogêneos em relação ao restante do grupo e formam novos tópicos; a junção de dois ou mais tópicos para formar outro; e o desaparecimento de tópicos. Mudanças nas relações de similaridade entre artigos ao longo do tempo, providas por projeções multidimensionais dinâmicas, são um bom indicativo destes eventos, dado que um tópico deve estar associado a um conjunto de artigos similares.

Outro aspecto importante é detectar as mudanças no vocabulário associado a um tópico em específico. Por exemplo, o artigo da revista Science "The Brain of Professor Laborde", publicado em 1903, pode estar associado ao mesmo tópico do artigo "Reshaping the Cortical MotorMap by Unmasking Latent Intracortical Connections", publicado em 1991, mas o estudo da neurociência evoluiu muito nesse período e os termos que melhor caracterizavam este tema com certeza mudaram entre 1903 e 1991. No entanto, detectar essa mudança no vocabulário só é possível se conseguirmos identificar os termos mais relevantes para caracterizar um tópico em diferentes momentos.

Coleções de artigos científicos também possuem propriedades diferentes de coleções de documentos em geral. Artigos citam outros artigos, geralmente para reconhecer trabalhos relacionados e fontes de informação. Um tópico de uma área de pesquisa pode surgir e passar anos em baixa, até atrair a atenção dos pesquisadores novamente. Essas informações e características não devem ser ignoradas e sim incorporadas na construção da representação visual.

\subsection{Objetivos}

De forma a prover uma solução para os problemas citados anteriormente, considerando o cenário caracterizado na discussão anterior, os objetivos desse trabalho de doutorado são:

Investigar como incorporar o tratamento da componente temporal em uma projeção multidimensional de modo que ela possa apoiar tarefas de análise exploratória envolvendo a evolução dos tópicos de grandes coleções de artigos científicos e análises em cenários mais complexos do que os suportados atualmente. Uma vez obtida essa projeção multidimensional dinâmica, detectar e incluir na representação visual informações sobre a evolução dos tópicos. Além disso, propor, implementar e validar um arcabouço visual que suporte a geração de mapas de documentos dinâmicos que incorporem o 
aspecto da evolução temporal de tópicos na visualização exploratória de coleções de artigos cientificos.

\subsection{Terminologia}

O objetivo desta seção é explicitar o significado de alguns termos que serão utilizados no restante desta tese. Esses termos são:

- Documento - Texto ou qualquer objeto que se colige como prova de autenticidade de um fato e que constitui elemento de informação; arquivo gerado por certos programas ou pacotes, como processadores de texto, planilhas eletrônicas, etc (Houaiss, 2009).

- Artigo Científico - Documento revisado contendo propriedade intelectual, que constitui uma contribuição científica de um autor ou conjunto de autores a certa área de pesquisa. Cada artigo inclui os nomes dos autores e seus endereços, título, resumo, possivelmente palavras-chave, o texto completo e referências. Artigos científicos são publicados em periódicos, conferências e outras publicações científicas (Börner, 2010).

- Termo - Parte constituinte, elemento (de oração); palavra (ou locução) rigorosamente definida que designa um conceito próprio de um determinado campo das ciências, da tecnologia, das artes, etc (Houaiss, 2009).

- Tópico - Conjunto de termos relacionados semanticamente, possivelmente possuindo uma distribuição probabilística associada, que coerentemente representa um tema comum abordado por um grupo de documentos. Definição inspirada nas definições elaboradas por Lopes et al. (2007) e Aggarwal e Zhai (2012).

\subsection{Organização do Texto}

Para a apresentação do que foi revisado e produzido neste doutorado, o restante desta tese está estruturado da seguinte forma:

- No Capítulo 2 são apresentadas operações de pré-processamento e representações que buscam capturar a natureza essencial do conteúdo de coleções de documentos. Parte dos conceitos apresentados nesse capítulo são necessários para o entendimento de técnicas apresentadas nos demais.

- No Capítulo 3 é apresentada uma revisão bibliográfica sobre ferramentas e técnicas para visualização de documentos mais relevantes no contexto desta tese, considerando tanto a análise estática como temporal dos dados. Também é apresentada uma revisão bibliográfica para a mineração de tópicos em coleções de documentos e abordagens para detecção da evolução temporal de tópicos. 
- No Capítulo 4 são apresentados conjuntos de técnicas desenvolvidas e utilizadas no contexto dessa tese para criação de um mapa de documentos dinâmico que captura e apoia a análise da evolução temporal de tópicos em coleções de documentos.

- No Capítulo 5 são apresentados estudos de caso, que buscam ilustrar a aplicabilidade da abordagem proposta para capturar e apoiar a análise da evolução temporal dos tópicos para coleções de artigos científicos de diferentes tamanhos e de diferentes enfoques. Também é apresentada a ferramenta Science View, desenvolvida como um arcabouço visual para aplicar e testar as técnicas desenvolvidas. Esse capítulo também apresenta um comparativo entre técnicas para construção de mapas de documentos dinâmicos baseados em projeções multidimensionais dinâmicas.

- Por fim, no Capítulo 6 são apresentadas as conclusões desta tese de doutorado, caracterizando as principais contribuições para o processo de visualização temporal de coleções de documentos, bem como suas limitações e possíveis trabalhos futuros. 


\section{Pré-Processamento e Representação de Coleções de Documentos}

Boa parte do esforço total de um projeto em visualização ou mineração é gasto coletando os dados e realizando seu pré-processamento. A qualidade dos dados determina tanto a qualidade dos resultados finais como os tipos de análise que poderão ser aplicadas. No caso de coleções de documentos, é necessário pré-processar o texto dos documentos de forma a melhor determinar quais palavras serão utilizadas para capturar a semântica dos documentos.

Outra questão é a necessidade de utilizarmos representações estruturadas para documentos, que descrevam a informação neles originalmente contida com a mínima perda de informação possível. Geralmente, algoritmos para extração de padrões são originalmente desenvolvidos para serem aplicados em dados estruturados, como dados vetoriais. Devido à sua natureza não estruturada, documentos necessitam de uma representação que possibilite sua mineração, recuperação e visualização. Dessa forma, uma representação adequada da coleção é uma etapa de suma importância por influenciar na qualidade dos resultados das atividades posteriores. Uma vez obtida tal representação é possível determinar, por exemplo, quão similares, do ponto de vista semântico, são dois documentos - uma informação fundamental para diversas tarefas de mineração e aplicações em visualização.

Neste capítulo, na Seção 2.1 são apresentadas operações capazes de extrair, unificar as variações dos termos e determinar aqueles mais importantes. A Seção 2.2 apresenta as principais representações que buscam capturar a semântica de coleções de documentos. Por fim, na Seção 2.3 são apresentadas medidas adequadas para quantificar a dissimilaridade entre dois documentos, de acordo com a representação utilizada. 


\subsection{Pré-processamento: Extração e Limpeza de Ter- mos}

Nem todas as palavras são igualmente significativas para representar a semântica de um documento. Algumas palavras carregam mais "conteúdo" do que outras. Geralmente, substantivo é o tipo de palavra que mais representa o conteúdo de um documento. Portanto, é necessário pré-processar o texto dos documentos de uma coleção de forma a melhor determinar quais palavras serão utilizadas para representar a sua semântica. Durante o pré-processamento de coleções de documentos, também é comum a execução de outras operações úteis como: a tokenização do texto; a eliminação de stopwords; a stemming (redução de um termo ao seu lemna); e controle do tamanho do vocabulário. Nesta seção analisamos brevemente como extrair e pré-processar os termos do vocabulário de uma coleção de documentos.

\subsubsection{Tokenização}

Dada uma sequência de caracteres em um documento, a tokenização é a tarefa de decompor essa sequência em unidades distintas e significativas (os tokens). Se esta sequência é perfeitamente pontuada, a tokenização torna-se uma tarefa simples: separar a sequência em tokens de palavras, números e pontuação simplesmente dividindo a sequência quando espaços em branco e caracteres de pontuação ocorrem. Tomando cuidado, por exemplo, para não separar palavras compostas por hífen. Números e sinais de pontuação geralmente são removidos da lista de tokens extraídos. Um exemplo de tokenização é apresentado a seguir:

Entrada: Após quase cinco horas de argumentação, o procurador-geral da República afirmou nesta sexta-feira (3) que o caso conhecido como mensalão "maculou gravemente a República".

Saída: Após quase cinco horas de argumentação o procurador-geral da República afirmou nesta sexta-feira que o caso conhecido como mensalão maculou gravemente a República

Ao se fazer a tokenização de uma sequência de caracteres, existem casos especiais que são dependentes da linguagem. Em inglês, por exemplo, utilizam-se apóstrofes para indicar possessão ou contração ( O'Neill e aren't). Uma estratégia simples é dividir a sequência segundo a posição da apóstrofe. No entanto, enquanto $\mathrm{O}$ Neill é aceitável, aren t não é. Também é uma abordagem comum passar todas as letras de um token escritas em maiúsculo para minúsculo. A biblioteca Apache Open $N L P^{1}$ em Java suporta muitos algoritmos de Processamento de Linguagem Natural (PLN), incluindo algoritmos de tokenização para Alemão, Espanhol, Inglês e Português.

\footnotetext{
${ }^{1}$ http://opennlp.apache.org
} 


\subsubsection{Remoção de Stopwords}

Existem termos que podem ser claramente considerados como irrelevantes por assumirem papéis complementares, como artigos, adjetivos, advérbios, conjunções e preposições (Baezayates; Ribeiro-neto, 1999). Esses termos são chamados stopwords e são dependentes da linguagem adotada no documento. Geralmente, as stopwords são termos comuns e que ocorrem com alta frequência, e devem ser eliminadas.

$\mathrm{Na}$ literatura encontram-se duas abordagens para determinar quais palavras de uma coleção serão consideradas como stopwords: (1) listas previamente compiladas de stopwords comuns a uma certa linguagem; ou (2) utilizar algoritmos de etiquetagem morfossintática (part-of-speech tagging), que marcam os termos com sua classe gramatical de acordo com o próprio termo e o contexto no qual ele está inserido, e eliminar aqueles marcados como, por exemplo, artigos, verbos, advérbios, conjunções e preposições. A segunda abordagem tem a vantagem de ser mais generalizável, no entanto adiciona o custo computacional da etiquetagem morfossintática à etapa de pré-processamento.

\subsubsection{Stemming}

Stemming (stemming) refere-se à análise morfológica e de vocabulário de termos, tendo em vista a remoção de finais inflexionados de forma a retornar ao seu lema. As variantes de um termo são, muitas vezes, semanticamente equivalentes e podem ser representadas por meio do radical, o que também reduz o tamanho do vocabulário de uma coleção. Por exemplo, os termos abaixo são similares e podem ser reduzidos ao radical escr:

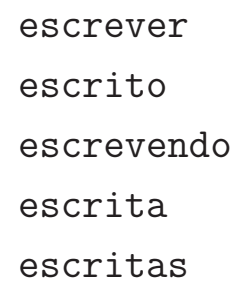

No entanto, alguns erros de stemming podem ocorrer:

1. Over-stemming - Termos com semânticas diferentes são reduzidos a um mesmo radical, por exemplo: barato e barata

2. Under-stemming - Termos com semânticas similares são reduzidos a radicais diferentes, por exemplo, viagem e viajar reduzidos aos radicais viag e viaj, respectivamente.

3. Miss-stemming - Final de um termo retirado por ser interpretado pelo algoritmo como um sufixo, por exemplo, redução do termo lápis para o radical lápi.

O algoritmo de stemming deve ser selecionado de forma a reduzir o número desses erros. Tais algoritmos também são dependentes da linguagem em que os documentos estão escritos. 
O algoritmo de Porter (Porter, 1980) é frequentemente utilizado, com bons resultados, para stemming de documentos em inglês.

\subsubsection{Lei de Zipf e Corte de Luhn}

Termos que ocorrem em muitos documentos não são representativos, pois não ajudam a discriminar o conteúdo semântico de documentos distintos. Já termos que ocorrem em poucos documentos também podem não ser representativos, por serem raros. Remover do vocabulário esses termos poucos representativos é interessante, pois reduz o tamanho do vocabulário e favorece a obtenção de melhores resultados nas análises. A Lei de Zipf (Zipf, 1949) baseia-se na frequência dos termos para encontrar esses termos menos representativos. Considerando o histograma de frequências dos termos de uma coleção de documentos, ao se ordenar esse histograma em ordem decrescente de acordo com as frequências obtém-se a "Curva de Zipf". Se o gráfico dessa curva for apresentado na escala logarítmica, a curva será semelhante à apresentada na Figura 2.1a. O eixo cartesiano $r$ representa os termos, em ordem decrescente de frequência, e o eixo cartesiano $f$ representa a frequência desses termos.

Luhn (1958) usou essa curva para especificar dois limiares (superior e inferior) para remover termos pouco representativos (ver Figura 2.1b). Os termos cuja frequência está à esquerda do limiar superior são considerados pouco representativos e removidos, assim como termos cuja frequência está à direita do limiar inferior.

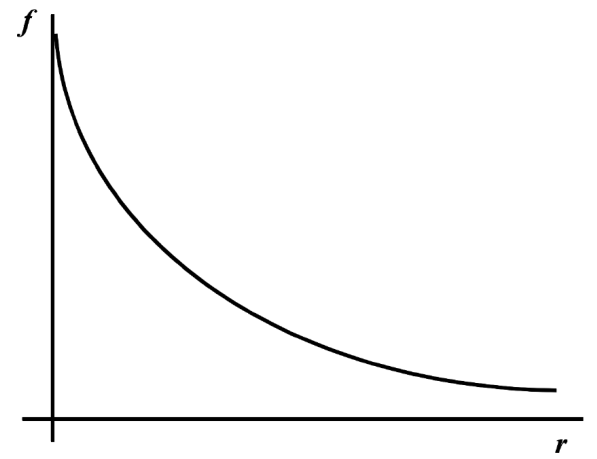

(a) Curva de Zipf

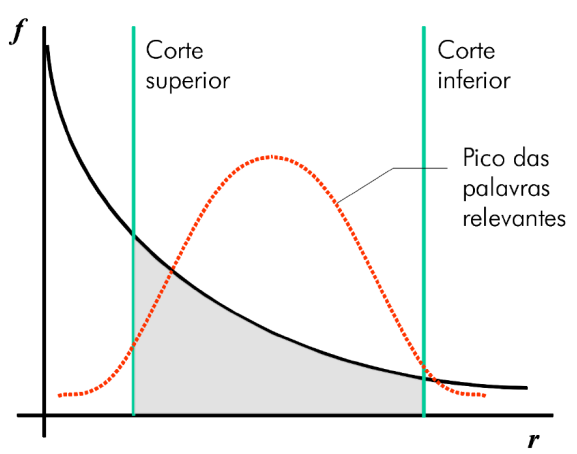

(b) Cortes de Luhn

Figura 2.1: A curva de Zipf e os cortes de Luhn. Extraído de Matsubara et al. (2003).

\subsection{Representações de Coleções de Documentos}

Geralmente, algoritmos para extração de padrões operam sobre dados estruturados, de modo que documentos devem ser representados de forma que possibilite sua mineração, recuperação e visualização. As representações devem descrever a informação originalmente contida, buscando a mínima perda de informação possível. Dessa forma, gerar uma representação adequada da coleção é de suma importância, por influenciar na qualidade dos resultados 
das atividades posteriores. Nas seções seguintes são apresentadas duas das principais representações encontradas na literatura e utilizadas nesta tese.

\subsubsection{Modelo Vetorial}

No modelo vetorial (Salton et al., 1975), também chamado representação bag-of-words, cada documento é descrito como um vetor de frequências dos termos que nele ocorrem, desconsiderando a gramática e a ordem entre os termos. Esta representação é ilustrada na Tabela 2.1 para um conjunto de $N$ documentos $D=\left\{d_{1}, d_{2}, \ldots, d_{N}\right\}$ que inclui $M$ termos $T=\left\{t_{1}, t_{2}, \ldots, t_{M}\right\}$. Cada documento $d_{i}$ é um vetor $\vec{v}\left(d_{i}\right)=\left\{f_{r e q} q_{i 1}, f r e q_{i 2}, \ldots, f r e q_{i M}\right\}$, no qual o valor $f_{r e q}$ é alguma medida que determina a influência do termo $t_{j}$ no documento $d_{i}$.

Tabela 2.1: Representação vetorial para uma coleção de documentos.

\begin{tabular}{|c||c|c|c|c|}
\hline & $t_{1}$ & $t_{2}$ & $\cdots$ & $t_{M}$ \\
\hline \hline$d_{1}$ & freq $_{11}$ & freq $_{12}$ & $\cdots$ & freq $_{1 M}$ \\
\hline$d_{2}$ & freq $_{21}$ & freq $_{22}$ & $\cdots$ & freq $_{2 M}$ \\
\hline$\cdots$ & $\cdots$ & $\cdots$ & $\cdots$ & $\cdots$ \\
\hline$d_{N}$ & freq $_{N 1}$ & freq $_{N 2}$ & $\cdots$ & freq $_{N M}$ \\
\hline
\end{tabular}

O valor freq $_{i j}$ pode ser calculado de várias maneiras. A seguir encontram-se algumas das mais utilizadas:

- boolean - A medida booleana indica que o termo $t_{i}$ ocorre no documento $d_{j}$ quando o valor de $f_{r e q} q_{i j}=1$, caso contrário $f r e q_{i j}=0$.

- terms frequency (tf) - A medida terms frequency (tf) conta o número de ocorrências do termo $t_{j}$ no documento $d_{i}$ :

$$
\operatorname{freq}_{i j}=t f\left(t_{j}, d_{i}\right)=\operatorname{freq}\left(t_{j}, d_{i}\right)
$$

- term frequency inverse document frequency (tf-idf) - Um termo muito frequente na coleção pode ocorrer em muitos documentos, oferecendo pouco poder de discriminação entre os documentos da coleção. Assim, um fator de ponderação chamado inverse document frequency (idf) (Jones, 1988), definido pela Equação (2.2), pode ser utilizado para, ao estimar a frequência, favorecer termos que aparecem em poucos documentos:

$$
i d f\left(t_{j}\right)=\log \frac{N}{d(t j)}
$$

onde $N$ é o número de documentos da coleção e $d\left(t_{j}\right)$ é o número de documentos na coleção nos quais o termo $t_{j}$ ocorre. O valor do fator idf de um termo raro, que oferece maior poder de discriminação, é alto, enquanto para um termo frequente o fator idf tende a ser um valor baixo. Assim, o fator de ponderação idf pode ser combinado 
com a medida tf em uma nova medida chamada term frequency inverse document frequency (tf-idf), calculada pela Equação (2.3):

$$
t f-i d f\left(t_{j}, d_{i}\right)=t f\left(t_{j}, d_{i}\right) \times i d f\left(t_{j}\right)=f r e q\left(t_{j}, d_{i}\right) \times \log \frac{N}{d(t j)}
$$

A matriz da representação vetorial pode apresentar uma alta dimensionalidade para coleções de documentos maiores, pois o vetor que representa cada documento contém, a princípio, todos os termos utilizados em toda a coleção. Matrizes com alta-dimensionalidade também tendem a ser mais esparsas, pois a frequência de muitos termos será possivelmente nula. Além disso, a alta dimensionalidade aumenta o custo do processamento. Dessa forma, é necessário que técnicas de pré-processamento, como as apresentadas na Seção 2.1, sejam utilizadas previamente a geração do modelo vetorial, pois assim somente os termos mais informativos do vocabulário serão retidos. Essa prática melhora a qualidade da representação vetorial e também reduz sua dimensionalidade.

Após a geração da matriz da representação vetorial, talvez observemos um cenário no qual os vetores que representam os documentos possam ter normas Euclidianas muito diferentes, o que pode prejudicar o resultado final. Neste cenário, um processo de normalização pode ser aplicado, fazendo que todos os vetores tenham norma Euclideana unitária, i.e., $\left\|\vec{v}\left(d_{i}\right)\right\|^{2}=\sum_{k=1}^{M} f_{r e q}=1$. O processo de normalização é aplicado dividindo cada coordenada do vetor $\vec{v}\left(d_{i}\right)$ por sua norma, freq $q_{i j}^{\prime}=$ freq $_{i j} /\left\|\vec{v}\left(d_{i}\right)\right\|$ para $1 \leq j \leq M$.

Outro fator importante é a padronização dos valores de $f_{r e q} q_{i j}$ de modo que tanto documentos grandes como documentos pequenos possam ser comparados na mesma escala. Documentos pequenos possuem poucos termos, enquanto documentos grandes possuem muitos termos. Dessa maneira, a probabilidade das frequências dos termos serem maiores em documentos grandes é mais alta do que em documentos pequenos. Isto tornaria um documento maior mais relevante do que um pequeno, mas todos os documentos devem ser tratados como igualmente importantes independente de seu tamanho. Primeiro, calcula-se a média $\overline{f r e q}_{j}=\frac{1}{N} \sum_{i=1}^{N} f r e q_{i j}$ e o desvio padrão $\sigma_{j}=\sqrt{\frac{1}{N} \sum_{i=1}^{N}\left(f r e q_{i j}-\overline{f r e q}_{j}\right)^{2}}$ para cada termo $(1 \leq j \leq M)$. A padronização é então obtida fazendo-se $f r e q_{i j}^{\prime}=\left(\right.$ freq $\left._{i j}-\overline{f r e q}_{j}\right) / \sigma_{j}$ para $1 \leq i \leq N$ e $1 \leq j \leq M$.

O modelo vetorial também descarta todo o contexto dos termos, e estima a frequência de cada termo independentemente. No entanto, esse contexto pode ser importante em alguns cenários. Em certas aplicações é comum o uso de duas ou mais palavras sequencialmente no texto, que juntas denotam um único termo semântico, e.g., "inteligência artificial", "mineração de textos" e "raciocínio baseado em casos". Este cenário motivou os pesquisadores a enriquecer o modelo vetorial utilizando sequências de termos (n-gram) ao invés de termos únicos (1-gram). Na década de 90, (Lewis, 1992) propôs um modelo vetorial utilizando 2-gram (pares de termos sequenciais), alegando que este representava melhor a semântica de uma coleção. No entanto, segundo Bekkerman e Allan (2003) somente 
alguns pesquisadores relataram melhoras significativas ao categorizar textos, enquanto muitos declaram que esta abordagem provê somente uma melhora marginal em algumas aplicações. A maioria das ferramentas permite a utilização de, no máximo, 3-gram.

\subsubsection{Representação Probabilística: Latent Dirichlet Allocation (LDA)}

O modelo vetorial reflete o conceito de que a informação contida em um documento pode ser representada pela soma das informações contidas nos termos que o compõem. No entanto, esta representação sofre um prejuízo causado pelo aumento da dimensionalidade do modelo. Modelos de tópicos (Blei et al., 2003; Griffiths; Steyvers, 2002, 2004; Hofmann, 1999, 2001) são baseados na ideia de que documentos são formados por uma mistura de tópicos, na qual um tópico é determinado por uma distribuição probabilística de termos. Nesses modelos, o número de tópicos é bem inferior ao tamanho do vocabulário de uma coleção, e determinado pelo usuário, ao mesmo tempo esses tópicos acumulam mais informação semântica. Dessa forma, pode-se ter uma representação vetorial na qual no lugar de termos como atributos temos tópicos, enquanto as medidas de influência (os valores $f r e q_{i j}$ ) medem a probabilidade de um tópico na geração de um documento.

Um modelo de tópico é um modelo generativo que especifica um procedimento probabilístico pelo qual documentos são gerados. Para cada documento, este modelo determina uma distribuição probabilística de tópicos, que especifica a probabilidade de cada tópico aparecer naquele documento. Para cada tópico é especificada uma distribuição probabilística de termos, que determina a probabilidade de cada termo do vocabulário ocorrer dado aquele tópico.

A Figura 2.2 ilustra um modelo de tópicos em suas duas abordagens: o modelo generativo e o problema da inferência estatística desse modelo. O modelo generativo descreve como termos em um documento são gerados com base em variáveis latentes (as distribuições probabilísticas de tópicos e de termos). A Figura 2.2a ilustra o modelo generativo com dois tópicos. Os tópicos 1 e 2 são relacionados aos temas dinheiro e rios, e são ilustrados como conjuntos de termos apresentando diferentes distribuições. Documentos distintos podem ser produzidos escolhendo-se termos de um tópico, dependendo do peso (valores nas setas) daquele tópico naquele documento. Por exemplo, os documentos 1 e 3 foram gerados pela amostragem somente dos tópicos 1 e 2, respectivamente, enquanto o documento 2 foi gerado por probabilidades iguais para os dois tópicos. Na Figura 2.2a, os sobrescritos associados aos termos nos documentos indicam de qual tópico essa palavra foi amostrada. Observe que um mesmo termo pode pertencer a mais de um tópico. Isso permite que modelos de tópicos capturem polissemia em documentos, quando um mesmo termo tem vários significados. Em contrapartida, na inferência do modelo generativo, ver Figura 2.2b, o objetivo é achar o 
melhor conjunto de variáveis latentes que explicam os termos observados em documentos conhecidos, assumindo que este foi o modelo que de fato gerou esses documentos.

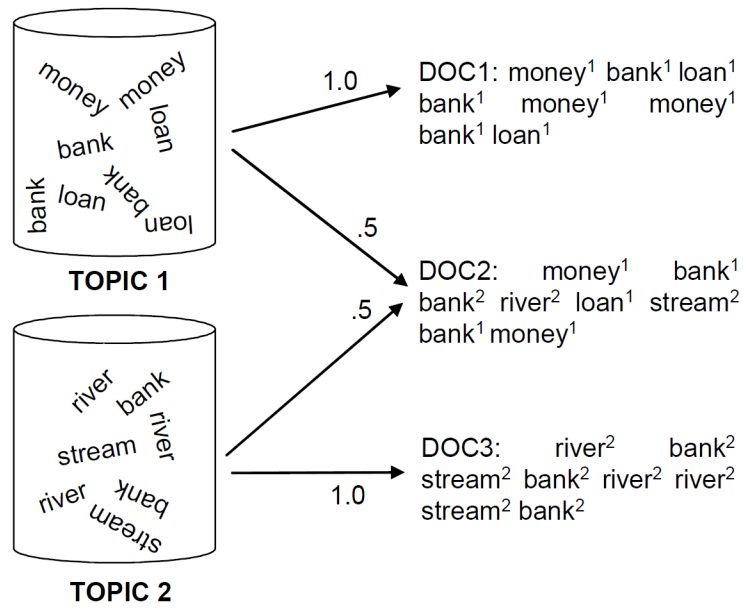

(a) Processo generativo.

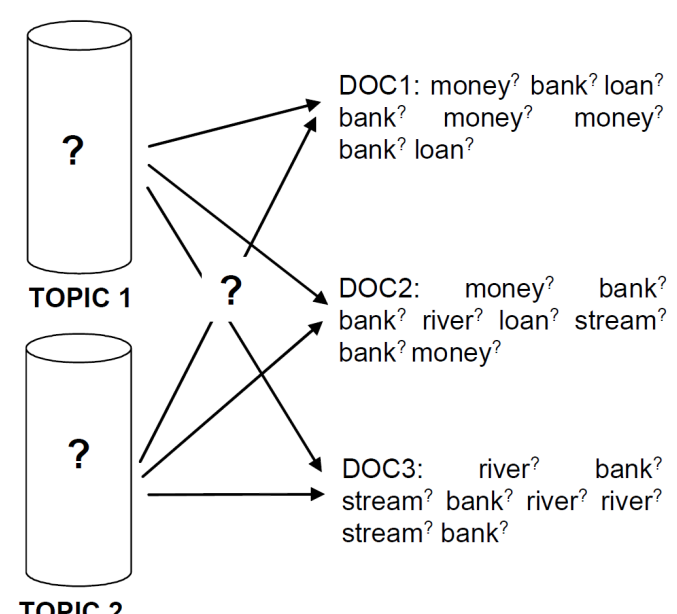

(b) Inferência estatística.

Figura 2.2: Modelo de tópicos: (a) Processo generativo; (b) Problema da inferência estatística dos tópicos que geraram uma coleção de documentos. Extraído de Steyvers e Griffiths (2007).

Todas as diferentes técnicas de modelos de tópicos possuem a mesma ideia fundamental: se temos $T$ tópicos, podemos escrever a probabilidade do $i$-ésimo termo $\left(w_{i}\right)$ em um documento segundo Equação (2.4).

$$
P\left(w_{i}\right)=\sum_{j=1}^{T} P\left(w_{i} \mid z_{i}=j\right) P\left(z_{i}=j\right)
$$

onde $z_{i}$ é uma variável latente que indica o tópico do qual o $i$-ésimo termo foi retirado; $P\left(w_{i} \mid z_{i}=j\right)$ é a probabilidade do termo $w_{i}$ ocorrer dado que o $j$-ésimo tópico foi escolhido; e $P\left(z_{i}=j\right)$ é a probabilidade de escolhermos o $j$-ésimo tópico para o atual documento. Tal distribuição varia para cada documento. Para simplificar a notação, geralmente utilizase $\phi_{w_{i}}^{(j)}=P\left(w_{i} \mid z_{i}=j\right)$ e $\theta_{j}^{(d)}=P\left(z_{i}=j\right)$, onde $d$ é o índice de um documento. Essas probabilidades definem distribuições probabilísticas multinomiais $\phi$ e $\theta$ - as principais variáveis latentes (desconhecidas) que desejamos inferir. Como apresentado na Figura 2.3, um modelo de tópicos pode ser visto como uma fatoração de matrizes, na qual os dados podem ser representados pelas matrizes $\phi$ e $\theta$. A distribuição $\phi$ é representada por uma matriz com um número de linhas igual ao tamanho do vocabulário da coleção e número de colunas igual ao número de tópicos $(T)$ - cada célula contém a probabilidade de um determinado termo ocorrer em um determinado tópico. A distribuição $\theta$ é representada por uma matriz com um número de linhas igual ao número de tópicos e um número de colunas igual ao número de documentos - cada célula contém a probabilidade de um determinado tópico ocorrer em um determinado documento.

Modelo generativo. Dentre as várias técnicas para modelagem de tópicos existentes, o Latent Dirichlet Allocation (LDA) (Blei et al., 2003) é o mais utilizado na literatura. O LDA combina 


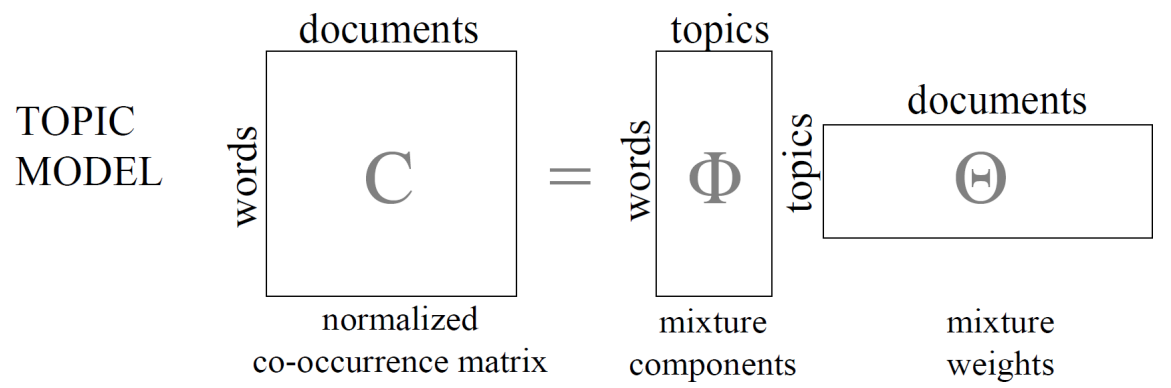

Figura 2.3: Visão de um modelo de tópicos por meio de fatoração de matrizes. Extraído de Steyvers e Griffiths (2007).

a Equação (2.4) com uma distribuição Dirichlet a priori em $\theta$ com parâmetro $\alpha$ - o que simplifica o problema de inferência estatística. Essa distribuição Dirichlet a priori também promove uma suavização, determinada pelo parâmetro $\alpha$, na distribuição probabilística de tópicos $(\theta)$. Quanto maior $\alpha$, maior a suavização: os documentos são influenciados por vários tópicos no modelo - o que dilui as probabilidades. Já para $\alpha<1$ (muito utilizado na prática), o modelo favorece apenas alguns tópicos para cada documento, atribuindo uma alta probabilidade a esses tópicos. Griffiths e Steyvers (2004) exploraram uma variante do modelo discutido por Blei et al. (2003) colocando também uma distribuição Dirichlet a priori em $\phi$ com parâmetro $\beta$. Este parâmetro também promove uma suavização, mas na distribuição probabilística de termos para um tópico $(\phi)$.

Inferência Estatística. O algoritmo Gibbs Sampler (Griffiths; Steyvers, 2004), um tipo de Cadeia de Markov de Monte Carlo, provê um método eficiente para inferir estatisticamente o modelo de tópicos para coleções de documentos grandes. Uma Cadeia de Markov de Monte Carlo é construída de forma a convergir para o modelo de tópicos que melhor descreve como os dados foram gerados. Em cada iteração a cadeia muda de estado, esse algoritmo considera cada termo $w_{i}$ na coleção de documentos por vez, e estima a probabilidade de que esse termo tenha ocorrido devido a cada tópico, condicionado pelas atribuições de todos os outros termos até o momento. A partir dessa distribuição condicional, um tópico é amostrado como o novo tópico para o termo $w_{i}$. As atribuições iniciais de tópicos para cada termo são aleatórias, mas mesmo assim ocorre uma conversão após em média 1.000 iterações. No entanto, o modelo inferido não é determinístico, i.e., para duas execuções com os mesmos parâmetros para o mesmo conjunto de dados obtém-se resultados diferentes, mas muito similares.

O algoritmo Gibbs Sampling fornece estimativas diretas de $z_{i}$ para todas as palavras. No entanto, para representação de documentos o interesse reside na matriz $\phi$. A distribuição multinomial representada por $\phi$ é utilizada para representar os documentos, utilizando os tópicos como atributos e pode ser calculada a partir das variáveis $z_{i}$, de acordo com fórmulas apresentadas por Griffiths e Steyvers (2004), que também oferecem fórmulas para calcular $\theta$.

Boas escolhas para os parâmetros $\alpha$ e $\beta$ irão depender do número de tópicos a serem inferidos ( $T$ - outro parâmetro a ser determinado pelo usuário) e do tamanho do vocabulário de termos. Segundo Steyvers e Griffiths (2007), os valores $\alpha=50 / T$ e $\beta=0,01$ funcionam 
bem para a maioria das coleções de documentos.

A escolha do número de tópicos $T$ pode afetar a interpretabilidade e a qualidade dos resultados, portanto deve ser cuidadosa. Um número de tópicos muito pequeno irá gerar tópicos muito amplos, enquanto valor muito alto irá resultar em tópicos não interpretáveis, que representam uma combinação não significativa de palavras. A escolha do parâmetro deve depender, em parte, do tamanho da coleção, mas segundo McCallum (2002) o intervalo $T=[200,400]$ costuma produzir resultados razoavelmente detalhados para a maioria das coleções. Também existem métodos objetivos para determinar o número de tópicos. Griffiths e Steyvers (2004) discutem uma abordagem de seleção baseada em uma estimativa da probabilidade posterior do modelo, a probabilidade daquele modelo ter gerado a coleção de documentos em questão, para vários valores de $T$. O número de tópicos a ser utilizado é aquele que obteve a maior probabilidade posterior. No entanto, isso implica em calcular o modelo de tópicos múltiplas vezes. Outros métodos para determinar o número de tópicos também são discutidos por Buntine (2009).

Antes de aplicar o LDA a uma coleção de documentos, também é indicado aplicar operações de pré-processamento como a eliminação de stopwords e o stemming dos termos.

Remoção de tópicos não ativados. A Figura 2.4 mostra a distribuição probabilística de tópicos para um artigo segundo um modelo LDA com $T=100$ inferido para uma coleção de 17.000 artigos publicados na Science. Apesar da distribuição de tópicos determinar que qualquer tópico pode ser utilizado para gerar o artigo, somente uma parte dos tópicos foi ativado, i.e., tiveram uma alta probabilidade. Em geral, alguns tópicos sempre apresentam probabilidades baixas para todos os documentos. Dessa forma, se a probabilidade média do tópico para todos os documentos for inferior a um limiar $\kappa$, é possível removê-lo da matriz $\theta$ para evidenciar as probabilidades dos demais tópicos, o que é executado removendo a coluna correspondente a esse tópico na matriz $\theta$. A Equação (2.5) define essa condição baseada na probabilidade média do $j$-ésimo tópico para uma coleção com $n$ documentos:

$$
\frac{\sum_{i=1}^{n} \theta_{j}^{(i)}}{n}<\kappa
$$

O valor $\kappa=0.01$ é adotado como padrão com base em teste empíricos, i.e., tópicos que em média não contribuem mais que $1 \%$ na geração dos tópicos são eliminados.

Essa operação é opcional e foi desenvolvida no contexto deste trabalho ao observarmos que produzia bons resultados. Se essa operação for executada, é necessário normalizar as distribuições probabilísticas de tópicos para que todos os vetores tenham novamente norma Euclideana unitária após essa operação, i.e., $\left\|\theta^{(d)}\right\|=\sum_{j=1}^{T} \theta_{j}^{(d)}=1$. 


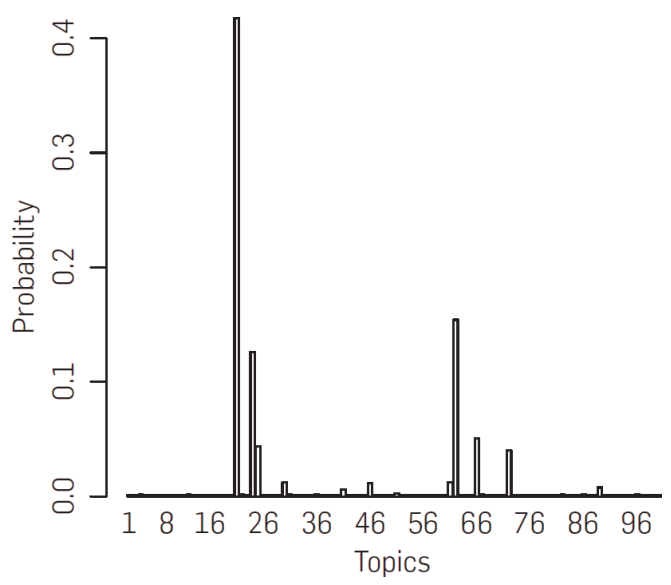

Figura 2.4: Distribuição probabilística de tópicos para um documento segundo um modelo LDA estimado com $T=100$. Extraído de Blei (2012).

\subsubsection{Outras Representações}

Existem muitas representações para coleções de documentos na literatura, cada uma buscando evidenciar melhor um certo aspecto em particular da coleção. A escolha da representação é crucial, pois ela deve reter o máximo de informação possível sobre os documentos e evidenciar um certo aspecto da coleção no qual o usuário está interessado.

As representações apresentadas até o momento são computacionalmente eficientes para representar de forma aproximada a semântica do documento como um todo. No entanto, essas representações são incapazes de capturar outras características, como as transições semânticas em diferentes partes do documento. A representação lowbow (Mao et al., 2007) consegue descrever as transições semânticas em um documento, gerando uma curva suave em um espaço de alta dimensionalidade que sumariza essas transições ao longo do texto. Essa representação espalha a presença de uma palavra que ocorre em certa localização no documento para a sua vizinhança, mas diminuindo a contribuição dependendo na distância entre duas localizações. A dimensão desse espaço no qual se encontra a curva é determinada pelo tamanho do vocabulário do documento analisado.

Quando a curva lowbow permanece na mesma região do espaço de alta dimensionalidade é indicativo de uma região semanticamente homogênea no documento. Assim, os autores utilizaram a norma do vetor gradiente da curva para medir a taxa de mudança nas diferentes dimensões, detectando fronteiras entre tópicos e promovendo uma segmentação do documento.

Extensões do modelo LDA original também podem ser encontradas na literatura, que visam geralmente permitir a incorporação de metadados ao modelo. Por exemplo, Rosen-Zvi et al. (2004) estendem o modelo LDA para incluir informação de autoria de documentos Cada autor está associado a uma distribuição probabilística multinomial de tópicos e cada tópico está associado a uma distribuição probabilística multinomial de palavras. Um documento com múltiplos autores é modelado como uma distribuição de tópicos, que é uma mistura das distribuições de tópicos associada a cada um dos autores. 


\subsection{Métricas de Dissimilaridade entre Documentos}

De posse de uma representação da coleção de documentos - seja o modelo vetorial ou um modelo de tópicos - é possível utilizar medidas de dissimilaridade para quantificar a semelhança semântica entre dois documentos. A escolha da métrica deve levar em consideração o tipo de representação adotada.

Para o modelo vetorial, indica-se métricas com motivação geométrica como a distância Euclidiana. O cálculo da distância Euclidiana entre dois documentos, representados pelos vetores $d_{1}$ e $d_{2}$, é dado pela seguinte equação:

$$
\operatorname{diss}_{\text {euclid }}\left(d_{1}, d_{2}\right)=\sqrt{\sum_{k=1}^{M}\left(\text { freq }_{1 k}-\text { freq }_{2 k}\right)^{2}}
$$

onde $M$ é o número de termos da representação e $f_{r e q} q_{i j}$ refere-se à medida de influência do termo $t_{j}$ no documento $d_{i}$. A distância Euclidiana é uma medida de dissimilaridade, ou seja, quanto mais próximo de 0 for o valor de $\operatorname{diss}_{\text {euclid }}\left(d_{1}, d_{2}\right)$, mais similares são os documentos $d_{1}$ e $d_{2}$.

No entanto, mesmo após a redução de dimensionalidade (eliminação de stopwords, etc.) da representação vetorial, os vetores que representam os documentos continuam tipicamente esparsos (muitos atributos, e poucos deles com valores não nulos). A similaridade entre dois documentos deve depender do número de características (termos) que eles compartilham, ao invés do número de características que eles não compartilham (Tan et al., 2005). Se comparações do tipo 0 - 0 forem consideradas e a representação for esparsa, alguns documentos serão indicados como sendo similares pelo número de termos que ambos não possuem. Dessa forma, a distância Euclidiana não é muito indicada para determinar a similaridade entre dois documentos, pois considera as comparações 0 - 0 . A similaridade do cosseno é uma das medidas mais utilizadas para definir a similaridade entre dois documentos representados pelo modelo vetorial, pois não favorece comparações do tipo 0 - 0 , sendo uma medida indicada justamente para espaços de alta dimensionalidade e esparsos. Se $\vec{v}\left(d_{1}\right)$ e $\vec{v}\left(d_{2}\right)$ são dois documentos representados por dois vetores de tamanho $M$, a similaridade do cosseno é calculada pela seguinte equação:

$$
\operatorname{sim}_{\cos }\left(d_{1}, d_{2}\right)=\frac{\vec{v}\left(d_{1}\right) \cdot \vec{v}\left(d_{2}\right)}{\left\|\vec{v}\left(d_{1}\right)\right\|\left\|\vec{v}\left(d_{2}\right)\right\|}
$$

onde o operador - indica o produto escalar entre dois vetores, $\vec{v}\left(d_{1}\right) \cdot \vec{v}\left(d_{2}\right)=\sum_{k=1}^{M} f_{r e q_{1 k}}$. $f_{r e q} q_{2 k}$, e $\left\|\vec{v}\left(d_{1}\right)\right\|$ é a norma do vetor $\vec{v}\left(d_{1}\right),\left\|\vec{v}\left(d_{1}\right)\right\|=\sqrt{\sum_{k=1}^{M} f r e q_{1 k}^{2}}=\sqrt{\vec{v}\left(d_{1}\right) \cdot \vec{v}\left(d_{1}\right)}$. O denominador na Equação (2.7) tem a função de normalizar os vetores $\vec{v}\left(d_{1}\right)$ e $\vec{v}\left(d_{2}\right)$ para vetores unitários, caso eles ainda não estejam normalizados. Dessa forma, a Equação (2.7) pode ser vista como o produto escalar das versões normalizadas dos vetores, i.e., o cosseno 
do ângulo entre eles.

A similaridade do cosseno retorna valores no intervalo $[0,1]$, i.e., se o valor é igual a 1, os vetores tem representações idênticas. Já se a similaridade do cosseno é igual a 0, os documentos não compartilham nenhum termo, e não são similares. Para transformar essa medida de similaridade em uma medida de dissimilaridade basta utilizar $\operatorname{diss}_{\cos }\left(d_{1}, d_{2}\right)=$ $1-\operatorname{sim}_{\cos }\left(d_{1}, d_{2}\right)$.

Já na representação LDA, os documentos são representados por distribuições probabilísticas. Métricas com motivação geométrica como a distância Euclidiana e similaridade do cosseno também funcionam nesse tipo de representação. No entanto, também existem métricas de similaridade para medir a diferença entre duas distribuições probabilísticas (Lin, 1991), sendo que uma medida padrão para medir a diferença entre duas distribuições $p$ e $q$ é a divergência de Kullback Leibler (KL):

$$
K L(p, q)=\sum_{k=1}^{T} p_{k} \log _{2} \frac{p_{k}}{q_{k}}
$$

Esta função é igual a zero quando para todos os valores de $p_{k}=q_{k}$, com $k=[1 . . T]$. Essa medida permite somente distribuições probabilísticas não-nulas, pois o contrário implicaria numa divisão por zero. A divergência de KL também é assimétrica $(K L(p, q) \neq K L(q, p))$, e em muitas aplicações é conveniente aplicar uma métrica simétrica baseada na divergência de KL:

$$
\operatorname{diss}_{K L}(p, q)=\frac{1}{2}[K L(p, q)+K L(q, p)]
$$

Outra opção para obter uma métrica simétrica a partir da divergência de KL é a divergência de Jensen-Shannon (JS):

$$
\operatorname{diss}_{J S}(p, q)=\frac{1}{2}[K L(p,(p+q) / 2)+K L(q,(p+q) / 2)]
$$

que determina que duas distribuições $p$ e $q$ são similares somente se elas são similares à sua média $(p+q) / 2$.

Outra opção também muito utilizada e indicada em Blei e Lafferty (2007) é a distância de Hellinger, que é simétrica e também obedece a desigualdade triangular $(H(p, q) \leq H(p, x)+H(x, q))$ :

$$
\operatorname{diss}_{H}(p, q)=\frac{1}{\sqrt{2}} \sqrt{\sum_{k=1}^{T}\left(\sqrt{p_{k}}-\sqrt{q_{k}}\right)^{2}}
$$

quanto menor o valor de $\operatorname{diss}_{H}(p, q)$, mais próximas são as distribuições probabilísticas $p$ e $q$.

As métricas de Kullback Leibler (KL), de Jensen-Shannon (JS) e de Hellinger são muito utilizadas no contexto de buscas para recuperação de informação. No entanto, essas métricas 
consideram que probabilidades baixas para um mesmo atributo é um indicativo de similaridade. O que pode não ser desejável em alguns cenários, quando, por exemplo, estamos calculando a similaridade par a par para um conjunto de distribuições e o número de probabilidades baixas que as distribuições compartilham é maior que o número de probabilidades altas compartilhadas. Nesse tipo de cenário, as distribuições do conjunto tornariam-se todas similares umas as outras, o que pode tornar a similaridade do cosseno mais indicada nesses casos.

Outra abordagem para o cálculo da dissimilaridade entre documentos é baseada na complexidade de Kolmogorov (Kolmogorov, 1965), que busca quantificar a complexidade (quantidade de informação) de strings e outros objetos de forma objetiva e absoluta. Medidas baseadas na complexidade de Kolmogorov não requerem representações intermediárias para a coleção de documentos, como o modelo vetorial, o que pode ser uma grande vantagem. No entanto, a complexidade de Kolmogorov não é uma função computável. Apesar disso, uma aproximação para a verdadeira complexidade é possível usando algoritmos de compressão.

Seguindo essa abordagem, Li et al. (2003) propuseram uma medida denominada Normalized Compression Distance (NCD) que dadas duas strings $x$ e $y$ calcula uma aproximação para a complexidade de Kolmogorov:

$$
N C D(x, y)=\frac{C(x y)-\min \{C(x), C(y)\}}{\max \{C(x), C(y)\}}
$$

onde $x y$ é a concatenação das strings $x$ e $y$, e $C(x)$ é o tamanho em bytes da compressão da string $x$ por um compressor. O valor de $N C D(x, y)$ é um número entre 0 e $1+\delta$, onde $\delta$ é uma função de limitação do compressor. Quanto menor o valor de $N C D(x, y)$, mais similares são $x$ e $y$. Algoritmos de compressão como o LZW, zip e PPMZ podem ser utilizados para comprimir as strings.

Baseando-se na medida NCD, Telles et al. (2007) criaram uma medida modificada chamada Scaled NCD (NCDs) que visa superar problemas relacionados à precisão do compressor:

$$
N C D_{s}(x, y)=N C D(x, y)+\frac{N C D(x, x)+N C D(y, y)}{2}
$$

A medida NCDs possui a vantagem de retornar 0 quando aplicada sobre dois documentos idênticos, o que é intuitivo. No entanto, o cálculo de medidas baseadas na complexidade de Kolmogorov tem um alto custo computacional.

Existem muitas outras medidas para quantificar a similaridade semântica entre dois documentos. Em particular, existe toda uma classe de medidas de similaridade baseadas na comparação direta entre strings (Salazar et al., 2013), que também não requerem representações intermediárias. Por exemplo, a distância Levenshtein ou distância de edição entre duas strings (duas sequências de caracteres) é dada pelo número mínimo de operações necessárias para transformar uma string em outra. Onde entende-se por "operações" a 
inserção, deleção ou substituição de um caractere.

Como mencionado anteriormente medidas baseadas na complexidade de Kolmogorov ou medidas baseadas na comparação entre strings não requerem representações intermediárias. Dessa forma, a etapa de pré-processamento não é necessária, evitando o custo computacional envolvido nessa etapa e a definição de parâmetros, como os limiares superior e inferior da Curva de Zipf. Além disso, em coleções que sofrem adição ou remoção de novos documentos, a representação vetorial deve ser gerada novamente a cada alteração da coleção. A medida NCDs e as medidas baseadas na comparação entre strings não sofrem com este problema, pois nenhuma representação é utilizada e a adição de novos documentos à coleção não altera as relações de similaridade entre os documentos que já estavam presentes, o que possibilita a paralelização do algoritmo.

\subsection{Considerações Finais}

Devido à sua natureza não estruturada, documentos necessitam de uma representação que possibilite sua mineração, recuperação e visualização. Neste capítulo foram apresentados algumas operações básicas para pré-processamento de textos, como a tokenização, eliminação de stopwords, stemming e cortes de Luhn. Também foram apresentadas duas das principais representações para coleções de documentos que buscam capturar sua informação semântica: a representação vetorial e a representação probabilística Latent Dirichlet Allocation (LDA). Por fim, foram apresentadas medidas de dissimilaridade para quantificar a semelhança semântica entre dois documentos de acordo com a representação adotada.

No próximo capítulo, serão apresentados diversos trabalhos que buscam associar técnicas de visualização com técnicas de mineração para ajudar na interpretação e exploração de coleções de documentos, enfatizando técnicas para visualização temporal de coleções de documento. O próximo capítulo também aborda o problema de mineração de tópicos, apresentando abordagens encontradas na literatura para detecção da evolução temporal de tópicos. 


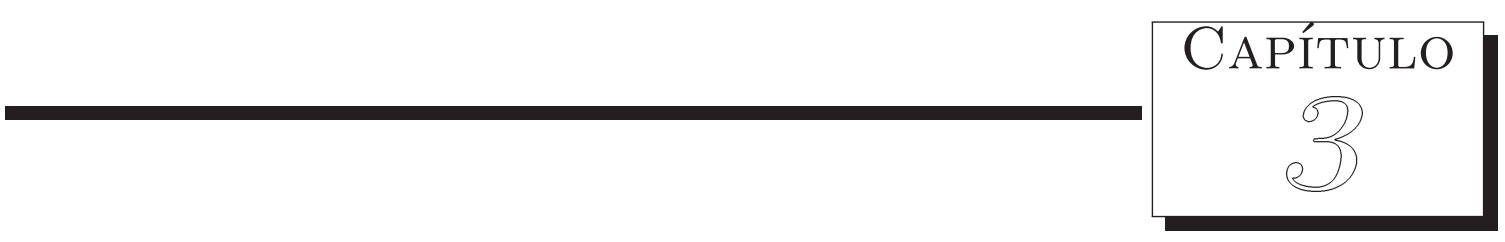

\section{Visualização de Documentos e Mineração de Tópicos}

Com o rápido crescimento de meios como a Internet, as pessoas têm acesso a uma grande quantidade de informação proveniente de bibliotecas digitais, sites de notícias e tantas outras fontes. Grande parte dessa informação está na forma de documentos eletrônicos. No entanto, acessar e interpretar tais dados e informações eficientemente representa um grande desafio em uma série de domínios e situações. Para analisar tal quantidade de documentos, os usuários podem se valer de técnicas de Visualização para criar modelos gráficos e representações visuais dos dados, com o objetivo de explorar a sofisticada capacidade visual do ser humano para facilitar a exploração e aquisição de informações úteis contidas nos dados (Oliveira; Levkowitz, 2003).

Enquanto isso, a mineração de textos envolve a descoberta de informações relevantes e previamente desconhecidas, extraídas automaticamente de uma grande coleção de documentos. A mineração de textos é complexa, pois envolve dados que são inerentemente não estruturados e às vezes imprecisos. Também é uma área multidisciplinar, que envolve temas como a recuperação de informações, aprendizado de máquina e mineração de dados (Tan, 1999). A integração de algoritmos de mineração e visualização permite associar a capacidade computacional com o conhecimento e capacidade de perceber padrões do ser humano, de modo a conceber ambientes adequados para usuários conseguirem extrair mais informações dos dados, de maneira mais efetiva.

Em coleções de documentos, um mecanismo que também pode auxiliar no processo de 
análise é a extração automática ou semiautomática de tópicos. Neste trabalho, adota-se a seguinte definição de tópico, inspirada nas definições elaboradas por Lopes et al. (2007) e Aggarwal e Zhai (2012):

Definição 3.1 Tópico - Conjunto de termos relacionados semanticamente, possivelmente possuindo uma distribuição probabilística associada, que coerentemente representa um tema comum abordado por um grupo de documentos.

Uma coleção de documentos também pode estar indexada temporalmente, o que permite, entre outras coisas, analisar a evolução temporal dos tópicos. Abordagens para detecção da evolução temporal dos tópicos de uma coleção geralmente buscam detectar eventos de transição, como a emergência de novos tópicos em instantes de tempo específicos, e mudanças no vocabulário de um tópico ao longo do tempo. Essa evolução temporal pode ser apresentada ao usuário por meio de uma representação visual.

Neste capítulo, são apresentados diversos trabalhos que buscam associar técnicas de visualização com técnicas de mineração para ajudar na interpretação e exploração de coleções de documentos. Uma revisão dessa área também pode ser encontrada em Alencar et al. (2012b). Na Seção 3.1, é apresentada uma visão geral de ferramentas e técnicas clássicas e recentes utilizadas na visualização de um único documento ou de coleções de documentos. Entre estas, enfatizamos técnicas para visualização temporal de coleções de documentos. A Seção 3.2 aborda o problema de mineração de tópicos, apresentando também abordagens encontradas na literatura para detecção da evolução temporal de tópicos.

\subsection{Visualização de Documentos}

Técnicas de visualização podem ser geradas para um único documento, com o interesse de mostrar o conteúdo relevante deste. Nessa linha destacam-se as $\boldsymbol{t a g}$ clouds, que se tornaram metáforas visuais populares nos últimos anos. Tag clouds simplesmente mostram os termos relevantes de um documento, considerando a frequência de ocorrência como uma medida de relevância. Dado um documento, é realizada sua tokenização e a contabilização da frequência para cada termo. As palavras mais frequentes são então apresentadas na visualização seguindo alguma ordem (alfabética, por exemplo) e layout, enquanto o tamanho de cada termo é proporcional ao número de ocorrências no documento.

A Figura 3.1a apresenta uma tag cloud gerada usando o site Many Eyes ${ }^{1}$ para visualizar o discurso de posse do presidente norte-americano Barack Obama. Nesta figura, o mouse foi posicionado sobre a palavra crisis (crise), mostrando o contexto das quatro ocorrências dessa palavra. A interface desta técnica no Many Eyes também permite procurar por determinadas palavras, usando a caixa de pesquisa no topo. Toda vez que uma tecla é pressionada, a visualização é atualizada para mostrar somente as palavras iniciadas com as letras digitadas.

${ }^{1}$ http://wwW-958.ibm.com 


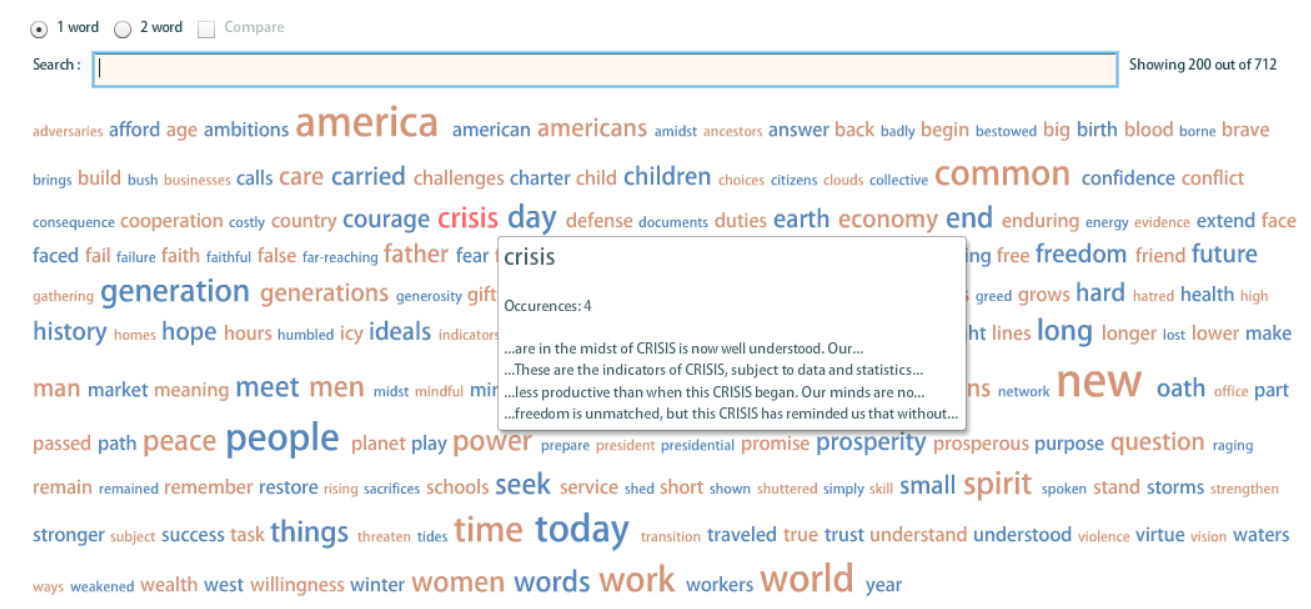

(a) Tag cloud gerada usando o site Many Eyes.

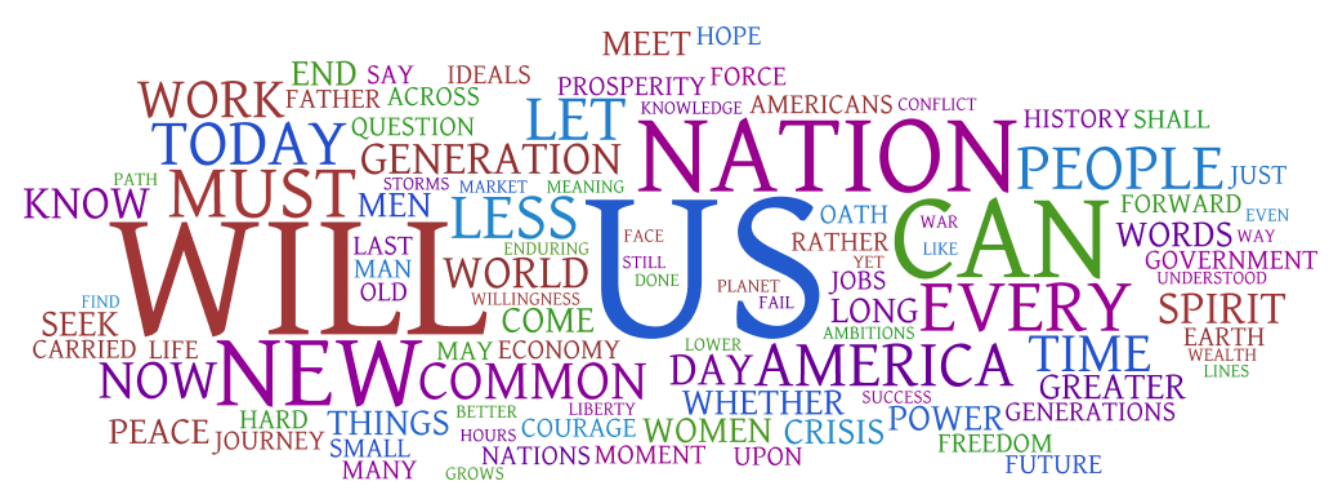

(b) Wordle.

Figura 3.1: Tag clouds para o discurso de posse do presidente norte-americano Barack Obama.

A técnica Wordle ${ }^{2}$ (Viegas et al., 2009) apresenta uma abordagem semelhante, mas adota uma heurística para otimizar a utilização da área visual disponível nas tag clouds. A diferença reside na maior preocupação com o aspecto visual do layout: uso de cores; uso mais eficiente do espaço tipográfico com palavras menores aparecendo dentro de outras; e várias opções de posicionamento das palavras (predominantemente horizontal; predominantemente vertical; horizontal e vertical; aleatório). A Figura 3.1b apresenta essa técnica aplicada ao discurso de posse do presidente Barack Obama, incluindo as 50 palavras mais frequentes na visualização. A técnica ManiWordle (Koh et al., 2010) dá controle sobre o layout produzido pela Wordle por meio de manipulações personalizadas.

Abordagens baseadas na frequência de termos, apesar de atraentes, são incapazes de representar os relacionamentos semânticos entre os mesmos. Diversas visualizações tentam superar esta limitação, por exemplo, visualizando o texto como uma árvore que permita uma rápida exploração do conteúdo. Esta é a lógica utilizada pela técnica Word Tree (Wattenberg; Viegas, 2008) ao criar uma "árvore de sufixos" que representa os termos como nós da árvore, enquanto os ramos representam a sequência entre termos. Os usuários podem fazer uma busca visual no documento fornecendo uma palavra ou frase a ser buscada na árvore do documento.

2 http://www. wordle.net 
Para criar a visualização, a técnica gera uma árvore com as frases encontradas, unindo repetições encontradas nessas frases. O tamanho da fonte de cada trecho é proporcional à sua frequência. A Figura 3.2a mostra uma visualização gerada usando o termo de busca "I" (eu) para o famoso discurso "I have a dream" (Eu tenho um sonho) do ativista político Martin Luther King, que falava da necessidade de união e coexistência harmoniosa entre negros e brancos. Note como a repetição one day é representada por um único nó. A técnica Word Tree também encontra-se disponível no site Many Eyes.

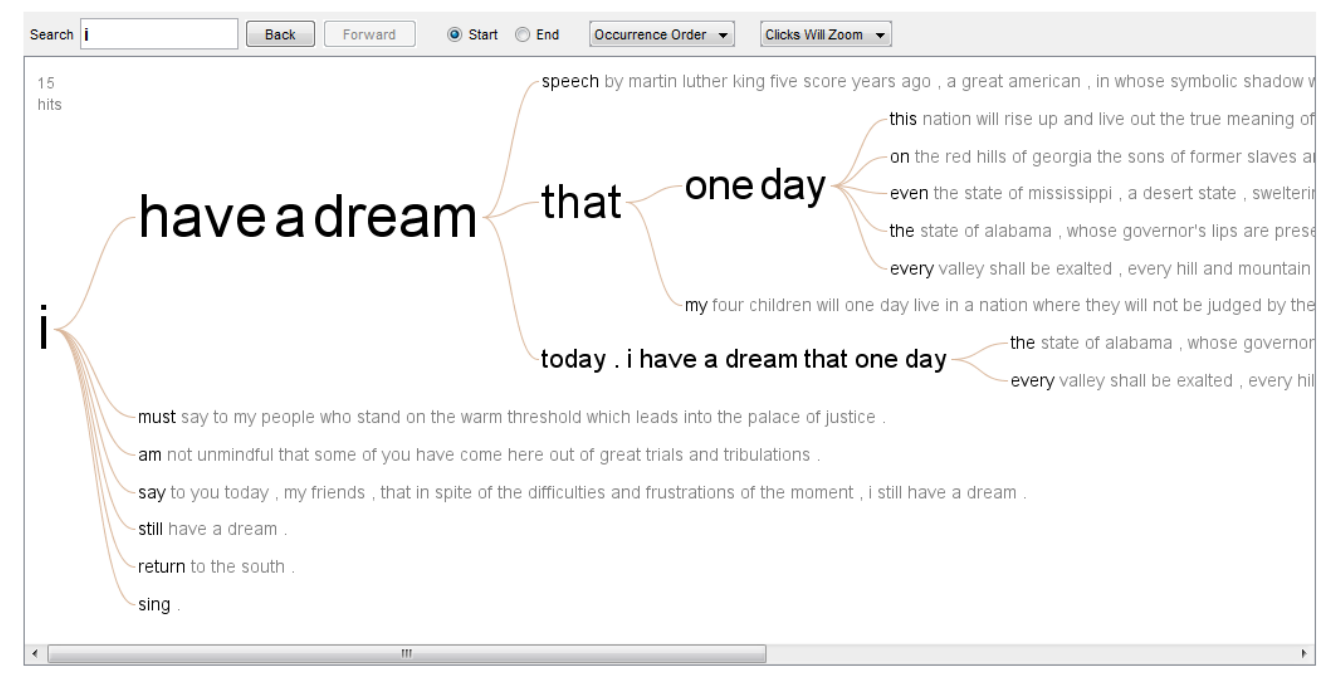

(a) Word Tree: discurso "I have a dream" (Eu tenho um sonho) de Martin Luther King.

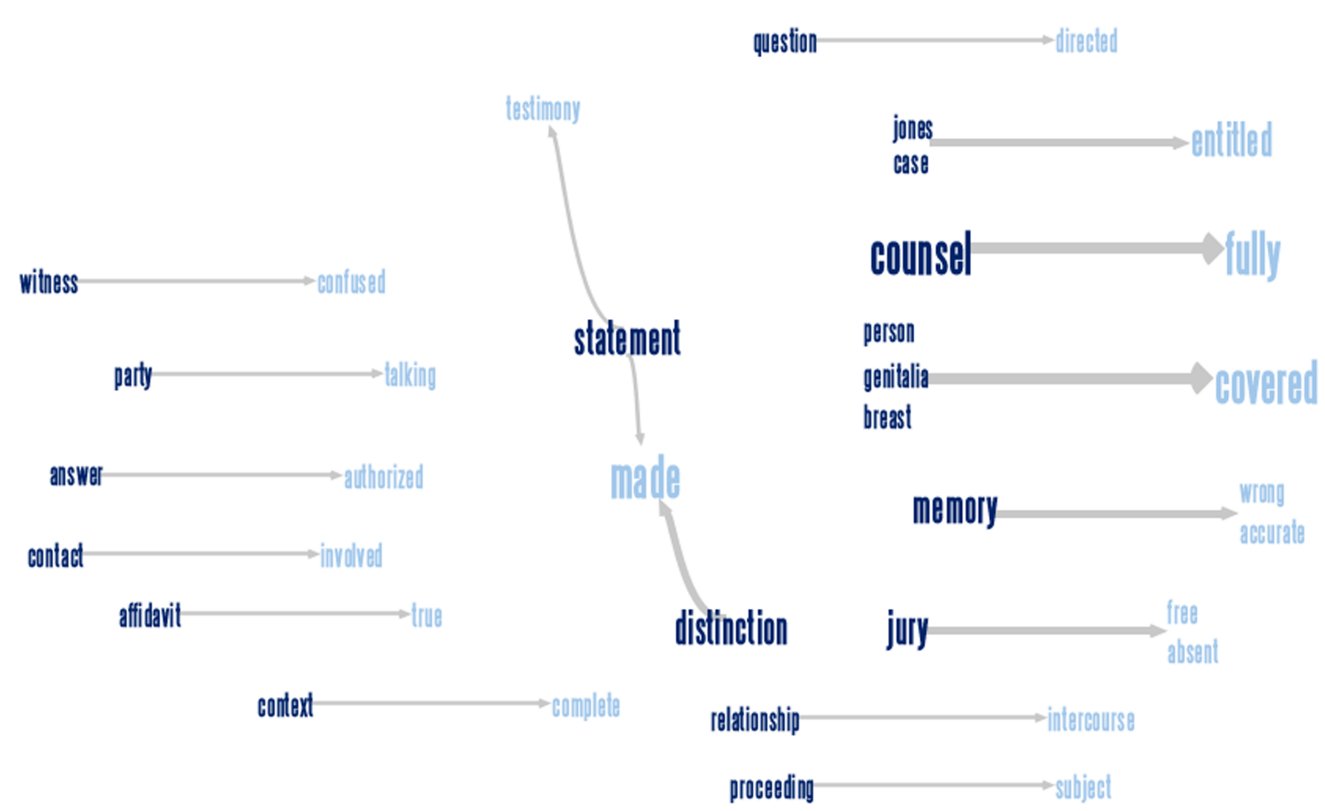

(b) Phrase Net: testemunho do ex-presidente norte-americano Bill Clinton em seu impeachment.

Figura 3.2: Técnicas Word Tree e Phrase Not.

Buscando apoiar análises mais detalhadas, a técnica Phrase Net (Ham et al., 2009) constrói um grafo cujos nós representam termos e arestas representam algum relacionamento entre os termos no nível sintático ou léxico. O tipo de relacionamento a ser visualizado é 
especificado pelo usuário por meio de um padrão. Por exemplo, o padrão "* and *" irá especificar dois termos unidos pela conjunção "and" (e) - frases do tipo "play and sing" obedecem a esse padrão. Phrase Net analisa o documento procurando por conjuntos de termos que se encaixam no padrão especificado, criando um grafo com os termos encontrados. Dois termos são conectados no grafo se eles ocorrem na mesma frase, obedecendo o padrão especificado. O tamanho de cada termo é proporcional ao número de vezes que ele ocorre, enquanto a espessura de uma aresta indica quantas vezes os dois termos ocorrem na mesma frase. A cor de um termo indica se este ocorre mais como primeiro ou como segundo termo de um padrão. Quanto mais escuro o termo, mais provável que apareça como primeiro termo. A Figura 3.2b mostra uma visualização obtida empregando a técnica Phrase Net para o testemunho do ex-presidente norte-americano William Jefferson "Bill" Clinton em seu impeachment em 1999, usando o verbo "is" (é ou está) como padrão representado. A técnica Phrase Net também encontra-se disponível no site Many Eyes.

\subsubsection{Visualização de Coleções de Documentos}

Quando o interesse é visualizar coleções de documentos, ao invés de um único documento, mapas são uma metáfora popular. Mapas de documentos são visualizações que refletem espacialmente algum relacionamento entre os documentos, provendo uma interface de navegação útil para acessar informações e melhorar a capacidade humana de resolver problemas relacionados ao gerenciamento de conhecimento (Becks et al., 2002). Metáforas baseadas em mapas são atraentes, pois elas imitam, em parte, mapas cartográficos, intuitivos para a maioria dos usuários. Por exemplo, duas soluções para visualizar coleções de documentos que adotam esta metáfora são as técnicas Cartographic Maps (Skupin, 2002) e Galaxies (Wise, 1999). A primeira gera uma visualização semelhante a um mapa geográfico, enquanto a última incorpora uma visualização que remete a um céu estrelado. Estas duas técnicas estão disponíveis no sistema de visualização de documentos IN-SPIRE ${ }^{T M}$ (Pnnl, 2008).

Dos métodos existentes para criar mapas de documentos, técnicas de projeção multidimensional estão entre as mais utilizadas.

Projeções Multidimensionais $\mathrm{O}$ termo projeção multidimensional tem sido empregado para denotar técnicas que mapeiam dados $m$-dimensionais em um espaço $p$-dimensional com $p=\{1,2,3\}$, preservando alguma informação sobre as relações de similaridade entre as instâncias de dados. O termo projeções multidimensionais engloba técnicas de três grandes grupos: técnicas baseadas na ideia de um sistema composto por objetos que estão sob a ação de forças de atração e repulsão (Chalmers, 1996; Tejada et al., 2003); técnicas que visam mapear o espaço original em um espaço visual (1D, 2D ou 3D) buscando preservar as relações de distância (Sammon, 1969; Paulovich et al., 2008; Joia et al., 2011); e técnicas que visam transformar o espaço original em um espaço de dimensão reduzida preservando algum tipo 
de característica dos objetos originais (Pearson, 1901; Faloutsos; Lin, 1995), i.e., técnicas de redução de dimensionalidade que são aplicáveis à geração de visualizações. Formalmente uma técnica de projeção multidimensional pode ser definida como:

Definição 3.2 Projeção Multidimensional (Tejada et al., 2003) - Seja X um conjunto de objetos em $\mathbb{R}^{m}$, e $\delta: \mathbb{R}^{m} \times \mathbb{R}^{m} \rightarrow \mathbb{R}$ uma medida de dissimilaridade entre os objetos em $\mathbb{R}^{m}$. Deseja-se encontrar um conjunto de pontos $X^{\prime}$ em $\mathbb{R}^{p}$ para $p \ll m$ (geralmente $p=2$ ) tal que se $f: X \rightarrow X^{\prime}$ é uma função que mapeia o conjunto de dados de $\mathbb{R}^{m}$ para $\mathbb{R}^{p}$, e $d: \mathbb{R}^{p} \times \mathbb{R}^{p} \rightarrow \mathbb{R}$ é uma medida de dissimilaridade em $\mathbb{R}^{p}$, então busca-se tornar $\left|\delta\left(x_{i}, x_{j}\right)-d\left(f\left(x_{i}\right), f\left(x_{j}\right)\right)\right|$ o mais próximo possível de zero para $\forall x_{i}, x_{j} \in X$.

O resultado da projeção é um conjunto de pontos $X^{\prime}$ em $\mathbb{R}^{p}$, cada um representando uma instância. Em geral $p=2$, o que resulta em conjunto de pontos no plano, cujas coordenadas podem ser utilizadas para gerar uma representação visual no espaço bidimensional. A similaridade é expressa pela vizinhança espacial entre os elementos no mapa, permitindo utilizar a habilidade humana de interpretação visual para analisar os dados. Idealmente, se pontos forem posicionados próximos nesse mapa, isso indica que as instâncias que eles representam são similares de acordo com a medida de dissimilaridade $\delta$ e, se os pontos forem projetados distantes, as instâncias são dissimilares ou pouco similares. Essas representações fornecem uma visão geral dos dados que favorece a identificação de elementos com padrões similares/dissimilares, provendo um ponto de partida para uma exploração mais detalhada.

Quando técnicas de projeção são aplicadas a coleções de documentos, elas dão origem a mapas de documentos. Neste contexto, essas técnicas geralmente tomam como entrada representações vetoriais (ver Seção 2.2.1), representações baseadas em tópicos (ver Seção 2.2.2) ou outras características extraídas. Alternativamente, algumas técnicas apenas necessitam de uma matriz de dissimilaridades, ou distâncias, entre todos os pares de documentos. Nesta seção, é utilizada uma coleção de 675 de artigos científicos intitulada $C B R-I L P-I R-S O N^{3}-$ cujo conteúdo inclui título, autores, resumos e referências - para criar mapas de documentos que ilustram algumas técnicas citadas. Esta coleção é composta por artigos de quatro áreas de pesquisa diferentes: Case-Based Reasoning (CBR), Inductive Logic Programming (ILP), Information Retrieval (IR) e Sonification (SON). Cores nos mapas indicam as áreas de pesquisa dos documentos, com vermelho para SON, verde-amarelado para IR, azul escuro para CBR e verde-água para ILP. Todos os mapas foram gerados com base na medida de dissimilaridade baseada em cosseno e na medida de frequência tf-idf, e também foram anotados com tópicos obtidos por uma técnica automática de extração de tópicos baseada em covariância (Paulovich, 2008) aplicada sobre agrupamentos identificados visualmente nas projeções.

Projeções multidimensionais do tipo Force-Directed Placement (FDP) (Fruchterman; Reingold, 1991) representam as instâncias a serem projetadas como um sistema de objetos

${ }^{3}$ Disponível em: http://vicg.icmc.usp.br/infovis2/DataSets 
conectados por molas que infligem forças de atração e repulsão sobre os objetos. Essas forças são proporcionais à diferença entre as dissimilaridades $\delta\left(x_{i}, x_{j}\right)$ no espaço $m$-dimensional e às dissimilaridades $d\left(f\left(x_{i}\right), f\left(x_{j}\right)\right)$ no espaço projetado $p$-dimensional. As forças geradas pelas molas são então usadas para iterativamente atrair ou repelir os objetos até o sistema atingir uma posição de equilíbrio. A representação matemática deste modelo de molas leva à definição de diferentes técnicas de FDP.

Na técnica Force Scheme (FS) (Tejada et al., 2003), o processo matemático característico de projeções do tipo FDP é simplificado utilizando deslocamentos em direções determinadas. Em cada interação, cada objeto tem seu posicionamento alterado $n-1$ vezes, pois ele é comparado a todos os outros objetos e sofre deslocamentos para cada uma dessas comparações de acordo com a diferença entre as dissimilaridades no espaço $m$-dimensional e no espaço $p$-dimensional. Para cada interação, o algoritmo tem uma complexidade $O\left(n^{2}\right)$. No entanto, por muitos deslocamentos serem realizados em uma única iteração, o algoritmo tende a convergir mais rapidamente do que abordagens tradicionais. A Figura 3.3a mostra um mapa obtido com a técnica FS para a coleção CBR-ILP-IR-SON. Neste mapa, apesar das diferentes áreas não se misturarem muito, elas não seriam visualmente distinguíveis se não fosse a cor. Isso se deve em parte à técnica considerar as distâncias entre todos os pares de instâncias, o que distorce as vizinhanças locais.

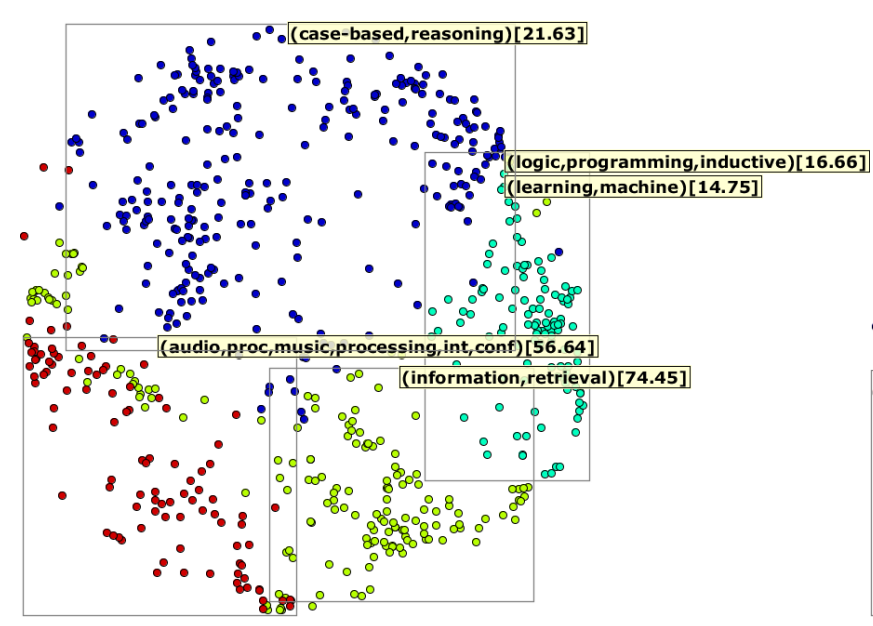

(a) Force Scheme (FS).

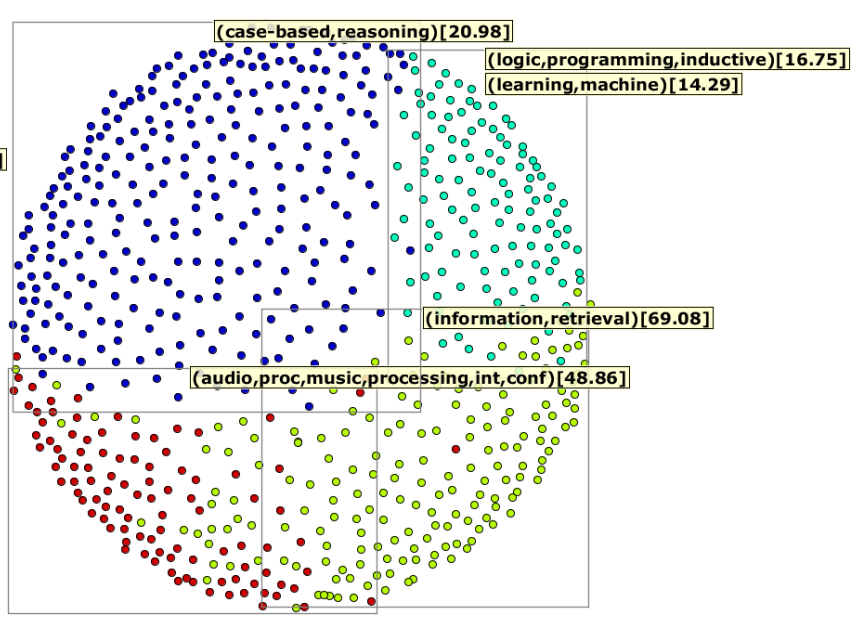

(b) Sammon's Mapping (SM).

Figura 3.3: Mapas de documentos para a coleção da artigos científicos CBR-ILP-IR-SON gerados com as técnicas Force Scheme (FS) e Sammon's Mapping (SM).

Técnicas de projeção multidimensional do tipo Multidimensional Scaling (MDS) estão entre as mais clássicas para gerar mapas de documentos. O MDS pode ser definido como um conjunto de técnicas que realizam um mapeamento injetivo entre as instâncias pertencentes a um espaço $m$-dimensional em pontos em outro espaço $p$-dimensional, buscando preservar ao máximo as relações de distância para todo par de instâncias do espaço $m$-dimensional no espaço p-dimensional. A forma como essa preservação de instâncias é realizada é que leva à 
definição de diferentes técnicas de MDS.

Dentre as técnicas de MDS mais conhecidas, temos o SM (Sammon, 1969), que busca encontrar uma configuração de distâncias $d\left(f\left(x_{i}\right), f\left(x_{j}\right)\right)$ que se aproximem de $\delta\left(x_{i}, x_{j}\right)$ para $\forall x_{i}, x_{j} \in X$. Esta aproximação é realizada minimizando uma função de stress na qual as pequenas dissimilaridades terão maior peso do que as grandes, obtendo um balanço entre preservação das estruturas locais e globais. Para a minimização da função de stress e consequente definição das coordenadas projetadas, é usado um método iterativo não-linear que emprega o gradiente dessa função para encontrar um mínimo local (Pekalska et al., 1999). A Figura 3.3b mostra um mapa de documentos obtido com a técnica SM para a coleção CBR-ILP-IR-SON. Neste mapa as diferentes áreas de pesquisa também não seriam visualmente distinguíveis se não fosse a cor. Isso também se deve em parte ao fato de considerar as distâncias entre todos os pares de documentos e, apesar de as distâncias maiores (globais) terem menor peso, nesta técnica elas também são consideradas. Outro problema desta e de muitas outras técnicas do tipo MDS é sua alta complexidade computacional, $O\left(n^{2}\right)$, o que inviabiliza sua aplicação a grandes conjuntos de dados.

Embora os mapas possam acelerar tarefas que exigem a exploração de coleções de documentos, esses mapas sofrem de alguns problemas críticos, como a sobreposição de elementos gráficos e a sobrecarga cognitiva enfrentada por usuários em layouts que mostram muitos documentos simultaneamente. Estratégias hierárquicas têm sido desenvolvidas para tratar essas limitações, permitindo aos usuários visualizar mapas em vários níveis de detalhe, partindo de grandes grupos de documentos e gradualmente refinando e navegando até chegar a pequenos grupos de documentos e documentos individuais.

A técnica InfoSky (Andrews et al., 2002) apresenta uma abordagem interessante para coleções de documentos organizadas hierarquicamente. O espaço visual é subdividido recursivamente em diagramas de Voronoi aninhados para visualizar a hierarquia. Usuários podem aumentar ou diminuir o zoom em certas áreas da projeção, como se estivessem utilizando um telescópio. Para coleções sem uma estrutura hierárquica inerente, a técnica Hierarchical Point Placement (HiPP) (Paulovich; Minghim, 2008) aplica um particionamento recursivo para inferir automaticamente uma árvore de agrupamentos a partir dos dados. Nós da árvore são projetados para criar uma visualização com múltiplos níveis de detalhe de grupos e subgrupos de documentos representados por círculos aninhados. A localização de círculos na representação visual reflete a similaridade entre os documentos que os compõe. Este processo de projeção hierárquica é realizado aplicando recursivamente a técnica Least Square Projection (LSP), a ser descrita na próxima seção, e evitando a sobreposição entre os diferentes grupos.

A Figura 3.4a mostra um mapa criado com a técnica HiPP para a coleção $C B R-I L P-I R$ $S O N$. Para atribuir uma cor a um grupo, utilizou-se a cor da área de pesquisa mais frequente nos documentos contidos pelo grupo. Se a área mais frequente em um grupo é responsável por menos de $70 \%$ dos seus documentos, utiliza-se uma cor neutra (bege). Esse mapa 
apresenta o nível mais alto do mapa (a projeção do nó raiz), onde os círculos representam grupos compostos por subgrupos. O usuário pode interagir com os nós de alto nível no mapa e verificar quais são os subgrupos de um nó raiz e como os dados estão organizados hierarquicamente. O usuário também pode reagrupar os nós conforme a sua escolha.

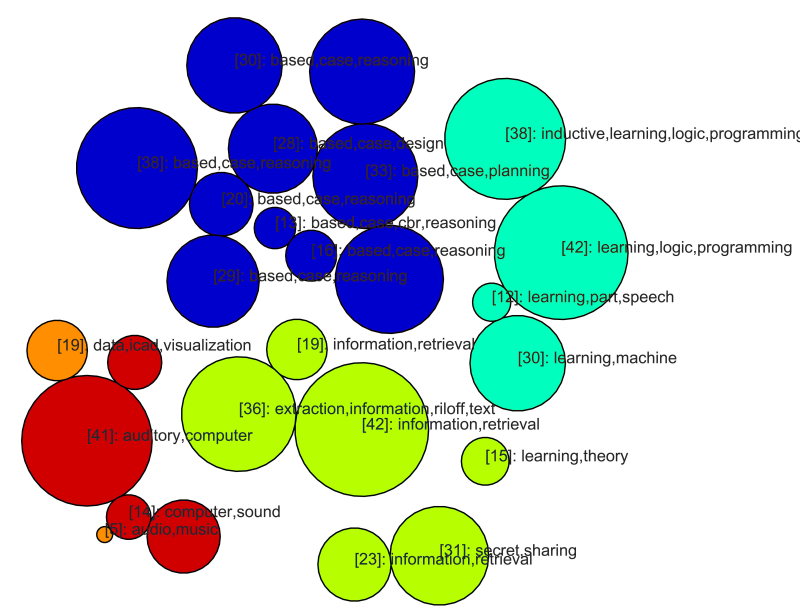

(a) Hierarchical Point Placement (HiPP).

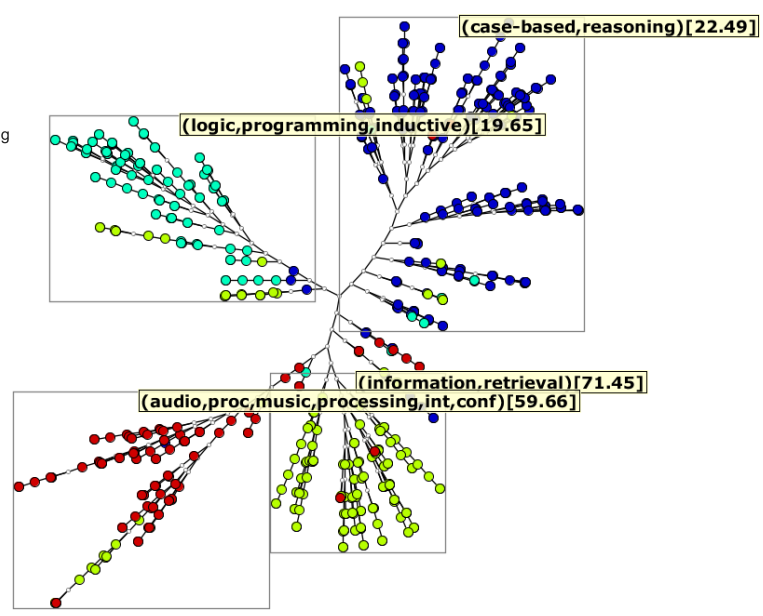

(b) Neighbor Joining (NJ).

Figura 3.4: Mapas de documentos para a coleção da artigos científicos CBR-ILP-IR-SON gerados com as técnicas Hierarchical Point Placement (HiPP) e Neighbor Joining (NJ).

Uma abordagem que difere das projeções é a técnica de posicionamento de pontos NJ (Cuadros et al., 2007). A NJ posiciona as instâncias em uma árvore por meio de um algoritmo de construção de árvores filogenéticas, que agrupa recursivamente pares de instâncias similares por meio de nós ancestrais. Essa árvore é então desenhada no plano por um algoritmo para layout radial (Bachmaier et al., 2005). Algumas interações simplificadas baseadas no modelo FDP também são aplicadas aos nós para evitar sobreposição. A Figura 3.4b mostra um mapa de documentos criado com a técnica NJ para a coleção CBR-ILP-IR-SON. Esse tipo de abordagem nos permite visualizar uma hierarquia de similaridade entre os documentos.

A técnica ProjCloud (Paulovich et al., 2012) cria um mapa de documentos que combina técnicas de projeção multidimensional com tag clouds. Primeiramente, a coleção é projetada utilizando a LSP (poderia ser utilizada qualquer outra técnica de projeção). Em uma segunda etapa, os grupos de documentos similares para os quais serão gerados tag cloud devem ser detectados, obtidos utilizando o algoritmo de agrupamento bisecting $k$-means (Steinbach et al., 2000). Nessa etapa, também é calculado o fecho convexo de cada grupo. Por fim, tag clouds são construídas para os termos mais frequentes em cada grupo, cujo formato e limites são determinados pelo fecho convexo do grupo. Os termos são organizados dentro da tag cloud de forma a preservar os relacionamentos semânticos entre eles. A Figura 3.5 mostra o mapa criado com a técnica ProjCloud para a coleção CBR-ILP-IR-SON. Essa abordagem ainda traz a vantagem de relacionar diretamente quais são os termos mais relevantes em cada grupo. 


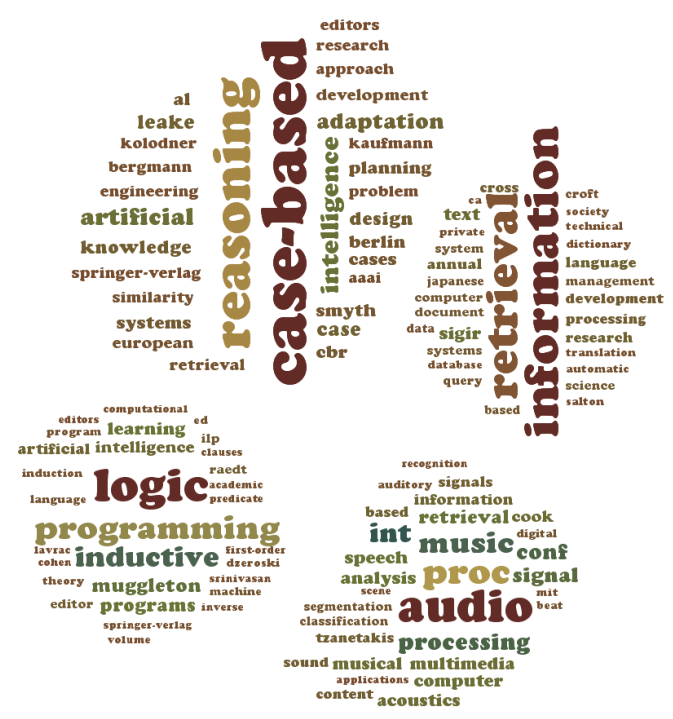

Figura 3.5: Mapa de documentos para a coleção da artigos científicos CBR-ILP-IR-SON gerado com a técnica ProjCloud.

A seguir explicamos em detalhes a técnica LSP, que é utilizada como parte do processo de criação da projeção multidimensional dinâmica desenvolvida nesta tese.

Least Square Projection (LSP) Muitas outras questões também devem ser consideradas ao gerar mapas de documentos por meio de técnicas de projeção multidimensional. A técnica de projeção Least Square Projection (LSP) (Paulovich et al., 2008) adota uma estratégia diferente ao tentar preservar as relações de vizinhança locais ao invés das relações de dissimilaridade entre documentos de forma global. Esta abordagem é executada em dois passos principais. No primeiro passo, um subconjunto de instâncias da coleção, chamados "pontos de controle", é projetado em $\mathbb{R}^{p}$ empregando uma técnica de projeção de alta precisão. Em um segundo passo, partindo de relações de vizinhança estabelecidas entre as instâncias de dados em $\mathbb{R}^{m}$ e das coordenadas cartesianas dos pontos de controle em $\mathbb{R}^{p}$ obtidas no primeiro passo, um sistema linear é construído e solucionado para obter as coordenadas projetadas das demais instâncias em $\mathbb{R}^{p}$. Essas demais instâncias são projetadas no fecho convexo de seus vizinhos, tomando os pontos de controle como âncoras que adicionam informações geométricas ao sistema.

A escolha dos pontos de controle deve ser cuidadosa, pois afeta a qualidade da projeção. Eles devem ser escolhidos de forma a representar o melhor possível a distribuição dos dados em $\mathbb{R}^{m}$. Uma boa abordagem para escolhê-los envolve a execução de um algoritmo de agrupamento, criando-se nc agrupamentos. Depois, escolhe-se o medóide (objeto mais próximo do centróide) de cada agrupamento como sendo o ponto de controle, obtendo nc pontos de controle. O algoritmo de agrupamento bisecting k-means (Steinbach et al., 2000) é o indicado por Paulovich et al. (2008) para a escolha dos pontos de controle, utilizando o valor de $n c$ como parâmetro para o número de agrupamentos a serem obtidos. Uma 
melhor representação dos possíveis grupos existentes nos dados (ou da distribuição presente) é um fator importante na LSP, já que essa é a informação global que será preservada. Uma vez definidos os pontos de controle, os mesmos devem ser projetados em $\mathbb{R}^{p}$ por meio de uma técnica de projeção multidimensional de alta precisão, tal como a técnica Force Scheme (FS) (Tejada et al., 2003).

Além da representatividade dos pontos de controle, deve-se atentar à quantidade de pontos, $n c$, a ser utilizada. Valores altos aumentam o custo computacional da projeção dos pontos de controle, pois geralmente técnicas de alta precisão são $O\left(n^{2}\right)$, onde $n$ é o número de instâncias. Quando o valor de nc é muito alto e próximo do número total de instâncias, a projeção final também preserva demasiadamente a informação global, distorcendo as vizinhanças locais. Paulovich et al. (2008) recomendam o valor $\sqrt{n}$ para o parâmetro $n c$. Se $\sqrt{n}$ pontos de controle forem escolhidos e uma técnica de projeção de alta precisão com complexidade $O\left(n^{2}\right)$ for utilizada para projetar os pontos de controle, a complexidade computacional para a definição dos pontos de controle é $O(n \sqrt{n})$ (Paulovich et al., 2008).

Juntamente com as coordenadas projetadas dos pontos de controle também é necessário definir uma lista de pontos vizinhos $V_{i} \in X$ para cada instância $x_{i} \in X$, formando as relações de vizinhança dos dados $V=\left\{V_{1}, \ldots, V_{n}\right\}$. Cada lista $V_{i}=\left\{x_{i 1}, \ldots, x_{i k_{i}}\right\}$ poderia ser criada com o algoritmo $k$-Nearest Neighbor $(\mathrm{k}-\mathrm{NN})$, que identifica as $k$ instâncias mais próximas do objeto $x_{i}$, segundo a função de distância no espaço multidimensional $\delta$. No entanto, essa abordagem teria alta complexidade, $O\left(n^{2}\right)$. Uma aproximação que tende a gerar bons resultados, segundo Paulovich et al. (2008), utiliza os agrupamentos definidos durante o processo de definição dos pontos de controle. Nessa abordagem aproximada, primeiramente é realizada uma busca pelos $k$ agrupamentos mais próximos de cada agrupamento, tomando com base a proximidade de seus respectivos medóides. Em um segundo momento, quando uma busca pelos vizinhos mais próximos de uma instância $x_{i}$ for realizada, somente o agrupamento a que $x_{i}$ pertence e os agrupamentos mais próximos desse serão examinados. Essa abordagem aproximada para definição das relações de vizinhança tem a vantagem de ser determinada pelo número de agrupamentos $(\sqrt{n})$, obtendo uma complexidade igual a $O(n \sqrt{n})$. Para o parâmetro $k$, número de vizinhos identificados para cada objeto na relação de vizinhança, Paulovich et al. (2008) recomendam o valor 10.

Também é necessário verificar a condição de sobreposição sobre as relações de vizinhança, que assegura que esta se comporta como se fosse um grafo com um único componente conexo. Se as relações de vizinhança forem examinadas e perceber-se que algum objeto $x_{i}$ está desconexo dos demais, deve-se incluir na sua lista de vizinhos $V_{i}$ um novo vizinho que seja próximo a ele e que faça parte do componente conexo principal.

Com as coordenadas projetadas dos pontos de controle e as relações de vizinhança, é possível construir o sistema linear, cuja solução é a projeção dos demais documentos no espaço bidimensional. Seja $V_{i}=\left\{x_{i 1}, \ldots, x_{i k_{i}}\right\}$ o conjunto de $k_{i}$ documentos na vizinhança do documento $x_{i}$. As coordenadas da projeção de $x_{i}$ em $\mathbb{R}^{p}, \widetilde{x_{i}}$, podem ser calculadas pela 
seguinte equação:

$$
\widetilde{x_{i}}-\frac{1}{k_{i}} \sum_{x_{j} \in V_{i}} \widetilde{x_{j}}=0
$$

Segundo a Equação 3.1, a projeção de cada objeto $x_{i}$ será no fecho convexo das projeções dos objetos em sua vizinhança $V_{i}$. A Equação 3.1 resulta em um conjunto de sistemas lineares, cujas soluções são as coordenadas dos objetos projetados:

$$
L x_{i}=0, L x_{2}=0, \ldots, L x_{p}=0
$$

onde $x_{1}, x_{2}, \ldots, x_{p}$ são vetores de tamanho $n$ que contém as coordenadas dos objetos projetados para cada uma das $p$ dimensões, e $L$ é a matriz $n \times n$ cujas entradas são dadas por:

$$
l_{i j}= \begin{cases}1 & i=j, \\ -\frac{1}{k i} & x_{j} \in V_{i}, \\ 0 & \text { caso contrário. }\end{cases}
$$

onde as entradas $l_{i j}$ juntas representam a Equação 3.1. O problema é que nenhuma informação geométrica está contida em $L$, então as soluções do sistema linear podem não ser úteis. De forma a possibilitar esse uso, a informação geométrica é inserida por meio das coordenadas dos pontos de controle projetados na primeira etapa.

Os pontos de controle $P=\left\{p_{1}, \ldots, p_{n c}\right\}$ são inseridos no sistema como novas linhas na matriz L. As coordenadas geométricas da projeção desses pontos são inseridas no lado direito do sistema, gerando um vetor não-nulo $b$. Dessa forma, reescreve-se a Equação 3.2 na forma da Equação 3.4:

$$
A x=b
$$

onde $A$ é uma matrix retangular $(n+n c) \times n$ dada por:

$$
A=\left(\begin{array}{c}
L \\
C
\end{array}\right), \quad c_{i j}= \begin{cases}1 & x_{j} \text { é um ponto de controle } \\
0 & \text { caso contrário. }\end{cases}
$$

e $b$ é o vetor não-nulo:

$$
b_{i}= \begin{cases}0 & i \leq n \\ p_{i_{c}} & n<i \leq n+n c\end{cases}
$$

onde $p_{i_{c}}$ é uma das coordenadas da projeção do ponto de controle $p_{i}$.

A Figura 3.6 apresenta um exemplo de matriz $A$ para um conjunto $X$ com seis pontos. 
Os vizinhos de cada ponto são dados pelas relações de incidência do grafo direcionado da Figura 3.6a e os nós em azul são pontos de controle.

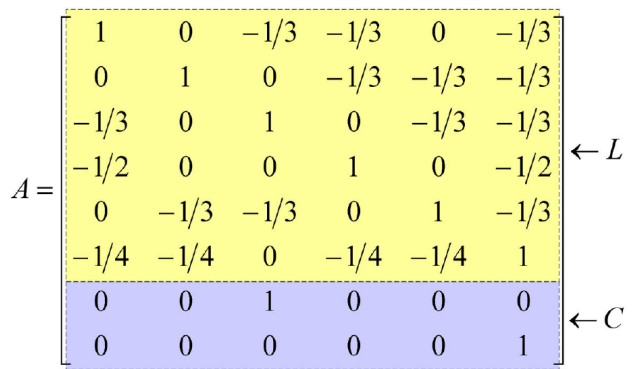

(a) Relações de vizinhança com pontos de controle $X_{3}$ e $x_{6}$.

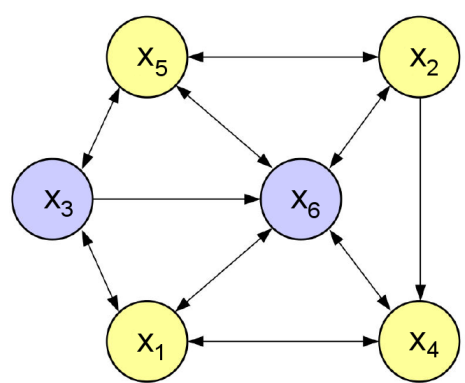

(b) Matriz $A$ do sistema linear.

Figura 3.6: Least Square Projection (LSP): Relações de vizinhança, pontos de controle e matriz A do sistema linear. Extraído de Paulovich et al. (2008).

Segundo Paulovich (2008), esse sistema linear apresenta rank completo e pode ser resolvido aplicando-se mínimos quadrados. Isso significa que se deve encontrar $x$ que minimize $\|A x-b\|^{2}$, i.e., $A^{T} A x=A^{T} b$. O sistema $A^{T} A x=A^{T} b$ é simétrico e esparso, o que permite empregar métodos eficientes de resolução, como a decomposição de Cholesky (Davis, 2006) (método direto) ou gradientes conjugados (Shewchuk, 1994) (método iterativo). Se um método iterativo como o gradientes conjugados for utilizado, a complexidade para resolver tal sistema é $O(n \sqrt{k})$, onde $k$ é o número de condição da matriz $A^{T} A$.

Dessa forma, Paulovich (2008) definem a complexidade global da LSP como $O(C+N+S)$, onde $C$ é a complexidade de escolher os pontos de controle, $N$ é a complexidade de definir as relações de vizinhança e $S$ é a complexidade para resolver o sistema linear. Como mencionado anteriormente, $C=N=O(n \sqrt{n})$ e $S=O(n \sqrt{k})$. Portanto, a complexidade computacional

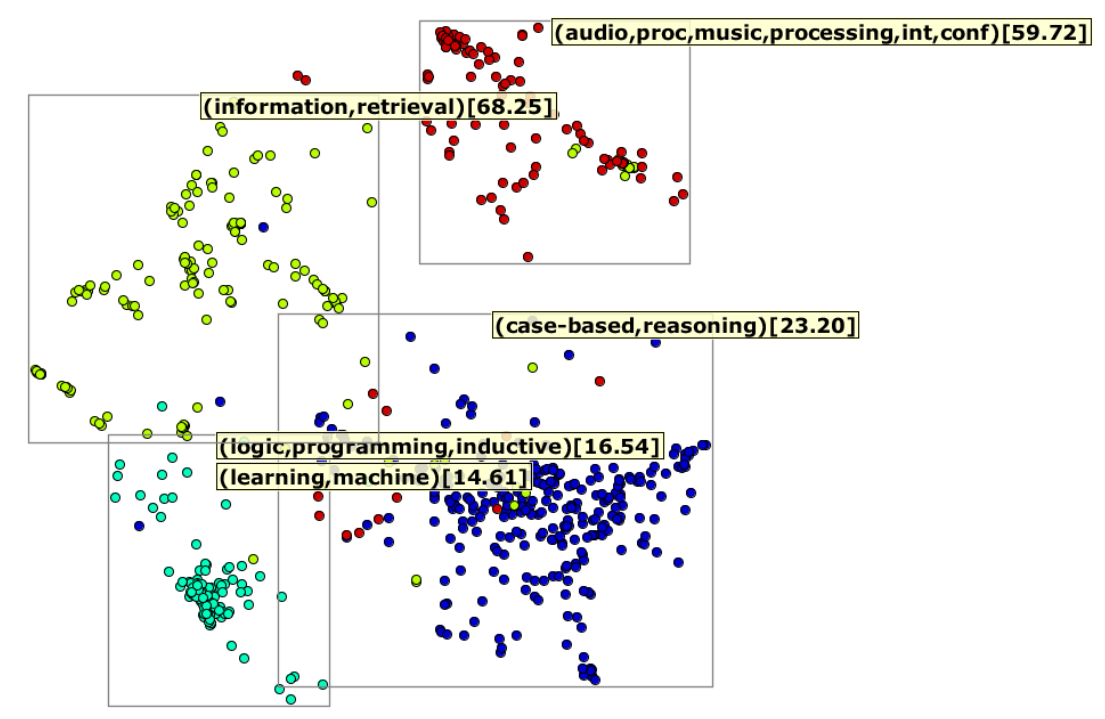

Figura 3.7: LSP- mapas de documentos para a coleção da artigos científicos CBR-ILP-IR$S O N$. 
final da LSP será $O(\max \{n \sqrt{n}, n \sqrt{k}\})$, o que permite que a LSP seja capaz de projetar grandes conjuntos de instâncias de alta dimensionalidade em tempos satisfatórios.

A Figura 3.7 mostra um mapa de documentos, obtido com a técnica LSP para a coleção $C B R-I L P-I R-S O N$. A cor de cada círculo indica a área de pesquisa a qual cada documento pertence. Como é possível observar, este mapa separa melhor os quatro grupos de artigos científicos.

\subsubsection{Visualização Temporal de Coleções de Documentos}

Atributos temporais também estabelecem relacionamentos relevantes em coleções de notícias, arquivos de e-mails ou artigos científicos, nas quais um atributo temporal informa qual foi a data/hora que uma notícia foi publicada, um e-mail foi enviado, ou um artigo científico foi publicado. Apesar de nem sempre ser tratada explicitamente, a componente temporal é fundamental para entender e analisar mudanças nos tópicos em coleções de documentos indexadas temporalmente. Trata-se de um problema difícil, que vem atraindo crescente atenção nos últimos anos.

Vários autores tentam adaptar técnicas existentes para visualização de documentos, como tag clouds, para tratar coleções indexadas temporalmente. A técnica SparkClouds (Lee et al., 2010), por exemplo, mostra uma sparkline (um gráfico de linha simplificado) debaixo de cada termo para evidenciar a variação na sua frequência ao longo do tempo. Cui et al. (2010) introduziram uma técnica que obtém uma sequência de tag clouds, buscando preservar a coerência semântica e de localização espacial dos termos ao longo do tempo. Cada tag cloud da sequência é associada a um gráfico de tendência, que expressa a sua significância temporalmente. A significância de uma tag cloud é maior quando essa traz mais informação por si só e compartilha pouca informação (termos) com as tag clouds adjacentes a ela.

Entretanto, a análise temporal de coleções de documentos é um processo muito mais complexo do que aquele que pode ser capturado por tag clouds variantes no tempo. A seguir são apresentadas técnicas relevantes encontradas na literatura para a visualização temporal de coleções de documentos.

ThemeRiver A metáfora de um "rio" é frequentemente aplicada na visualização temporal de documentos, como no protótipo ThemeRiver (Havre et al., 2002) que descreve mudanças temáticas ocorridas em um conjunto de documentos ao longo do tempo. Temas selecionados são representados utilizando a metáfora de um 'rio' que corre da esquerda para a direita, associado à evolução do tempo. Esse 'rio' é composto por camadas coloridas, que representam os temas, e cuja largura é proporcional à força (número de ocorrências) do tema na coleção em um determinado instante de tempo. A largura total em um determinado ponto indica a força total dos temas selecionados. Temas podem desaparecer e depois ressurgir com a mesma cor e ordem em relação aos outros temas. O usuário também pode adicionar marcadores 
para indicar eventos históricos que possam estar relacionados com as mudanças temáticas. O foco desta abordagem está em mudanças temporais relativas à frequência dos temas. Não é apresentado nenhum evento de transição, como a junção de dois ou mais tópicos para formar outro.

A Figura 3.8 mostra uma visualização, gerada com o ThemeRiver, de um conjunto de documentos referentes à crise cubana-americana ocorrida em 1960. A visualização foi anotada manualmente pelos autores com eventos externos que podem ter gerado mudanças na frequência de certos temas.

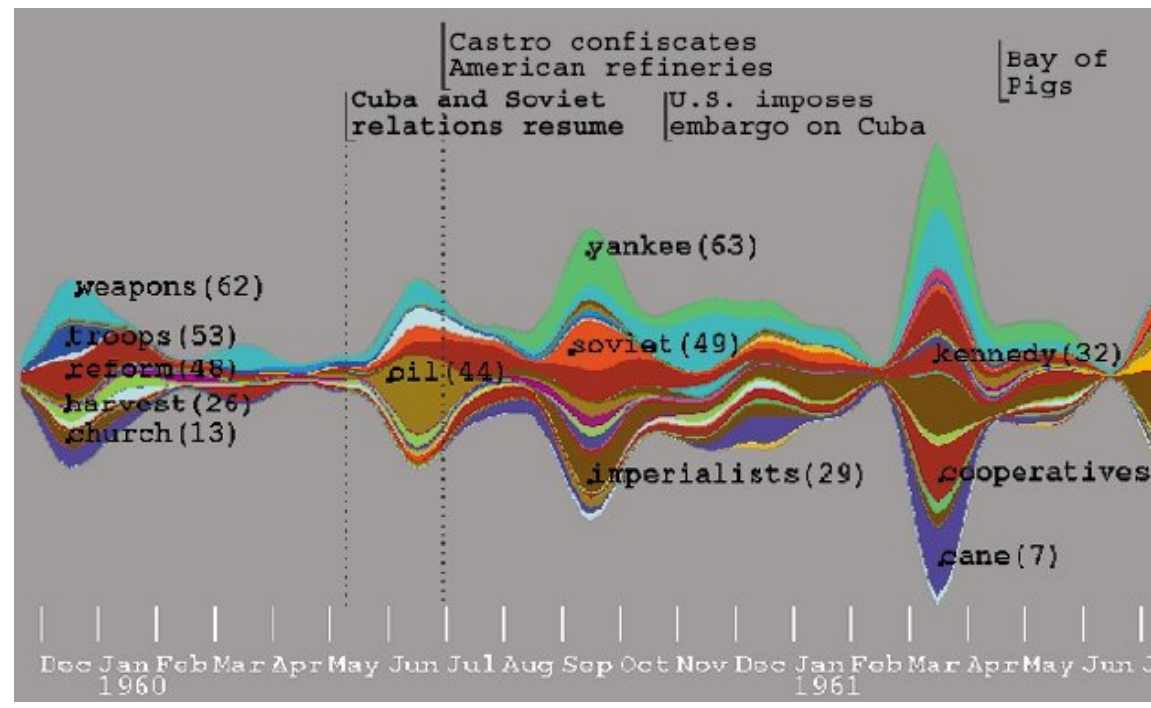

Figura 3.8: ThemeRiver: metáfora de um rio para indicar mudanças temáticas relativas a frequência ocorridas ao longo do tempo em uma coleção de documentos referentes à crise cubana-americana em 1960. Extraído de Havre et al. (2002).

O ThemeRiver é classicamente utilizado como exemplo de visualização temporal de documentos, mas, apesar da técnica ser interessante e inovadora, ela apresenta algumas limitações. Os autores não esclarecem como são escolhidos os temas a serem visualizados, o que vem a ser uma etapa fundamental e crítica. Supõe-se que essa escolha seja baseada no número de ocorrências de um termo dentro da coleção, o que nem sempre é uma abordagem adequada. Outra limitação ocorre quando um grande número de temas for selecionado, já que o uso de cor para diferenciá-los pode ocasionar uma baixa distinção visual.

TIARA A ferramenta TIARA (Text Insight via Automated Responsive Analytics) (Liu et al., 2012) também busca evidenciar a evolução temporal do conteúdo dos tópicos de uma coleção de documentos. A técnica de extração de tópicos Latent Dirichlet Allocation (LDA) (ver Seção 2.2.2) é aplicada para determinar automaticamente quais são os tópicos abordados pela coleção, permitindo gerar uma representação visual baseada nos tópicos. Para determinar exatamente que documentos pertencem a cada tópico segundo o modelo LDA, somente probabilidades de um documento $d$ pertencer a um tópico $t$ maiores do que 0,3 são 
consideradas.

Para permitir a análise da evolução temporal do conteúdo de uma coleção, esta ferramenta seleciona automaticamente palavras-chave temporais para cada tópico. Dada uma coleção, primeiro os documentos são separados em subcoleções, cada uma associada a um intervalo de tempo diferente. Então, para um tópico em particular no qual é provável um conjunto de palavras, as palavras mais "importantes" são determinadas para cada subcoleção segundo dois critérios: (1) se uma palavra ocorre frequentemente nesta subcoleção ela é importante; (2) porém, se esta palavra também ocorre frequentemente nas demais subcoleções, sua importância é diminuída. A frequência das palavras é medida por meio de uma mistura da frequência terms frequency (tf) com a probabilidade de ocorrência daquela palavra naquele tópico segundo o modelo LDA.

Para visualizar os tópicos extraídos por LDA e suas palavras-chave temporais, a ferramenta utiliza um gráfico de área empilhado com eixo central. Cada camada colorida representa um tópico e é preenchida com tag clouds de palavras-chave temporais, representando a mudança no conteúdo dos tópicos ao longo do tempo. A altura de cada camada muda ao longo do tempo, pois representa a força daquele tópico naquele instante de tempo, medida com base no número de documentos abordando o tópico.

A Figura 3.9 mostra os 8 tópicos mais importantes (prováveis) em uma coleção de 10.000 e-mails pessoais dos autores. O primeiro tópico (cor verde), por exemplo, aborda as palavras "harvest, table, data..." em março, enquanto que em agosto as palavras "java, code, vjit..." são mais mencionadas. Um sumário do segundo tópico considerando todo o intervalo de tempo é apresentado por uma tooltip.

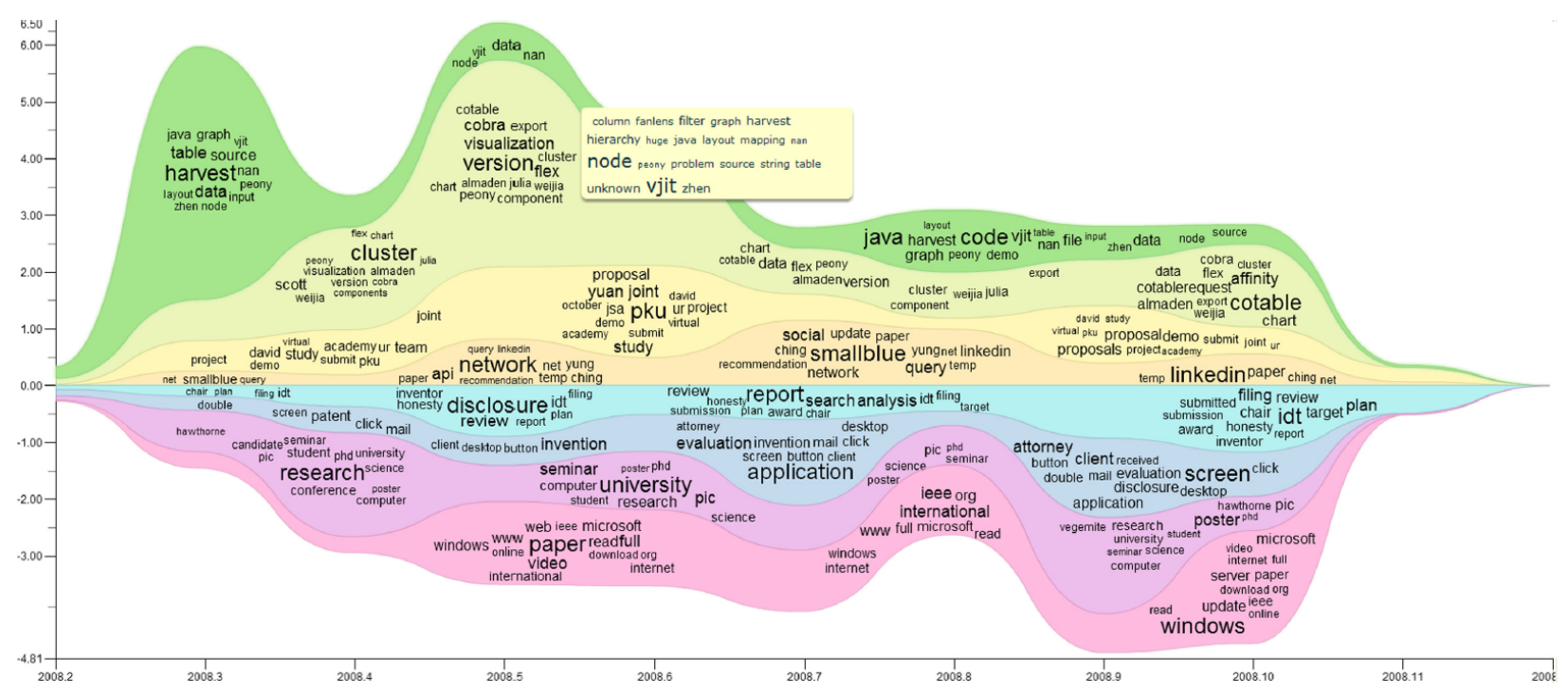

Figura 3.9: TIARA: sumário visual criado para 10.000 e-mails em 2008. Extraído de Liu et al. (2012).

A metáfora visual utilizada assemelha-se à adotada pelo ThemeRiver, porém com maior poder de representação dos tópicos. No entanto, considera-se somente um número fixo de 
tópicos ao longo do tempo, ignorando que tópicos podem sofrer, por exemplo, junções ou subdivisões. Também somente alguns poucos tópicos mais prováveis, segundo o modelo LDA, são mostrados simultaneamente.

TextFlow A ferramenta TextFlow (Cui et al., 2011), desenvolvida pelos mesmos autores da ferramenta TIARA, também busca analisar a evolução temporal dos tópicos de uma coleção de documentos, porém focando sua análise na detecção de eventos críticos entre os tópicos - surgimento, junção, subdivisão e desaparecimento de tópicos. Primeiramente, um conjunto de tópicos (representados por grupos de documentos) e seus eventos críticos são detectados automaticamente por meio da técnica de agrupamento evolucionário Processo Hierárquico Incremental de Dirichlet (Teh et al., 2006). De modo a auxiliar o usuário na identificação do conteúdo dos tópicos e entender os principais motivos que impulsionaram o surgimento dos eventos críticos, correlações entre palavras-chave são detectadas por meio da contagem de suas coocorrências nos documentos. Esta informação é então representada visualmente como um fluxo de tópicos, formado por três elementos visuais: correntes que representam os tópicos; marcadores em vermelho que representam eventos críticos e são colocados nos instantes que eles ocorrem; e linhas azuis que representam as palavras-chave, com seu entrelaçamento significando interações entre essas palavras-chave. Também existem dois outros componentes visuais nessa ferramenta que ajudam a compreender o conteúdo de um tópico selecionado no fluxo de tópicos: uma tag cloud que exibe os termos mais frequentes para o tópico selecionado; e uma linha do tempo que mostra os snippets para os documentos pertencentes ao tópico selecionado ordenados temporalmente (somente aplicável a coleções de notícias).

Em Cui et al. (2011), os autores mostram a aplicação dessa ferramenta para uma coleção de 993 artigos científicos publicados nas conferências IEEE Information Visualization (Info Vis) e IEEE Visualization (Vis) de 2001 até 2010. A Figura 3.10 mostra o fluxo de tópicos relacionado aos tópicos da conferência Info Vis. O evento crítico "d", por exemplo, indica que

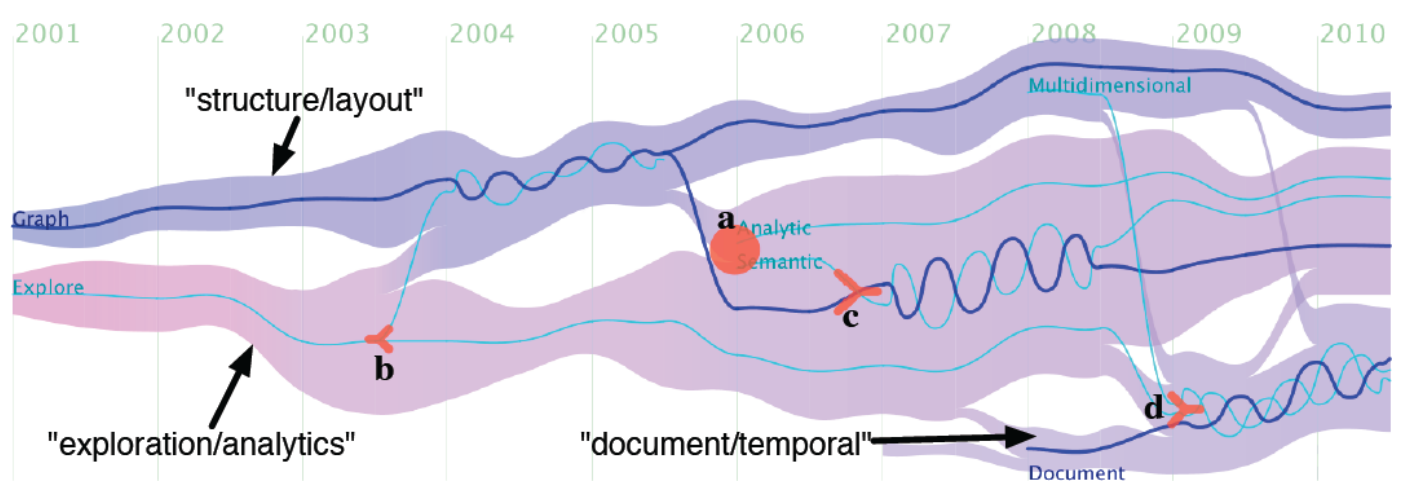

Figura 3.10: TextFlow: fluxo de tópicos para parte dos artigos publicados na conferência IEEE Information Visualization (InfoVis) de 2001 até 2010. Pares de palavras-chave com setas e letras identificando eventos foram adicionados manualmente. Extraído de Cui et al. (2011) 
o tópico "document/temporal" (caracterizado pelas palavras-chave explore e document) tornouse um tópico importante na conferência InfoVis perto de 2009. O tópico "document/temporal" também é bastante relacionado aos tópicos "exploration/analytics" e "structure/layout". Já a palavra-chave 'analytic', por exemplo, tornou-se relevante em 2006, o que coincide com a primeira edição do simpósio IEEE Symposium on Visual Analytics Science and Technology (IEEE VAST). Esse simpósio acontece juntamente com as conferências InfoVis e Vis desde 2006.

Uma limitação dessa técnica é a escolha de palavras-chave significantes. Se somente algumas palavras-chave são incluídas no fluxo de tópicos, muita informação é perdida. Por outro lado, se muitas palavras-chave são mostradas, a visualização pode sofrer de oclusão visual.

CiteSpace II Segundo Chen (2006a), áreas de pesquisa apresentam dois padrões de citação: artigos clássicos que são consistentemente citados ao longo do tempo e artigos transitórios com picos de citação por curtos períodos de tempo, sendo o segundo padrão mais comum do que o primeiro. O caráter transitório na citação de artigos ocorre devido à tendência de pesquisadores citarem os artigos publicados mais recentemente. Os artigos transitórios podem estar associados a novas descobertas científicas ou tendências de pesquisa, sendo responsáveis pela transformação de uma área de pesquisa. A ferramenta CiteSpace II (Chen, 2006a) constrói representações visuais que mostram como as frentes de pesquisa e as bases intelectuais mudam ao longo do tempo e seus padrões transitórios.

Termos da frente de pesquisa são identificados pelo algoritmo de detecção de bursts de palavras de Kleinberg (2002), que retorna uma lista ordenada dos bursts de palavras - quando uma palavra tem um aumento repentino e significante no seu uso durante um intervalo de tempo - e o intervalo de tempo no qual eles ocorreram. A base intelectual é formada por grupos de artigos citados por artigos que incluem os termos da frente de pesquisa. A representação visual final é uma grande rede híbrida que evidencia o mapeamento dos artigos das bases intelectuais e termos das frentes de pesquisa ao longo do tempo, composta tanto por nós que representam os artigos da base intelectual como por nós que representam os termos da frente de pesquisa. Três tipos de arestas ocorrem nesta rede: coocorrência de termos da frente de pesquisa; co-citação de artigos da base intelectual; e termos da frente de pesquisa citando artigos da base intelectual.

A abordagem "dividir para conquistar" é utilizada para criar essa rede híbrida. O intervalo de tempo que abrange o conjunto de artigos analisados é particionado em segmentos temporais. Redes híbridas são geradas para cada um desses segmentos, aplicando-se o algoritmo Pathfinder Network Scaling (PFNet) (Schvaneveldt, 1990) para reduzir o número de arestas e reter somente as arestas mais importantes para cada segmento. Redes de diferentes segmentos de tempo têm parte dos nós e arestas em comum. Como último passo, essas redes devem ser agrupadas, o que é alcançado pela união de todos os nós e pela seleção 
somente das arestas que não violam uma condição de desigualdade triangular em áreas de sobreposição entre redes. A medida de centralidade betweenness - que mede a importância do nó para a rede - é utilizada para identificar e destacar nós pivôs nos quais ocorrem mudanças de paradigma ao longo do tempo.

A Figura 3.11a ilustra os atributos visuais utilizados para representar cada artigo da base intelectual como um nó composto por anéis, um anel para cada segmento de tempo a partir da publicação do documento. A cor de um anel representa o segmento de tempo correspondente, de acordo com o mapeamento que associa cores a segmentos de tempo, apresentado na parte inferior da figura. A largura de um anel é proporcional ao número de citações que um artigo obteve em determinado segmento de tempo. O número próximo ao centro dos nós é o número de citações obtidas durante todo o intervalo de tempo. Arestas indicam a co-citação de artigos, com a cor da aresta indicando o ano da primeira co-citação. Para facilitar a identificação dos nós pivôs, este tipo de nó é destacado com um anel roxo na parte mais externa. Já os termos são representados simplesmente por seus caracteres no layout com tamanho proporcional ao peso de seu burst.

A Figura 3.11b apresenta uma rede relativa a uma coleção de 1.776 artigos sobre terrorismo publicados entre 1990 a 2003. O grupo no canto superior esquerdo em verde está relacionado a ferimentos em ataques terroristas, e sua frente de pesquisa inclui os seguintes termos: body injuries e terrorist bombing. Já um agrupamento no canto superior direito em amarelo-laranja está relacionado a pesquisas na área de saúde em resposta a ameaças de armas químicas e biológicas, e contém os termos health care e chemical weapon. Por fim, o grupo no canto inferior em laranja está relacionado aos impactos psicológicos do ataque terrorista de 11 de Setembro de 2001, contendo os termos September 11, United States e post-traumatic stress disorder.

\subsubsection{Projeções Multidimensionais Dinâmicas}

Uma estratégia para visualizar temporalmente coleções de documentos é criar novas técnicas de projeção multidimensionais dinâmicas, ou adaptar as técnicas existentes para tratar a componente temporal explicitamente de forma a evidenciar as mudanças nas relações de similaridade ao longo do tempo. Essa estratégia está relacionada ao problema de calcular layouts que evoluem para mostrar as mudanças nos dados.

Muitas projeções multidimensionais dinâmicas utilizam animação para apresentar as mudanças ao longo do tempo. Neste contexto, também é necessário evitar o fenômeno chamado change blindness quando as instâncias se movem. Esse fenômeno ocorre quando o usuário permanece alheio à mudança ou ao movimento na representação, mesmo quando esperados e perceptíveis, por exemplo, quando múltiplas mudanças ocorrem na visualização simultaneamente, ou quando a mudança é muito rápida ou excessivamente lenta. Nesse cenário, o usuário é forçado a comparar as cenas anteriores e posteriores em sua memória 


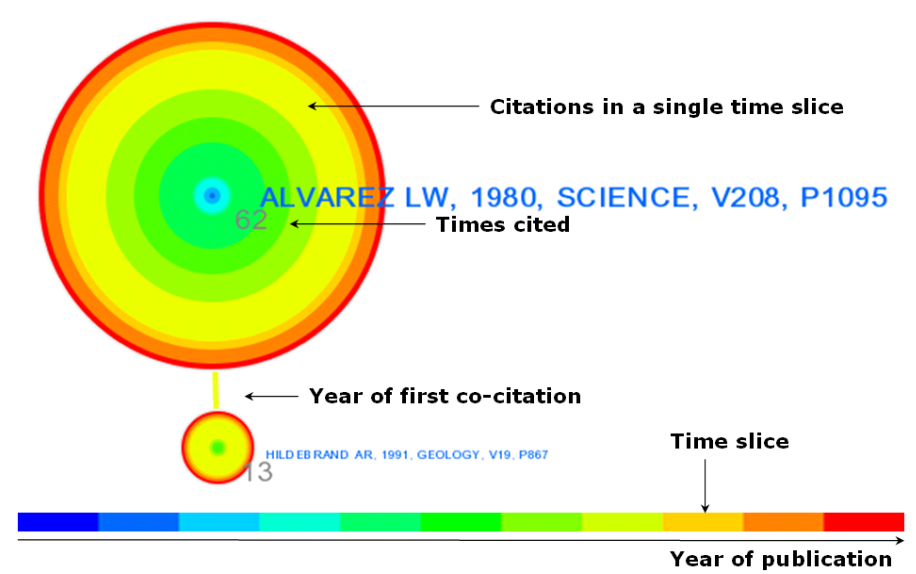

(a) Representação visual de artigos na base intelectual.

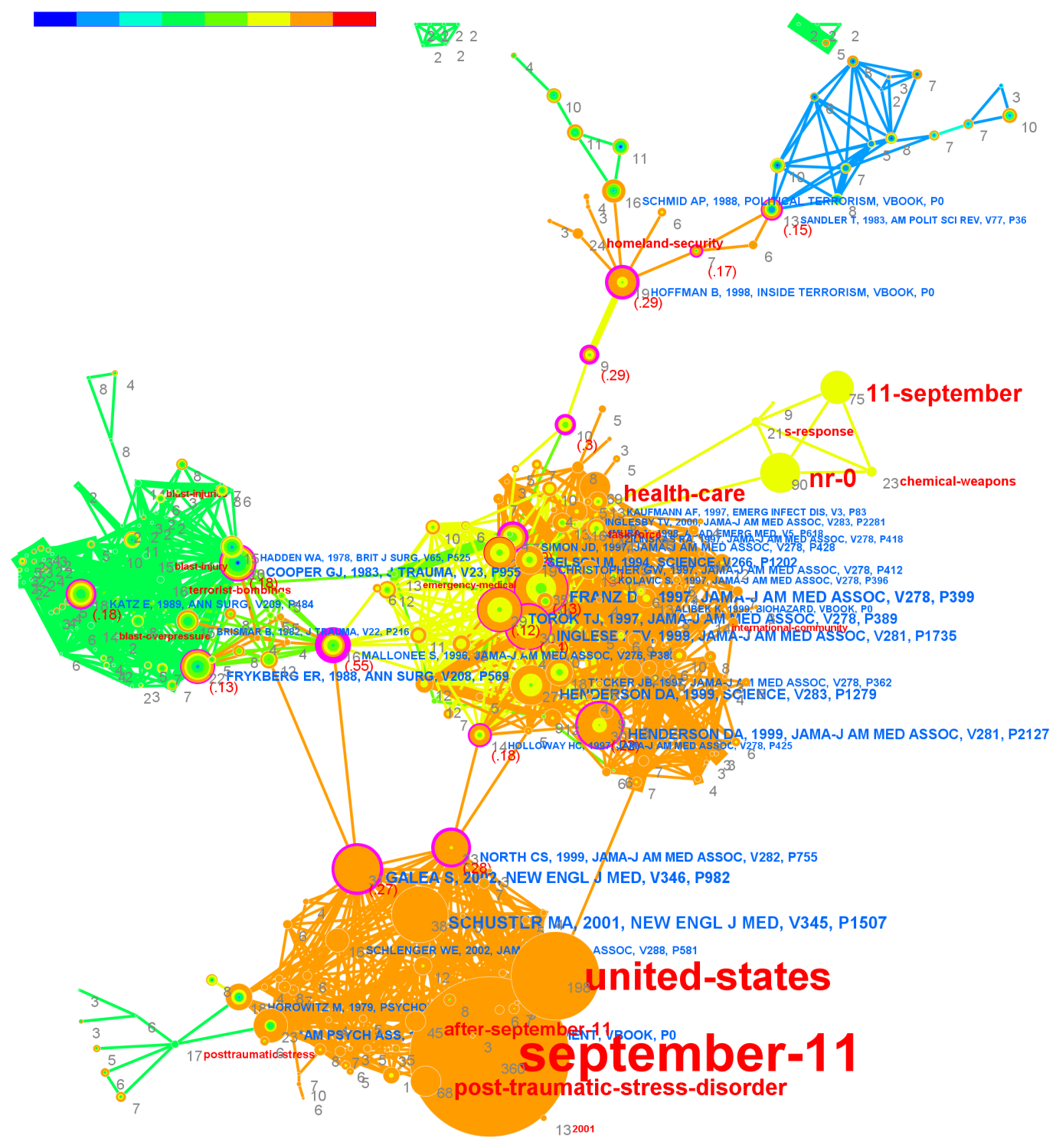

(b) Rede híbrida

Figura 3.11: CiteSpace II: Rede híbrida composta por termos de uma frente de pesquisa, artigos de uma base intelectual e seus relacionamentos ao longo do tempo para uma coleção de artigos sobre terrorismo publicados entre 1990 a 2003. Extraído de Chen (2006a). 
visual na tentativa de descobrir o que ocorreu. Dessa forma, a visualização temporal gerada não deve ser difícil de acompanhar e deve dar controle ao usuário para avançar ou retroceder no tempo.

No entanto, nem toda técnica de projeção dinâmica é aplicável diretamente a coleções de documentos. Por exemplo, a técnica Part-Linear Multidimensional Projection (PLMP) (Paulovich et al., 2010) busca inferir a transformação linear $f: X \rightarrow X^{\prime}$, com $X$ em $\mathbb{R}^{m}$ e $X^{\prime}$ em $\mathbb{R}^{p}$, capaz de projetar eficientemente todo o conjunto de dados $X$ sem precisar calcular as relações de similaridade entre todas as instâncias. Essa transformação $f$ é inferida a partir do resultado da projeção de instâncias representativas, escolhidas utilizando uma técnica de agrupamento, por meio de uma técnica de projeção FDP. Esta técnica também pode ser aplicada em cenários streaming, pois se as instâncias representativas e suas posições forem conhecidas a priori, é possível inferir $f$ e projetar novas instâncias a medida que elas chegam. Segundo os autores, com algum conhecimento prévio sobre os dados é possível "manufaturar" instâncias representativas sem precisar percorrer todos os dados. No entanto, esta técnica mostrou-se eficiente somente em dados que possuem um número muito maior de instâncias do que de atributos, o que a torna inapropriada para coleções de documentos.

A seguir, são apresentadas técnicas e ferramentas dedicadas a gerar projeções dinâmicas para coleções de documentos.

Streamit A maioria das ferramentas de visualização de documentos variantes no tempo baseia-se na suposição de que toda a coleção encontra-se disponível a priori. Buscando uma solução incremental que permitisse a adição e remoção de elementos durante a geração da visualização, Alsakran et al. (2012) desenvolveram a ferramenta Streamit para visualizar coleções de documentos em streaming, que constantemente recebem novos documentos.

A ferramenta utiliza uma projeção multidimensional dinâmica baseada em uma técnica de projeção do tipo Force-Directed Placement (FDP), que iterativamente aproxima pontos projetados mais longe e repele pontos projetados mais próximos do que deveriam. O processo iterativo deste tipo de técnica dá o comportamento dinâmico necessário à ferramenta.

Para determinar a posição inicial de novos documentos a serem inseridos na projeção, o layout atual é dividido em células retangulares, para posterior inserção do novo documento no centro de uma célula da grade que contém o maior número de documentos similares a ele. A representação visual é então atualizada executando novas iterações na técnica de projeção. Uma resolução apropriada da grade deve ser selecionada para cada coleção de documentos dependendo do seu tamanho. Os autores argumentam que grades com tamanho $50 \times 50$ são geralmente uma boa escolha.

Para trabalhar com uma dimensionalidade menor do que a que seria obtida em uma representação vetorial da coleção, a técnica LDA é empregada. Além de reduzir a dimensionalidade do espaço de termos-documentos, o LDA também obtém tópicos que são 
utilizados como atributos e possuem maior poder de representação. No entanto, o LDA é na verdade aplicado a uma outra coleção de documentos que deve ser muito similar a que o usuário deseja visualizar. Cada documento novo a ser adicionado à representação visual deve então ser comparado aos tópicos extraídos para esta outra coleção de forma a determinar os tópicos que melhor o representam. O documento é então representado por um vetor de probabilidades de acordo com a sua similaridade a esses tópicos mais representativos.

Agrupamentos são identificados em cada momento na projeção e depois analisados quanto à sobreposição de elementos entre instantes de tempo sucessivos para identificar a sua evolução, e.g., quando dois grupos unem-se formando um novo tópico que é a junção dos dois. Uma técnica que define a importância (peso) de um termo ao longo do tempo também é empregada, que dá mais importância a termos mais antigos, mais frequentes e que aparecem em diversos documentos.

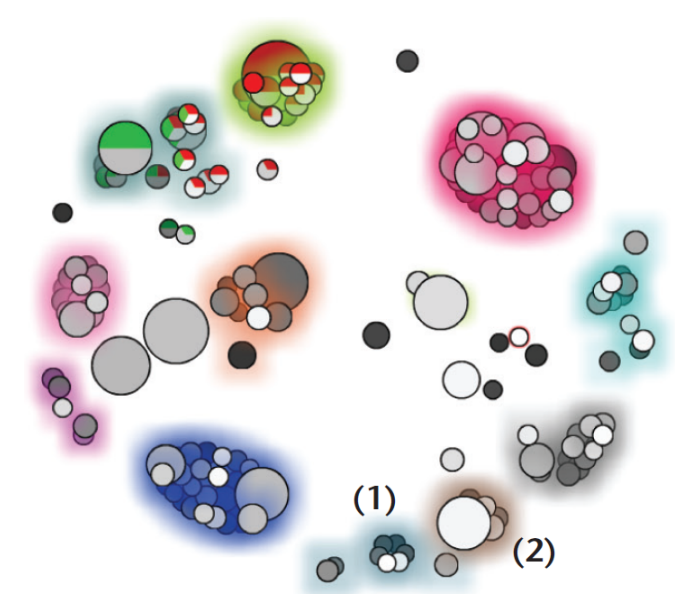

(a) Setembro de 2000 (172 projetos de pesquisa).

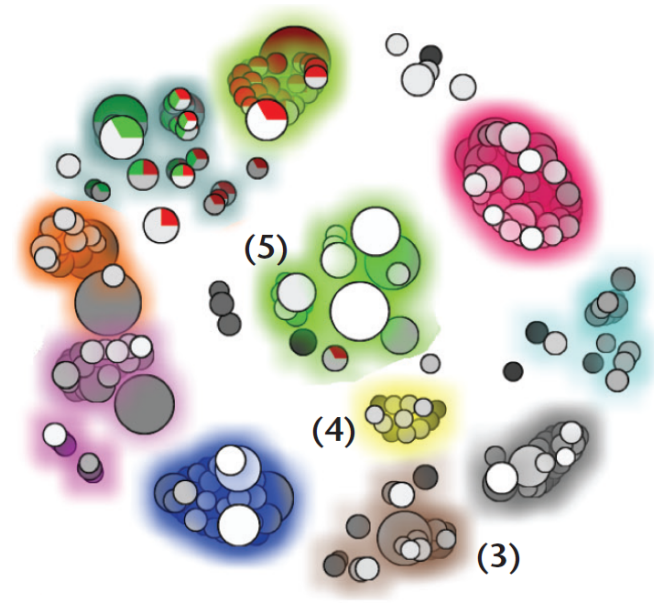

(b) Setembro de 2001 (330 projetos de pesquisa).

\begin{tabular}{|c|l|}
\hline Número do tópico & Termos com maior peso \\
\hline \hline 2 & Data, Mine, Cluster, Graph, Biology, Analysis, Discovery \\
\hline 6 & Image, Scene, Model, Recognition, Language, Shape, Speech \\
\hline 12 & Biological, Protein, Genome, Search, Gene, Sequence, Patent \\
\hline 13 & Video, Motion, ASL, 3D, Camera, Sign, Dance \\
\hline 15 & Image, Speech, Haptic, Display, Impair, Auditory, Graphic \\
\hline 16 & Query, Database, Data, XML, Stream, Edu \\
\hline 19 & Data, Workflow, Privacy, Management, Web, Metadata \\
\hline
\end{tabular}

(c) Tabela de tópicos.

Figura 3.12: Streamit: Coleção de 1.000 projetos de pesquisa do US National Science Foundation Information and Intelligence Systems (NSF IIS) que foram coletados entre março de 2000 e agosto de 2003. Extraído de Alsakran et al. (2012).

A Figura 3.12 apresenta dois instantes de tempo da projeção dinâmica obtida com a ferramenta Streamit para uma coleção de 1.000 projetos de pesquisa do US National Science Foundation Information and Intelligence Systems (NSF IIS). Esses projetos de pesquisa 
foram representados por seus respectivos abstracts e foram coletados pelos autores entre março de 2000 e agosto de 2003. A Figura 3.12c apresenta parte dos tópicos extraídos pela técnica LDA relacionados aos projetos na figura. Cada círculo representa um projeto e seu tamanho é proporcional ao valor do financiamento recebido. Os grupos maiores, identificados por um algoritmo de agrupamento, têm auréolas coloridas para identificá-los. Documentos associados a tópicos selecionados pelo usuário na interface da ferramenta são representados por gráficos de pizza, com a fatia proporcional ao peso daquele tópico no documento. A Figura 3.12a apresenta o instante de tempo de setembro de 2000. Gráficos de pizza em vermelho indicam o tópico 16 e gráficos de pizza em verde indicam o tópico 19. Já a Figura 3.12b apresenta o instante de tempo de setembro de 2001. Os grupos (1) e (2) na Figura 3.12a sofreram uma junção que gerou o grupo (3) na Figura 3.12b. Já os grupos (4) (principalmente sobre tópico 13) e (5) (principalmente sobre tópico 12) na Figura 3.12b são novos.

A necessidade de ter uma coleção de documentos auxiliar que deve ser similar a que se deseja visualizar é um ponto negativo nessa abordagem. Para obter uma coleção de documentos tão similar sem um custo adicional de criar tal coleção, geralmente é necessário dividir a coleção original em duas. É possível fazer o download de um vídeo de demonstração da ferramenta na página http://www.cs.kent.edu/ zhao/streamit.htm. Neste vídeo é possível perceber o efeito de change blindness ocorrendo na representação visual, e.g., os documentos movem-se muito rapidamente dificultando a percepção de eventos relacionados. A ferramenta não se encontra disponível online.

TextPool O sistema TextPool (Albrecht-buehler et al., 2005) busca gerar visualizações capazes de detectar e refletir a evolução temporal de uma coleção de documentos. Esse sistema também gera um grafo, sendo que os vértices representam os termos mais frequentes (salientes) e as arestas entre os vértices indicam a coocorrência dos termos nos documentos. O tamanho dessas arestas é inversamente proporcional à coocorrência: quanto maior a coocorrência entre dois termos, menor a aresta correspondente entre eles. O grafo é animado de acordo com a mudança temporal.

O grafo também é desenhado utilizando uma técnica de projeção baseada em forças FDP. O grafo representa somente os termos recentes, segundo uma janela temporal controlada pelo usuário. Um documento pode expirar e fazer com que os termos presentes nesse documento tenham sua coocorrência diminuída, aumentando a distância entre esses termos. Se um termo passa a ocorrer menos do que o número de vezes necessárias para que um termo seja considerado saliente, esse termo desaparece. Quando isso ocorre, ele vai tornando-se transparente até deixar de ser representado e os termos restantes movem-se suavemente para ocupar o espaço deixado. Já um termo que se torna saliente é apresentado primeiro na borda do grafo e vai sendo lentamente reposicionado na posição adequada para refletir os seus relacionamentos com os demais termos. A Figura 3.13 apresenta o grafo gerado pela ferramenta TextPool para uma coleção de sumários de notícias abrangendo um período de 6 
horas em 5 de abril de 2004.

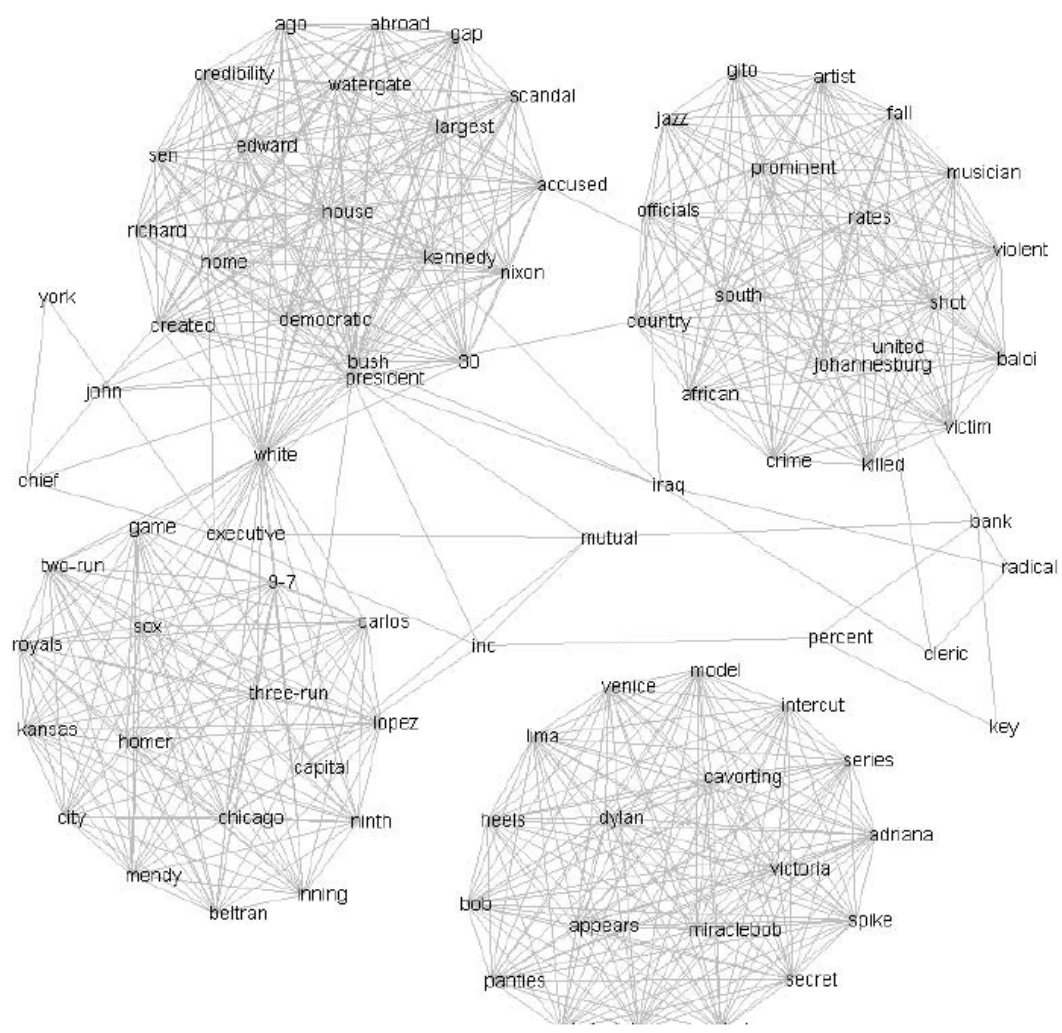

Figura 3.13: TextPool: relacionamentos de coocorrência entre os termos salientes de uma coleção de sumários notícias abrangendo um período de 6 horas em 5 de abril de 2004 . Extraído de Albrecht-Buehler et al. (2005).

Esse sistema permite a atualização em tempo real da coleção. A escolha de representar os termos por texto, ao invés de usar glyphs, por exemplo, confere um poder de comunicação maior, mas agrava a oclusão visual quando o número de termos é grande. Outras questões são o foco em termos isolados (como associá-los com documentos específicos?) e a dificuldade em determinar quando um termo deve ser considerado como saliente, e até que ponto ele o é, de fato. Os autores também não analisaram os termos salientes para detectar a evolução dos tópicos (e.g., o surgimento de um tópico). Apesar da complexidade computacional não ter sido mencionada por Albrecht-Buehler et al. (2005), inferimos que seu valor é $O\left(n^{2} \times T\right)$, onde $n$ é o numero de instâncias atualmente dentro da janela temporal e $T$ é o número ou número de vezes que novos documentos foram adicionados. Essa ferramenta também não se encontra disponível online.

Visone A pesquisa em desenho de grafos combina métodos da teoria de grafos com métodos de visualização de informação para criar representações bidimensionais de grafos para diversos tipos de aplicações. Diversos critérios são considerados para o processo de desenho. Por exemplo, um dos critérios estéticos mais utilizados é evitar ao máximo arestas que se cruzam. O algoritmo de desenho de grafos proposto por Kamada e Kawai (1989) pode ser visto como 
uma versão especial do conceito utilizado por projeções do tipo MDS, pois ele não busca minimizar o número de arestas que se cruzam, mas sim otimizar iterativamente uma função de stress.

No entanto, grafos dinâmicos podem ser modificados ao longo do tempo pela adição e/ou remoção de arestas e nós, o que torna seu desenho mais complexo. Um grafo dinâmico é composto por um conjunto de grafos $G=\left\{G_{t}=\left\{V_{t}, E_{t}\right\}: t \in T\right\}$ e um conjunto de intervalos de tempo associados $T=\{1,2, \ldots, N\}$, onde cada grafo $G_{t}$ da sequencia temporal é composto por um conjunto de vértices $V_{t}$ e um conjunto de arestas $E_{t}$. Dois grafos $G_{t}$ e $G_{t+1}$ podem ter ou não interseção dos seus conjuntos de vértices e dos seus conjuntos de arestas.

Leydesdorff e Schank (2008) estenderam o algoritmo de Kamada e Kawai (1989), baseado em uma projeção do tipo MDS, para gerar layouts de um grafo dinâmico, gerando um layout para cada grafo $G_{t}$. Esse novo algoritmo que otimiza uma função de stress dinâmica que considera ao mesmo tempo o layout atual, o do momento de tempo anterior e o do momento de tempo subsequente. Este algoritmo integra a ferramenta $V_{i s o n e}{ }^{4}$, que disponibiliza modelos e algoritmos para análise e visualização de redes sociais.

A função de stress dinâmica é definida pela seguinte equação:

$$
S=\left[\sum_{t} \sum_{i \neq j} \frac{1}{{d_{i j, t}}^{2}}\left(\left\|x_{i, t}-x_{j, t}\right\|-d_{i j, t}\right)^{2}\right]+\left[\sum_{t} \sum_{i} \omega\left\|x_{i, t}-x_{i, t+1}\right\|^{2}\right]
$$

onde a distância $d_{i j, t}$ é igual ao comprimento do menor caminho entre os vértices $x_{i}$ e $x_{j}$ no instante $t$, enquanto a variável $x_{i, t}$ refere-se a posição do vértice $x_{i}$ no instante $t$.

$\mathrm{Na}$ Equação 3.7, o termo à esquerda é igual ao stress estático, enquanto o termo à direita representa o componente temporal, i.e., o stress entre anos subsequentes. Se o parâmetro $\omega$ é igual a zero, o método é equivalente à análise estática e o layout de cada intervalo de tempo é otimizado independentemente. Essa função de stress penaliza movimentos drásticos da posição do vértice $i$ no instante $t\left(x_{i, t}\right)$ para sua próxima posição $\left(x_{i, t+1}\right)$ aumentando o valor do stress. O parâmetro $\omega$ determina o grau de estabilidade da projeção dinâmica, o que favorece a identificação de estruturas correspondentes ao longo do tempo.

Para calcular iterativamente a nova posição do objeto $x_{i}$ na dimensão $d$ utiliza-se a seguinte equação:

$$
n e w-x_{i, t}^{(d)}=\frac{\left[\sum_{j \neq i} \frac{1}{d_{i j, t^{2}}}\left(x_{j, t}^{(d)}+d_{i j, t} \frac{x_{i, t}^{(d)}-x_{j, t}^{(d)}}{\left\|x_{i, t}-x_{j, t}\right\|}\right)\right]+\omega\left(x_{i, t-1}^{(d)}+x_{i, t+1}^{(d)}\right)}{\left[\sum_{j \neq i} \frac{1}{d_{i j, t^{2}}}\right]+2 \omega}
$$

onde $x_{i, t}^{(d)}$ refere-se à posição do vértice $x_{i}$ na dimensão $d$ e no instante de tempo $t$. Nesta Equação 3.8, novamente os termos à esquerda representam o stress estático, enquanto o termo

${ }^{4}$ http://www.visone.info/ 


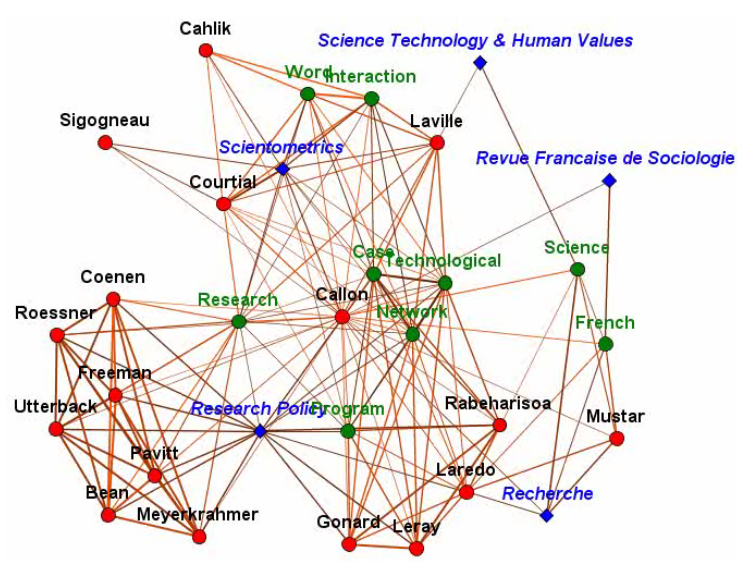

(a) $1990-1995$

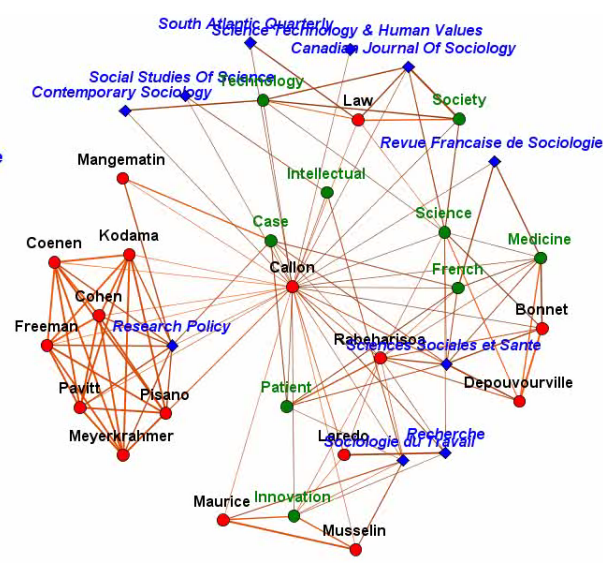

(b) $1995-2000$

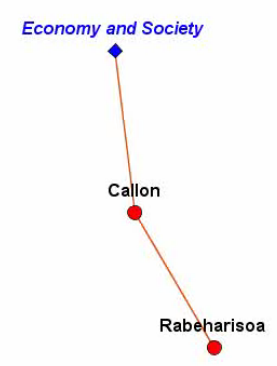

(c) 2000-2005

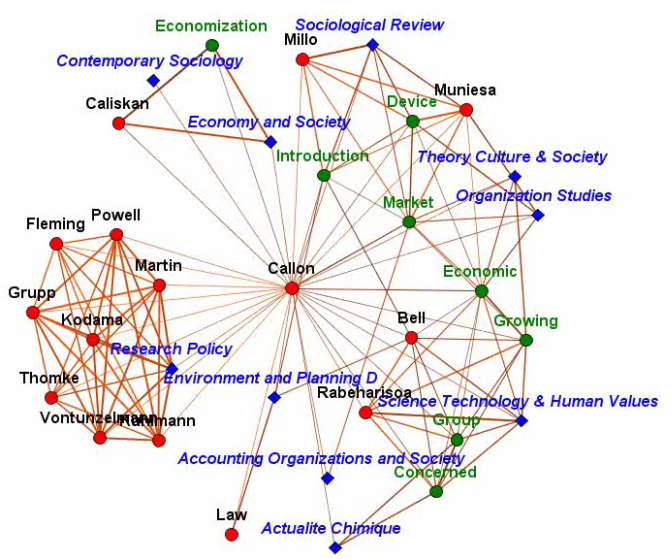

(d) $2005-2010$

Figura 3.14: Visone: grafo dinâmico da coleção de artigos publicados por Michel Callon entre 1975 e 2010 - somente os últimos 4 intervalos de tempo. Extraído de Leydesdorff (2010).

à direita representa o stress temporal que compara o layout de um ano com os layouts do ano anterior $(t-1)$ e do próximo ano $(t+1)$. Desta forma, a configuração da projeção dos objetos para cada ano é otimizada em termos da solução estática e em relação às configurações do ano anterior e do ano seguinte.

Para cada instante de tempo $t$, para cada vértice $x_{i}$ e para cada dimensão $d$ : o algoritmo atualiza a posição do vértice $x_{i}$ no instante de tempo $t, x_{i, t}^{(d)} \leftarrow$ new $-x_{i, t}^{(d)}$, até que o stress total (Equação 3.7) seja minimizado.

Leydesdorff (2010) exemplifica o uso deste algoritmo para gerar uma rede dinâmica multimodal com base em 65 artigos científicos publicados pelo pesquisador Michel Callon que foram recuperados a partir do (Social) Science Citation Index entre 1975 e 2010. O intervalo de tempo entre 1975 e 2010 foi dividido em subintervalos de 5 anos de duração. Esta rede dinâmica multimodal pode incluir três tipos de vértices: os periódicos nos quais os artigos foram publicados; os coautores de Callon nesses artigos; e os termos que ocorreram duas vezes ou mais nos títulos dos artigos. Para esta coleção de publicações de Michel Callon, todos os 26 periódicos, os 27 termos extraídos de títulos e os nomes dos 48 coautores foram considerados 
como variáveis e tiveram suas ocorrências contadas para cada um dos artigos. Cada variável transformou-se em um vértice e este vértice foi incluído nas redes cujos subintervalos de tempo correspondentes continham algum documento que contribua para a existência daquele vértice. Para determinar a existência ou não de uma aresta entre dois vértices, foi utilizada a similaridade do cosseno que determina a coocorrência entre as duas variáveis correspondentes. Para valores superiores a 0,2 , arestas entre os vértices foram criadas com peso igual ao valor da similaridade. A Figura 3.14 apresenta os layouts relativos aos últimos 4 intervalos de tempo para esta coleção. Uma animação dos layouts para esta rede dinâmica multimodal está disponível em http://www. leydesdorff.net/callon/animation/.

O algoritmo tem complexidade computacional $O\left(n^{2} T\right)$, onde $T$ é o número de intervalos de tempo e $n$ é o número de vértices em cada instante. A estabilidade é determinada pelo parâmetro $\omega$, que penaliza movimentos drásticos na posição de um vértice em momentos consecutivos. No entanto, essa estabilidade deveria ser ditada pelo conjunto de dados, e não por um parâmetro. Somente os termos dos títulos são considerados, o que gera um número pequeno de vértices desse tipo, mas que pode ser pouco representativo semanticamente comparado aos termos do resumo de um artigo. Outra questão é a escalabilidade visual limitada desta abordagem: somente um número reduzido de nós pode ser apresentado para cada momento. Essa ferramenta encontra-se disponível online no site http://www. leydesdorff . net/visone, mas de forma muito segmentada, pois é necessário executar vários programas diferentes para gerar a visualização, o que dificulta o seu uso.

IncBoard Também buscando uma solução incremental que permitisse a adição e remoção de elementos em uma visualização, Pinho et al. (2010) desenvolveram a ferramenta Incremental Board (incBoard) para dados dinâmicos. O layout da visualização gerada remete à disposição dos dados em um tabuleiro que ocupa células em uma grande bidimensional. Para evitar que o usuário permaneça alheio à mudanças na representação visual durante a chegada ou remoção de um elemento, o tabuleiro deve permanecer coerente, evitando grandes alterações entre configurações consecutivas. Para alcançar tal objetivo, os autores consideraram distâncias relativas dos elementos no espaço original, ao invés de distâncias absolutas.

A técnica busca posicionar os elementos no tabuleiro de forma que para cada elemento, o ranking obtido pela similaridade, $\delta$, deste elemento em relação aos demais no espaço original seja o mais similar possível ao ranking obtido pela distância de Chebyshev da sua localização em relação à localização dos demais no tabuleiro. A distância de Chebyshev define quantos movimentos seriam necessários para sair de uma posição no tabuleiro para outra posição. Então, para cada elemento é calculado um erro relativo que indica o nível de concordância entre o ranking no espaço original e o ranking no espaço bidimensional do tabuleiro.

A abordagem desenvolvida assume que o tabuleiro está sempre em um de dois estados: (1) instável, quando dois elementos compartilham a mesma célula; (2) estável, quando cada célula é ocupada por somente um elemento. Com exceção do primeiro que é colocado no 
centro, os elementos são colocados sempre na célula que atualmente contém o elemento mais similar a ele. Tal ação torna a célula instável. Para estabilizá-la novamente, dois tipos de solução são avaliados: manter o novo elemento no centro e mover o antigo elemento para uma das 8 células vizinhas; ou manter o antigo elemento no centro e mover o novo elemento para uma das 8 células vizinhas. A opção que adiciona o menor erro relativo para ambos os elementos é escolhida. No entanto, com este processo é possível gerar outra célula com dois elementos. Neste caso, o processo é repetido para essa nova célula até que nenhuma célula contenha dois elementos e termine com uma célula vazia na borda do tabuleiro sendo ocupada. É possível remover elementos segundo sua idade, de acordo com um parâmetro de antiguidade definido pelo usuário.

A Figura 3.15 mostra representações intermediárias e final geradas pela ferramenta incBoard para a coleção CBR-ILP-IR-SON. Cada elemento é representado por um ícone que é composto pelas primeiras palavras do documento. As cores representam as classes (áreas de pesquisa) dos documentos.

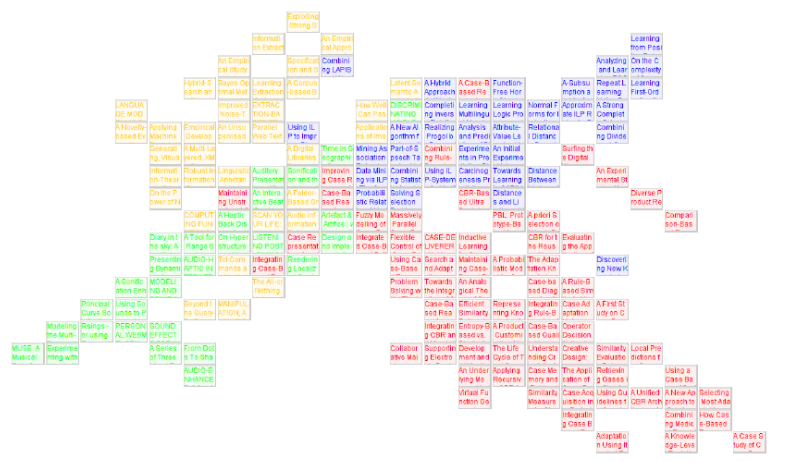

(a) 178 documentos.

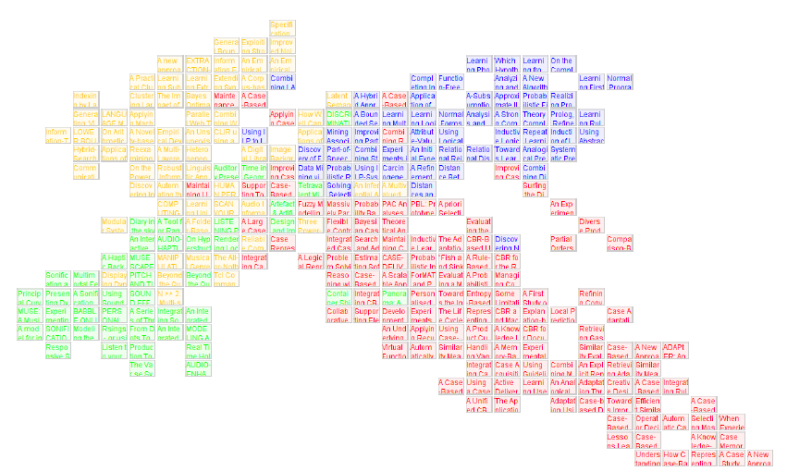

(b) 294 documentos.

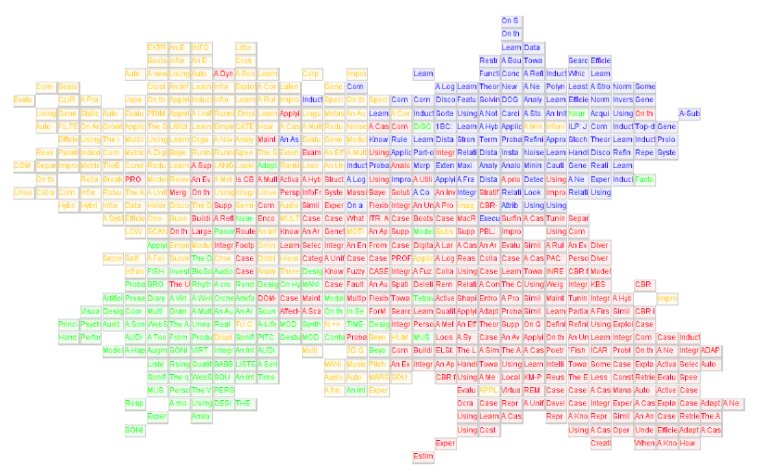

(c) 675 documentos.

Figura 3.15: incBoard: Visualização incremental de uma coleção de 675 artigos de quatro áreas de pesquisa diferentes: CBR, ILP, IR e SON. Extraído de Pinho et al. (2010).

Essa solução apresenta coleções dinâmicas adequadamente por meio de um layout incremental, compacto e sem oclusão. No entanto, não é possível atualmente identificar no tabuleiro, por exemplo, dentro dos vizinhos de um elemento qual é o mais similar a ele. Isso ocorre porque são apresentadas somente informações sobre a vizinhança de um documento, 
mas não quanto às grandezas das distâncias entre os documentos. Dessa forma, para dados sem uma classificação, i.e., sem um identificação por cores da classe, também pode ser difícil perceber agrupamentos visuais.

Buscando solucionar esse problema, os autores Pinho et al. (2010) também propuseram outra versão do espaço visual chamada Incremental Space (incSpace), que reposiciona os documentos no espaço bidimensional com base na similaridade entre vizinhos segundo o tabuleiro da incBoard. Por essa nova versão ser livre das restrições impostas pelo tabuleiro, ela também está sujeita a problemas de oclusão visual. Também não é possível ver o histórico de todas as movimentações executadas tanto no tabuleiro como na versão bidimensional. Esta ferramenta encontra-se disponível mediante contato com o autor.

\subsection{Mineração de Tópicos}

Uma forma simples e direta de extrair tópicos seria selecionar termos mais frequentes segundo uma medida como a tf-idf, por exemplo. No entanto, tal abordagem não considera as relações de ocorrência entre os termos selecionados. Uma técnica que identifica tais relações em um subconjunto de documentos selecionado em um mapa visual foi definida por Lopes et al. (2007). A partir da matriz da representação vetorial dos documentos selecionados, regras de associação são geradas e filtradas, identificando os termos mais relacionados na seleção. No entanto, essa técnica sofre dos mesmos problemas de regras de associação em geral: gera um grande volume de regras e muitas regras compostas por termos irrelevantes (ruído), o que dificulta a interpretação dos tópicos obtidos. Tais problemas se tornam ainda mais evidentes se esta técnica é aplicada sobre todo o mapa de documentos, seguindo alguma estratégia de partição deste em grupos de documentos similares.

A técnica de extração de tópicos apresentada por Paulovich (2008) busca expressar as relações de ocorrência entre termos por meio da covariância entre eles. Primeiramente, identificam-se os dois termos com maior covariância na representação vetorial dos documentos dos quais se deseja extrair tópicos, os quais são adicionados ao tópico. Em seguida, a média da covariância dos dois termos selecionados em relação a cada termo remanescente é calculada. Se essa média for maior ou igual a um limiar pré-estabelecido $\alpha$ (um valor entre [0,1]), o termo é adicionado ao tópico. A escolha inicial considera tão somente os dois termos com maior covariância, sendo que podem existir outros pares de termos com alta covariância e interessantes para indicar temas. Por isso, qualquer par de termos cuja razão de sua covariância pela maior covariância for maior ou igual a um limiar $\beta$ (também um valor entre $[0,1])$ também irá gerar um novo tópico. Os valores $\alpha=0,5$ e $\beta=0,75$ são adotados como padrão pelo autor, com base em testes empíricos. Essa técnica tem a vantagem de apresentar tópicos mais concisos comparados à técnica baseada em regras de associação

Pons-Porrata et al. (2007) propuseram um método para descrever agrupamentos de notícias por meio de sumarização automática. Dado um conjunto de grupos de documentos, 
com cada grupo representando um tópico diferente, o método primeiramente determina os termos mais frequentes em cada grupo, mas que não são frequentes nos demais. Então, para cada grupo detectam-se as coocorrências desses termos que distinguem este grupo. Uma vez que estes termos foram selecionados, extrai-se todas as sentenças que os contém. Para reduzir sentenças redundantes, cada sentença selecionada é comparada às demais para detectar sobreposições. No caso de sobreposição, somente a sentença maior é incluída no sumário. Finalmente, para impor uma organização ao sumário, ordenam-se as sentenças de acordo com a data de publicação da notícia e a posição da sentença no texto.

Outra linha de pesquisa busca extrair hierarquias de tópicos a partir dos documentos (Moura; Rezende, 2010; Teh et al., 2006). Teh et al. (2006), por exemplo, apresentam um modelo probabilístico hierárquico de tópicos detectado por meio de um processo hierárquico de Dirichlet, i.e., uma versão hierárquica do modelo LDA. Nesta abordagem, cada nó na hierarquia está associado a um tópico, e cada tópico é definido por uma distribuição probabilística de termos. Um documento é gerado escolhendo-se um caminho da raiz até uma folha, e repetidamente amostrando um dos tópicos neste caminho, e amostrando as palavras dos tópicos selecionados. Desta forma, essa organização hierárquica de tópicos captura ao mesmo tempo noções de generalidade e especificidade. Uma vantagem do algoritmo proposto por Teh et al. (2006) é sua capacidade de determinar automaticamente o número de tópicos (número de nós na árvore de tópicos) a serem inferidos.

\subsubsection{Abordagens para detecção da evolução temporal de tópicos}

Quando estamos analisando a evolução dos tópicos em uma coleção, é desejável detectar eventos de transição, como a emergência de novos tópicos em momentos específicos; a subdivisão de um tópico, quando subgrupos de documentos tornam-se heterogêneos em relação ao restante do grupo e formam um novo tópico; e a junção de dois ou mais tópicos para formar outro. Outro aspecto importante é detectar as mudanças no vocabulário de um tópico em específico. Por exemplo, o artigo da revista Science "The Brain of Professor Laborde", publicado em 1903, pode estar associado ao mesmo tópico do artigo "Reshaping the Cortical MotorMap by Unmasking Latent Intracortical Connections", publicado em 1991, mas o estudo da neurociência evoluiu muito nesse período e os termos que melhor caracterizavam esta área com certeza mudaram entre 1903 e 1991.

Nesta seção, serão apresentadas diferentes abordagens encontradas na literatura para detectar a evolução temporal de tópicos em uma coleção de documentos indexada temporalmente, que possuem como objetivo detectar eventos de transição entre os tópicos e/ou mudanças no vocabulário desses tópicos. 


\section{Topic Detection and Tracking (TDT) - Projeto DARPA}

Uma das primeiras iniciativas de organizar um fluxo de textos com base em seus tópicos foi definida pelo projeto Topic Detection and Tracking (TDT) ${ }^{5}$. Este projeto promoveu uma pesquisa por métodos que organizassem fluxos de notícias com base em seus tópicos de forma não supervisionada, com o objetivo de facilitar ao usuário o acesso, a correlação, e a interpretação de fontes multilíngues de informação, em tempo real. O projeto foi desenvolvido por instituições acadêmicas e industriais, como a Universidade de Massachusetts e a IBM, de 1998 a 2004, com financiamento do governo dos Estados Unidos.

As coleções de notícias utilizadas no contexto deste projeto foram fornecidas pelo Linguistic Data Consortium (LDC) ${ }^{6}$ e compostas por notícias em texto ou áudio, obtidas de diversas fontes ( $C N N$, Reuters, etc.) em inglês e mandarim. Notícias em áudio foram previamente transcritas usando sistemas de reconhecimento de fala, e os textos em mandarim foram traduzidos por sistemas automáticos. Essa necessidade de transcrever e traduzir parte das notícias introduziu erros na coleção, tornando o monitoramento ainda mais difícil.

Uma das principais tarefas do projeto TDT foi a de Detecção de Tópicos, uma tarefa não supervisionada que busca agrupar notícias apresentadas uma a uma em tópicos sem nenhum conhecimento prévio sobre quantos ou quais são os tópicos, e o que os caracterizam. No contexto do projeto TDT, um tópico é um conjunto de notícias que tratam de um mesmo evento, e que geralmente ocorrem em um intervalo de tempo delimitado. As notícias são apresentadas sequencialmente de acordo com sua data de publicação, e o algoritmo deve decidir se a notícia sendo analisada pertence a algum tópico já detectado no passado ou pertence a um tópico novo. Técnicas de detecção de tópicos podem adotar dois tipos de abordagem: a abordagem retrospectiva, na qual toda a coleção está presente e pode ser analisada durante a atribuição de uma notícia a um tópico; ou a abordagem online, na qual não é permitido ou possível utilizar notícias com data de publicação posterior a da notícia sendo analisada no momento e uma vez tomada a decisão sobre qual tópico é o mais representativo de uma notícia em particular não são permitidas alterações. A abordagem online é mais interessante por ser aplicável a streams de notícias, no entanto é também mais difícil.

Os primeiros trabalhos para detecção de tópicos foram publicados por Allan et al. (1998) e Yang et al. (1998). Yang et al. (1998) propõem um método de detecção de tópicos online utilizado como base por muitos outros trabalhos subsequentes, que processa sequencialmente os documentos de entrada, e cria e atualiza de forma incremental os tópicos. Dada uma sequencia de documentos indexados por sua data de publicação $\left\{d_{1}, d_{2}, \ldots, d_{t}, \ldots\right\}$, para cada documento novo $d_{t}$ computa-se sua similaridade em relação aos últimos $k$ documentos $-d_{t-k}, \ldots, d_{t-1}$. É atribuída então uma pontuação ao novo documento $d_{t}$ com base nessas

\footnotetext{
5 http://www.itl.nist.gov/iad/mig/tests/tdt

6 http://www. ldc.upenn.edu
} 
similaridades, de acordo com a Equação 3.9:

$$
\operatorname{score}\left(d_{t}\right)=\max _{i \in\{t-k \ldots t-1\}}\left(1-\operatorname{sim}\left(d_{t}, d_{i}\right)\right)
$$

Se a pontuação score $\left(d_{t}\right)$ for inferior um limiar pré-estabelecido $\lambda$, o novo documento é declarado como pertencente ao mesmo tópico de seu documento mais similar dentre os documentos $\left\{d_{t-k}, \ldots, d_{t-1}\right\}$. Caso contrário, o novo documento é declarado como pertencente a um novo tópico. Yang et al. (1998) também definiram uma nova versão para a pontuação $\operatorname{score}\left(d_{t}\right)$, que incorpora a ideia de que um documento pertence a um novo tópico somente se a última ocorrência de um documento similar não aconteceu "muito" recentemente. Dessa forma, essa versão para a pontuação $\operatorname{score}\left(d_{t}\right)$ incorpora a noção de localidade temporal do tópico é definida como:

$$
\operatorname{score}\left(d_{t}\right)=\max _{i \in\{t-k \ldots t-1\}}\left(1-\frac{(k+i-t+1)}{k} \times \operatorname{sim}\left(d_{t}, d_{i}\right)\right)
$$

Cada documento é representado por um vetor de frequências dado pela representação vetorial, e a similaridade do cosseno utilizada para quantificar a similaridade. Como métodos de detecção de tópicos online não usam informações contidas nas notícias com data de publicação posterior a da notícia sob análise, os autores definiram uma versão incremental da estatística idf, que é atualizada segundo o crescente vocabulário. Como mencionado pelos próprios autores, também é possível comparar um novo documento aos tópicos previamente identificados, o que reduz o número de comparações. Neste caso, os tópicos são representados pelo vetor normalizado da soma dos vetores dos documentos que os compõem, mantendo-se no final somente os termos mais frequentes no vetor.

Apesar da sua simplicidade, o método proposto por Yang et al. (1998) foi o sistema com melhor desempenho nas avaliações oficiais do projeto TDT em 2002 e 2003, porém apresenta uma alta taxa de falsos negativos. Buscando melhores resultados e utilizando uma abordagem geral similar aos conceitos propostos por Yang et al. (1998), Zhang et al. (2005) utilizaram o modelo probabilístico LDA para representar os tópicos detectados. Este modelo deve ser atualizado toda vez que um documento é adicionado a um tópico ou um novo tópico é criado. O parâmetro $\lambda$ também foi eliminado, pois um novo documento agora é atribuído ao tópico com maior probabilidade de tê-lo gerado. Mesmo utilizando uma representação mais "rica" para os tópicos, os resultados não foram significativamente melhores.

A etapa de identificar se o documento sendo analisado no momento pertence a um tópico já detectado ou representa um novo tópico é crucial. Um falso negativo, que identifica um documento como pertencente a um tópico existente quando ele é um novo tópico, desencadeia uma série de erros ao analisar os próximos documentos. Essa etapa é muito difícil em geral, e falha em uma variedade de cenários, como descrito por Allan et al. (2000). Dessa forma a tarefa de deteç̧ão de tópicos no projeto TDT não foi muito bem sucedida, mas foi uma 
importante iniciativa na área.

\section{Agrupamentos Streaming, Evolucionários e Incrementais}

Quando aplicadas em coleções de documentos, técnicas de agrupamento que consideram a componente temporal podem ser utilizadas para rastrear transições temporais de tópicos, pois cada grupo, por ser composto por documentos semanticamente similares entre si, pode ser considerado como representativo de um tópico. Cenários nos quais o conjunto de dados a ser agrupado evolui ao longo do tempo geram novos desafios aos algoritmos de agrupamento tradicionais. Em algoritmos de agrupamento tradicionais, o principal objetivo é particionar os objetos em grupo de forma que objetos em um mesmo grupo sejam similares entre si e aqueles em grupos diferentes sejam dissimilares. Já algoritmos de agrupamento que consideram a componente temporal devem produzir uma sequência de agrupamentos, possivelmente relacionando esses agrupamentos entre si. O cenário de aplicação e as propriedades que devem ser otimizadas durante a produção dessa sequência de projeções, é o que diferencia os tipos de algoritmos de agrupamento que consideram a componente temporal.

Em dados streaming, por exemplo, grandes quantidades de dados chegam a todo momento, tornando impraticável armazenar tudo em memória ou varrer os dados múltiplas vezes. Nesse cenário, o agrupamento de dados streaming investiga como agrupar eficientemente conjuntos de dados tão massivos usando uma quantidade limitada de memória e varrendo os dados uma única vez. Esse problema já foi amplamente estudado no contexto de dados numéricos streaming (O'callaghan et al., 2002; Aggarwal et al., 2003; Aggarwal, 2007), e recentemente no contexto de dados textuais streaming (Zhong, 2005; Aggarwal; Yu, 2010; Gong et al., 2011).

Já o agrupamento evolucionário está, de certa forma, relacionado ao agrupamento de streams, que recebem continuamente novas instâncias de dados. No entanto, ao invés de buscar resolver problemas relacionados à escalabilidade e varrer os dados uma única vez, o foco está em obter agrupamentos que evoluem suavemente ao longo do tempo - um problema não abordado no agrupamento de streams. No agrupamento evolucionário, além da contínua adição de instâncias de dados, as instâncias podem mudar suas propriedades ao longo do tempo, e por isso são observadas em diferentes momentos. Esse tipo de algoritmo também deve simultaneamente otimizar dois critérios conflitantes: o agrupamento em qualquer instante de tempo deve permanecer fiel aos dados atuais o máximo possível, e o agrupamento não deve mudar dramaticamente em momentos subsequentes (Chakrabarti et al., 2006). Esses dois critérios são utilizados pois na maioria das aplicações dinâmicas, os dados não mudam drasticamente em momentos consecutivos - a mudança nos dados acontece gradualmente. Tal cenário surge em aplicações que requerem, por exemplo, identificar comunidades em redes sociais dinâmicas (Falkowski et al., 2006; Tantipathananandh et al., 2007) ou detectar agrupamentos espaço-temporais ao rastrear grupos de objetos que se movem de forma similar 
no espaço por um período significativo de tempo (Kalnis et al., 2005; Carmi et al., 2009; Galasso et al., 2011).

Também existe uma vasta literatura sobre agrupamentos incrementais, nos quais o modelo é atualizado incrementalmente a medida que novos dados chegam, e.g., atualizando dinamicamente os centróides ou medóides dos grupos (Gupta; Grossman, 2004), ou atualizando uma árvore hierárquica (Charikar et al., 1997). O algoritmo proposto por Gao et al. (2011), por exemplo, detecta transições temporais entre grupos de documentos ao longo do tempo, utilizando como base um modelo hierárquico de tópicos LDA (Teh et al., 2006) que é atualizado incrementalmente a medida que novos documentos chegam. Os tópicos extraídos são interpretáveis em modelos de tópicos LDA. Dessa forma, também é possível detectar mudanças no vocabulário dos tópicos na versão incremental. Um problema comum das técnicas incrementais é que um erro durante a atribuição de um documento a um grupo durante a atualização incremental do modelo é propagado até o final e poderá incorrer em novos erros.

O foco principal dos algoritmos apresentados nesta seção quando aplicados à conjuntos de documentos indexados temporalmente é rastrear as transições temporais entre grupos. Muitos algoritmos de agrupamento também utilizam somente a similaridade entre as instâncias, o que permite que mesmo algoritmos não desenvolvidos para conjuntos textuais possam ser utilizados nesse contexto. Já mudanças de vocabulário podem ser detectadas, utilizando-se técnicas para extrair tópicos para os documentos em cada grupo e observando as mudanças entre os termos dos tópicos extraídos para um grupo ao longo do tempo.

\section{Modelagem de Tópicos Dinâmica}

Os tópicos de uma coleção evoluem ao longo do tempo, porém a representação probabilística LDA não considera a ordem dos documentos em seu processo. A técnica apresentada por Blei e Lafferty (2006) captura a evolução dos tópicos em uma coleção de documentos organizada sequencialmente, captando a mudança no vocabulário dos tópicos. Os dados são divididos em intervalos temporais, e.g., por ano de publicação. Os documentos em cada intervalo são representados por um modelo com $T$ tópicos, sendo que os tópicos associados ao intervalo $t$ evoluem a partir dos tópicos associados ao intervalo $t-1$.

Como resultado, cada tópico é agora uma sequência de distribuições probabilísticas de termos. Dessa forma, para cada combinação de tópico e ano, é possível obter a probabilidade dos termos e visualizar um tópico como um conjunto de séries temporais que definem a probabilidade dos termos mais prováveis ao longo do tempo, oferecendo uma visão global de como os termos mais "importantes" de um tópico mudam sua probabilidade ao longo do tempo. Também é possível examinar a popularidade deste tópico ao longo dos anos, calculando quantas palavras foram atribuídas a ele a cada ano, segundo o modelo. Outra análise possível consiste em examinar a variação temporal da probabilidade de um termo em 
particular ocorrer em um tópico.

A Figura 3.16 mostra um dos tópicos dinâmicos extraídos por essa técnica quando aplicada a toda a coleção de 140.000 artigos publicados pela revista Science entre 1880 até 2002. A Figura 3.16a mostra uma visão global dos principais termos deste tópico dinâmico ao longo do tempo. Já a Figura 3.16b exibe a popularidade desse tópico ao longo dos anos, e também o título de alguns dos artigos que o contém. Por fim, na Figura 3.16c tem-se a probabilidade de ocorrência dos termos 'war', 'european' e 'nuclear' ao longo dos anos.

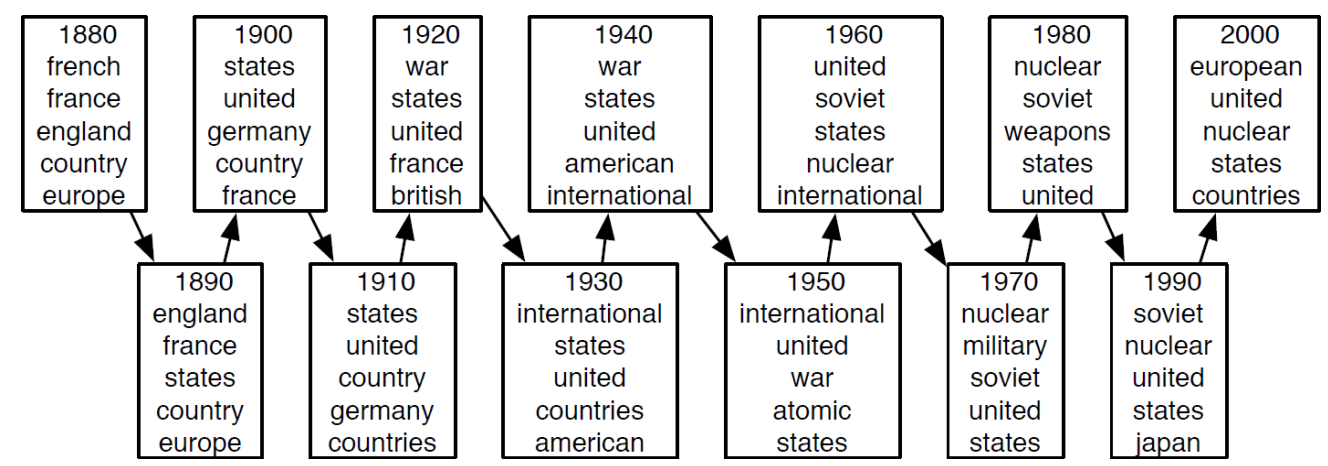

(a) Visão global.

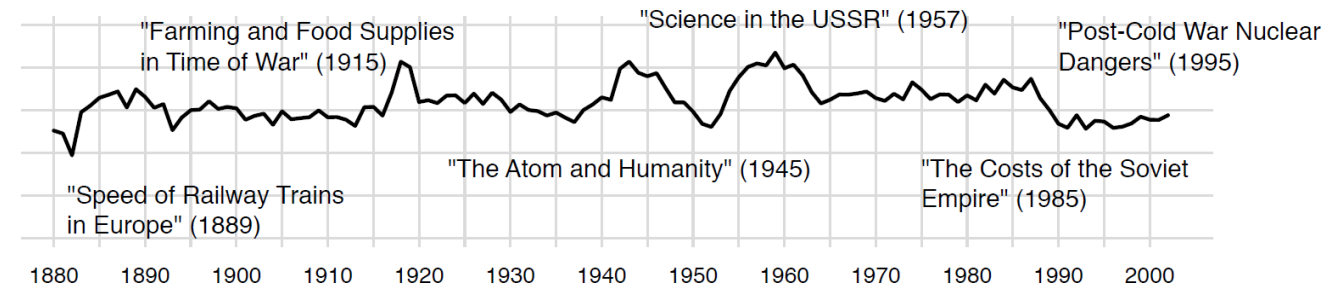

(b) Probabilidade de ocorrência do tópico ao longo dos anos.

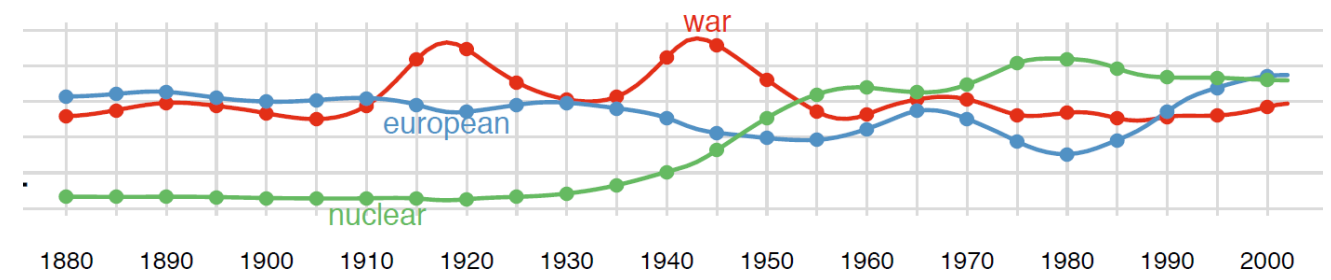

(c) Probabilidade de ocorrência dos termos 'war', 'european' e 'nuclear' ao longo dos anos.

Figura 3.16: Tópico dinâmico extraído para a coleção de 140.000 artigos publicados pela revista Science entre 1880 até 2002. Extraído de Blei e Lafferty (2009).

Um aspecto interessante é como medidas de distância para distribuições probabilísticas, como a distância de Hellinger (ver Seção 2.3, Equação (2.11)), funcionam com esse modelo de tópicos dinâmico. Por exemplo, as distribuições probabilísticas de tópicos para dois documentos publicados nos anos 1910 e 2000 referem-se a dois intervalos de tempo diferentes - a distribuição com a probabilidade atual dos tópicos em 1910 para o primeiro documento e outra distribuição com a probabilidade atual dos tópicos em 2000 para o segundo documento. No entanto, essas duas distribuições estão ligadas pelo modelo sequencial utilizado. Essa característica promove uma "correção temporal" na medida de distância. Dois artigos sobre 
química podem ser considerados similares, mesmo se houve uma mudança de vocabulário de 1910 para 2000.

Esse modelo é indicado principalmente para coleções grandes de documentos que abrangem um período longo, no qual ocorrem mudanças no vocabulário. Apesar de nesta seção termos mostrado esta técnica para analisar a evolução dos tópicos quanto aos seus termos, ela também pode ser utilizada para representar uma coleção de documentos assim como o LDA clássico, porém com um custo computacional maior. Esta técnica analisa sempre o mesmo número fixo de tópicos em cada intervalo de tempo, i.e., transições entre tópicos não são detectadas.

\subsection{Considerações Finais}

Neste capítulo, foram apresentados diversos trabalhos que buscam associar técnicas de visualização com técnicas de mineração para ajudar na interpretação e exploração de coleções de documentos. Inicialmente, foram apresentadas técnicas de visualização que podem ser geradas para um único documento, onde geralmente o interesse é mostrar o conteúdo relevante do mesmo. Nessa linha destacam-se as tag clouds, que mostram os termos relevantes de um documento, considerando a frequência de ocorrência. Tag clouds tornaram-se metáforas visuais populares nos últimos anos, o que implicou no surgimento de diversas técnicas para geração de tag clouds com diferentes propriedades. Algumas técnicas que, além de representar a relevância dos termos por meio de sua frequência, também buscam representar os relacionamentos semânticos entre eles, foram apresentadas.

Em seguida, foram descritos técnicas de visualização para coleções de documentos. Quando o interesse é visualizar coleções de documentos, mapas são uma metáfora popular. Mapas de documentos são visualizações que refletem espacialmente algum relacionamento entre os documentos, provendo uma interface de navegação útil para acessar informações e melhorar a capacidade humana para extrair conhecimento útil da coleção. Metáforas baseadas em mapas são atraentes, pois imitam, em parte, mapas cartográficos, intuitivos para a maioria dos usuários. Dos métodos existentes para criar mapas de documentos, técnicas de projeção multidimensional estão entre as mais utilizadas. Foram apresentadas diferentes técnicas para projeção multidimensional, cada uma buscando solucionar um problema, evidenciar alguma propriedade da coleção ou buscando obter um layout mais informativo. A técnica multidimensional Least Square Projection (LSP) foi explicada em mais detalhes por ser utilizada como parte do processo de criação da projeção multidimensional dinâmica desenvolvida nesta tese.

Apesar de nem sempre ser tratada explicitamente, a componente temporal é fundamental para entender e analisar mudanças nos tópicos em coleções de documentos indexadas temporalmente. Devido a essa importância da componente temporal e por este tema estar relacionado aos objetivos dessa tese, também foram apresentadas técnicas relevantes 
encontradas na literatura para a visualização temporal de documentos. Foi dado um enfoque especial, para projeções multidimensionais dinâmicas que visam incorporar a componente temporal em seu processo de geração.

Por fim, abordou-se o problema de mineração de tópicos, e foram apresentadas abordagens encontradas na literatura para deteç̧ão da evolução temporal de tópicos, que buscam detectar transições temporais entre tópicos e mudanças nos seus vocabulários ao longo do tempo.

No próximo capítulo, será apresentada a abordagem proposta - um mapa de documentos dinâmico para capturar e apoiar a análise da evolução temporal de tópicos para coleções de documentos. 


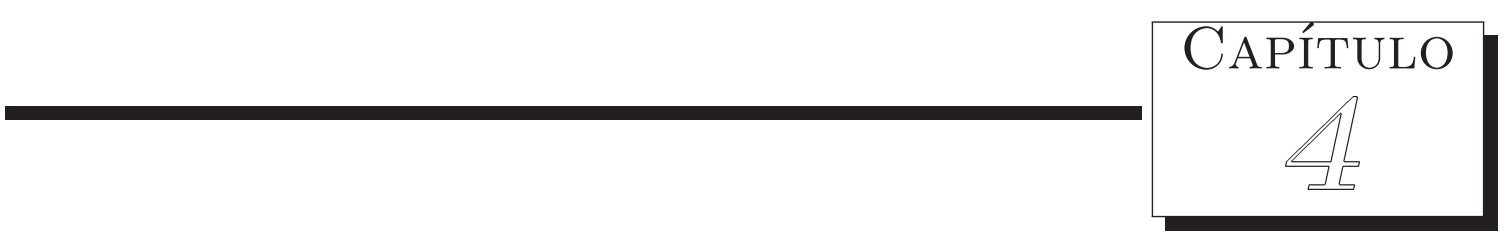

\section{Time-based Least Square Projection (T-LSP) e Mapa Dinâmico de Documentos}

Técnicas de projeção multidimensional têm sido empregadas para gerar visões globais de dados com alta-dimensionalidade, que podem ser representados no espaço vetorial, ou para os quais é possível calcular a similaridade entre duas instâncias. Técnicas de projeção buscam mapear dados $m$-dimensionais em um espaço $p$-dimensional com $p \in\{1,2,3\}$, preservando alguma informação sobre as relações de similaridade entre as instâncias de dados de forma a revelar o máximo possível as estruturas existentes. Já foi demonstrado que estas técnicas, quando aplicadas a coleções de documentos, são úteis para visualizar e explorar intuitivamente o espaço tópico abordado pela coleção (Paulovich et al., 2008; Paulovich; Minghim, 2008; Pnnl, 2008).

Considerando uma coleção em que novos documentos foram adicionados gradualmente como uma série de artigos publicados anualmente em uma conferência, ou artigos de autoria de um pesquisador em particular ao longo de um determinado período de tempo - esse espaço tópico não é estático ao longo do tempo, já que tópicos ascendem e decaem, de acordo com o interesse científico. Apesar da componente temporal ter um papel crucial em muitos tipos de dados, inclusive em textos, muitas técnicas de projeções multidimensionais existentes não a consideram explicitamente em seu processo de mapeamento. Existem algumas poucas técnicas de projeção multidimensional dinâmicas (Alsakran et al., 2012; Pinho et al., 2010; Joia et al., 2011; Paulovich et al., 2010; Leydesdorff; Schank, 2008; Albrecht-buehler et al., 2005) e todas elas buscam obedecer duas propriedades principais conflitantes: 
- Manutenção da acurácia local - A projeção relativa a cada período deve representar corretamente a estrutura inerente aos dados para o período de tempo relacionado. Em outras palavras, em cada momento a projeção dinâmica deve buscar os mesmos objetivos de uma projeção convencional, i.e., representar bem as estruturas globais e as vizinhanças locais dos dados.

- Manutenção da coerência espacial global - É esperado que instâncias de dados que têm conteúdo similar e foram posicionadas em uma certa região da projeção no instante de tempo $t$ mantenham-se aproximadamente na mesma região da projeção no instante de tempo subsequente $t+1$. Este comportamento favorece a preservação do "mapa mental" do usuário: apesar das modificações, os layouts devem se manter consistentes ao longo da sequência de mapas de forma a evitar confusão do usuário. O termo "mapa mental" refere-se à estrutura cognitiva que um usuário cria internamente ao observar o layout de uma representação visual (Diehl; Görg, 2002).

Muitas técnicas de projeção multidimensional dinâmicas utilizam como base técnicas interativas do tipo Force-Directed Placement (FDP) ou Multidimensional Scaling (MDS), pois o processo iterativo desse tipo de técnicas viabiliza o comportamento dinâmico necessário. No entanto, técnicas desse tipo tendem a não ser muito estáveis, o que prejudica a manutenção da coerência espacial global. Portanto, adaptações são necessárias para promover uma maior estabilidade para estas versões dinâmicas. Por exemplo, Leydesdorff e Schank (2008) promovem a estabilidade por meio de um parâmetro incorporado à função de stress que penaliza movimentos drásticos na posição de um elemento entre instantes de tempo sucessivos. No entanto, essa estabilidade deveria ser ditada pelo conjunto de dados, e não por um parâmetro.

Neste capítulo, é apresentada uma nova técnica de projeção multidimensional dinâmica chamada Time-based Least Square Projection (T-LSP), que busca mostrar mudanças nas relações de similaridade em conjuntos de dados multidimensionais, em particular coleções de documentos, ao longo do tempo. A saída é uma sequência de projeções indexada temporalmente, que pode ser animada para evidenciar as mudanças entre instantes de tempo sucessivos tais como a adição de novas instâncias ou a alteração da posição de instâncias que já tinham sido adicionadas previamente. Sua maior estabilidade, comparada a outras técnicas, é baseada nos dados por meio de um esquema retroativo, que utiliza informação de projeções geradas anteriormente para preservar o contexto do usuário. Nesta tese, a técnica T-LSP é aplicada a coleções de artigos científicos com o intuito de obter um mapa de documentos dinâmico que evidencie a evolução temporal dos tópicos.

Embora o mapa seja útil para revelar relações de similaridade entre os documentos e grupos de documentos, nenhuma informação é dada sobre o porquê de certos grupos se formarem no layout. Para adicionar essa informação aos mapas de documentos, um mecanismo auxiliar é a extração automática de tópicos. Em um mapa de dinâmico é interessante, por exemplo, identificar os tópicos associados a um grupo de documentos em 
um certo momento e como esses tópicos mudaram em um próximo momento pela adição de novos documentos similares a este grupo. Neste capítulo também são introduzidas duas técnicas de extração automática de tópicos aplicadas neste contexto: a extração de tópicos baseada em Principal Component Analysis (PCA), um método muito utilizado para detecção de padrões em dados multidimensionais; e a extração de tópicos baseada em Latent Dirichlet Allocation (LDA), um modelo que busca representar documentos como uma distribuição probabilística de seus tópicos.

Ao analisar a evolução dos tópicos em uma coleção de documentos, também é desejável detectar eventos de transição, como: a emergência de novos tópicos em instantes de tempo específicos; a subdivisão de um tópico, quando parte dos documentos daquele tópico tornam-se heterogêneos em relação ao restante do grupo e formam um novo tópico; e a junção de dois ou mais tópicos para formar outro. Neste capítulo, apresentamos a abordagem utilizada para detectar esses eventos de transição baseada em agrupamentos evolucionários, a qual é composta por dois algoritmos: um algoritmo de agrupamento baseado em densidade e um algoritmo de rastreamento de transições temporais entre grupos, baseado na sobreposição entre os grupos.

A partir das técnicas acima mencionadas, desenvolvemos uma estratégia para projeção multidimensional dinâmica que, ao ser aplicada a uma coleção de artigos científicos e em conjunto com as demais técnicas mencionadas, nos dá suporte para detectar a evolução temporal de tópicos na trajetória de um pesquisador ou de uma área de pesquisa específica representada pela coleção. Na Seção 4.1, é apresentada a técnica de projeção multidimensional dinâmica T-LSP. A Seção 4.2 apresenta as técnicas de extração de tópicos baseadas em PCA e LDA. Por fim, a Seção 4.3 apresenta a abordagem utilizada para detectar a evolução temporal dos tópicos.

\section{1. $\quad$ Time-based Least Square Projection (T-LSP)}

A técnica de projeção multidimensional dinâmica T-LSP incorpora explicitamente a componente temporal no processo de obtenção da projeção LSP (ver Seção 3.1.1), de modo a transmitir as mudanças nas relações de similaridade em um conjunto de dados multidimensional ao longo do tempo. A saída é uma sequência temporal de mapas baseados em similaridade, dado um conjunto de dados multidimensional indexado temporalmente. A técnica recebeu o nome de Time-based Least Square Projection (T-LSP) por utilizar a LSP como parte do seu processo.

A T-LSP pode ser aplicada a conjuntos de instâncias de dados indexados temporalmente, nos quais é possível definir intervalos de tempo. Por exemplo, uma coleção de $n$ artigos científicos publicados entre 1990 e 2000, na qual cada ano corresponde a um intervalo de tempo. As seguintes etapas descrevem a técnica: 
1. Dado um conjunto (possivelmente pré-processado) de dados multidimensionais indexados no tempo, subdivida os dados em uma lista de lotes $X=\left\{X_{1}, X_{2}, \ldots, X_{T}\right\}$, de acordo com alguma propriedade temporal, como o ano de publicação, ou data de ocorrência. Essa lista deve ser ordenada em ordem crescente de acordo com a propriedade temporal escolhida.

2. Projete a coleção inteira usando a técnica LSP, criando a projeção $P_{T}$, utilizando $n c$ pontos de controle e $k$ vizinhos para cada instância nas relações de vizinhança (valores default $n c=\sqrt{n}$ e $k=10$, onde $n$ é igual ao número de instâncias). Adicione esta projeção à lista de projeções $P$. Crie um índice current_map com valor $T$.

3. Remova o último lote da lista $X$. Decremente de um o valor do índice current_map, i.e., current_map $=$ current_map -1 .

4. A próxima projeção, $P_{\text {current_map }}$, é gerada usando o esquema retroativo descrito a seguir. Identifique na projeção anterior, $P_{\text {current_map+1 }}$, as seguintes instâncias de dados:

4.1. Instâncias que pertenciam ao lote removido no passo 3, as quais devem ser removidas da projeção $P_{\text {current_map. }}$.

4.2. Instâncias que tiveram sua vizinhança no espaço multidimensional alterada como resultado do passo anterior, i.e., que tinham em sua vizinhança instâncias removidas no passo 4.1. As relações de vizinhança calculadas ao utilizar a LSP para gerar a projeção anterior são inspecionadas para encontrar instâncias com vizinhanças modificadas.

4.3. Instâncias que não pertencem às vizinhanças das instâncias removidas no passo 4.1 .

5. Projete novamente com a LSP as instâncias que tiveram sua vizinhança modificada, identificadas no passo 4.2, tomando como pontos de controle as instâncias que não tiveram suas vizinhanças alteradas, identificadas no passo 4.3. Estas ações irão criar a

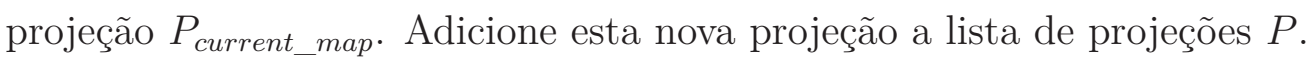

6. Repita os passos 3 até 5 , até restarem somente dois lotes na lista $X$.

6.1. Obtenha a projeção $P_{1}$ simplesmente removendo, da projeção anterior $\left(P_{2}\right)$, os documentos que pertencem ao lote $X_{2}$. Adicione a projeção $P_{1}$ à lista de projeções $P$.

7. Reverta a ordem da lista de projeções para $\left\{P_{1}, \ldots, P_{T}\right\}$ para gerar a visualização.

Para que a técnica T-LSP funcione corretamente são necessários pelo menos três intervalos de tempo e os lotes referentes a esses intervalos não devem estar vazios. A Figura 4.1 mostra as etapas da técnica T-LSP visualmente.

Utilizando informação do mapa anterior para construir o mapa atual, busca-se manter a coerência espacial global ao longo da sequência de mapas. É esperado que instâncias de dados que têm conteúdo similar e foram posicionadas em uma certa região do mapa $P_{i}$ mantenham-se na mesma região no mapa subsequente $P_{i+1}$. 


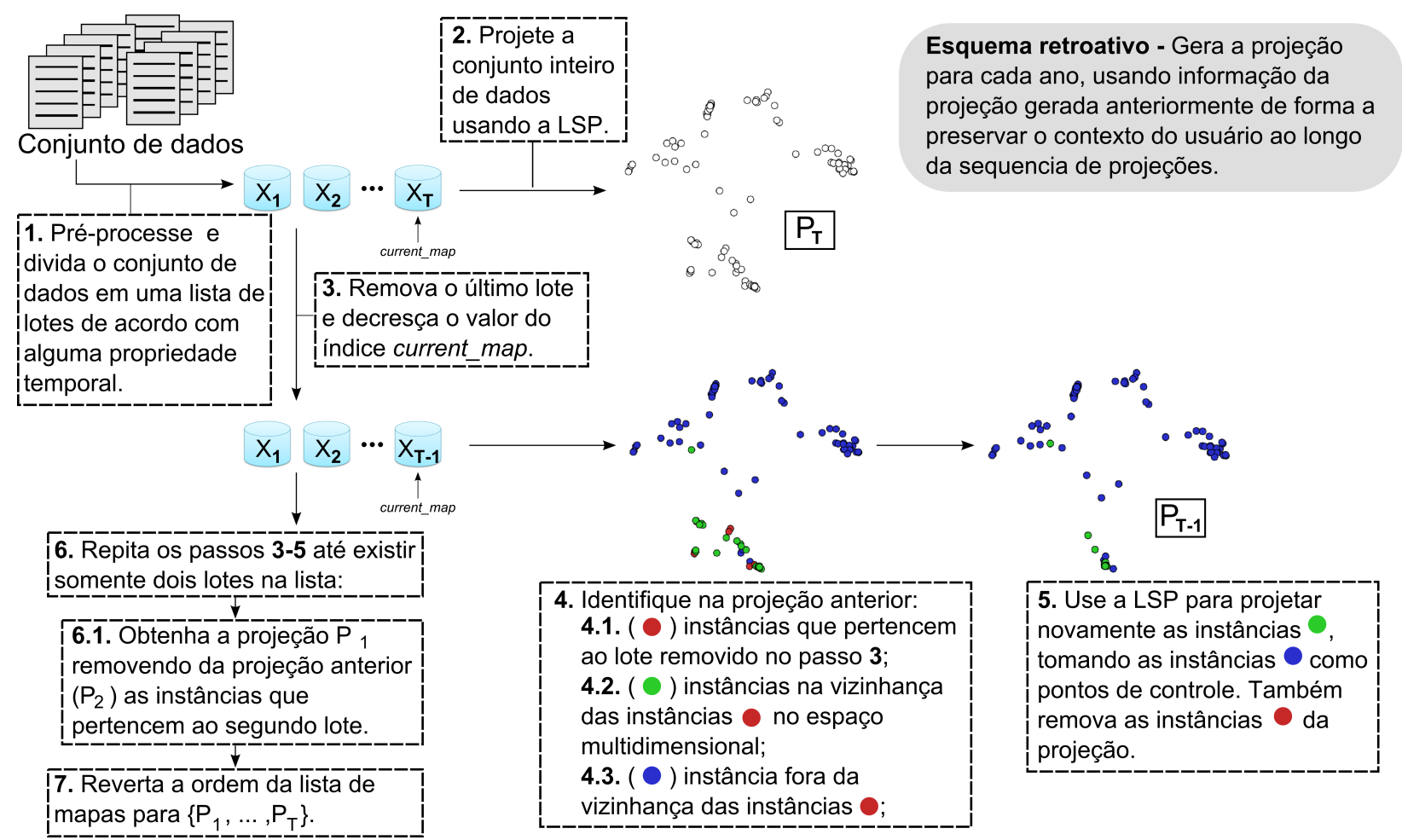

Figura 4.1: Esquema retroativo adotado pela técnica T-LSP.

Casos especiais Um problema pode ocorrer quando existe um número insuficiente de pontos de controle. Isto ocorre quando as posições da maioria das instâncias de dados precisam ser atualizadas na projeção. Este cenário é resolvido escolhendo novos pontos de controle entre as instâncias de dados que precisam ser atualizadas. Para isto é atribuído um peso para cada instância $x_{i}$ a ser atualizada, que infere o quão perto ela estava das instâncias removidas em sua vizinhança:

$$
\omega\left(x_{i}\right)=\sum_{j=1}^{k} \operatorname{diss}_{\text {euclid }}\left(f\left(x_{i}\right), f\left(x_{j}\right)\right), \forall x_{j} \in r\left(x_{i}\right)=\left\{x_{1}, \ldots, x_{k}\right\}
$$

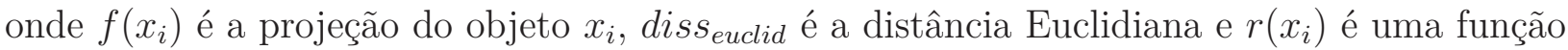
que retorna uma lista das instâncias removidas na vizinhança da instância $x_{i}$. Todas as instâncias a serem atualizadas são ordenadas em ordem crescente em relação ao peso $\omega$. Supondo que o mapa atual tem $l$ pontos de controle e são necessários no mínimo min_cp

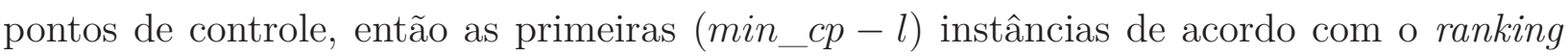
baseado em $\omega$ são incluídas como pontos de controle. Adotou-se o valor padrão min_cp $=10$ para $n_{i} \geq 20$, onde $n_{i}$ é igual ao número de instâncias contidas na atual projeção de índice $i$, $P_{i}$. Para $5 \leq n_{i}<20$, min_cp $=5$, e para $n_{i}<5$, min_cp $=3$.

Outro cenário problemático acontece quando existe um número excessivo de pontos de controle. No sistema linear da LSP, equações representando os pontos de controle também são inseridas no sistema. Parte dessas equações representam as relações de vizinhança dos pontos controle com as demais instâncias, enquanto as outras representam as coordenadas dos 
pontos de controle obtidas no primeiro passo da LSP empregando uma técnica de projeção de alta precisão. Dessa forma, os pontos de controle são projetados novamente agora segundo o sistema linear da LSP. No entanto, a diferença entre as coordenadas dos pontos de controle segundo a técnica de projeção de alta precisão e segundo o sistema linear da LSP é geralmente insignificante.

Em contrapartida, quando temos um número muito maior de pontos de controle do que de instâncias que não foram selecionadas como pontos de controle, essa diferença entre as coordenadas dos pontos de controle no primeiro passo da LSP e pela solução do sistema linear torna-se significante. Portanto, nesse cenário não se tem a garantia de que os pontos de controle se comportarão como âncoras estáveis, o que prejudica a coerência espacial global da T-LSP. Para resolver esse problema, ao invés de se utilizar como pontos de controle na T-LSP todas as instâncias que não tiverem em sua vizinhança instâncias removidas, é escolhido apenas um subconjunto desses. Nesse subconjunto de pontos de controle, entram somente instâncias que não tiveram em sua vizinhança instâncias removidas e que tem em sua vizinhança instâncias que devem ser projetadas novamente. Essa medida é tomada por padrão quando a coleção a ser projetada possui mais que 1.000 documentos. Segundo testes realizados, essa medida não altera em nada a qualidade da projeção, apenas garante a estabilidade dos pontos de controle.

\subsubsection{Modelo Vetorial Estendido}

Palavras não são o único elemento compartilhado entre documentos capazes de indicar similaridade. Outros tipos de documentos possuem metadados que podem definir relacionamentos entre documentos, e.g., artigos científicos incluem citações para reconhecer trabalhos relacionados e fontes de informação. Dessa forma, referências em comum também denotam similaridade semântica entre dois artigos. Com o intuito de agregar ainda mais informação nas relações de similaridade e consequentemente melhorar a qualidade do mapa dinâmico de coleções de artigos científicos, estendemos o modelo vetorial apresentado na Seção 2.2.1 para incorporar as referências de uma coleção como atributos em sua representação.

Suponha a existência da seguinte referência citada por algum artigo: VESPIGNANI A, 2009, SCIENCE, V325, P425, DOI 10.1126/science.1171990. Para analisar se duas referências são iguais e citam a mesma informação, é preciso determinar quando duas referências em artigos diferentes referem-se ao mesmo trabalho. Adotou-se que duas referências são iguais se elas possuem o mesmo Digital Object Identifier (DOI) ou se compartilham os seguintes campos - primeiro autor, nome da conferência ou revista, ano de publicação e o número da página inicial. Uma vez unificadas as referências, estendeu-se o modelo vetorial incluindo também como atributos as referências. Considere uma coleção de artigos científicos com $n$ documentos que possui $M$ termos e $K$ referências, o modelo vetorial apresentado na Seção 2.2.1 é estendido como apresentado na Tabela 4.1: 
Tabela 4.1: Modelo vetorial estendido.

\begin{tabular}{|c||c|c|c|c|c|c|c|c|}
\hline & $t_{1}$ & $t_{2}$ & $\cdots$ & $t_{m}$ & $r_{1}$ & $r_{2}$ & $\cdots$ & $r_{K}$ \\
\hline \hline$d_{1}$ & freq $_{11}$ & freq $_{12}$ & $\cdots$ & freq $_{1 M}$ & $\beta_{11}$ & $\beta_{12}$ & $\cdots$ & $\beta_{1 K}$ \\
\hline$d_{2}$ & freq $_{21}$ & freq $_{22}$ & $\cdots$ & freq $_{2 M}$ & $\beta_{21}$ & $\beta_{22}$ & $\cdots$ & $\beta_{2 K}$ \\
\hline$\cdots$ & $\cdots$ & $\cdots$ & $\cdots$ & $\cdots$ & $\cdots$ & $\cdots$ & $\cdots$ & $\cdots$ \\
\hline$d_{N}$ & freq $_{n 1}$ & freq $_{n 2}$ & $\cdots$ & freq $_{n M}$ & $\beta_{n 1}$ & $\beta_{n 2}$ & $\cdots$ & $\beta_{n K}$ \\
\hline
\end{tabular}

Para determinar o valor de $f_{r e q}$ recomenda-se utilizar a medida tf-idf (ver Seção 2.2.1). Para determinar o valor de $\beta_{i j}$ adota-se o seguinte esquema:

$$
\begin{aligned}
\text { freq }_{i j} & =t f-i d f\left(d_{i}, t_{j}\right) \\
\beta_{i j} & = \begin{cases}1, & \text { se a referência } r_{j} \text { ocorre no documento } d_{i} ; \\
0, & \text { caso contrário. }\end{cases}
\end{aligned}
$$

Caso se tenha utilizado a medida tf-idf para determinar os valores de $f r e q_{i j}$, o fator idf também deve ser aplicado aos valores de $\beta_{i j}$. Assim como nas medidas de influência dos termos, o fator de ponderação idf favorece referências que aparecem em poucos documentos e portanto são mais discriminativas. Para evitar que a matriz de dados fique ainda mais esparsa e com dimensionalidade ainda maior, o usuário também pode aplicar cortes que eliminam referências muito frequentes ou raras. Por exemplo, o valor padrão para o corte inferior determina que uma referência deve aparecer pelo menos duas vezes na coleção para ser incluída no modelo vetorial estendido. Uma desvantagem é a necessidade das referências estarem em um formato pré-definido (exemplo: VESPIGNANI A, 2009, SCIENCE, V325, P425, DOI 10.1126/science.1171990). No entanto, esse não é um grande problema no contexto desta tese, porque utilizamos bancos de dados acadêmicos que adotam tal formato.

A citação de um artigo a outro é uma propriedade de artigos científicos, que se mostrou valiosa nesta tese para melhorar a qualidade de mapas com artigos de um único pesquisador. Um pesquisador em particular tende a ser mais condizente com as citações realizadas ao longo do tempo, do que múltiplos autores ou autores de artigos publicados em um periódico ou área de pesquisa.

\subsubsection{Animação e Elementos Visuais}

De forma a exemplificar a aplicação da T-LSP para gerar um mapa de documentos dinâmico e determinar que tipo de elementos visuais podem ser utilizados nesse mapa, aplicou-se a técnica T-LSP para observar a trajetória do pesquisador Alessandro Vespignani, considerando intervalos de um ano. Foram coletados 152 artigos científicos publicados entre 1990 e 2012 por este pesquisador (como primeiro autor ou não) e indexados no Thomson Reuters Web of 


\section{Science.}

Alessandro Vespignani é um físico italiano, atualmente professor de Informática e Computação e professor adjunto em Física e Estatística na Universidade de Indiana, nos Estados Unidos. Ele também é diretor do Center for Complex Networks and Systems Research (CNetS) e diretor associado do Instituto de Tecnologia Pervasiva. Ele obteve seu doutorado em Física na Universidade de Roma "La Sapienza" em 1993. Após um pós-doutorado na Universidade de Yale e na Universidade de Leiden de 1993 a 1996, trabalhou no Centro Internacional de Física Teórica em Trieste de 1997 a 2002. Ele também trabalhou brevemente na Universidade de Paris-Sud de 2002 a 2004, antes de se mudar para Universidade de Indiana em 2004. Vespignani contribuiu em diversas áreas da Física, incluindo characterization of non-equilibrium phenomena e phase transitions. No entanto, é mais conhecido por sua pesquisa na área de redes complexas. Atualmente, foca na aplicação interdisciplinar de métodos de simulação estatísticos e numéricos para analisar fenômenos epidemiológicos de contaminação; e também no estudo de redes biológicas, sociais e tecnológicas. Ao longo deste capítulo, a coleção de artigos publicados pelo pesquisador Alessandro Vespignani é utilizada para ilustrar a abordagem proposta. A coleção completa encontra-se disponível em http: //vicg.icmc.usp.br/ aretha/tlsp/datasets/AlessandroVespignaniDataset.isi.

A sequência de projeções obtida aplicando a técnica T-LSP a essa coleção de artigos é mostrada na Figura 4.2b. Foi utilizado o modelo vetorial estendido (ver Seção 4.1.1) com corte de Luhn inferior igual à 10 para os termos e corte de Luhn inferior à 2 para as referências. A medida de similaridade do cosseno foi utilizada para quantificar a similaridade entre dois documentos.

Dada uma projeção, pode-se mapear informações adicionais, por exemplo, ao tamanho ou cor dos círculos que representam os documentos. Para esta sequência, a cor de cada círculo indica o ano de publicação do artigo correspondente, de acordo com a escala de cor mostrada na Figura 4.2a. Já as arestas são baseadas no acoplamento bibliográfico entre dois artigos: uma aresta é adicionada entre dois artigos se eles têm ao menos uma referência em comum e a cor da aresta é uma cor intermediária das cores dos círculos que ela conecta. As arestas baseadas em acoplamento bibliográfico permitem visualizar a similaridade entre dois tópicos quanto as suas referências.

Dada a sequência de projeções, é necessário adotar um mecanismo que consiga evidenciar gradualmente as mudanças entre dois instantes consecutivos nesta sequência. Para isso, geramos uma animação da sequência de projeções que destaca dois tipos de eventos em cada momento: a alteração da posição de documentos que existiam no momento anterior e a adição de novos documentos publicados no momento atual. Documentos que tiveram sua posição alterada de um momento para o próximo movimentam-se em uma linha reta da posição inicial para a final, calculada por meio de interpolação linear. São calculados 60 quadros intermediários para cada dois instantes de tempo consecutivos da sequência de projeções, de forma a obter uma animação suave que mostre estes eventos de 
(a) Legenda de cor.

\begin{tabular}{|c|c|c|c|c|c|}
\hline$\therefore$ & & & & & \\
\hline 1996 & 1997 & 1998 & 1999 & 2000 & 2001 \\
\hline 2002 & 2003 & 2004 & 2005 & 2006 & 2007 \\
\hline
\end{tabular}

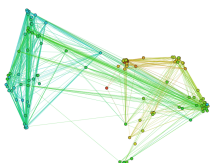

2008

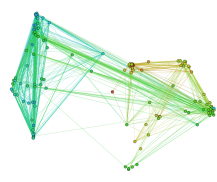

2009

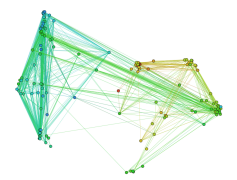

2010

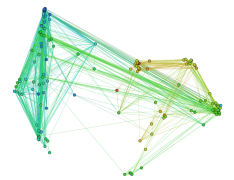

2011

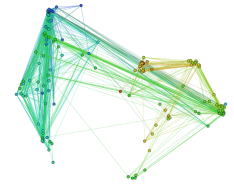

2012

(b) Sequência de projeções.

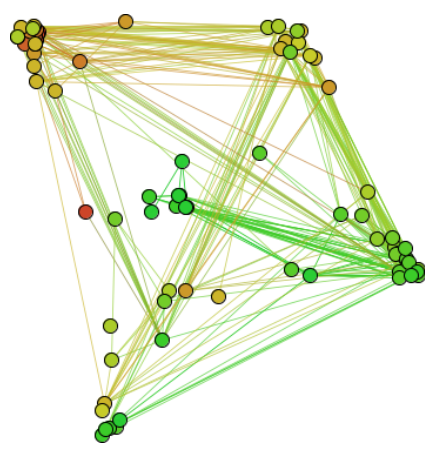

(c) 2002

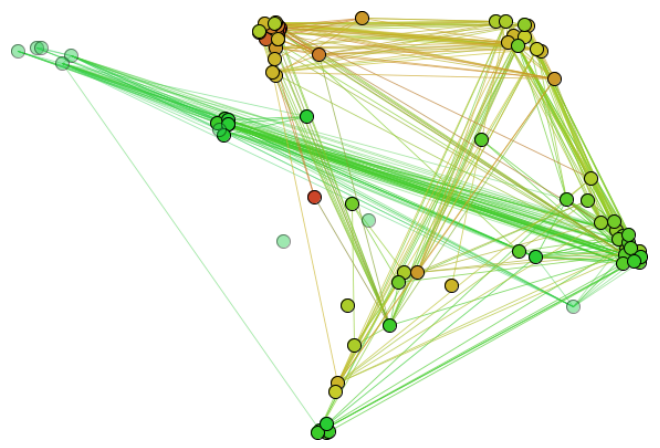

(d) Frame intermediário.

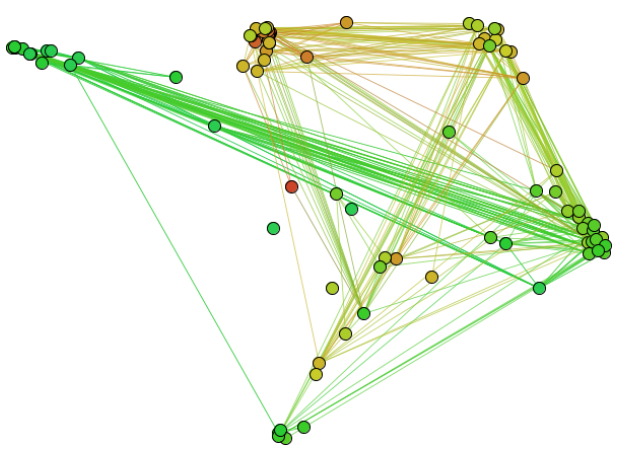

(e) 2003

Figura 4.2: Animação da sequência de projeções obtida com a técnica T-LSP para a coleção de artigos publicados por Alessandro Vespignani.

alteração da posição dos documentos e de adição de novos documentos. Já o surgimento de novos documentos é indicado por um efeito visual baseado em transparência, no qual esses documentos são visualizados inicialmente totalmente transparentes e vão tornando-se opacos durante a animação. As Figuras 4.2c e 4.2e mostram, respectivamente, os anos de 2002 e 2003, enquanto a Figura 4.2d mostra um frame intermediário entre esses dois anos. Neste frame intermediário, é possível notar: o surgimento de novos documentos (transparência); e a movimentação de outros já existentes em 2002, que estão se deslocando em direção aos documentos adicionados pois são similares a eles. O vídeo disponível em 
http://vicg.icmc.usp.br/ aretha/tlsp/examples/animation.avi mostra a animação completa para essa coleção.

\subsubsection{Avaliação Numérica da Técnica T-LSP}

Para avaliar projeções multidimensionais não apenas por inspeção visual, uma função de stress (Kruskal, 1964; Kruskal; Wish, 1978) pode ser utilizada. Funções desse tipo computam o erro acumulado entre as dissimilaridades observadas no espaço original $m$-dimensional e no espaço projetado p-dimensional para todos os objetos, i.e., calculam a perda de informação em projeções multidimensionais. Técnicas do tipo MDS geralmente utilizam funções de stress como uma função a ser otimizada para encontrar uma configuração ótima dos objetos no espaço projetado (ver Seção 3.1.1). A Equação 4.2 apresenta a função de stress definida por Kruskal (1964):

$$
\text { stress }=\sqrt{\frac{\sum_{i<j}\left(\delta\left(x_{i}, x_{j}\right)-d\left(f\left(x_{i}\right), f\left(x_{j}\right)\right)\right)^{2}}{\sum_{i<j} \delta\left(x_{i}, x_{j}\right)^{2}}}
$$

onde $f\left(x_{i}\right)$ é a projeção do objeto $x_{i}$. Também se deve observar que as dissimilaridades na projeção resultante $d\left(f\left(x_{i}\right), f\left(x_{j}\right)\right)$ podem se encontrar no intervalo $[0, \infty[$, enquanto as dissimilaridades no espaço original $\delta\left(x_{i}, x_{j}\right)$ são tipicamente normalizadas no intervalo $[0,1]$. Dessa forma, deve-se normalizar os valores de $d\left(f\left(x_{i}\right), f\left(x_{j}\right)\right)$ para cada par de elementos antes de aplicar a Equação 4.2.

No entanto, a Equação 4.2 não pode ser diretamente aplicada a projeções multidimensionais dinâmicas como a T-LSP. Projeções dinâmicas atualizam sua configuração ao longo do tempo, conforme novos objetos são adicionados. Nesse caso, não devemos analisar somente quanta informação foi perdida durante o processo da projeção, deve-se também quantificar a acurácia local e a coerência espacial global.

Considere a saída de uma técnica de projeção multidimensional dinâmica sobre um conjunto de dados, como uma sequência temporal de projeções $P=\left\{P_{1}, P_{2}, \ldots, P_{T}\right\}$. Para quantificar a acurácia global, definiu-se a medida stress estático que apresenta uma série temporal com valores do stress para cada projeção $P_{t}$ no momento $t$. A Equação 4.3 apresenta o valor:

$$
\text { stress_estático } t=\sqrt{\frac{\sum_{i<j}\left(\delta\left(x_{i}, x_{j}\right)-d\left(f\left(x_{i, t}\right), f\left(x_{j, t}\right)\right)\right)^{2}}{\sum_{i<j} \delta\left(x_{i, t}, x_{j, t}\right)^{2}}}, \text { com } t=1 \ldots T
$$

onde $x_{i, t}$ é a posição do objeto $x_{i}$ na projeção $P_{t}$. Quanto menores os valores da série de stress estático para cada momento, melhor a qualidade da projeção naquele instante. Os valores dessa série encontram-se no intervalo $[0,1]$. A Figura 4.3 a apresenta a série temporal 
que representa o stress estático (i.e., a acurácia local) para a projeção dinâmica da coleção de artigos publicados por Alessandro Vespignani apresentada na Figura 4.2b.

Já a medida denominada stress dinâmico, apresentada na Equação 4.4, também é uma série temporal, mas que busca quantificar a coerência espacial global:

$$
\text { stress_dinâmico } t=\frac{1}{\left|P_{t-1}\right|} \sum_{i \in V\left(P_{t-1}\right)}\left|f\left(x_{i, t-1}\right)-f\left(x_{i, t}\right)\right|, \text { com } t=1 \ldots T
$$

onde $V\left(P_{t-1}\right)$ são os vértices que existiam na projeção anterior $P_{t-1},\left|P_{t}\right|$ é o número de objetos representados na projeção $P_{t}$ e $x_{i, t}$ é a posição do objeto $x_{i}$ na projeção $P_{t}$. A medida do stress dinâmico deve ser analisada com cuidado. A série do stress dinâmico em cada instante $t$ indica movimentações de instâncias de dados que já existiam na projeção $P_{t-1}$ para a projeção seguinte $P_{t}$. Observe que essa medida não leva em consideração atualmente instâncias

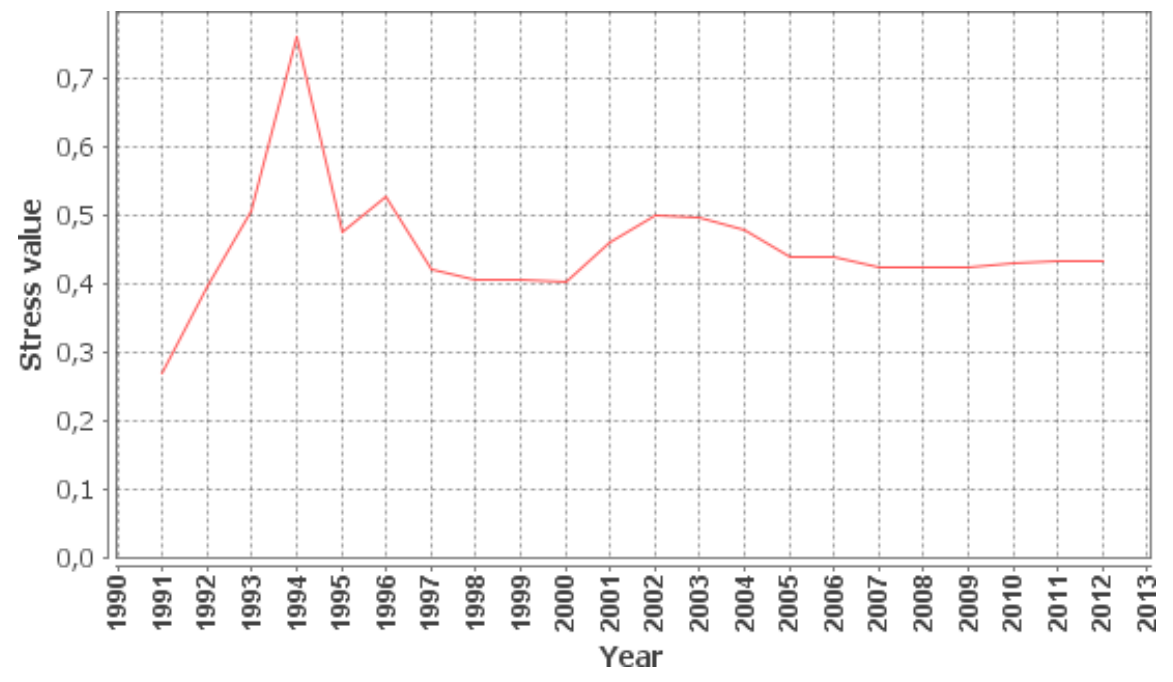

(a) Stress estático.

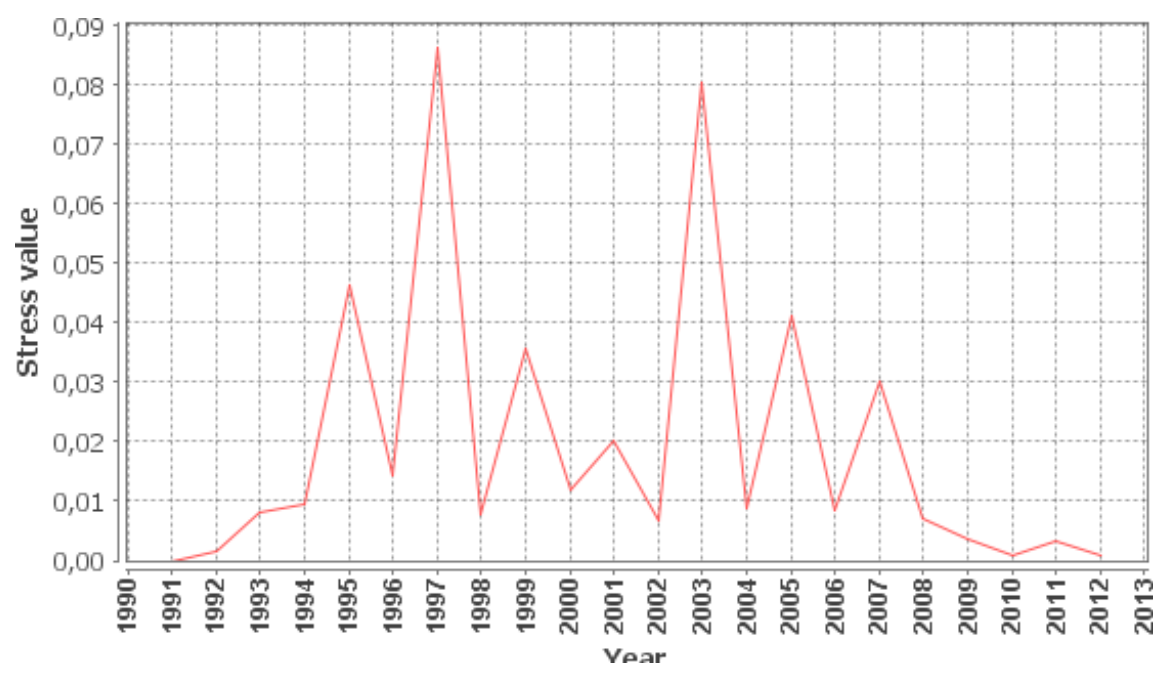

(b) Stress dinâmico.

Figura 4.3: Stress estático e stress dinâmico para a projeção dinâmica da coleção de artigos publicados por Alessandro Vespignani mostrada na Figura 4.2b. 
adicionadas no instante atual. Estas movimentações podem ser causadas simplesmente pelo surgimento de novos grupos proeminentes, o que não é um indicativo de má qualidade da projeção dinâmica, mas sim de um padrão presente nos dados. No entanto, se essa medida apresentar valores excessivamente altos em vários instantes de tempo, isto indica falta de estabilidade na sequência de projeções.

A Figura 4.3b apresenta a série temporal que quantifica o stress dinâmico (i.e., a coerência global) para a mesma sequência de projeções. Na Figura 4.3b, existe, por exemplo, um pico em 1997 e outro em 2003 que são causados pelo surgimento de novos grupos de documentos. O pico em 1997 está associado ao surgimento do um segundo grupo de documentos relacionado a área de Física. Já o pico em 2007 está associado ao surgimento do primeiro grupo de documentos relacionado à área de Redes Complexas. O pesquisador Alessandro Vespignani lentamente mudou o foco de sua pesquisa de Física para Redes Complexas.

\subsubsection{Complexidade Computacional}

A técnica de projeção multidimensional dinâmica T-LSP utiliza a técnica LSP para gerar a sequência temporal de projeções. Portanto, definimos a complexidade computacional da T-LSP com base na complexidade computacional da LSP. Como mencionado na Seção 3.1.1, a complexidade computacional da LSP é igual a $O(C+N+S)$, onde $C$ é a complexidade de escolher os pontos de controle, $N$ é a complexidade de definir as relações de vizinhança e $S$ é a complexidade para se resolver o sistema linear, com $C=N=O(n \sqrt{n})$ e $S=O(n \sqrt{k})$, onde $k$ é o número de condição da matriz $A^{T} A$ e $A$ é a matriz que representa o sistema linear. Portanto, a complexidade computacional final da LSP é $O(\max \{n \sqrt{n}, n \sqrt{k}\})$.

Considere uma coleção com $n$ instâncias e $T$ intervalos de tempo. A T-LSP adota um esquema retroativo no qual primeiramente se projeta toda a coleção de dados com a LSP para gerar a projeção $P_{T}$. Assim, a complexidade para obter $P_{T}$ é igual a $O(\max \{n \sqrt{n}, n \sqrt{k}\})$. Já para as projeções $P_{T-1}, \ldots, P_{2}$, a LSP também é aplicada, mas não é necessário escolher os pontos de controle. Os pontos de controle para essas projeções serão as instâncias que não tiveram suas vizinhanças alteradas devido à remoção de instâncias pertencentes ao último lote removido. Mesmo assim, a complexidade para obter as projeções $P_{T-1}, \ldots, P_{2}$ é igual a $O(\max \{n \sqrt{n}, n \sqrt{k}\} \times T-2)$. Por fim, a projeção $P_{1}$ é obtida simplesmente removendo de $P_{2}$ as instâncias que pertencem ao segundo lote. Dessa forma, o custo computacional para obter $P_{1}$ é praticamente inexistente.

Assim, a complexidade computacional final da técnica T-LSP é $O(\max \{n \sqrt{n}, n \sqrt{k}\}+$ $\max \{n \sqrt{n}, n \sqrt{k}\} \times T-2)$, ou seja, $O(\max \{n \sqrt{n}, n \sqrt{k}\} \times T-1)$, sendo que o valor de $n$ diminui a cada intervalo. 


\subsubsection{Comparação da T-LSP com a LSP}

Com o intuito de observar quão estável a T-LSP é ao longo do tempo, em comparação a uma técnica convencional como a LSP, considerando os mesmos intervalos de tempo, aplicamos as duas técnicas à coleção de artigos publicados por Alessandro Vespignani. A Figura 4.4 mostra uma comparação entre os mapas gerados com a abordagem proposta T-LSP para os anos de 2010, 2011 e 2012, e os mapas correspondentes obtidos com a técnica LSP. Já que a técnica T-LSP é cumulativa, a Figura 4.4a, por exemplo, representa o mapa obtido com a LSP para o ano de 2010 e inclui todos os artigos publicados entre 1990 e 2010. As Figuras 4.4c e 4.4f são idênticas, pois o mapa do último instante de tempo na T-LSP consiste em projetar todo o conjunto de dados usando a LSP - retrocedendo em seguida para gerar as projeções dos momentos anteriores segundo os passos descritos na Seção 4.1. Como esperado, na LSP a orientação dos mapas muda significantemente em momentos consecutivos. Grupos equivalentes formados nos mapas ocupam diferentes posições e também se encontram mais distribuídos na área disponível.

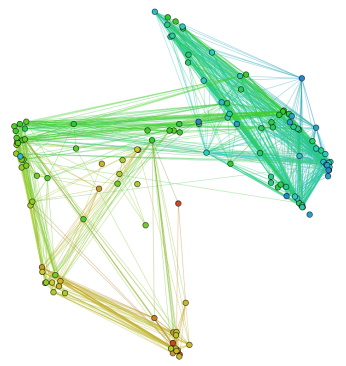

(a) LSP: ano 2010

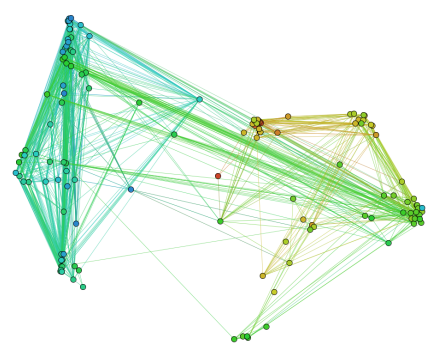

(d) T-LSP: ano 2010

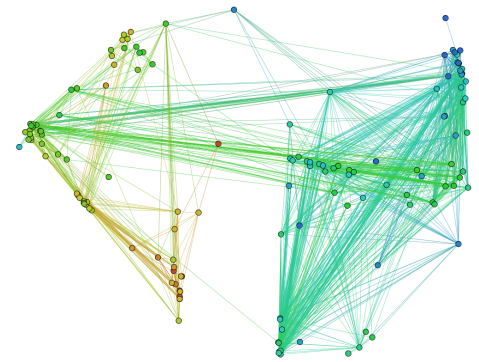

(b) LSP: ano 2011

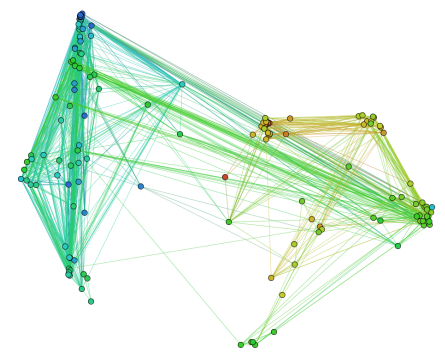

(e) T-LSP: ano 2011

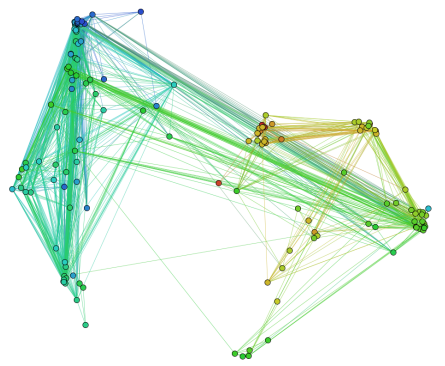

(c) LSP: ano 2012

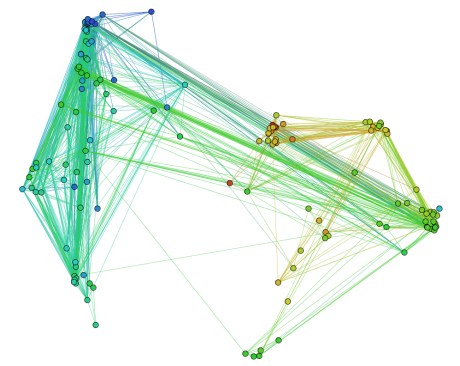

(f) T-LSP: ano 2012

Figura 4.4: Comparação da LSP com a T-LSP para coleção de artigos publicados por Alessandro Vespignani: (a), (b) e (c) projeções obtidas com a técnica LSP para os anos 2010, 2011 e 2012, respectivamente; (d), (e) e (f) projeções obtidas com a técnica T-LSP para os anos 2010, 2011 e 2012, respectivamente. 


\subsection{Técnicas de Extração de Tópicos}

Embora um mapa de documentos seja potencialmente útil para revelar relações de similaridade entre instâncias e grupos de instâncias, nenhuma informação é dada sobre por que certos grupos se formaram no layout final. Para apoiar a interpretação dos mapas, um mecanismo auxiliar é a extração automática de tópicos (ver Seção 3.2). No caso de um mapa de documentos dinâmico é interessante, por exemplo, identificar tópicos associados a um grupo de documentos em um certo momento e como esses tópicos mudaram posteriormente pela adição de novos documentos similares a esse grupo. Geralmente, um documento pode ser associado a múltiplos tópicos e um mesmo tópico pode estar associado a múltiplos documentos.

Nesta seção são apresentadas duas novas técnicas de extração automática de tópicos: a extração de tópicos baseada em PCA, um método muito utilizado para detecção de padrões; e a extração de tópicos baseada em LDA, um modelo que busca representar documentos como uma distribuição probabilística de seus tópicos.

\subsubsection{Extração de Tópicos baseada em PCA}

A extração de tópicos baseada em covariância (Paulovich, 2008) (ver Seção 3.2) possui a vantagem de ser concisa se comparada a outros métodos. No entanto, esta técnica analisa a covariância entre os termos par a par para detectar valores significativos de covariância entre eles, não analisando os termos globalmente. O Principal Component Analysis (PCA) é um método utilizado para detecção de padrões que também utiliza covariância em seu cálculo. Esse método cria vetores formados por combinações lineares dos atributos que representam os padrões nos dados. Com o intuito de obter tópicos mais "informativos" do que os obtidos na extração baseada em covariância, desenvolveu-se uma nova técnica para extração de tópicos baseada em PCA.

A próxima subseção apresenta a técnica PCA e como ela pode ser aplicada para detectar padrões em conjuntos de dados. Em seguida, apresenta-se o algoritmo para a extração de tópicos baseado em PCA.

\section{Principal Component Analysis (PCA)}

Dada uma matriz $m$-dimensional de dados $X_{n \times m}=\left\{x_{i j}: 1 \leq i \leq n, 1 \leq j \leq m\right\}$ com $n$ instâncias e $m$ atributos, técnicas de redução de dimensionalidade buscam encontrar uma representação de menor dimensão $S_{n \times p}=\left\{s_{i j}: 1 \leq i \leq n, 1 \leq j \leq p\right\}$, com $p \leq m$, que capture o conteúdo original dos dados de acordo com algum critério (Fodor, 2002).

Principal Component Analysis (PCA) (Pearson, 1901) é uma técnica de redução de dimensionalidade que busca transformar um conjunto de atributos possivelmente correlacionados em um conjunto menor de atributos não correlacionados denominados 
componentes principais. Seu processo é baseado em determinar combinações lineares ortogonais - os componentes principais - que capturem melhor a variabilidade dos dados. Nesse processo, o primeiro componente principal será a combinação linear com maior variância, o segundo componente será a combinação linear, ortogonal à primeira, com a segunda maior variância, e assim por diante. O número de componentes principais é igual ao número original de atributos. No entanto, em geral os primeiros componentes principais capturam a maior parte da variância dos dados, de forma que muitos componentes podem ser descartados com pouca perda de informação. Apesar do PCA ser aplicado principalmente no contexto de redução de dimensionalidade, ele também pode ser utilizado na detecção de padrões.

Para aplicar o PCA, calcula-se a matriz de covariância $C_{m \times m}$ cujos termos $c_{i j}$ são formados pela covariância entre cada par de atributos originais $a_{i}=\left(x_{1 i}, \ldots, x_{n i}\right)$ e $a_{j}=\left(x_{1 j}, \ldots, x_{n j}\right)$ :

$$
c_{i j}=\operatorname{cov}\left(a_{i}, a_{j}\right)=\frac{1}{n-1} \sum_{k=1}^{n}\left(a_{k i}-\overline{a_{i}}\right)\left(a_{k j}-\overline{a_{j}}\right)
$$

onde $\overline{a_{i}}=(1 / n) \sum_{k=1}^{n} a_{k i}$ e $\overline{a_{j}}=(1 / n) \sum_{k=1}^{n} a_{k j}$.

A análise das componentes principais inicia-se com o cálculo dos autovalores e correspondentes autovetores da matriz de covariância $C_{m \times m}$. Dada uma matriz de dados $X_{n \times m}$, aplica-se uma decomposição espectral:

$$
C=U \Lambda U^{T}
$$

onde $C_{m \times m}$ é a matriz de covariância calculada anteriormente; $\Lambda=\operatorname{diag}\left(\lambda_{1}, \ldots, \lambda_{m}\right)$ é uma matriz diagonal dos autovalores ordenados de forma decrescente $\lambda_{1} \geq \ldots \geq \lambda_{m}$; e $U_{m \times m}$ é uma matriz ortogonal, onde cada coluna $u_{i}=\left(u_{1 i}, \ldots, u_{m i}\right)$ corresponde a um autovetor $u_{i}$ (componente principal) associado ao autovalor $\lambda_{i}$. Quanto mais alto o autovalor associado a um autovetor, maior a sua significância.

Por fim, a redução de dimensionalidade é obtida projetando-se os dados em um nova base, formada somente pelos $p$ componentes com autovalores mais significativos.

$$
S=B^{T} X
$$

onde a matriz $B=\left[u_{1}, \ldots, u_{p}\right]$ é formada pelas primeiras $p$ colunas de $U$.

Muitos métodos, tanto heurísticos como estatísticos, têm sido propostos para determinar o número $p$, i.e., o número de componentes "significativos". Alguns métodos podem ser facilmente calculados enquanto outros são computacionalmente caros. Entre os métodos disponíveis estão: o gráfico scree, o critério de Guttman-Kaiser, o teste de correlações parciais de Velicer, o gráfico Log-Eigenvalue (LEV), o percentual cumulativo da variância explicada, entre outros. Para uma descrição aprofundada desses e de outros métodos veja Jackson (1991) e Jolliffe (2002). 
No contexto desta tese, utilizamos o percentual cumulativo da variância explicada para determinar o valor de $p$ por se tratar de um método que permite ao usuário definir o quanto de informação deseja reter. Se $p$ componentes são mantidos, então pode-se representar o percentual cumulativo da variância explicada pelos primeiros $p$ componentes, $V_{p}$, por:

$$
V_{p}=\frac{\sum_{k=1}^{p} \lambda_{k}}{\operatorname{traço}(C)}
$$

sendo o traço de uma matriz igual à soma dos elementos da sua diagonal principal, traço $(C)=c_{11}+c_{22}+\ldots+c_{m m}$, i.e., o traço da matriz $C$ é igual a soma de todos os autovalores. Dada a porcentagem de variância que se deseja reter, basta escolher o valor de $p$ que obtém um valor igual ou imediatamente superior à porcentagem desejada na Equação 4.8. Esse método para determinar $p$ é relativamente eficiente, o que torna a extração de tópicos baseada em PCA mais rápida e mais interativa para o usuário.

Como dito anteriormente, também é possível empregar o PCA para detecção de padrões. Para cada autovetor também é possível obter os fatores de carregamento (loading factors), que indicam o peso e a correlação entre cada atributo original e o autovetor correspondente. Fatores de carregamento, $l f_{i}=\left(l f_{i 1}, \ldots, l f_{i m}\right)$, de um autovetor, $u_{i}$, são calculados multiplicando o autovetor pela raiz quadrada do autovalor associado:

$$
l f_{i j}=u_{i j} \times \sqrt{\lambda_{i}}, \quad 1 \leq j \leq m
$$

onde $i$ é o índice do autovetor e $j$ é o índice do atributo original. Tais carregamentos podem ser considerados como uma medida da relativa importância de cada atributo em relação às componentes principais e os respectivos sinais, se positivos ou negativos, indicam relações diretamente ou inversamente proporcionais.

\section{Algoritmo para Extração de Tópicos baseada em PCA}

A extração de tópicos baseada em PCA parte da ideia de que cada autovetor significativo pode representar um tópico em potencial e que os fatores de carregamento podem determinar que termos compõem um tópico em específico. Considerando um mapa de documentos, normalmente o processo de extração de tópicos por PCA se inicia com o usuário selecionando uma determinada área na projeção. Dados o subconjunto de documentos selecionados, as seguintes etapas para extrair tópicos relativos a esse subconjunto são executadas:

1. Definição de valores para os parâmetros min_topics e min_terms:

1.1. O parâmetro min_topics, com intervalo entre [0,1], limita a quantidade de tópicos extraídos para o subconjunto de documentos. O valor de min_topics define qual a porcentagem cumulativa que os tópicos extraídos devem representar da variância explicada. Quanto maior o seu valor, maior o número de tópicos extraídos. Valor default: min_topics $=0,5$. 
1.2. Já o parâmetro min_terms, com intervalo entre $[0,1]$, representa o valor mínimo que um fator de carregamento deve ter para que o termo associado seja incluído no tópico a ser extraído. Quanto maior o valor desse parâmetro, menor o número de termos associados a cada tópico. Valor default: min_terms $=0,6$.

2. Cria-se a representação vetorial para os documentos selecionados mantendo como atributos somente os 100 termos (sem stemming e no singular) mais frequentes.

3. Aplica-se o PCA a matriz da representação vetorial, obtendo-se os autovalores e autovetores correspondentes.

4. Determinar-se, por meio do percentual cumulativo de variância explicada, o número $p$ de autovalores que devem ser mantidos, para reter uma porcentagem igual ou imediatamente superior à min_topics.

5. Dado um contador $i$ inicializado com o valor 1 , repete-se os seguintes passos até que $i=p$ :

5.1. Selecione o autovetor $u_{i}$ e crie um novo tópico $A$ com peso igual ao percentual explicado por $u_{i}$ da variância explicada.

5.2. Calcule os fatores de carregamento, $l f_{i}$, para esse autovetor.

5.3. Dado um contador $j$ inicializado com o valor 1 , repita os seguintes passos até que $j=m$ :

5.3.1. Se $l f_{i j} \geq$ min_terms, adicione o termo $t_{j}$ da matriz de representação vetorial ao tópico $A$ com peso igual a $l f_{i j}$.

5.3.2. Incremente o contador $j$ em 1 unidade.

5.4. Caso nenhum termo tenha sido adicionado ao tópico $A$ na etapa anterior 5(c), reduza iterativamente o valor de min_terms (o novo valor será $75 \%$ do valor anterior) e repita a etapa anterior até que pelos menos dois termos sejam adicionados ao tópico. Existem casos onde o autovetor é significativo, mas nenhum termo possui um fator de carregamento alto, pois existem vários termos que possuem uma contribuição intermediária (diluição das contribuições).

5.5. Adicione $A$ a lista de tópicos extraídos $L$ e incremente o contador $i$ em 1 unidade.

\subsubsection{Extração de Tópicos baseada em LDA}

O Latent Dirichlet Allocation (LDA) (ver Seção 2.2.2) é baseado no conceito de que documentos podem ser descritos como uma combinação de tópicos, no qual um tópico é uma distribuição probabilística de palavras. Para gerar um documento segundo esse modelo, primeiro escolhe-se uma distribuição probabilística de tópicos. Então, para cada palavra a ser incluída no documento, escolhe-se um tópico aleatoriamente de acordo com a distribuição de tópicos, escolhendo-se em seguida uma palavra daquele tópico (cada tópico também é uma distribuição probabilística de palavras). Técnicas estatísticas podem ser usadas para inverter este processo, ou seja, para inferir os tópicos que foram responsáveis pela geração do 
conjunto de documentos.

Neste processo de inferência, é necessário que o usuário defina o parâmetro $T$ - o número de tópicos a serem extraídos da coleção. A saída do LDA para uma coleção com $n$ documentos e $m$ palavras são duas matrizes (ver Tabela 4.2): $\theta$, que contém a distribuição probabilística de tópicos para cada documento e tem tamanho $T \times n$; e $\phi$, que contém a distribuição probabilística dos termos para cada tópico e tem tamanho $m \times T$. A escolha do número de tópicos afeta a qualidade dos resultados. Uma solução com poucos tópicos irá resultar em tópicos muito amplos, enquanto uma solução com muitos tópicos irá resultar em tópicos não interpretáveis com combinações pouco significativas de palavras. A escolha do parâmetro $T$ depende em parte do tamanho da coleção, mas o intervalo $T=[200,400]$ costuma produzir resultados razoavelmente detalhados. Já para os demais parâmetros para inferência de um modelo LDA, assume-se os seguintes valores padrões: $\alpha=0,1, \beta=0,01$ e 1.500 iterações.

Tabela 4.2: Exemplo de matrizes de saída do LDA para $T$ tópicos e $N$ documentos com $M$ termos

(a) Matrix $\theta$.

\begin{tabular}{|c||c|c|c|c|c|c|}
\hline & $d_{1}$ & $d_{2}$ & $d_{3}$ & $d_{4}$ & $\cdots$ & $d_{N}$ \\
\hline \hline$t_{1}$ & 0.14351 & 0.61310 & 0.27188 & 0.00188 & $\cdots$ & 0.00832 \\
\hline$t_{2}$ & 0.12064 & 0.00314 & 0.25524 & 0.00444 & $\cdots$ & 0.25778 \\
\hline$t_{3}$ & 0.06131 & 0.04516 & 0.05724 & 0.00276 & $\cdots$ & 0.01439 \\
\hline$\cdots$ & $\cdots$ & $\cdots$ & $\cdots$ & $\cdots$ & $\cdots$ & $\cdots$ \\
\hline$t_{T}$ & 0.00487 & 0.00187 & 0.00312 & 0.75264 & $\cdots$ & 0.25407 \\
\hline
\end{tabular}

(b) Matrix $\phi$.

\begin{tabular}{|c||c|c|c|c|c|c|}
\hline & $t_{1}$ & $t_{2}$ & $t_{3}$ & $t_{4}$ & $\cdots$ & $t_{T}$ \\
\hline \hline$w_{1}$ (networks) & 0.24751 & 0.00010 & 0.00334 & 0.00521 & $\cdots$ & 0.04021 \\
\hline$w_{2}$ (social) & 0.24783 & 0.00014 & 0.00426 & 0.00334 & $\cdots$ & 0.00321 \\
\hline$w_{3}$ (fractal) & 0.00000 & 0.31002 & 0.00330 & 0.07219 & $\cdots$ & 0.00621 \\
\hline$\cdots$ & $\cdots$ & $\cdots$ & $\cdots$ & $\cdots$ & $\cdots$ & $\cdots$ \\
\hline$w_{M}($ epidemic $)$ & 0.09471 & 0.00030 & 0.51005 & 0.00021 & $\cdots$ & 0.00110 \\
\hline
\end{tabular}

Desenvolvemos um técnica para determinar os tópicos mais prováveis e suas palavras significativas de acordo com o modelo LDA, dado um subconjunto de documentos selecionados no mapa. Primeiramente, é necessário inferir o modelo LDA para a coleção inteira. Escolhemos inferir o modelo a partir da coleção ao invés de a partir de cada subconjunto de documentos, pois um número de documentos maior confere mais informatividade ao modelo e também torna o processo mais dinâmico. Dado o subconjunto de documentos selecionados e o modelo LDA inferido, a seguintes etapas são executadas:

1. Considere $n$ documentos selecionados $\left\{d_{1}, d_{2}, \ldots, d_{n}\right\}$ para os quais devemos extrair tópicos. 
2. Definição de valores para os parâmetros min_topics e min_terms:

2.1. O parâmetro min_topics, com intervalo entre $[0,1]$, representa a porcentagem mínima de informação que deve ser mantida em relação aos tópicos. Valor default: min_topics $=0,5$

2.2. Já o parâmetro min_terms, com intervalo entre $[0,1]$, representa a porcentagem mínima de informação que deve ser mantida em relação aos termos. Valor default: min_terms $=0,3$

3. Selecione as colunas da matriz $\theta$ referentes aos documentos selecionados, i.e., $\left\{\theta\left[\cdot, d_{1}\right], \ldots, \theta\left[\cdot, d_{n}\right]\right\}$.

4. Em seguida, calcule um vetor $v_{\text {sum }}($ tamanho $1 \times T)$ que é o vetor transposto da somatória dos vetores $\left\{\theta\left[\cdot, d_{1}\right], \ldots, \theta\left[\cdot, d_{n}\right]\right\}$, i.e., $v_{\text {sum }}[1, i]=\theta\left[i, d_{1}\right]+\cdots+\theta\left[i, d_{n}\right]$ para $i=1 \ldots T$. Esse vetor $v_{\text {sum }}$ dá a probabilidade de cada tópico do LDA ocorrer considerando o conjunto de documentos selecionados.

5 . Ordene o vetor $v_{\text {sum }}$ por ordem decrescente de valor, mantendo em um segundo vetor index_topics os índices originais de cada valor antes da ordenação.

6. Dado o vetor $v_{\text {sum }}$, selecione os $k$ primeiros tópicos cuja soma de seus valores no vetor $v_{\text {sum }}$ completa a porcentagem min_topics. Os $k$ primeiros índices armazenados no vetor index_topics também são guardados, $\left\{\right.$ inde $_{t_{1}}, \ldots$, inde $\left._{t_{k}}\right\}$.

7. Para cada índice na lista $\left\{i n d e x_{t_{1}}, \ldots, i n d e x_{t_{k}}\right\}$, será gerado um novo tópico. Dado um contador $i$ inicializado com o valor 1 , repita os seguintes passos até que $i=k$ :

7.1. Selecione a coluna $\phi\left[\right.$, index $\left.x_{t_{i}}\right]$ e crie um novo tópico $A$ com peso $v_{\text {sum }}[1, i]$.

7.2. Para determinar quais termos compõem o tópico $i n d e x_{t_{i}}$ adicione os termos da coluna $\phi\left[.\right.$, index $\left._{t_{i}}\right]$ ao tópico $A$, em ordem decrescente de valor, até completar o valor min_terms. Suponha que o termo $t_{j}$ tenha sido adicionado ao tópico $A$, seu peso dentro de $A$ será igual a $\phi\left[t_{j}\right.$, index $\left._{t_{i}}\right]$.

7.3. Adicione $A$ a lista de tópicos extraídos $L$ e incremente o contador $i$ em 1 unidade.

A inferência do modelo LDA é baseada em interações que promovem o seu refinamento a cada iteração, o que torna o processo demorado. Isto torna a extração de tópicos baseada em LDA mais lenta, do que a extração baseada em PCA. No entanto, se o modelo LDA tiver sido empregado para gerar a projeção dinâmica, não é necessário inferir o modelo novamente. É possível utilizar o mesmo modelo utilizado para gerar a projeção para extrair os tópicos. Salienta-se também que o modelo LDA não é determinístico, podendo-se obter tópicos levemente diferentes em duas execuções com os mesmos parâmetros para o mesmo conjunto de dados. Utilizou-se a biblioteca em Java MALLET ${ }^{1}$ (Mccallum, 2002) que inclui um algoritmo paralelo para inferência de modelos LDA.

${ }^{1}$ http://mallet.cs.umass.edu 


\subsubsection{Comparação entre Técnicas de Extração de Tópicos}

Nesta seção, comparamos, quanto ao resultado e tempo de execução, as técnicas de extração automática de tópicos baseada em PCA, em LDA e a técnica baseada em covariância introduzida na Seção 3.2. A técnica de extração de tópicos baseada em covariância é a que mais se assemelha às técnicas desenvolvidas neste trabalho, tanto quanto à representação de um tópico como quanto ao processo empregado para extrair os tópicos. Na técnica de extração de tópicos baseada em covariância, primeiramente identificam-se os dois termos com maior covariância na representação vetorial dos documentos selecionados. Esses dois termos com maior covariância são adicionados ao tópico a ser extraído. Para cada termo remanescente, a média da covariância dos dois primeiros termos selecionados em relação a cada termo remanescente é calculada. Se essa média for maior ou igual a um limiar pré-estabelecido $\alpha$ (um valor entre $[0,1]$ ), o termo é adicionado ao tópico. De forma a identificar se existem outros pares de termos iniciais com alta covariância e interessantes para indicar temas, qualquer par de termos cuja razão de sua covariância pela maior covariância for maior ou igual a um limiar $\beta$ (também um valor entre $[0,1]$ ) irão gerar um novo tópico. Os valores $\alpha=0,5$ e $\beta=0,75$ foram adotados como padrão pelos autores.

A Figura 4.5 apresenta os tópicos extraídos por cada uma das técnicas acima quando aplicadas ao ano de 2012 da projeção dinâmica criada usando-se a T-LSP para o conjunto de artigos publicados por Alessandro Vespignani. Oito grupos encontrados pelo algoritmo de agrupamento DBSCAN (a ser apresentado na Seção 4.3.1) foram fornecidos como entrada para essas técnicas. Os polígonos em cinza delimitam esses grupos, com identificadores $\left(C_{i}\right)$ adicionados manualmente para facilitar a análise. Um tópico é representado visualmente como uma lista de seus termos, e com o seu peso em colchetes. Quando um tópico é muito longo, os últimos termos não são exibidos, utilizando-se reticências no fim para indicar a existência de mais termos. Para exibir todos os termos de um tópico, basta o usuário selecioná-lo na representação visual. A Figura 4.5a apresenta os tópicos extraídos utilizando-se a técnica baseada em covariância com valores padrão para os parâmetros $(\alpha=0,5$ e $\beta=0,75)$. A Figura 4.5b mostra os tópicos extraídos utilizando a técnica baseada em PCA também com valores padrão para os parâmetros ( min_topics $=0,5$ e min_terms $=0,6$ ). Por fim, a Figura 4.5c apresenta os tópicos extraídos utilizando-se a técnica baseada em LDA com valores padrão para os parâmetros ( min_topics $=0,5$ e min_terms $=0,3$ ).

A extração em tópicos baseada em covariância tende a ser mais concisa do que a técnica baseada em PCA. Por exemplo, todos os termos dos dois tópicos extraídos para o grupo $C_{7}$ na Figura 4.5a (covariância) - (simililarity, semantic, web) (graph, statistical) aparecem nos três tópicos - (internet, network, sampled, statistical, sampling, ...) (statistical, graph, web, sampling, sampled, mapping, ...) (internet, semantic, similarity) - para o mesmo grupo na Figura 4.5b (PCA). Apesar de não serem concisos, os tópicos baseados em PCA oferecem mais evidências de qual tema está sendo discutido nos documentos selecionados, 


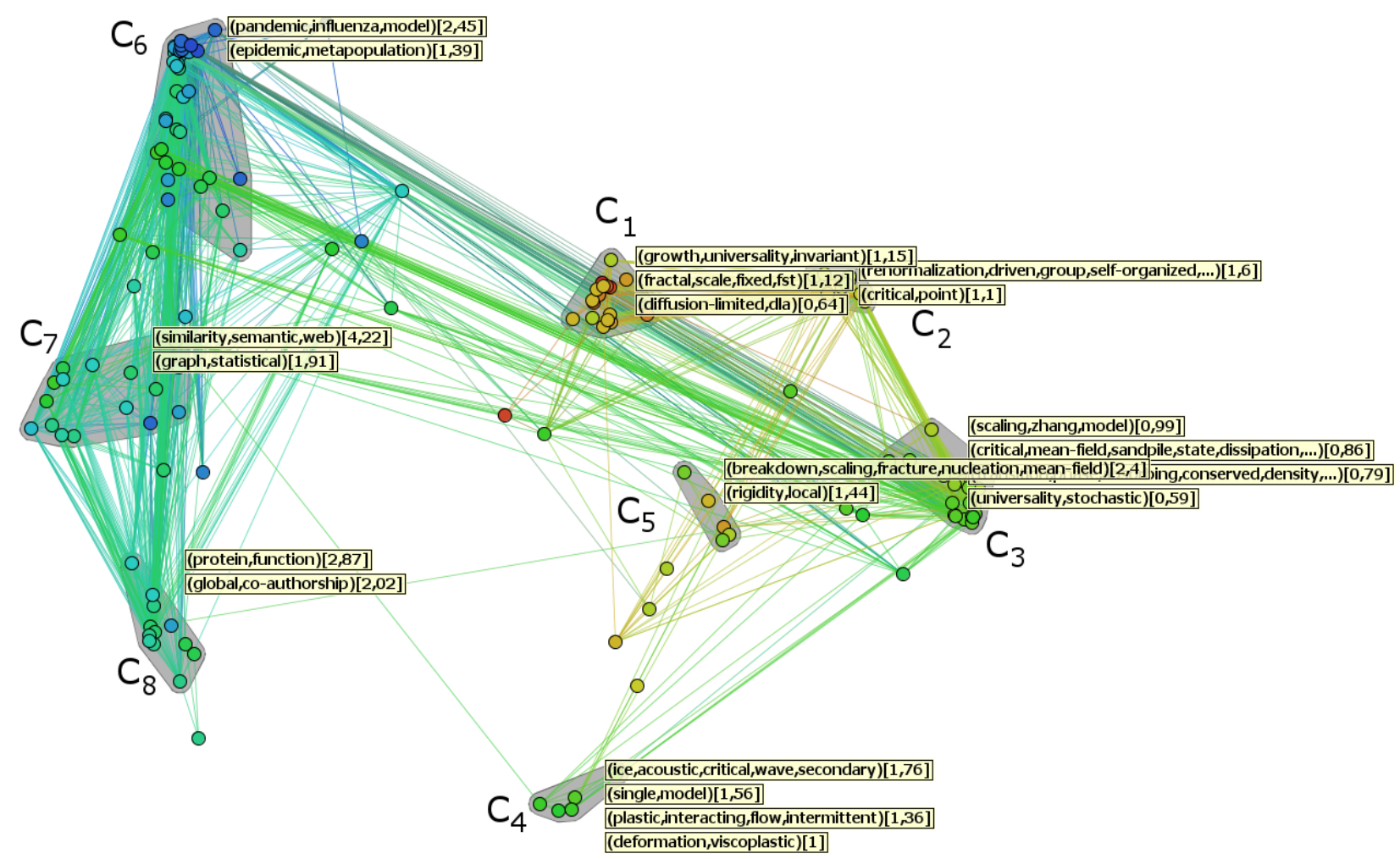

(a) Extração de tópicos baseada em covariância com parâmetros $\alpha=0,5$ e $\beta=0,75$.

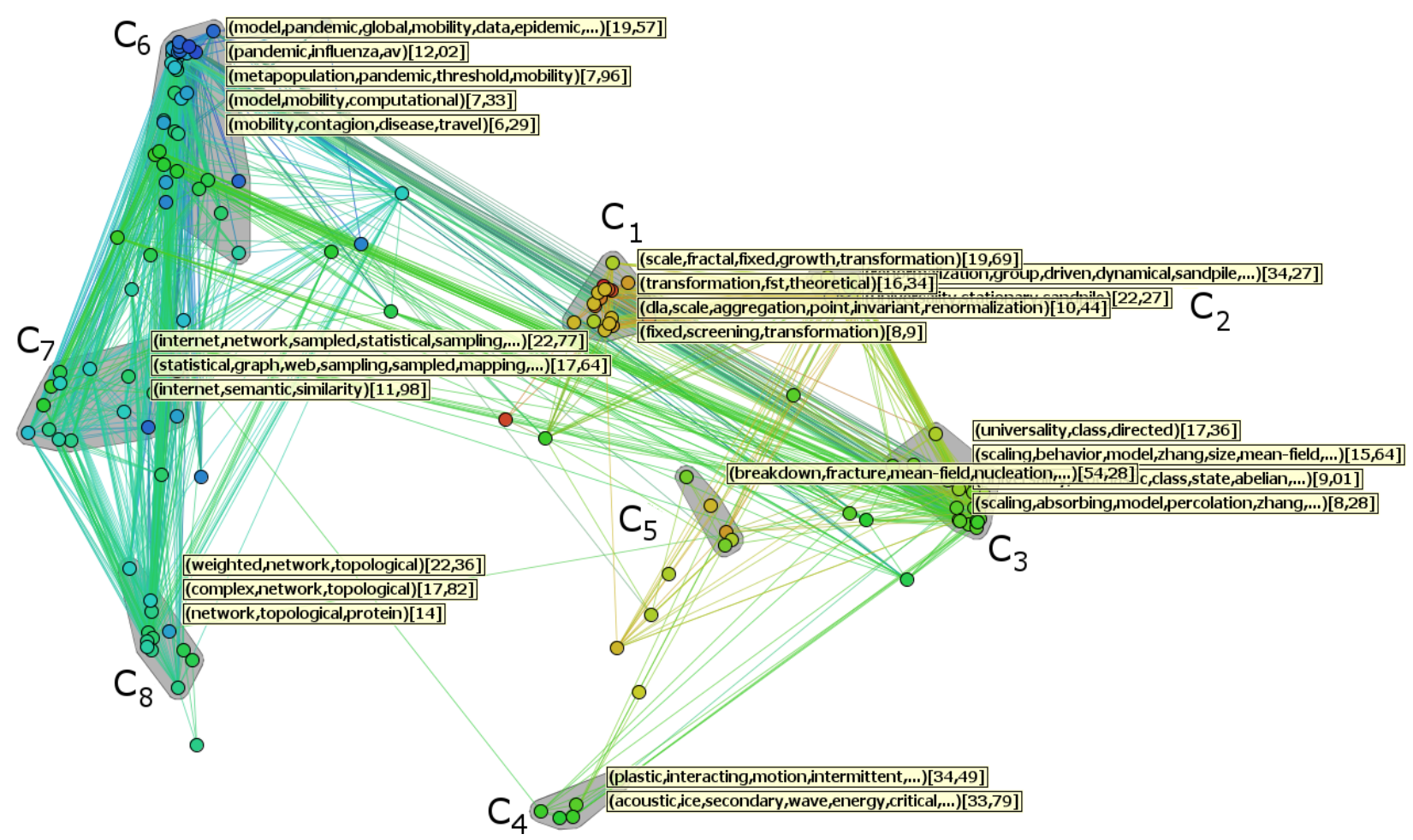

(b) Extração de tópicos baseada em PCA com parâmetros min_topics $=0,5$ e min_terms $=0,6$.

Figura 4.5: Tópicos extraídos para o ano de 2012 da projeção dinâmica criada usando-se a T-LSP para o conjunto de artigos publicados por Alessandro Vespignani (mesma projeção da Figura 4.4f). 


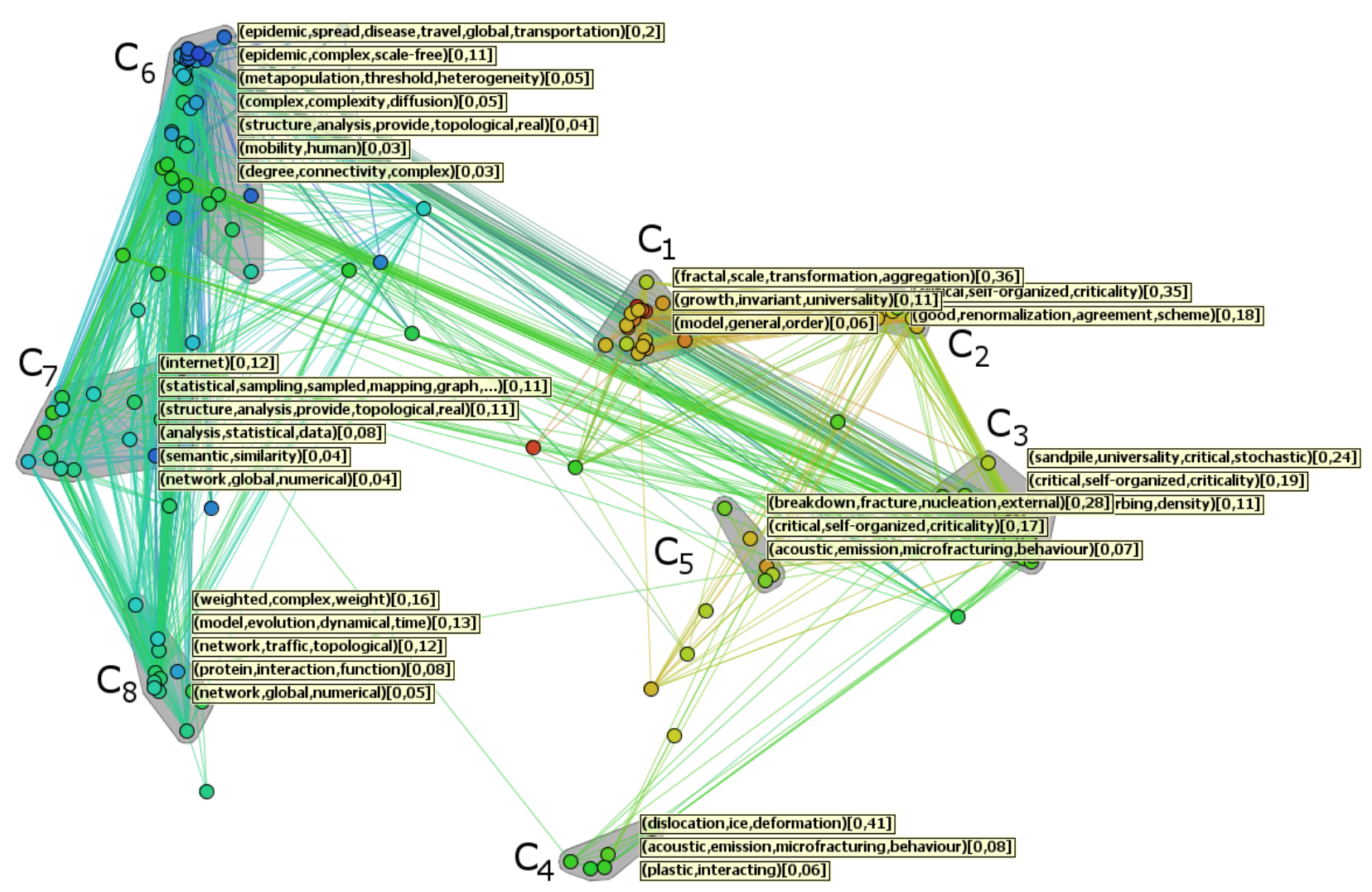

(c) Extração de tópicos baseada em LDA com parâmetros min_topics $=0,5$ e min_terms $=0,3$.

Figura 4.5: Tópicos extraídos para o ano de 2012 da projeção dinâmica criada usando-se a T-LSP para o conjunto de artigos publicados por Alessandro Vespignani (mesma projeção da Figura 4.4f) (cont.).

por incluírem mais termos relevantes. Os tópicos também diferem entre si em relação aos seus pesos e a ordem de seus termos.

A técnica baseada em covariância também tende a ser suscetível a uma alta ocorrência de um conjunto de termos que acontece em um único documento do grupo. Por exemplo, os termos similarity e semantic, que compõem o tópico (simililarity, semantic, web) listado como o tópico com maior peso para o grupo $C_{7}$ segundo a técnica baseada em covariância, ocorrem somente em um documento dentre os 16 desse grupo. O termo semantic ocorre 7 vezes nesse documento, enquanto o termo similarity ocorre 5 vezes. Dessa forma, esse tópico não é o mais representativo para o grupo $C_{7}$, apesar de ser listado como tal. Esses termos também aparecem nos tópicos extraídos por PCA, mas no tópico com menor peso dentre os extraídos. Já o tópico (graph, statistical) referente à caracterização de propriedades estatísticas de redes complexas aparece em 10 documentos, e é listado como somente o segundo tópico mais importante segundo a técnica em covariância. Já a técnica baseada em PCA caracteriza o tópico correspondente (internet, network, sampled, statistical, sampling, ...) como o mais importante do grupo, respondendo por 22,77 da variância. Esse tópico também foi capaz de detectar que os documentos desse subconjunto discutem principalmente a caracterização de propriedades estatísticas de redes complexas representando domínios da Internet. Essa 
menor suscetibilidade a esse tipo cenário pela técnica baseada em PCA pode ser explicada pelo fato desta técnica avaliar a covariância entre os termos globalmente, e não par a par como na técnica baseada em covariância.

Já a técnica baseada em LDA tende a gerar mais tópicos em alguns casos (e.g., grupos $C_{6}, C_{7}$ e $C_{8}$ ) nos quais o modelo LDA encontra-se mais diluído para alguns grupos de documentos - com contribuições menores de vários tópicos. Esse tipo de cenário pode tornar um pouco mais difícil para o usuário inferir quais os temas associados aquele grupo de documentos. Também se observa maior probabilidade de um único tópico estar associado a múltiplos grupos de documentos. Por exemplo, o tópico (critical, self-organized, criticality) encontra-se associado aos grupos $C_{2}, C_{3}$ e $C_{5}$ com diferentes pesos. Um tópico pode estar associado a múltiplos documentos e a técnica de extração de tópicos baseada em LDA consegue capturar melhor esse tipo de situação. Já se uma projeção for gerada com o modelo LDA, o mesmo modelo também é utilizado para a extração dos tópicos, caso se opte pela técnica baseada em LDA. Dessa forma, obtém-se uma maior conexão entre a representação da coleção e os tópicos extraídos.

Dessa forma, acredita-se que a técnica PCA funcione melhor em coleções pequenas como a apresentada nessa seção. Em contrapartida, quando se tem uma coleção relativamente grande (> 1.000 documentos) recomenda-se a técnica baseada LDA, pois o modelo LDA funciona melhor em cenários mais complexos (vasto vocabulário) do que o modelo vetorial utilizado pela técnica baseada em PCA.

Quanto à diferença nos tempos de execução, a técnica baseada em covariância gastou 51 milissegundos para gerar os tópicos exibidos na Figura 4.5a. Já para a técnica baseada em PCA foram necessários 242 milissegundos para gerar os tópicos exibidos na Figura 4.5b. Por fim, foram necessários 7 milissegundos para gerar os tópicos exibidos na Figura 4.5c segundo a técnica de extração de tópicos por LDA. Também foram necessários 46 segundos adicionais para inferir o modelo LDA para essa coleção de documentos antes de extrair os tópicos, utilizando 1.500 iterações e parâmetros $T=100, \alpha=0,1$ e $\beta=0,01$. No entanto, a inferência do modelo LDA para uma coleção só precisa ser realizada uma única vez, mesmo que desejemos também extrair os tópicos para um outro conjunto de grupos em outro instante de tempo da projeção dinâmica. Esses tempos de execução foram calculados em um computador com processador Intel Core it7 de 3.4 G.Hz e com 16 GB de memória RAM.

No geral, os tópicos extraídos foram similares. A questão é que não existe uma ground truth para avaliar um tópico. Todos os tópicos extraídos existem naqueles documentos, o que pode divergir é que o tópico extraído pode não ser necessariamente o mais frequente ou o mais relevante.

Quanto à representação visual de tópicos por meio de uma lista, um problema pode ocorrer quando dois ou mais tópicos eventualmente se sobrepõem na representação visual. No entanto, a colocação automática de labels é um problema difícil e complexo, que neste 
trabalho foi contornado por meio de uma iteração, que destaca o tópico do grupo sobre o qual o usuário posicionou o mouse e oculta os demais.

\subsubsection{Topic Clouds}

Com o intuito de tornar a visualização dos termos de um tópico mais atrativa e intuitiva, também foram utilizadas tag clouds para gerar representações visuais alternativas para exibir os tópicos extraídos. A técnica tag cloud é uma metáfora visual ubíqua que explora a ideia de que o conteúdo de um documento pode ser visualizado por meio da frequência de seus termos.

Nesta tese, o nome topic clouds foi adotado para se referir às tag clouds de tópicos extraídos. A ordem dos termos é a mesma apresentada nos tópicos. No entanto, observa-se que em várias ocasiões, mais de um tópico é extraído para um mesmo subconjunto de documentos. A solução adotada foi simplesmente concatenar os termos de cada tópico em sequência, separando um tópico do outro pelo caractere 'l'. Já o tamanho da fonte é baseado em uma combinação do peso do tópico com o peso do termo. Uma vez gerada, a topic cloud é posicionada no canto superior direto do bounding box que delimita o grupo de documentos para o qual a topic cloud foi gerada.

A Figura 4.6 apresenta topic clouds geradas para tópicos extraídos por meio da técnica baseada em PCA para grupos detectados pelo algoritmo DBSCAN, utilizando os valores default dos parâmetros (min_topics $=0,35$ e min_terms $=0,7$ ).

Como a topic cloud pode ficar muito longa e promover uma oclusão visual no mapa de documentos, é dada ao usuário a opção de reduzir seu tamanho para um número escolhido de termos $k$. Dado um conjunto de tópicos extraídos para um grupo de documentos, todos os termos de todos os tópicos são ordenados de forma decrescente com base em seu peso, e somente os $k$ termos com maior peso serão adicionados à topic cloud. Dessa forma, serão mostrados na topic cloud os termos com maiores pesos de cada tópico. Assim, mesmo os termos dos tópicos com menores pesos podem eventualmente aparecer na topic cloud, o que evita que os termos do tópico com maior peso dominem o seu conteúdo. Na Figura 4.6, foi definido que cada topic cloud poderia conter no máximo 10 termos.

Um problema pode ocorrer quando duas ou mais topic clouds eventualmente se sobrepõe. Como mencionado anteriormente, esse problema é contornado por meio de uma interação, que destaca a topic cloud do grupo sobre o qual o usuário posicionou o mouse e oculta as demais. 


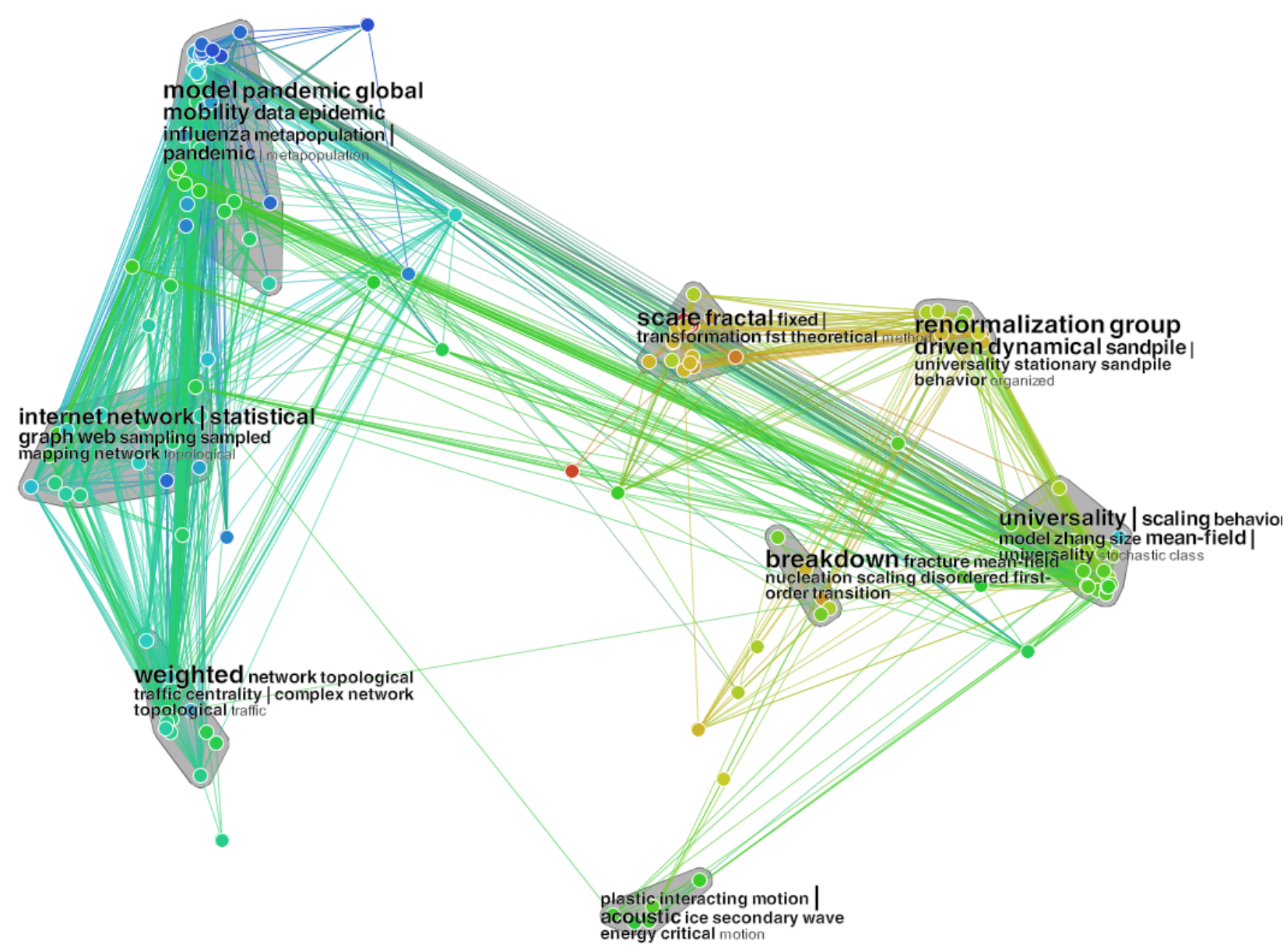

Figura 4.6: Topic cloud de tópicos extraídos por PCA com parâmetros min_topics $=0,35$ e min_terms $=0,7$.

\subsection{Detecção da Evolução Temporal de Tópicos base- ada na T-LSP}

Nos mapas de documentos, grupos de documentos representam os tópicos abordados na coleção. Uma vez detectados esses grupos, seja pelo usuário ou por uma técnica de agrupamento, tópicos associados podem ser identificados automaticamente por técnicas como as descritas na Seção 4.2. Além disso, técnicas de projeção multidimensional dinâmicas, como a T-LSP, buscam evidenciar as mudanças nas relações de similaridade dos documentos ao longo do tempo. Tais mudanças temporais são um bom indicativo da evolução temporal de tópicos, já que tópicos estão em principio associados a grupos de documentos similares. Utilizando essas informações é possível detectar eventos de transição, como,e.g., o surgimento de novos tópicos ou a subdivisão de um tópico em momentos específicos, e detectar as mudanças no vocabulário de um tópico em específico.

Na técnica T-LSP, os círculos que representam os documentos mudam de posição ao longo do tempo, enquanto outros são adicionados. Em cada momento da projeção dinâmica é possível observar o aparecimento de diferentes grupos visuais. Esse cenário favorece a 
utilização de técnicas de agrupamento que consideram o componente temporal do espaço bidimensional da projeção dinâmica para "rastrear" tópicos. Nesta Seção, será apresentada a abordagem usada neste trabalho para a detecção da evolução temporal de tópicos com base na T-LSP. Essa detecção é feita em três estágios:

- Algoritmo de agrupamento - Um algoritmo de agrupamento é usado para identificar os grupos para cada instante de tempo na sequência de projeções gerada pela T-LSP. Dessa forma, obtém-se um conjunto de agrupamentos independentes para cada instante de tempo. O algoritmo de agrupamento Density Based Spatial Clustering of Applications with Noise (DBSCAN) foi escolhido para esta tarefa por seu bom resultado quando aplicado a projeções e será apresentado na Seção 4.3.1.

- Rastreamento das transições temporais entre grupos - A técnica MONIC (a ser apresentada na Seção 4.3.2) é capaz de rastrear transições temporais entre grupos entre conjuntos de grupos em instantes de tempo consecutivos. Os seguintes tipos transições podem ser detectados: o surgimento de um novo grupo, a junção de dois ou mais grupos em um único, a subdivisão de um grupo em dois ou mais grupos, a sobrevivência de um grupo e o desaparecimento de um grupo. O mecanismo de rastreamento de transições é baseado somente no grau de sobreposição no conteúdo dos grupos entre dois instantes consecutivos, portanto é independente do algoritmo usado no primeiro estágio para detectar tais agrupamentos.

- Extração de tópicos para agrupamentos encontrados - Com o resultado do segundo estágio sabemos, por exemplo, que um grupo detectado em um momento pode ter sobrevivido no momento seguinte. A sobrevivência de um grupo significa que a maior parte dos documentos permaneceu em momentos consecutivos, mas alguns documentos podem ter sido adicionados e outros removidos. Como o conteúdo do grupo mudou mesmo que em pequena proporção, tópicos extraídos por técnicas como as apresentadas na Seção 4.2 também mudam em algum grau - o que evidencia a mudança no vocabulário de um tópico ao longo do tempo.

\subsubsection{Algoritmo de Agrupamento: DBSCAN}

Em algumas técnicas de agrupamento, como o K-means e o Expectation Maximization (EM) (Dempster et al., 1977), é necessário que o usuário defina o número de agrupamentos que deseja encontrar. Enquanto isso, na técnica de agrupamento Density Based Spatial Clustering of Applications with Noise (DBSCAN) (Sander et al., 1998), o número de agrupamentos é automaticamente definido pelo algoritmo com base na densidade dos dados, o que o torna especialmente adequado para aplicações exploratórias como mapas de documentos gerados por projeções. O DBSCAN também é capaz de identificar grupos de formatos arbitrários, ao contrário, por exemplo, do k-means que identifica grupos com formatos esféricos. Essa técnica também trabalha com a noção de ruído (objetos que não fazem parte de nenhum 
grupo) e por isso não é afetada por outliers.

O DBSCAN busca localizar regiões de alta densidade separadas de outras por regiões de baixa densidade. Como mencionado, este algoritmo é capaz de identificar grupos de formatos arbitrários em bases de dados que podem ser inseridas em espaços métricos e com ruídos. O DBSCAN produz um agrupamento particional, no qual o número de grupos é determinado automaticamente. Objetos em região de baixa densidade no espaço métrico são classificados como ruído e omitidos de qualquer partição, portanto, o resultado não atribui necessariamente todo objeto a um agrupamento.

Para apresentar os conceitos nesta seção, será utilizado um conjunto de pontos no espaço bidimensional e a distância Euclidiana. No entanto, o DBSCAN pode ser aplicado também a espaços $m$-dimensionais que possam ser inseridos no espaço métrico por meio de alguma medida de dissimilaridade.

Para definir a densidade da vizinhança de um ponto arbitrário qualquer, contam-se todos os pontos com distância inferior ou igual a um valor de limiar $\varepsilon$ em relação ao ponto em questão, o qual também é incluído nessa contagem. Este conceito é ilustrado na Figura 4.7a. A densidade de qualquer ponto depende do parâmetro $\varepsilon$. Se o valor de $\varepsilon$ for muito grande, então todos os pontos terão densidade igual a $n$ (número de pontos no conjunto de dados a ser agrupado). Da mesma forma, se o valor de $\varepsilon$ for muito pequeno, então a densidade de todos os pontos será igual a 1 . O parâmetro $\varepsilon$ define a granularidade dos grupos encontrados pelo algoritmo DBSCAN.

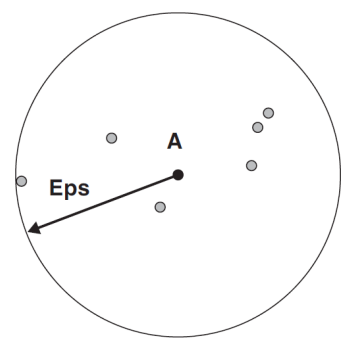

(a) Vizinhança em torno de um ponto $A$

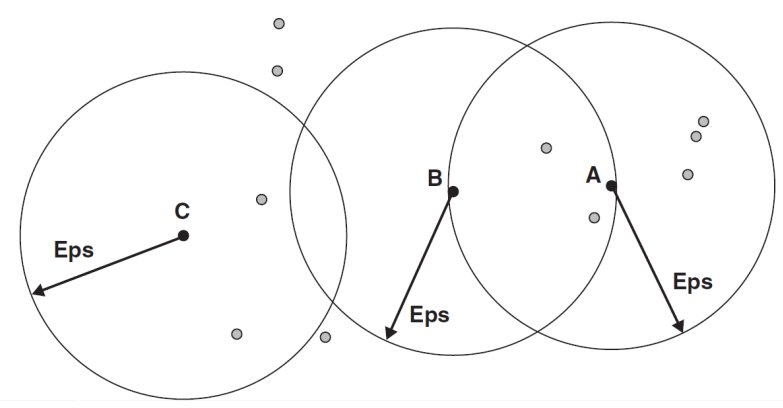

(b) Em relação ao ponto $A$ (ponto central): Ponto $B-$ ponto de borda; e Ponto $C$ - ruído

Figura 4.7: Noção de vizinhança e tipos de ponto no contexto do algoritmo DBSCAN.

Para achar os agrupamentos, também é necessário classificar cada ponto como um dos seguintes tipos:

- Ponto central - No interior de uma região densa. Um ponto é central se o número de pontos em sua vizinhança, de acordo com o parâmetro $\varepsilon$, exceder um dado limiar MinPts, que também é um parâmetro especificado pelo usuário. Na Figura 4.7b, o ponto $A$ é central se considerarmos o raio indicado $(\varepsilon)$ e MinPts $<=7$.

- Ponto de borda - Um ponto de borda não é central, mas está na vizinhança de um ponto central. Na Figura 4.7b, o ponto $B$ é de borda. Um ponto de borda pode estar 
na vizinhança de mais de um ponto central.

- Ruído - Qualquer ponto que não é nem central e nem de borda é considerado como ruído. Na Figura 4.7b, o ponto $C$ é considerado ruído.

Dadas essas definições, o algoritmo DBSCAN pode ser informalmente descrito como segue. Quaisquer dois pontos centrais que estejam próximos - a uma distância relativa inferior ou igual a $\varepsilon$ - são colocados no mesmo grupo. Qualquer ponto de borda que esteja perto de um ponto central qualquer é colocado no mesmo grupo do ponto central. Pontos considerados como ruído não são incluídos em nenhum grupo.

A complexidade do DBSCAN é $O(n \times$ complexidade para achar a vizinhança- $\varepsilon)$, onde $n$ é o número de pontos. Assim, no pior caso a complexidade será $O\left(n^{2}\right)$ em uma busca linear. No entanto, para conjuntos de dados de baixa dimensionalidade, existem estruturas de particionamento espacial, como kd-trees (Bentley, 1975), que permitem uma busca eficiente por todos os pontos a uma dada distância de um ponto, reduzindo a complexidade para $O(n \log n)$. Neste trabalho, não foi utilizada estruturas como a $k d$-trees. Existe um custo para construir a $k d$-tree e como, neste trabalho, a organização espacial das instância muda ao longo do tempo na projeção, seria necessário uma $k d$-tree para cada instante no tempo.

Definição dos parâmetros. Existe a questão de como definir os valores para os parâmetros $\varepsilon$ e MinPts. Como mencionado, o parâmetro $\varepsilon$ define a granularidade dos grupos encontrados pelo algoritmo DBSCAN, e, portanto, deve ser definido de acordo com a aplicação. Já o parâmetro MinPts interfere na definição de um ponto central e também define o tamanho mínimo de um grupo. No artigo original, Sander et al. (1998) defende que o valor MinPts = 4 é uma boa escolha para a maioria dos dados bidimensionais.

A Figura 4.8 mostra os resultados obtidos pelo DBSCAN quando aplicado à projeção do ano 2012 da sequência de projeções apresentada na Figura 4.2b, com três conjuntos diferentes de valores para os parâmetros. Os grupos identificados são destacados por meio de regiões em cinza. Observe que alguns documentos nas Figuras 4.8c e 4.8a, identificados como ruído, não se encontram em nenhum grupo. Na Figura 4.8a, os parâmetros $\varepsilon=0.15$ e MinPts $=4$ foram utilizados. $O$ valor $\varepsilon=0.15$ pode ser considerado alto para essa aplicação, pois o algoritmo identificou somente dois grandes grupos formados pelas áreas de pesquisa em física, a direita, e em redes complexas, a esquerda. Já na Figura 4.8b, os parâmetros $\varepsilon=0.07$ e MinPts $=3$ resultaram em grupos mais refinados que correspondem a subáreas de pesquisa. Por fim, os parâmetros $\varepsilon=0.06$ e MinPts $=4$ foram utilizados na Figura 4.8c. Esse valor menor para o parâmetro $\varepsilon$ subdividiu em dois o maior grupo da Figura 4.8c.

Representação Visual dos Grupos. Uma vez encontrados grupos de documentos similares, é necessário delimitar eficientemente esses grupos por uma área cujo formato reflita o formato do grupo. Para delimitar essa área para um grupo qualquer, emprega-se primeiro o fecho convexo - o menor polígono convexo que contém todos os pontos do grupo (ver Figura 4.9b). No entanto, uma das características e vantagens do algoritmo DBSCAN é produzir grupos de formatos arbitrários. Se um dos grupos possuir uma distribuição não-convexa, o fecho 


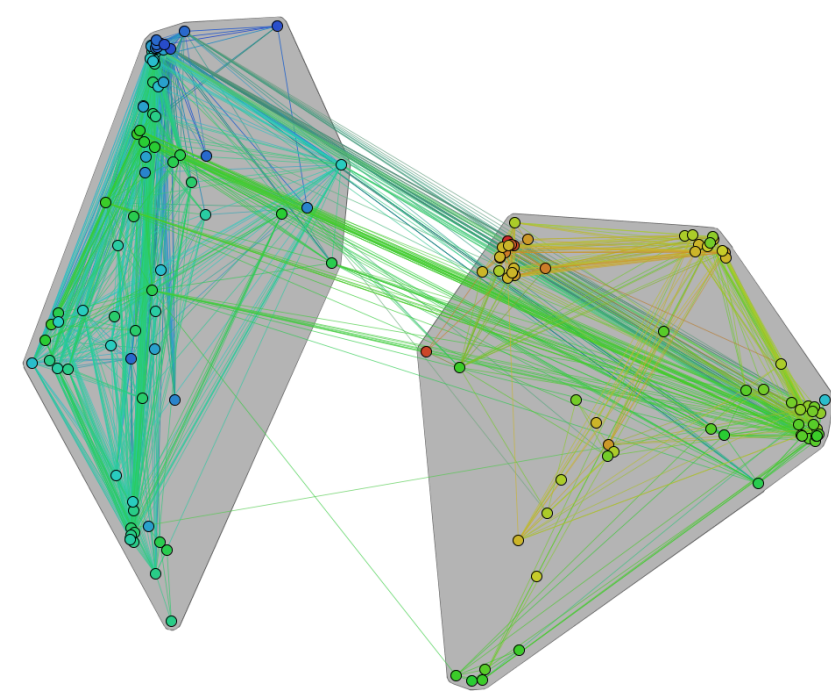

(a) $\varepsilon=0.15$ e MinPts $=4$.

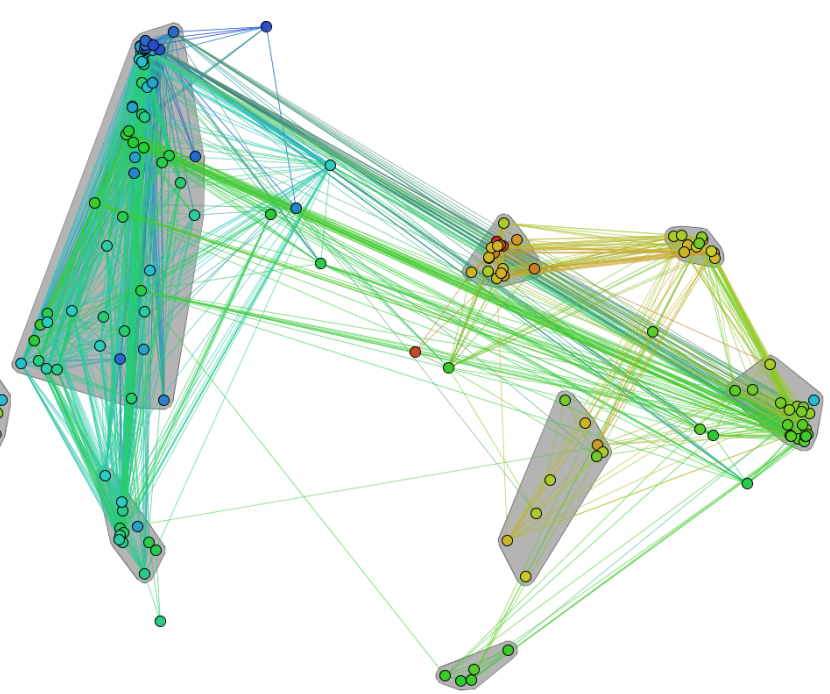

(b) $\varepsilon=0.07$ e MinPts $=3$.

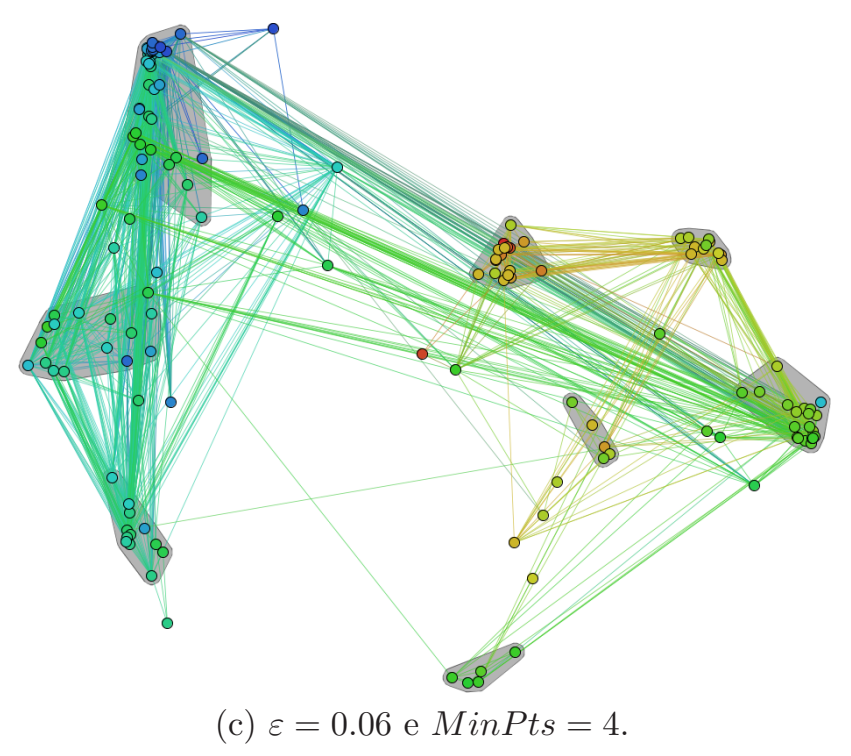

Figura 4.8: Agrupamentos gerados pelo DBSCAN quando aplicado a projeção do ano 2012 da sequência de projeções apresentada na Figura $4.2 \mathrm{~b}$ com três conjuntos diferentes de valores para os parâmetros $\varepsilon$ e MinPts.

convexo pode incluir em seu interior pontos que não pertencem ao grupo. Se isto ocorrer, utiliza-se o algoritmo para cálculo de contornos implícitos Bubble Sets (Collins et al., 2009), que reflete melhor o formato do grupo, criando um contorno que inclui todos os seus pontos, mas não inclui em seu interior pontos não-membros (ver Figura 4.9c). Essa preferência pelo fecho convexo justifica-se por seu resultado ser mais estável visualmente quando necessário fazer uma animação, e pelo seu cálculo possuir uma complexidade computacional menor. A abordagem baseada no fecho-convexo foi utilizada nos mapas de documentos mostrados até o momento, ver Figuras 4.6 e 4.8.

No cálculo de contornos implícitos segundo o algoritmo Bubble Sets ${ }^{2}$, primeiramente é

${ }^{2}$ http://faculty.uoit.ca/collins/research/bubblesets 
gerado um conjunto de arestas virtuais que conectam todos os pontos do conjunto sem passar sobre nenhum ponto não-membro e com o mínimo de arestas possível. Essas arestas são adicionadas procurando conectar primeiro pontos próximos entre si. Em um segundo passo, é calculado um campo de energia sobre os pontos e suas arestas virtuais. O contorno é então extraído, executando uma versão bidimensional do algoritmo Marching Cubes (Lorensen; Cline, 1987). Esse algoritmo possui complexidade $O(k \times n(n+H \times W))$ para $k$ grupos, $n$ artigos no instante sendo analisado da projeção, e um plano com $H$ pixels por $W$ onde a projeção está sendo desenhada.

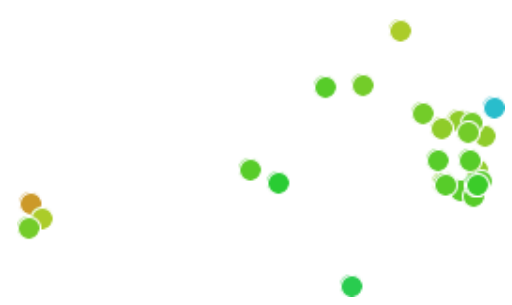

(a) Conjunto de pontos.

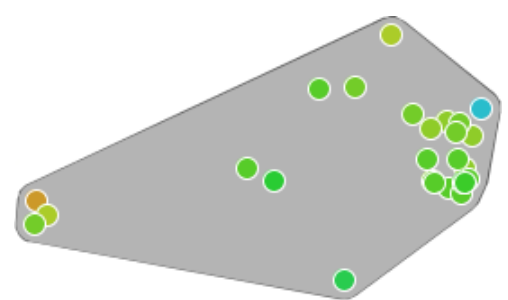

(b) Fecho convexo.

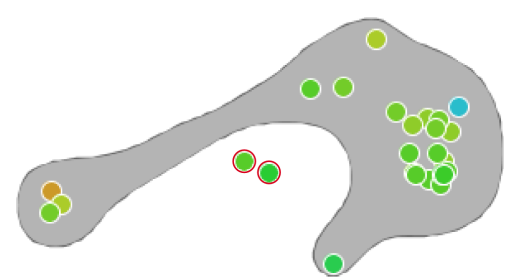

(c) Contorno implícito (Bubble Set) para conjunto de pontos com exceção dos circundados em vermelho.

Figura 4.9: Diferença entre fecho convexo e Bubble Set.

Já para o cálculo do fecho convexo utilizou-se a biblioteca JTS Topology $y^{3}$, que implementa o algoritmo Graham Scan (Graham, 1972) com complexidade $O(n \log n)$, onde $n$ é o número de pontos. No entanto, algoritmos para geração do fecho convexo produzem polígonos com bordas muito próximas aos pontos, e às vezes com vértices pontiagudos. Buscando suavizar a borda e distanciar um pouco a borda dos pontos delimitados pelos polígonos, utilizamos a operação de buffer implementada também pela biblioteca JTS Topology. O buffer de um polígono, de acordo com a distância $d$, é o polígono que contém todos os pontos a uma certa distância $d$ do polígono antigo, i.e., como se um círculo com raio $d$ passasse sobre a borda do polígono, com o centro do círculo sempre localizado na borda, suavizando seu formato. Essa operação de buffer corresponde a dilatação morfológica, utilizada em processamento de imagens.

\subsubsection{Rastreamento das Transições Temporais entre Grupos: MONIC}

O algoritmo de detecção de agrupamentos temporais MONIC (Spiliopoulou et al., 2006) toma como entrada agrupamentos em instantes de tempo consecutivos e identifica transições temporais que descrevem a evolução dos grupos, como a sobrevivência de um grupo, a junção de dois ou mais grupos em um único, a subdivisão de um grupo em dois ou mais grupos, o surgimento de um novo grupo e o desaparecimento de um grupo existente.

\footnotetext{
${ }^{3}$ http://tsusiatsoftware.net/jts
} 
Seja $t_{1}, \ldots, t_{T}$ uma sequência de instantes no tempo relativos a um conjunto de dados $D$, onde $D_{i}(i=1, \ldots, T)$ é um subconjunto de instâncias de dados de $D$ acumuladas de $t_{1}$ até $t_{i}$, com $D_{T}$ sendo igual ao conjunto total de dados, de forma que $D_{i} \cap D_{j} \neq \emptyset$ para $i \neq j$. Considerando esses subconjuntos, um agrupamento no instante de tempo $t_{i}, \zeta_{i}$, pode ser definido como:

Definição 4.1 Agrupamento $\zeta_{i}$ - Um agrupamento $\zeta_{i}$ é uma partição do conjunto de dados $D_{i}$ em grupos $X_{1}, \ldots, X_{k}$ de tal forma que: (a) $\forall u \neq w: X_{u} \cap X_{w}=\emptyset$; e (b) algum critério de otimização é satisfeito, e.g., os membros de cada grupo são mais similares entre si do que a outras instâncias.

Supondo que um grupo $X \in \zeta_{i}$, identificado no instante de tempo $t_{i}$, irá sofrer alguma transição no instante de tempo posterior $t_{i+1}$. Ele pode: sobreviver, ser absorvido, dividido ou desaparecer. Para identificar o tipo da transição, utilizam-se os conceitos de sobreposição e equivalência de grupos:

Definição 4.2 Sobreposição de grupos - Sejam $\zeta_{i}$ e $\zeta_{i+1}$ os agrupamentos obtidos nos instantes de tempo $t_{i}$ e $t_{i+1}$, e $X \in \zeta_{i}$ e $Y \in \zeta_{i+1}$ dois grupos. A sobreposição entre os grupos $X$ e $Y$ é definida pela sua intersecção:

$$
S(X, Y)=\frac{|X \cap Y|}{|X|}
$$

Definição 4.3 Equivalência de grupos - Seja $X$ um grupo no agrupamento $\zeta_{i}$ e $Y$ um grupo em $\zeta_{i+1}$, e $\tau \in[0.5,1]$ um limiar de equivalência. $Y$ é equivalente a $X$ em $\zeta_{i+1}$ com respeito a $\tau\left(Y=\right.$ equivalente $\left._{\tau}\left(X, \zeta_{i+1}\right)\right)$ se e somente se $Y \in \zeta_{i+1}$ é o grupo com o máximo de sobreposição com $X$ e o valor da sobreposição é maior ou igual a $\tau$ :

$$
Y=\text { equivalente }_{\tau}\left(X, \zeta_{i+1}\right) \text {, se } S(X, Y) \geq \tau
$$

Se não existe nenhum $Y \in \zeta_{i+1}$ que obedeça a essas propriedades, então $S(X, U)=\emptyset$.

Segundo a Definição 4.3, um agrupamento $\zeta_{i+1}$ pode conter no máximo uma equivalência para cada grupo em $\zeta_{i}$, mas o mesmo grupo em $\zeta_{i+1}$ pode ser equivalente a mais de um grupo em $\zeta_{i}$ (transição de absorção). Já que o limiar de equivalência $\tau$ é restrito ao intervalo [0.5, 1], um grupo somente é equivalente a outro se contém pelo menos metade das instâncias em comum. Empates podem ocorrer quando $\tau=0.5$, apesar de raros. Neste caso, adota-se como grupo equivalente o $Y$ que é mais semelhante em tamanho com $X$.

Dado o conceito de equivalência de grupos, diferentes cenários (transições) podem ocorrer comparando todos os grupos de um momento, $\zeta_{i}$, com os grupos do momento subsequente, $\zeta_{i+1}$ : 
1. Sobrevivência de um grupo $(X \rightarrow Y)$ - Um grupo $X \in \zeta_{i}$ sobreviveu em $\zeta_{i+1}$ se obedece às seguintes condições:

1.1. Existe um grupo $Y$ em $\zeta_{i+1}$ equivalente a $X$ de acordo com o parâmetro $\tau$ :

$$
Y=\text { equivalente }_{\tau}\left(X, \zeta_{i+1}\right)
$$

1.2. Não existe mais nenhum grupo em $\zeta_{i+1}$ que é equivalente a $Y$ de acordo com o parâmetro $\tau$ :

$$
\nexists Z \in \zeta_{i} \backslash\{X\}: Y=\text { equivalente }_{\tau}\left(Z, \zeta_{i+1}\right)
$$

2. Junção de dois ou mais grupos em um único $\left(\left\{X_{1}, X_{2}, \ldots\right\} \rightarrow Y\right)$ - Se $X_{1}$ em $\zeta_{i}$ é equivalente a $Y$ em $\zeta_{i+1}$ e existe pelo menos mais um grupo $X_{2}$ em $\zeta_{i}$ que também é equivalente a $Y$ em $\zeta_{i+1}$, então $X_{1}$ e $X_{2}$ foram absorvidos por $Y$ :

$$
Y=\text { equivalente }_{\tau}\left(X_{1}, \zeta_{i+1}\right) \text { AND } \exists X_{2} \in \zeta_{i} \backslash\{X\}: Y=\text { equivalente }_{\tau}\left(X_{2}, \zeta_{i+1}\right)
$$

3. Subdivisão de um grupo em dois ou mais grupos $\left(X \subseteq\left\{Y_{1}, \ldots, Y_{p}\right\}\right)$ - Se não existe nenhum grupo equivalente a um grupo $X$ em $\zeta_{i}$, então uma subdivisão pode ter ocorrido. O conteúdo de $X$ está em mais de um grupo em $\zeta_{i+1}$. Para detectar este tipo de transição, utiliza-se o parâmetro $\tau_{\text {split }}\left(\operatorname{com} \tau_{\text {split }}<\tau\right.$ e valor padrão $\tau_{\text {split }}=0,3$ ), procurando grupos que tenham uma sobreposição com $X$ maior do que $\tau_{\text {split }}$ :

$$
\forall u=1, \ldots, p: S\left(X, Y_{u}\right) \geq \tau_{\text {split }}
$$

Além disso, a união de todos os grupos $\cup_{u=1}^{p} Y_{u}$ deve formar um grupo que tenha uma sobreposição com $X$ maior do que $\tau$ :

$$
S\left(X, \cup_{u=1}^{p} Y_{u}\right) \geq \tau
$$

4. Surgimento de um novo grupo $(\odot \rightarrow Y)$ - Novos grupos são detectados depois de rastrear todas as transições para cada grupo em $\zeta_{i}$. Grupos novos são aqueles que, no instante de tempo $t_{i+1}, \zeta_{i+1}$, não resultam de nenhuma transição entre $\zeta_{i}$ e $\zeta_{i+1}$.

5. Desaparecimento de um grupo $(X \rightarrow \odot)$ - Um grupo desaparece quando ocorre um destes dois cenários: não é identificado um grupo equivalente que possa ser seu sobrevivente no próximo instante de tempo e não foram identificados grupos no qual seu conteúdo possa estar dividido (com uma sobreposição acima do limiar $\tau_{\text {split }}$ ); ou foram identificados grupos no qual seu conteúdo está dividido no próximo instante de tempo, mas a união desses grupos não forma um grupo que tenha sobreposição maior que $\tau \operatorname{com} X$.

A cada novo grupo é atribuído um identificador não utilizado previamente, que permanece o mesmo se este grupo sobreviver ao longo das sucessivas transições. Grupos resultantes de 
transições de junção ou subdivisão também recebem novos identificadores não previamente utilizados. O identificador associado a um grupo que desapareceu também nunca deve ser reutilizado.

O algoritmo completo, ver Apêndice A, consiste em analisar e detectar essas transições para os pares de agrupamentos de instantes de tempo consecutivos, observando-se os parâmetros $\tau$ e $\tau_{\text {split }}$. A complexidade deste algoritmo para cada dois agrupamentos consecutivos é $O\left(K^{2}\right)$ para $K=\max \left\{\left|\zeta_{i}\right|,\left|\zeta_{i+1}\right|\right\}$.

\subsubsection{Representação Visual das Transições Temporais}

Como mencionado, para calcular um polígono que delimita a área de um grupo qualquer, se emprega primeiro o fecho convexo nos pontos pertencentes àquele grupo. No entanto, o grupo pode possuir uma distribuição não convexa e o fecho convexo pode incluir pontos que não pertencem ao grupo. Neste caso, utiliza-se um algoritmo para cálculo de contornos implícitos, que reflete melhor o formato do grupo. Uma vez que os grupos são delimitados como polígonos a cada momento na sequência de projeções, é necessário animar esses polígonos nos quadros intermediários da animação, de forma a representar as transições de surgimento, subdivisão, junção, sobrevivência e desaparecimento de grupos detectados.

Por exemplo, supondo a sobrevivência de um grupo $X$ que está presente no instante $t$ e seu equivalente $Y$ presente em $t+1$, é possível observar as seguintes modificações: alguns documentos foram removidos; alguns documentos foram adicionados; e a maior parte dos documentos permaneceram, mas podem ter tido sua posição alterada dentro do grupo. Dados um polígono $\mathrm{Pol}_{t}$, que representa o grupo $X$ em $t$, e outro polígono $P_{o l+1}$, que representa o grupo $Y$ em $t+1$, a questão resume-se em como calcular uma animação que transforma o polígono Pol $_{t}$ em Pol Part $_{t}$ para os quadros intermediários. Quando um novo documento está se movendo em direção ao polígono ao qual deve ser adicionado, e inicialmente sua posição de partida é fora deste polígono, o polígono deve lentamente se expandir na direção desse documento de forma a incluí-lo. Já quando um documento deve ser removido do polígono que representa seu grupo, o polígono deve lentamente se contrair na direção dos documentos que irão permanecer. Tanto para a transição de sobrevivência como para as outras transições devemos frequentemente calcular esse tipo de animação que transforma um polígono em outro pela adição e remoção de documentos.

Neste trabalho, a animação de um polígono em outro é dada por uma sequência que contém um polígono para cada um dos $N$ quadros intermediários entre $t$ e $t+1$. Cada polígono na sequência apresenta uma pequena alteração em relação ao seu anterior, de forma a promover uma animação suave. O cálculo utilizado para a animação de um polígono é apresentado no Apêndice B.

Para as figuras e vídeo apresentados nesta seção, aplicou-se a técnica de projeção dinâmica T-LSP para a coleção de artigos do pesquisador Alessandro Vespignani entre 1990 e 2012. Os 


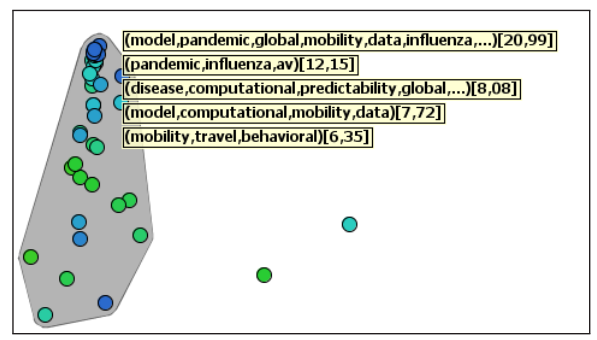

(a) Entrada em 2011: um grupo.

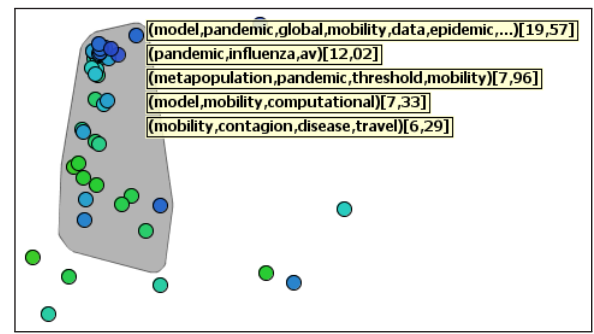

(c) Frame intermediário.

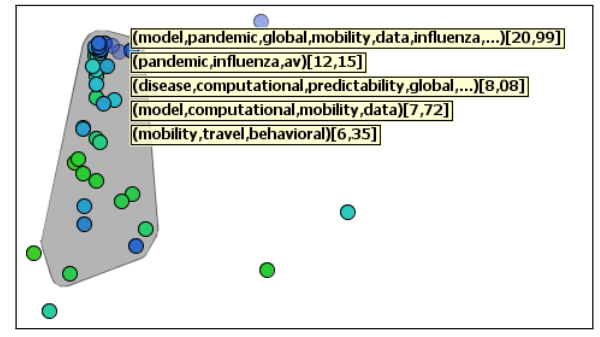

(b) Frame intermediário.

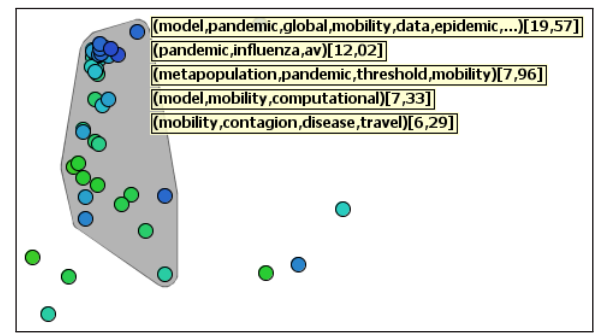

(d) Saída em 2012: um grupo.

Figura 4.10: Representação visual da sobrevivência de um grupo.

grupos foram detectados aplicando o algoritmo de agrupamento DBSCAN com parâmetros $\varepsilon=0.06$ e MinPts $=4$, enquanto as transições entre estes grupos foram detectadas aplicando o algoritmo MONIC com parâmetros $\tau=0,5$ e $\tau_{\text {split }}=0,2$. Já os tópicos foram extraídos com a técnica baseada em PCA com os parâmetros min_topics $=0,5$ e min_terms $=0,6$.

A Figura 4.10 apresenta um exemplo da representação visual utilizada para representar a sobrevivência de um grupo entre 2011 e 2012. Neste caso, é mostrado um único polígono que se expande em uma região do seu perímetro para incluir novos documentos (ver Figura 4.10c) e se contrai em outra região do seu perímetro para remover outros documentos (ver Figura 4.10b). Até a primeira metade dos quadros intermediários (ver Figuras 4.10a e 4.10b), são mostrados os tópicos relativos ao conteúdo deste grupo no instante $t$. Já na segunda metade (ver Figuras 4.10c e 4.10d), são mostrados os tópicos extraídos com base no conteúdo deste grupo no instante $t+1$. É possível observar que os tópicos se mantiveram razoavelmente estáveis durante a transição. A maior parte dos termos dos tópicos permaneceu com alguma mudança às vezes em sua ordem, enquanto alguns outros termos foram removidos ou adicionados.

Já a Figura 4.11 mostra um exemplo da representação visual utilizada para representar a junção de dois grupos em 2008 em um único em 2009. Inicialmente, são apresentados dois polígonos (ver Figura 4.11a), representando os dois grupos de entrada que irão se unir. Estes dois polígonos vão se tornando cada vez mais transparentes e passam a exibir também uma borda pontilhada (ver Figuras 4.11b e 4.11c), enquanto outro polígono que engloba esses dois é apresentado inicialmente totalmente transparente e se torna cada vez mais opaco (ver Figuras 4.11b e 4.11c). Este polígono maior representa o grupo formado pela junção dos dois grupos de entrada. Documentos a serem removidos influenciam tanto a animação do polígono maior como dos polígonos de entrada. Já os documentos a serem adicionados influenciam somente na animação do polígono maior. Até a primeira metade dos quadros intermediários 


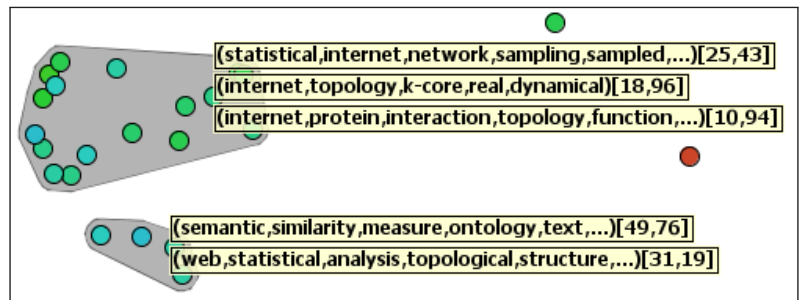

(a) Entrada em 2008: dois grupos.

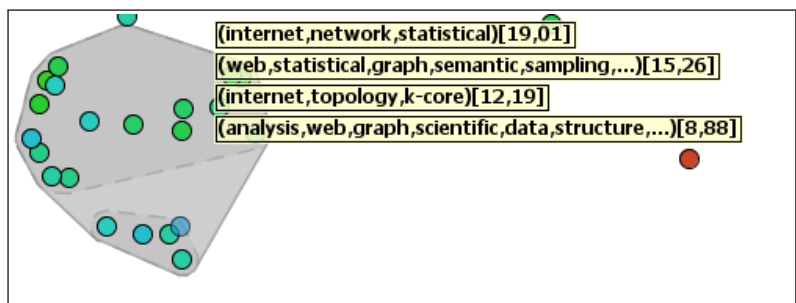

(c) Frame intermediário.

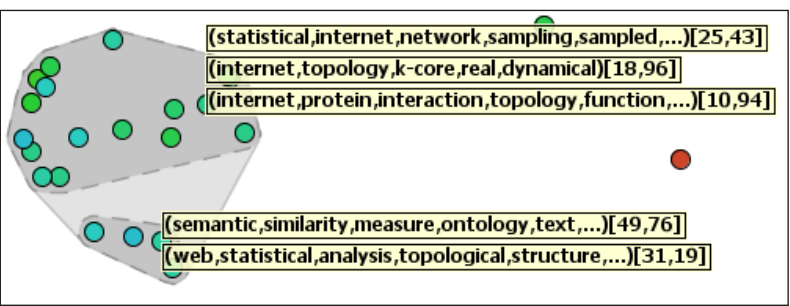

(b) Frame intermediário.

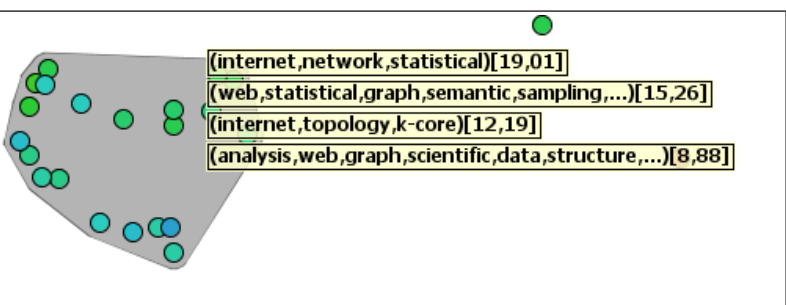

(d) Saída em 2009: um grupo.

Figura 4.11: Representação visual da junção de dois grupos.

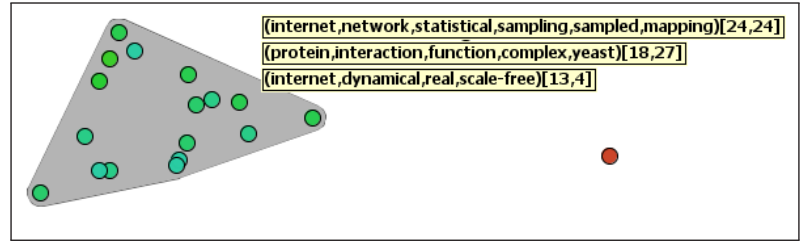

(a) Entrada em 2006: um grupo.

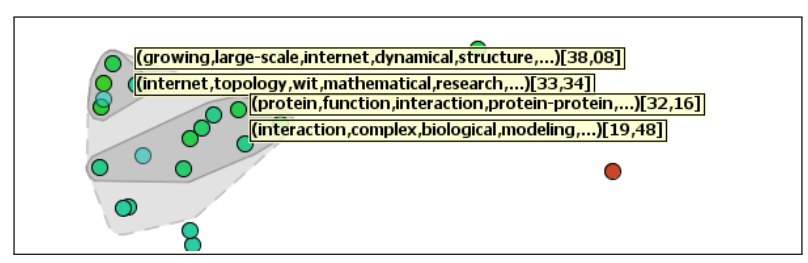

(c) Frame intermediário.

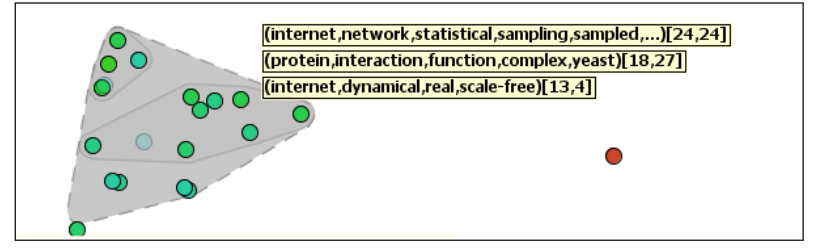

(b) Frame intermediário.

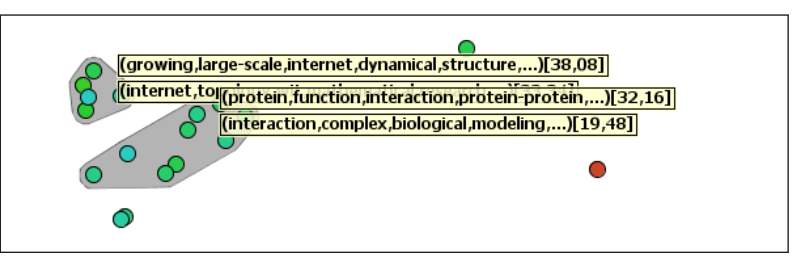

(d) Saída em 2007: dois grupos.

Figura 4.12: Representação visual da subdivisão de um grupo.

(ver Figura 4.11a e 4.11b), são mostrados os tópicos relativos aos dois grupos que irão se unir. Já na segunda metade (ver Figuras 4.11c e 4.11d), são mostrados os tópicos extraídos para o resultado dessa junção.

A Figura 4.12 exemplifica da representação visual utilizada para a subdivisão de um grupo em 2006 em dois em 2007. Esta representação visual é o inverso da representação para a junção de grupos. Inicialmente, tem-se apenas um polígono (ver Figura 4.12a) que representa o grupo que será subdividido, que se torna cada vez mais transparente (ver Figuras 4.12b e 4.12c). Ao mesmo tempo, dois polígonos que englobam o resultado dessa subdivisão tornam-se cada vez menos transparentes e mais visíveis (ver Figuras 4.12b e 4.12c). Documentos a serem removidos influenciam somente na animação do polígono maior. Já documentos a serem adicionados influenciam tanto a animação do polígono de saída como os de entrada. Até a primeira metade dos quadros intermediários (ver Figura 4.12a e 4.12b), são mostrados 


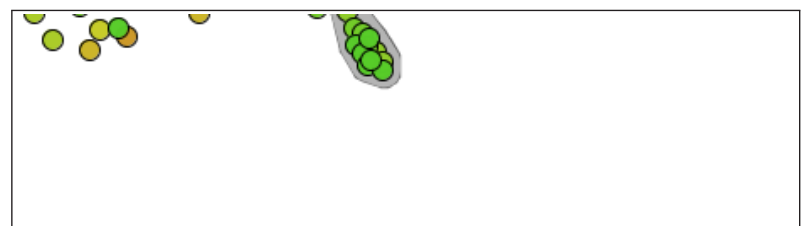

(a) Entrada em 2000: conjunto de documentos não relacionados.

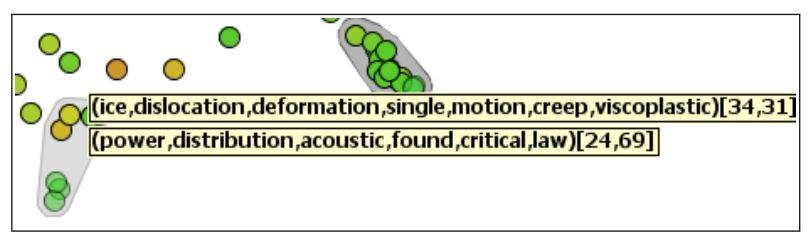

(c) Frame intermediário.

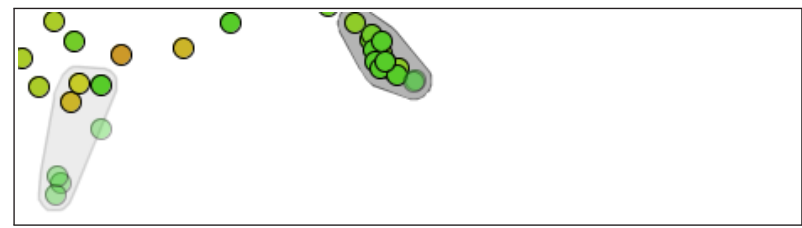

(b) Frame intermediário.

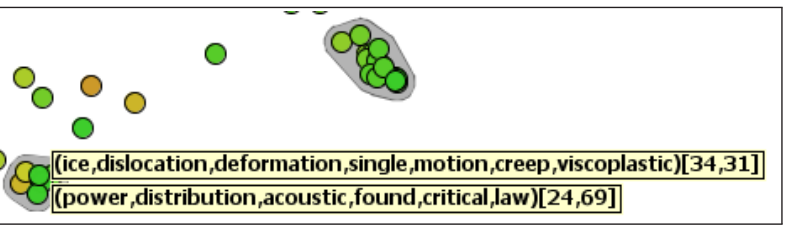

(d) Saída em 2001: um grupo.

Figura 4.13: Representação visual do surgimento de um grupo no canto inferior esquerdo.

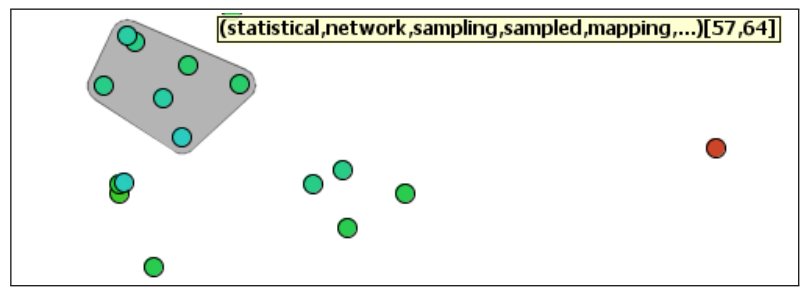

(a) Entrada em t: um grupo.

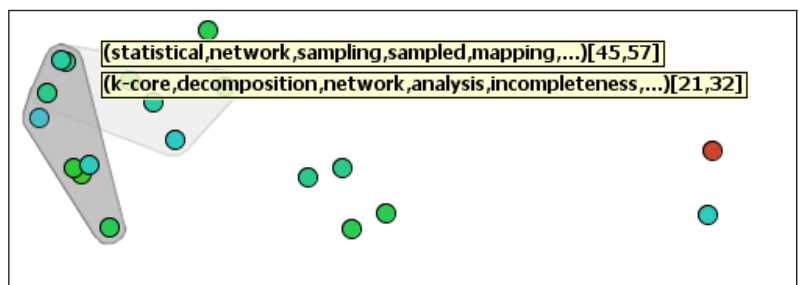

(c) Frame intermediário.

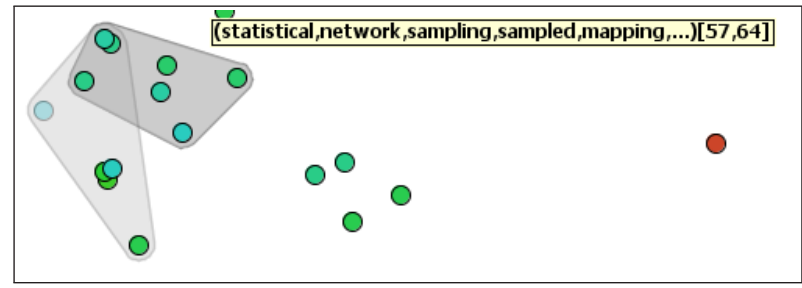

(b) Frame intermediário.

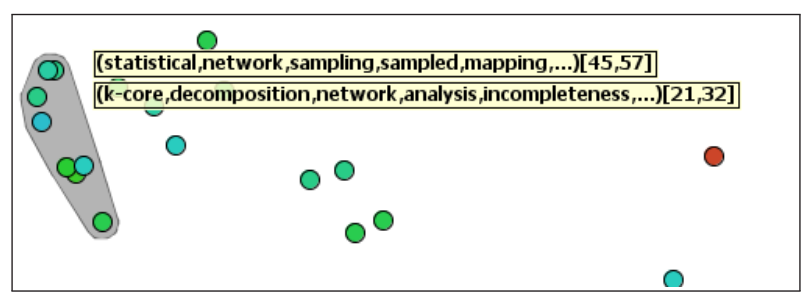

(d) Saída em $t+1$ : conjunto de documentos não relacionados.

Figura 4.14: Representação visual do desaparecimento de um grupo seguido pelo surgimento de outro.

os tópicos relativos ao grupo que irá se subdividir. Já na segunda metade (ver Figuras 4.12c e 4.12d), são mostrados os tópicos extraídos para os resultados dessa subdivisão.

Por fim, as Figuras 4.13 e 4.14 ilustram o surgimento de um novo tópico e o desaparecimento de um tópico, respectivamente. Para representar o surgimento de um novo tópico, tem-se um polígono que vai se tornando cada vez mais visível ao diminuir sua transparência. Enquanto no desaparecimento de um novo tópico, utiliza-se um polígono que se torna cada vez mais transparente. No caso do surgimento de um grupo, os tópicos são exibidos somente depois da primeira metade dos quadros intermediários. No caso do desaparecimento de um grupo, os tópicos somem depois da primeira metade dos quadros intermediários.

Um vídeo mostrando o mapa dinâmico completo para essa coleção encontra-se disponível em http://vicg.icmc.usp.br/ aretha/tlsp/examples/VespignaniDynamicMap.avi. 


\subsection{Considerações Finais}

Nesse capítulo foi apresentada a Time-based Least Square Projection (T-LSP), uma nova técnica de projeção multidimensional dinâmica que é capaz de projetar conjuntos de dados de alta dimensionalidade em um tempo computacional satisfatório, mostrando as mudanças nas relações de similaridade ao longo do tempo entre objetos multidimensionais, como coleções de artigos científicos. A saída é uma sequência de projeções indexada temporalmente, que pode ser animada para evidenciar as mudanças entre dois instantes de tempo. A T-LSP busca obedecer duas propriedades principais conflitantes: a manutenção da acurácia local e a manutenção da coerência espacial global. Nesta tese, a técnica T-LSP é aplicada a coleções de artigos científicos com o intuito de obter um mapa de documentos dinâmico que evidencia a evolução temporal dos tópicos. No entanto, esta técnica também pode ser empregada para mostrar mudanças temporais nas relações de similaridade para qualquer tipo de coleção de dados indexada temporalmente, que possa ser representada em um espaço multidimensional ou para a qual relações de similaridade possam ser definidas.

Com intuito de adicionar informação ao mapa de documentos dinâmico sobre o porquê certos grupos se formaram em determinados instantes de tempo, foram desenvolvidas duas novas técnicas de extração automática de tópicos: a extração de tópicos baseada em Principal Component Analysis (PCA), um método utilizado para detecção de padrões; e a extração de tópicos baseada em Latent Dirichlet Allocation (LDA), um modelo que busca representar documentos como uma distribuição probabilística de seus tópicos.

Com base no mapa dinâmico de documentos obtido com a T-LSP, também é possível detectar a evolução temporal de tópicos, buscando por eventos de transição como: a emergência de novos tópicos em instantes de tempo específicos; a subdivisão de um tópico, quando parte dos documentos daquele tópico tornam-se heterogêneos em relação ao restante do grupo e formam um novo tópico; e a junção de dois ou mais tópicos para formar outro. Para detectar essa evolução temporal de tópicos com base na T-LSP, combinamos as técnicas de extração de tópicos com: o algoritmo de detecção de agrupamentos baseado em densidade DBSCAN; e com o algoritmo MONIC para rastreamento das transições temporais entre grupos. Uma vez detectada, a informação sobre a evolução temporal de tópico pode ser adicionada ao mapa dinâmico de documentos por meio de efeitos visuais.

Dessa forma, a T-LSP fornece informações valiosas quanto as mudanças nas relações de similaridade entre os documentos ao longo do tempo. Informações que podem ser analisadas por algoritmos de mineração para extrair outros padrões interessantes, como eventos de transição. 


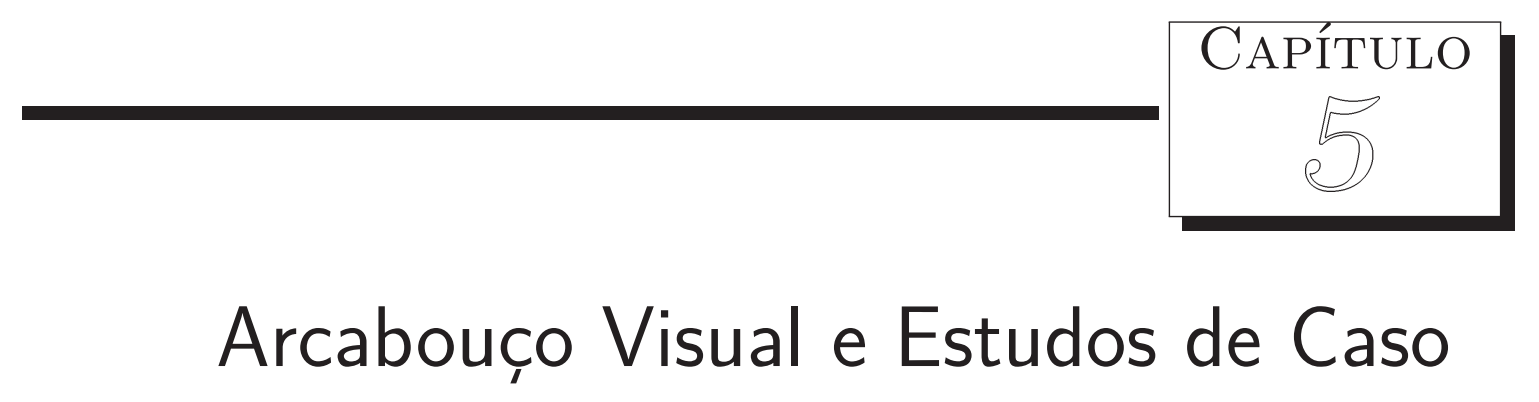

Este capítulo tem o objetivo de descrever aplicações da abordagem proposta no Capítulo 4, fornecendo evidências de sua aplicabilidade. Na Seção 5.1, são apresentadas as características e funcionalidades da ferramenta Science View, que foi desenvolvida como um arcabouço visual para aplicar e testar as técnicas apresentadas no capítulo anterior. Já na Seção 5.2 são apresentados a abordagem de coleta das coleções de artigos científicos para análise de forma a priorizar a qualidade dos dados, e alguns cenários de análise temporal de coleções, com seus resultados correspondentes. A Seção 5.3 apresenta os tempos de processamento para gerar os mapas de documentos dinâmicos apresentados neste capítulo. Por fim, a Seção 5.4 apresenta um comparativo entre técnicas para construção de mapas de documentos dinâmicos baseados em projeções multidimensionais, que traz uma análise mais crítica e profunda das técnicas segundo uma série de quesitos, contextualizando a contribuição deste trabalho em relação ao estado da arte.

\subsection{Arcabouço Visual: Ferramenta Science View}

A ferramenta Science View ${ }^{1}$ aceita como entrada coleções de artigos nos formatos ISI, Endnote Export Format ou BibTeX. A escolha desses formatos deve-se, principalmente, à sua larga

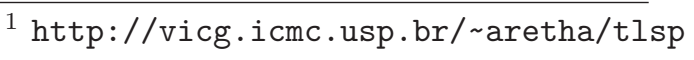


utilização no meio acadêmico. O formato ISI, por exemplo, é adotado pela base de artigos científicos Thomsons Reuters Web of Science ${ }^{2}$. Essa base permite a navegação e pesquisa em mais de 10.000 periódicos e 120.000 conferências, sendo atualizada diariamente. Isto significa que o usuário pode fazer uma pesquisa por artigos utilizando termos de seu interesse e salvar a coleção de artigos resultante no formato ISI para ser analisada na ferramenta Science View. O resultado final não é alterado pelo formato no qual a coleção será fornecida, com exceção do formato BibTeX para o qual não se encontra disponível opções envolvendo as referências, como o modelo vetorial estendido ou arestas baseadas em acoplamento bibliográfico.

\subsubsection{Funcionalidades}

Um assistente de projeção guia o usuário na criação de uma nova projeção multidimensional dinâmica, no qual o primeiro passo é definir a coleção de entrada. O usuário pode escolher entre uma coleção já existente no banco de dados ou carregar uma nova coleção. O assistente auxilia o usuário na escolha de parâmetros referentes ao pré-processamento, à definição de similaridade entre os documentos e à projeção T-LSP. Ao fim do assistente, será obtido o mapa dinâmico correspondente, mas sem informação quanto à evolução temporal dos tópicos. Essa informação pode ser adicionada por meio de um comando do usuário para executar os algoritmos DBSCAN e MONIC com os parâmetros especificados. Essa última parte é obtida separadamente, pois se o usuário desejar é possível refazê-la, com outros parâmetros, para o mesmo mapa. Valores default são definidos para todos os parâmetros.

A ferramenta mostra o mapa dinâmico resultante em seu painel principal, ilustrado na captura de tela da Figura 5.1. A janela principal tem três painéis principais: o painel de projeção na parte central, o painel de detalhes-sob-demanda na região esquerda e o painel de atributos visuais na região direita.

O painel de projeção mostra os documentos projetados, em que cada círculo representa um único artigo. Ao posicionar o mouse sobre um círculo, será mostrada uma dica identificando o título e ano de publicação do artigo. Já um clique duplo sobre esse círculo irá mostrar todo o conteúdo (título, autores, nome do periódico ou conferência, ano de publicação, resumo, palavras-chave, DOI, referências, entre outros atributos) do artigo correspondente em uma janela pop-up. Na região inferior do painel de projeção, um slider permite que os usuários interajam com a animação, que pode ser iniciada, pausada, avançada ou retrocedida. Portanto, usuários podem ver e rever diferentes estágios da visualização, o que elimina a necessidade de o usuário manter em sua memória toda a informação apresentada.

O painel de detalhes-sob-demanda mostra detalhes de documentos ou tópicos selecionados no painel de projeção. Para auxiliar na seleção de elementos no painel de projeção, existe uma barra de ferramentas vertical no lado direito da ferramenta que possui alguns botões que podem ser utilizados para ativar certos comportamentos quanto a seleção

2 http://www.webofknowledge.com 


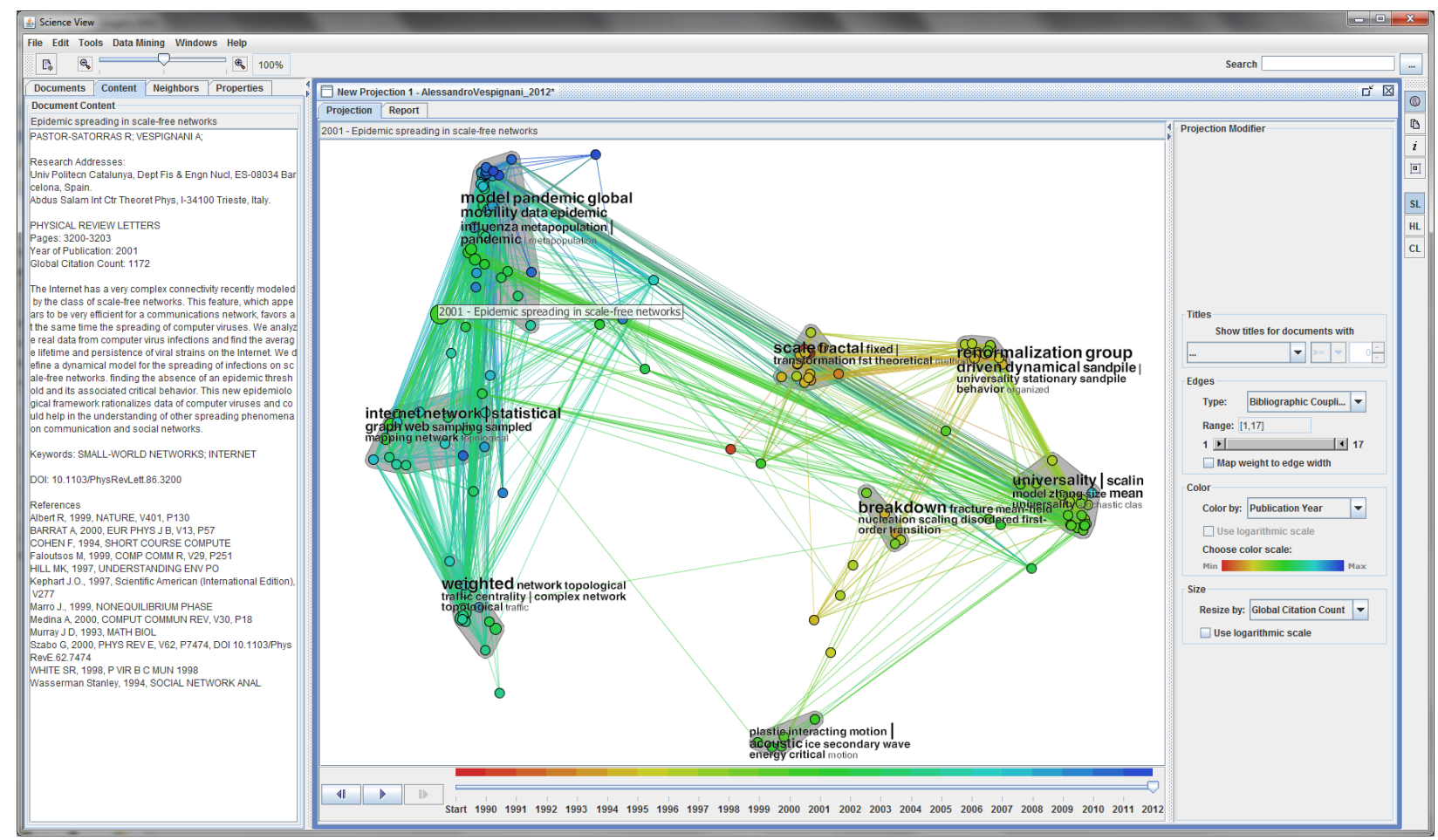

Figura 5.1: ScienceView: (Centro) Painel de projeção com projeção dinâmica obtida com a técnica T-LSP para conjuntos de artigos científicos publicados por Alessandro Vespignani; (Esquerda) Painel de detalhes-sob-demanda com conteúdo do artigo mais citado "Epidemic spreading in scale-free networks"; (Direita) Painel de atributos visuais, indicando a utilização de cores para indicar o ano de publicação, com tamanho ajustado de acordo com a quantidade de citações em escala logarítmica e com arestas indicando acoplamento bibliográfico.

de elementos na projeção. Por exemplo, ao selecionar um tópico no painel de projeção, após clicar no botão 'HL' (highlight label) e passar o mouse sobre um tópico (áreas em cinza), o painel de detalhes-sob-demanda será aberto na aba 'Documents' e também na aba filha 'By Topic'. Em seguida, serão mostradas informações relativas ao tópico correspondente, como: uma lista de todos os artigos associados àquele tópico, os principais autores dos artigos desse tópico, e o ano de publicação médio dos artigos desse tópico.

No painel de atributos visuais existem controles que permitem mudar atributos da projeção: cor e tamanho dos círculos, e que tipo de aresta pode ser adicionada à projeção.

Os seguintes atributos podem ser mapeados para cor ou tamanho dos círculos: ano de publicação, número de citações locais (número de vezes que um artigo foi citado por outros artigos na própria coleção) e número de citações globais (número de citações do artigo). Usuários podem escolher entre seis escalas de cor pré-definidas. A escala logarítmica pode ser usada para mapear um grande intervalo de valores para a escala de cor selecionada. Se o ano de publicação for usado para mapear as cores dos círculos, uma legenda indicando a cor associada a cada ano aparece no topo do slider que controla a animação.

Os usuários também podem escolher entre arestas que representam acoplamento bibliográfico (número de referências compartilhadas por dois artigos), citações locais (citações 
que se referem a artigos contidos na coleção) ou número de autores compartilhados. Arestas baseadas no acoplamento bibliográfico ou no número de autores compartilhados possuem pesos e não são direcionadas. Já arestas baseadas em citações locais não possuem peso e são direcionadas do artigo que cita para o artigo sendo citado. Um range slider permite determinar limites superiores e inferiores dos pesos, de modo que arestas com pesos maiores que o limite superior ou com pesos menores que o limite inferior não sejam exibidas na projeção.

Muitas outras interações também são possíveis: zoom em uma área específica da projeção; recuperar na Internet a página que dá acesso ao arquivo PDF de artigos representados na projeção; identificar os principais autores de um tópico, com base no número de artigos de sua autoria; entre outras. Estes painéis e iterações disponíveis são ilustradas no vídeo http://vicg.icmc.usp.br/ aretha/tlsp/examples/LaszloBarabasiDynamicMap.avi.

\subsubsection{Coleta de Artigos Científicos}

Antes de analisar a trajetória de pesquisa de um pesquisador ou de uma área de pesquisa, é necessário coletar os artigos publicados por este pesquisador ou que contêm termos que definem a área de pesquisa de interesse. Coleções de artigos científicos diferem quanto à cobertura e resolução temporal (número de dias, meses ou anos cobertos), geografia (linguagens ou países considerados) e temas (conjuntos de disciplinas ou periódicos selecionados). O tamanho da coleção pode ser pequeno (menos de 500 documentos), médio (entre 500 e 1.000 documentos) ou grande (mais de 1.000 documentos). Artigos científicos podem ser adquiridos de várias formas, variando de web crawling a buscas por palavras-chave em bases indexadas internacionais. No entanto, recomenda-se o uso de bases indexadas devido à qualidade superior de seus dados.

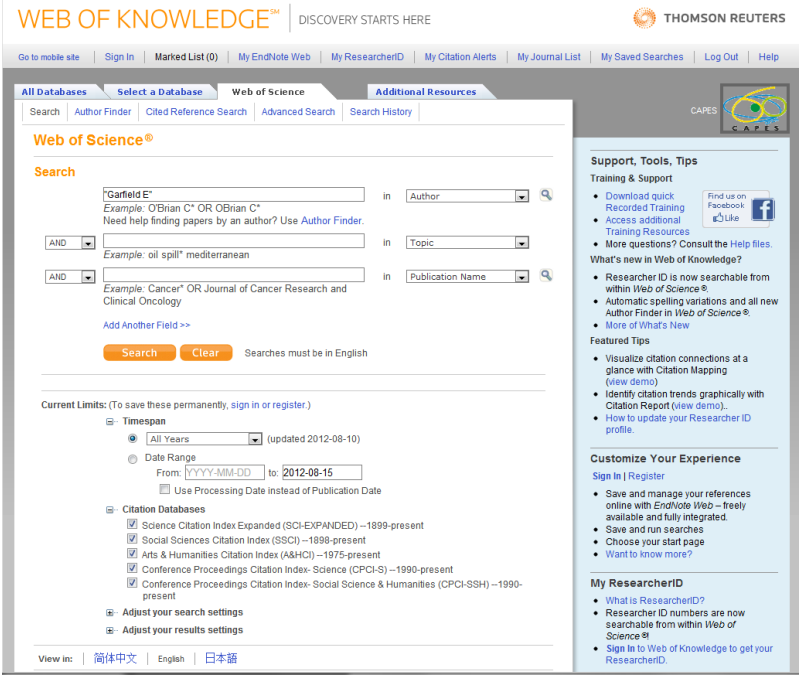

(a) Termo de busca "Garfield E" no campo autor.

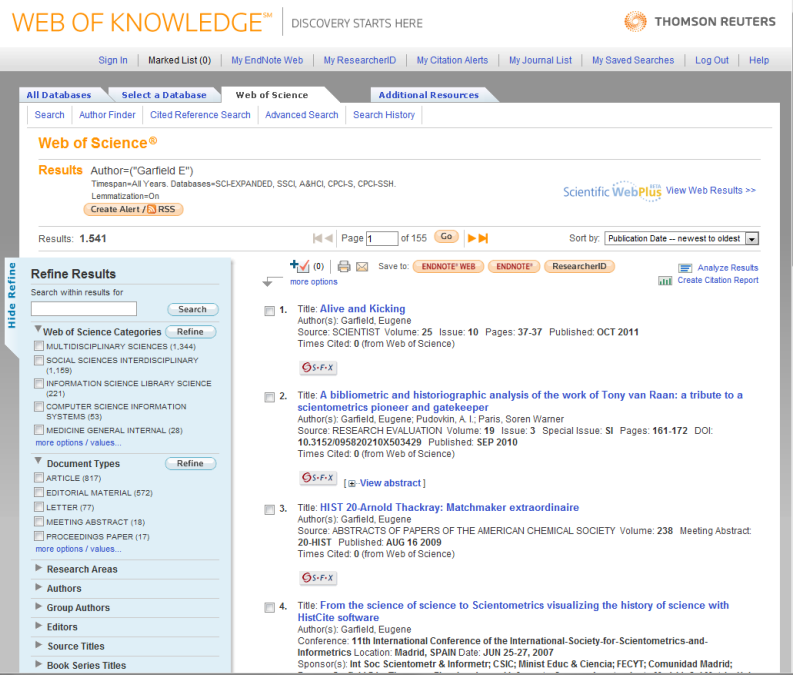

(b) Resultado: 1.541 artigos.

Figura 5.2: Busca pelos artigos do autor Eugene Garfield no portal Web of Science. 
O portal Thomsons Reuters Web of Science $^{3}$ indexa os artigos publicados em mais de 10.000 jornais e 120.000 conferências. O acesso é restrito a assinantes pagos. Devido à qualidade de seus dados e à grande quantidade de artigos indexados, essa é uma das bases mais utilizadas na atualidade. Na Figura 5.2, por exemplo, a busca por todas as publicações de Eugene Garfield retornou 1.541 artigos em 15 de Agosto de 2012. O portal Scopus ${ }^{4}$ da Elsevier também têm um amplo catálogo de artigos publicados em periódicos e conferências, sendo também um portal pago. Resultados de buscas no portal Web of Science podem ser salvos, por exemplo, nos formatos ISI, Endnote e BibTeX, enquanto resultados no Scopus podem ser salvos, por exemplo, no formato BibTeX. A CAPES é assinante dos portais Web of Science e Scopus.

Salienta-se que as bases indexadas acima descrevem cada artigo como um conjunto de campos: autores, título, resumo, nome do periódico ou da conferência, palavras-chave, ano de publicação, referências, DOI, etc. Não é padrão utilizar o texto do corpo de cada artigo de uma coleção para representá-la, pois campos como título, resumo e palavras-chave são suficientemente representativos semanticamente. Utilizar o texto do corpo de cada documento também iria incorrer em uma representação de dimensionalidade excessivamente alta.

\subsubsection{Estrutura do Banco de Dados}

O sistema gerenciador de banco de dados $H 2^{5}$ foi utilizado para o gerenciamento do banco de dados na ferramenta Science View. A escolha deste sistema está relacionada ao fato dele poder ser incorporado em aplicações Java, suportar diferentes plataformas, executar operações no banco rapidamente, ter código aberto e ser gratuito.

Uma vez que uma coleção de documentos é carregada no banco de dados da ferramenta, ela permanece no banco a menos que usuário escolha removê-la. Dessa forma, quando a ferramenta é executada, todas as coleções prévias aparecem na lista de coleções disponíveis. Isso traz a vantagem de que o carregamento e parte do pré-processamento da coleção não precisam ser executados novamente, mesmo se o usuário quiser gerar duas projeções, com parâmetros diferentes, da mesma coleção. O banco de dados também melhora o uso da memória disponível no computador, o que é essencial para visualizar coleções maiores, com alguns milhares de documentos.

A Figura 5.3 mostra o modelo do banco de dados utilizado para armazenar as coleções de artigos científicos. Os artigos armazenados na base de dados são organizados em coleções. As principais informações utilizadas pela ferramenta Science View são armazenadas nas entidades de documentos, referências e autores de documentos, bem como nos atributos de título, ano e termos extraídos para cada documento (grams). Ao fazer o carregamento de uma

\footnotetext{
3 http://www. webofknowledge.com

${ }^{4}$ http://www. scopus. com

${ }^{5}$ http://www.h2database.com
} 


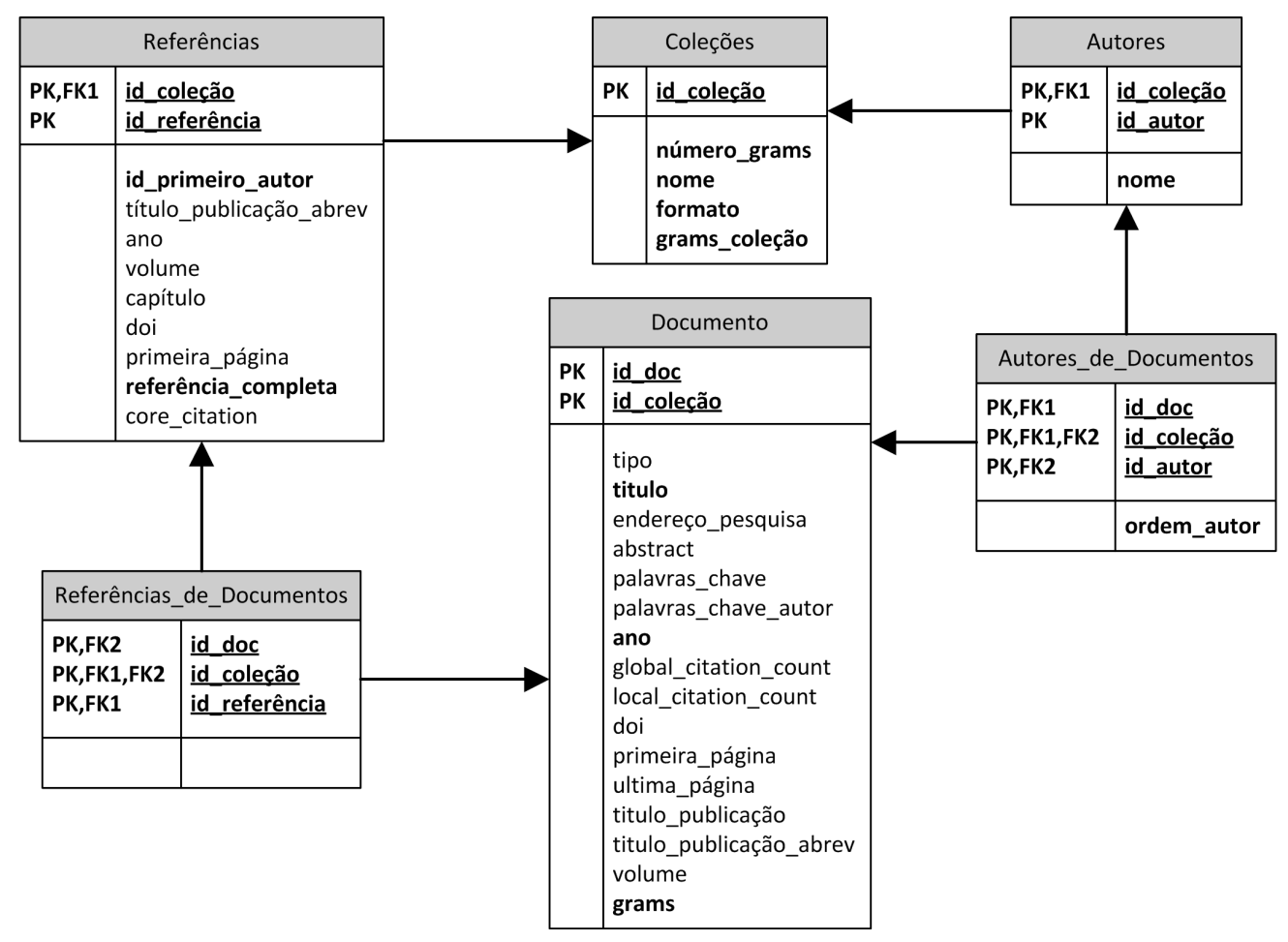

Figura 5.3: Modelo relacional do banco de dados da ferramenta ScienceView.

coleção no banco de dados, são realizadas algumas operações como a unificação dos nomes dos autores e a unificação das referências para que, por exemplo, uma mesma referência que foi citada por dois artigos diferentes não seja incluída na entidade referências duas vezes. Isso exige que uma referência seja comparada a todas as referências já inseridas no banco de dados, o que torna a etapa de carregamento uma das mais demoradas no processo de geração do mapa dinâmico.

\subsection{Estudos de Caso}

As próximas seções são dedicadas a apresentar alguns cenários de análise temporal para coleções de artigos científicos utilizando a abordagem proposta. Primeiramente, a Seção 5.2.1 apresenta uma análise do mapa dinâmico obtido para a trajetória do pesquisador AlbertLászló Barabási entre 1989 e 2012. Em seguida, a Seção 5.2.2 apresenta uma análise do mapa dinâmico obtido para observar a evolução das áreas de pesquisa representadas pelos artigos publicados no periódico IEEE Transactions on Knowledge and Data Engineering (TKDE) entre 1992 e 2012. Por fim, na Seção 5.2.3 é apresentado um exemplo de cenário no qual a abordagem proposta pode não funcionar adequadamente, i.e., os mapas são poucos informativos, e os motivos para tal. 


\subsubsection{Trajetória de Pesquisa: Albert-László Barabási}

Albert-László Barabási é professor emérito na Universidade de Northeastern em Boston nos Estados Unidos, onde é diretor do Centro de Pesquisa para Redes Complexas, e possui cargos nos departamentos de Física, Ciência da Computação e Biologia. Ele também possui ligações com a Escola de Medicina de Harvard e o Hospital Brigham para Mulheres, e é um membro do instituto para pesquisas sobre câncer Dana-Farber. Ele recebeu seu título de mestre em Física Teórica em 1991 na Universidade de Eötvös em Budapeste na Hungria, posteriormente obtendo o título de doutor na Universidade de Boston, em 1994. Depois de um ano no centro de pesquisa T. J. Watson da IBM, afiliou-se à Universidade de Notre Dame como professor assistente e em 2001 foi promovido como Professor Emil T. Hofman. Em 2007, Barabási deixou seu cargo em Notre Dame para assumir sua atual posição como professor emérito da Universidade de Northeastern.

Seu trabalho em redes complexas levou à descoberta de redes livres de escala em 1999, propondo o modelo Barabasi-Albert para explicar o padrão de conexões em alguns sistemas naturais, tecnológicos e sociais. Redes desse tipo são bastante comuns e surgem nos contextos mais variados, como a internet, redes sociais, a redes aéreas entre aeroportos e redes metabólicas.

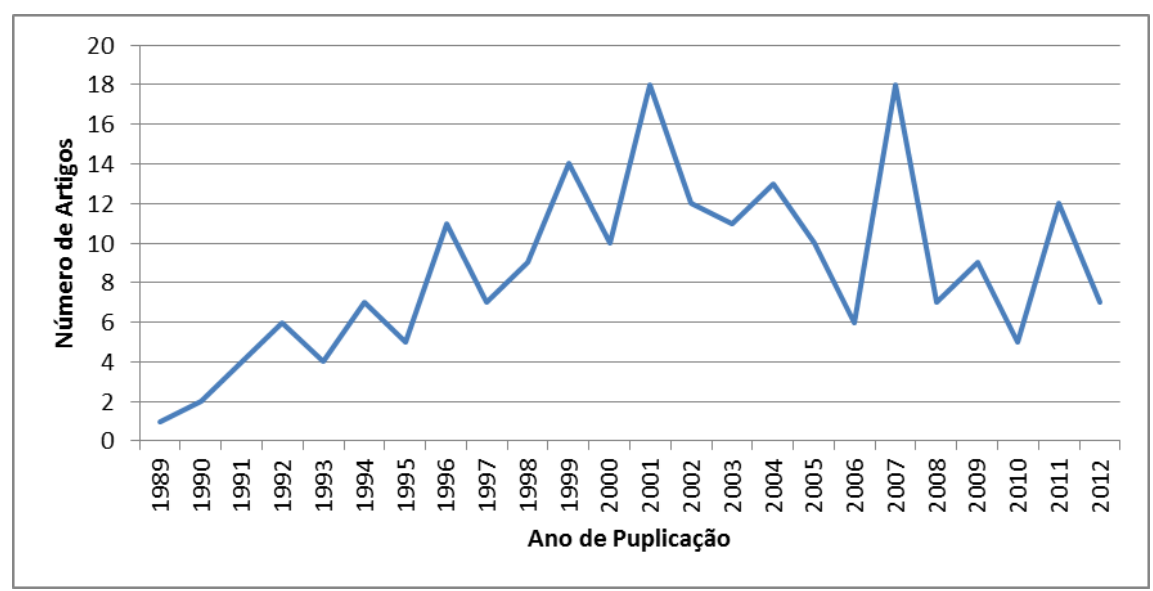

Figura 5.4: Número de artigos publicados por ano pelo pesquisador Albert-László Barabási.

Para analisar a sua trajetória de pesquisa, foram recuperados no portal Web of Science 208 artigos publicados por László Barabási como autor ou coautor entre 1989 e 2012. A Figura 5.4 mostra o número de artigos publicados por ano. Essa coleção encontra-se disponível em http://vicg.icmc.usp. br/ aretha/tlsp/datasets/LaszloBarabasiDataset. isi.

A sequência de projeções obtida aplicando a técnica T-LSP a esta coleção é mostrada na Figura 5.5. A cor de cada círculo indica o ano de publicação do artigo correspondente, de acordo com a escala na Figura 5.5b. O tamanho de cada círculo é proporcional à citação global do artigo (número de citações de acordo com o portal Thomson Reuters Web of Science) em escala logarítmica. As arestas são baseadas no acoplamento bibliográfico entre 


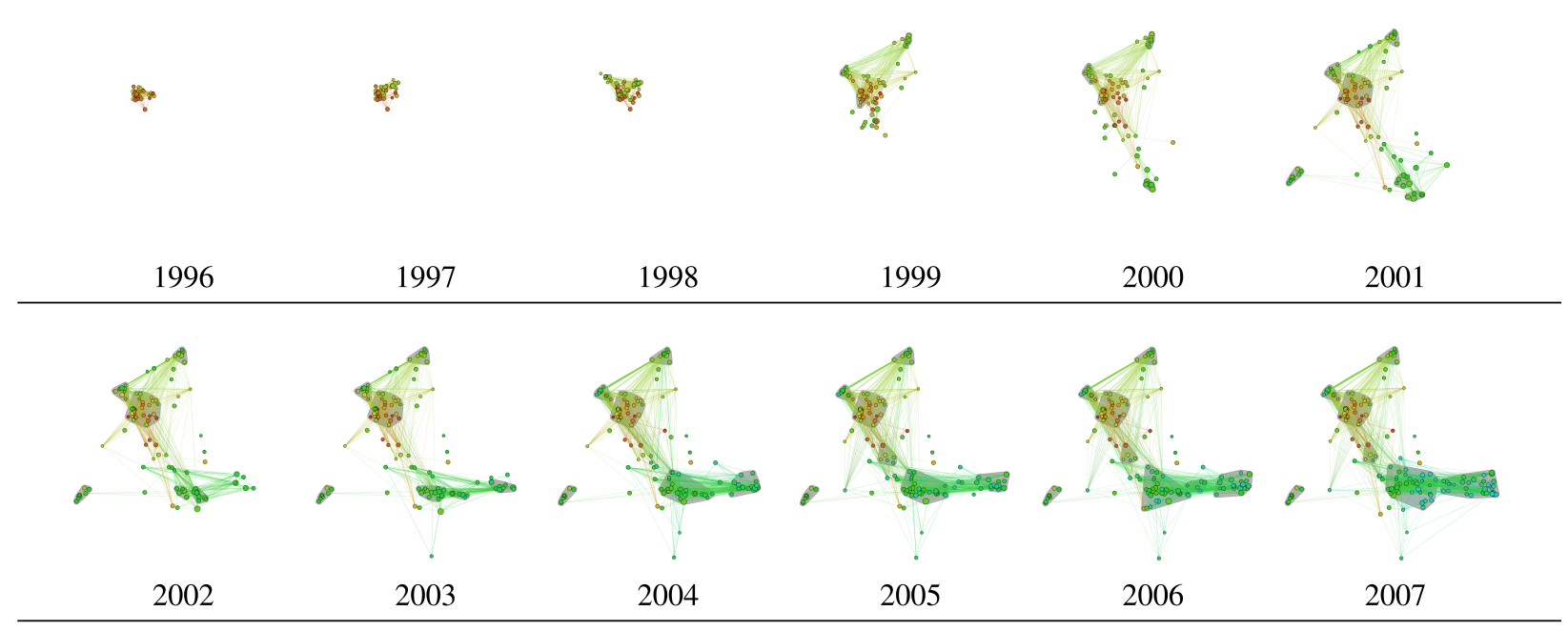

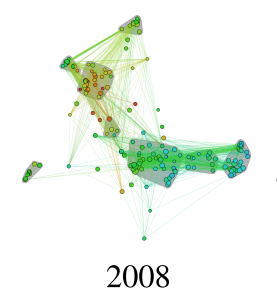

2008

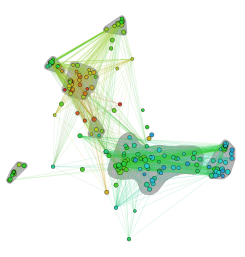

2009

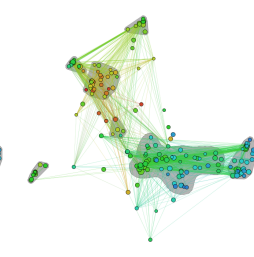

2010

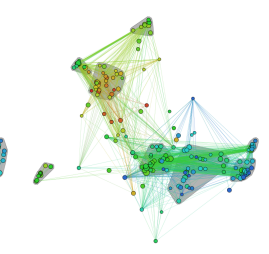

2011

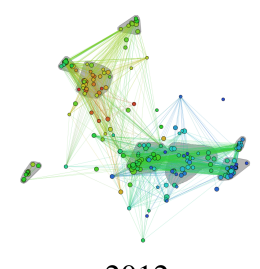

2012

(a) Sequência de projeções.

1989

(b) Legenda de cor.

Figura 5.5: Sequência de projeções obtida com a técnica T-LSP para a coleção de artigos publicados por Albert-László Barabási. Grupos encontrados para cada projeção da sequência também são exibidos (áreas em cinza).

dois artigos: uma aresta é adicionada entre dois artigos se eles têm ao menos uma referência em comum e a cor da aresta é uma cor intermediária baseada na interpolação linear das cores dos círculos que ela conecta. Um vídeo mostrando o mapa dinâmico completo para essa coleção encontra-se disponível em http://vicg.icmc.usp.br/ aretha/tlsp/examples/ LaszloBarabasiDynamicMap.avi.

Para obtenção dessa projeção dinâmica, utilizou-se o modelo vetorial estendido com corte de Luhn inferior igual a 10 e superior igual a 152 para os termos, e corte de Luhn inferior a 2 para as referências. Uma lista de stopwords genérica e pré-compilada foi utilizada para determinar os stopwords a serem removidos. Também se empregou o stemming dos termos. A medida de similaridade do cosseno foi utilizada para quantificar a similaridade entre os documentos. Foram utilizados $n c=20$ pontos de controle e $k=11$ vizinhos para cada artigo nas relações de vizinhança para obter a última projeção da sequência (ano de 2012), 
a partir da qual é aplicado o esquema retroativo da T-LSP. Para rastrear as transições temporais entre os grupos, empregou-se o algoritmo DBSCAN com parâmetros $\epsilon=0,05$ e MinPts $=5$ e o algoritmo MONIC com parâmetros $\tau=0,5$ e $\tau_{\text {split }}=0,3$. Utilizou-se também a técnica baseada em PCA para extração dos tópicos desses grupos, com parâmetros min_topics $=0,35$ e min_terms $=0,65$. Por questões de espaço e legibilidade, tópicos não são mostrados visualmente sobre as projeções, somente seus grupos são identificados, visualmente delimitados em cinza.

Por restrições de espaço, analisaremos somente alguns subintervalos da sequência. Os mapas referentes ao subintervalo entre 2002 e 2004 são mostrados na Figura 5.6. A direita de cada figura existem tabelas contendo os tópicos extraídos a partir dos grupos identificados. Para cada grupo, têm-se: o identificador desse grupo, o número de artigos contidos no grupo (em parênteses), e os tópicos extraídos - com cada tópico sendo seguido por seu peso (em colchetes). Quanto maior o peso de um tópico, maior a sua relevância para o grupo associado. Na ferramenta, o usuário pode observar os tópicos posicionando o mouse sobre o grupo correspondente, ou optar por exibi-los todos ao mesmo tempo. Já as transições temporais entre os grupos são mostradas na Tabela 5.1, juntamente com a taxa de sobreposição entre os grupos envolvidos em uma transição. Transições temporais que são explicadas em detalhe no texto são evidenciadas com um preenchimento em cinza claro na tabela. As notações matemáticas utilizadas para apresentar as transições seguem o formato definido na Seção 4.3.2.

O mapa mostrado na Figura 5.6a mostra os artigos publicados até 2002. Nesse mapa, é observada uma grande área na parte superior composta pelos grupos $C_{2}, C_{3}, C_{4}$ e $C_{6}$, que inclui principalmente artigos relacionados à área de Física, a primeira área na qual Barabási conduziu pesquisas. O grupo $C_{2}$ é o mais antigo dentre esses, sendo composto por 30 artigos que, em média, foram publicados em 1994, quando o pesquisador ainda estava na Universidade de Boston obtendo seu doutorado. O físico H. Eugene Stanley, também da Universidade de Boston, aparece como coautor em 15 artigos nesse grupo, pois ele orientou Barabási no doutorado. O grupo $C_{4}$ refere-se ao estudo de como o processo chamado sputtering, que remove material de uma superfície sólida por meio do bombardeamento de átomos, pode afetar a morfologia de uma superfície, tornando uma superfície rugosa devido ao aparecimento de estruturas chamadas ripples. O grupo $C_{6}$ inclui artigos publicados sobre o estudo da dinâmica em meios granulares, mais especificamente sobre a força de arrasto (drag force) que faz resistência ao movimento de um objeto sólido através de um meio granular. O físico Peter Schiffer, da Universidade Penn State, é um grande colaborador de Barabási nesse tópico, pois aparece como autor em todos os artigos desse grupo.

Também no mapa da Figura 5.6a, dois grupos $C_{7}$ e $C_{8}$, que possuem poucos artigos associados e surgiram pela primeira vez entre 2001 e 2002, representam o início da mudança gradual do foco de pesquisa de Barabási de Física para Redes Complexas. Esta mudança é marcada pela sua descoberta de redes livres de escala em 1999 - redes que apresentam um 


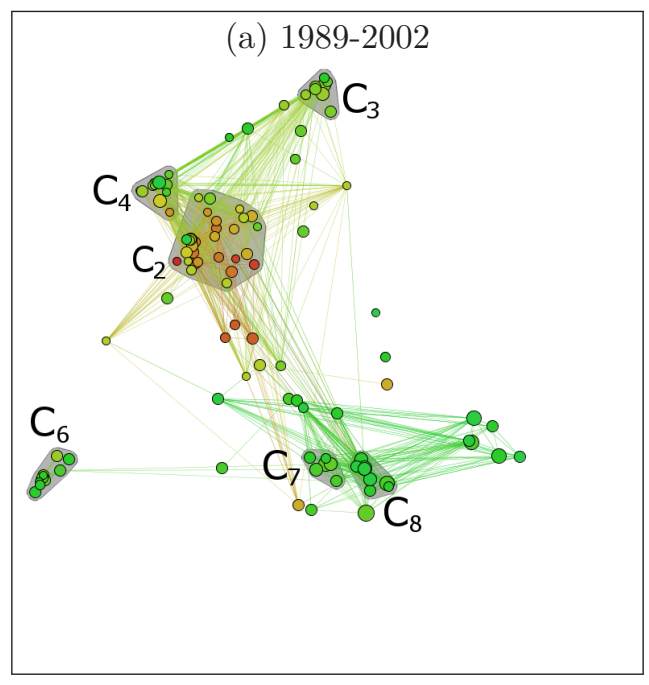

\begin{tabular}{cl}
\hline Id (\# Docs) & Tópicos \\
\hline$C_{2}(30)$ & (universality, depinning, transition, find, class, \\
& exponent, alpha, scaling, equation, beta, \\
& phase) $[32,32]$ (interface, directed, current, roughe- \\
& ning) $[12,98]$
\end{tabular}

$C_{3}(8) \quad$ (island, formation, ripening, equilibrium, heteroepitaxial) $[27,24]$ (saqd, kinetic, quantum, dot) $[18,69]$

$C_{4}(12) \quad$ (surface, ripple, morphology, nonlinear, diffusion, theory, formation, continuum, roughening, sputtering) $[36,49]$

$C_{6}(11) \quad$ (force, drag, object) $[41,23]$

$C_{7}(6) \quad$ (scale-free, scaling, random, mean-field, model, $C_{8}(9) \quad$ recently, distribution, power-law, display) [45,93]

$C_{8}(9) \quad$ (tolerance, error, display, robustness, complex, degree, attributed, communication, high, redundant, networks, surprising, ability, attack)[42,67]

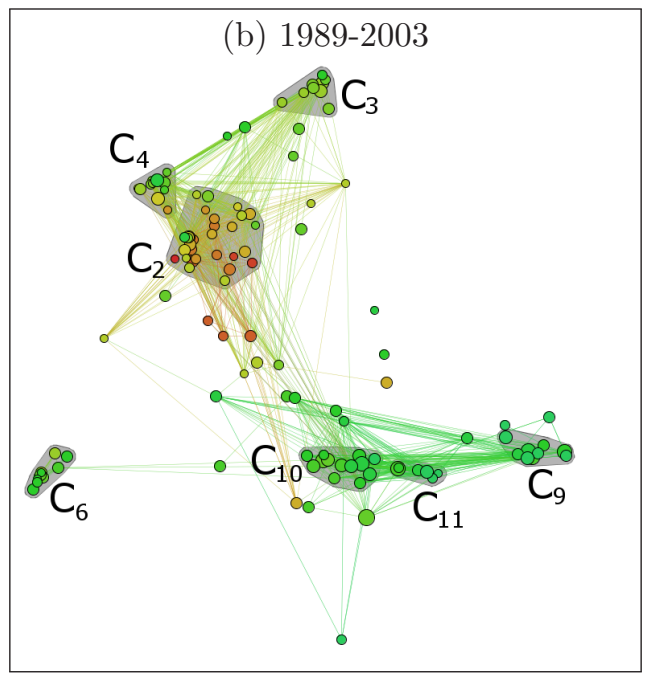

\begin{tabular}{cl}
\hline Id (\# Docs) & Tópicos \\
\hline$C_{2}(30)$ & (universality, depinning, transition, find, class, \\
& exponent, alpha, scaling, equation, beta, \\
& phase) $[32,32]$ (interface, directed, current, roughe- \\
& ning) $[12,98]$
\end{tabular}

$C_{3}(9) \quad$ (island, ripening, equilibrium, heteroepitaxial, formation) $[21,83]$ (sl, formation, miscut, superlattice, iii-v) $[19,27]$

$C_{4}(12) \quad$ (surface, ripple, morphology, nonlinear, diffusion, theory, formation, continuum, roughening, sputtering) $[36,49]$

$C_{6}(11) \quad$ (force, drag, object) $[41,23]$

$C_{9}(9) \quad$ (metabolic, evolutionary, essential)[27,93] (essential, analysis, functional, coli, data, preserved, level, system, growth) [21,09]

$C_{10}(13) \quad$ (network, evolution, topology, time, complex, model, internet)[25,79] (internet, attachment, preferential) $[20,34]$

$C_{11}(6) \quad$ (hierarchical, real, organization, clustering, scalefree, law, topology, scaling) $[57,4]$

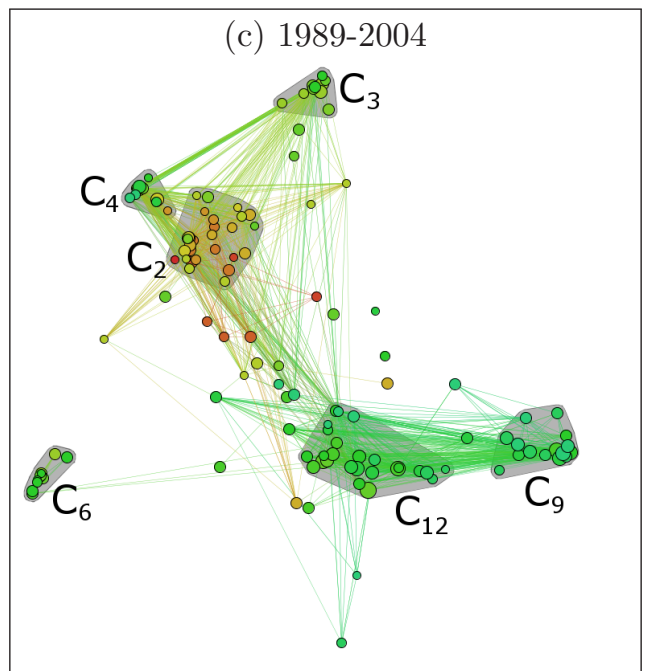

\begin{tabular}{cl}
\hline Id (\# Docs) & Tópicos \\
\hline$C_{2}(28)$ & (universality, depinning, transition, find, class, \\
& exponent, alpha, scaling, beta, equation, \\
& phase)[33,45] (aggregation, diffusion, deposition, \\
& model)[13,25] \\
& (island, ripening, growth, equilibrium, heteroepi- \\
& taxial) $[21,48]$ (sl, formation, miscut, superlattice, \\
& iii-v) $[17,53]$ \\
& $($ surface, sputtering, ion, morphology, yield, rough- \\
& ness) $[36,75]$ \\
$C_{4}(16)$ & (force, drag, object)[41,23] \\
& (protein, interaction, network, localization, functi- \\
$C_{6}(11)$ & onal) $[24,04]$ (metabolic, organization, large-scale, \\
$C_{9}(15)$ & metabolism, complex, coli, interaction, topologi- \\
& cal)[15,09] \\
& (tolerance, error, complex, degree, display, hierar- \\
& chical, robustness)[19,05] (hierarchical, scale-free, \\
& topology, real, organization, clustering)[16,92]
\end{tabular}

Figura 5.6: Subintervalo entre 2002-2004 do mapa dinâmico de artigos publicados por Albert-László Barabási. 
Tabela 5.1: Transições entre grupos para o subintervalo entre 2002-2004 do mapa dinâmico de artigos publicados por Albert-László Barabási.

\begin{tabular}{|ll||ll|}
\hline \multicolumn{2}{|c|}{ Transições 2002 $\rightarrow$ 2003 } & \multicolumn{2}{c|}{ Transições 2003 $\rightarrow \mathbf{2 0 0 4}$} \\
\hline \hline$C_{2} \rightarrow C_{2}$ & $S\left(C_{2}, C_{2}\right)=1.0$ & $C_{2} \rightarrow C_{2}$ & $S\left(C_{2}, C_{2}\right)=0.93$ \\
\hline$C_{3} \rightarrow C_{3}$ & $S\left(C_{3}, C_{3}\right)=1.0$ & $C_{3} \rightarrow C_{3}$ & $S\left(C_{3}, C_{3}\right)=1.0$ \\
\hline$C_{4} \rightarrow C_{4}$ & $S\left(C_{4}, C_{4}\right)=1.0$ & $C_{4} \rightarrow C_{4}$ & $S\left(C_{4}, C_{4}\right)=1.0$ \\
\hline$C_{6} \rightarrow C_{6}$ & $S\left(C_{6}, C_{6}\right)=1.0$ & $C_{6} \rightarrow C_{6}$ & $S\left(C_{6}, C_{6}\right)=1.0$ \\
\hline$\odot \rightarrow C_{9}$ & & $C_{9} \rightarrow C_{9}$ & $S\left(C_{9}, C_{9}\right)=1.0$ \\
\hline$\left\{C_{7}, C_{8}\right\} \rightarrow C_{10}$ & $S\left(C_{7}, C_{10}\right)=1.0$ & $\left\{C_{10}, C_{11}\right\} \rightarrow C_{12}$ & $S\left(C_{10}, C_{12}\right)=1.0$ \\
& $S\left(C_{8}, C_{10}\right)=0.66$ & & $S\left(C_{11}, C_{12}\right)=1.0$ \\
\hline$\odot \rightarrow C_{11}$ & & & \\
\hline
\end{tabular}

alto grau de tolerância contra falhas aleatórias, o que melhora a sua robustez - e que ganhou força a partir de 2002, quando ele continuou a publicar outros artigos importantes sobre o assunto.

A Figura 5.6b inclui os artigos publicados até 2003. Os grupos relacionados à área de Física - grupos $C_{2}, C_{3}, C_{4}$ e $C_{6}$ - sobreviveram e persistem nas mesmas posições relativas, com tópicos similares aos extraídos anteriormente. Enquanto isso, os grupos $C_{7}$ e $C_{8}$ do ano anterior uniram-se, formando o grupo $C_{10}$ em 2003. Já o surgimento do grupo $C_{11}$ está relacionado à pesquisa sobre redes livres de escala, que apresentam um alto grau de agrupamento, pois representam dados com uma organização hierárquica. Outra importante mudança ocorre em 2003, quando Barabási continua a pesquisar sobre redes complexas, mas agora também aplicando redes a problemas na área de Biologia. Essa mudança é representada pelo surgimento do grupo $C_{9}$ que se refere ao estudo sobre redes metabólicas.

Por fim, a Figura 5.6c inclui os artigos publicados até 2004. Os grupos relacionados à área de Física - grupos $C_{2}, C_{3}, C_{4}$ e $C_{6}$ - sobreviveram e não sofreram nenhuma mudança significativa. O grupo $C_{9}$ aumentou de tamanho e o tópico sobre redes metabólicas tornou-se o segundo mais relevante, enquanto o tópico sobre o uso de redes para prever a função de proteínas assumiu a liderança. Os grupos $C_{10}$ e $C_{11}$ sofreram uma junção e formaram o grupo $C_{12}$ em 2004.

Os mapas referentes ao subintervalo entre 2010 e 2012 são mostrados na Figura 5.7, e as transições temporais entre os seus grupos são mostradas na Tabela 5.2. Os artigos publicados até 2010 são apresentados na Figura 5.7a. Os grupos relacionados à área de Física sobreviveram sem mudanças significativas. O grupo $C_{17}$ é o resultado de uma série de transições e é composto em parte pelos artigos do grupo $C_{12}$ do subintervalo anterior e por outros artigos adicionados posteriormente. O último tópico do grupo $C_{17}$ é referente ao começo do estudo de redes que buscam modelar a dinâmica do movimento humano, o que é útil, por exemplo, para prever a propagação de vírus de doenças e eletrônicos, e no gerenciamento de recursos de redes de telecomunicações móvel. O grupo $C_{15}$ também é o resultado de uma série de transições e é composto em parte pelo conteúdo do grupo $C_{9}$ 
Tabela 5.2: Transições entre grupos para o subintervalo entre 2010-2012 do mapa dinâmico de artigos publicados por Albert-László Barabási.

\begin{tabular}{|c|c|c|c|}
\hline \multicolumn{2}{|c|}{ Transições $2010 \rightarrow 2011$} & \multicolumn{2}{|c|}{ Transições $2011 \rightarrow 2012$} \\
\hline$C_{2} \rightarrow C_{2}$ & $S\left(C_{2}, C_{2}\right)=1.0$ & $C_{2} \rightarrow C_{2}$ & $S\left(C_{2}, C_{2}\right)=1.0$ \\
\hline$C_{3} \rightarrow C_{3}$ & $S\left(C_{3}, C_{3}\right)=1.0$ & $C_{3} \rightarrow C_{3}$ & $S\left(C_{3}, C_{3}\right)=1.0$ \\
\hline$C_{4} \rightarrow C_{4}$ & $S\left(C_{4}, C_{4}\right)=1.0$ & $C_{4} \rightarrow C_{4}$ & $S\left(C_{4}, C_{4}\right)=1.0$ \\
\hline$C_{6} \rightarrow C_{6}$ & $S\left(C_{6}, C_{6}\right)=1.0$ & $C_{6} \rightarrow C_{6}$ & $S\left(C_{6}, C_{6}\right)=1.0$ \\
\hline$C_{13} \rightarrow \odot$ & & $C_{15} \rightarrow C_{15}$ & $S\left(C_{15}, C_{15}\right)=1.0$ \\
\hline$C_{15} \rightarrow C_{15}$ & $S\left(C_{15}, C_{15}\right)=0.61$ & $C_{18} \rightarrow C_{18}$ & $S\left(C_{18}, C_{18}\right)=1.0$ \\
\hline \multirow[t]{2}{*}{$C_{17} \rightarrow\left\{C_{18}, C_{19}\right\}$} & $S\left(C_{17}, C_{18}\right)=0.48$ & $C_{19} \rightarrow C_{19}$ & $S\left(C_{19}, C_{19}\right)=0.77$ \\
\hline & $S\left(C_{17}, C_{19}\right)=0.44$ & $C_{20} \rightarrow C_{20}$ & $S\left(C_{20}, C_{20}\right)=1.0$ \\
\hline & & & \\
\hline
\end{tabular}

no subintervalo anterior. O tópico mais relevante deste grupo é sobre redes metabólicas, enquanto o segundo tópico mais relevante é sobre o estudo de redes de metástase de câncer, cujos nós representam os sites de câncer primários e os sites de metástases subsequentes, e as arestas indicam a força da coocorrência entre os sites.

Na Figura 5.7b têm-se os artigos publicados até 2011. Novamente, os grupos relacionados à área de Física permanecem. Em contra partida, o grupo $C_{17}$ sofreu uma subdivisão e gerou os grupos $C_{18}$ e $C_{19}$. Os tópicos do grupo $C_{18}$ assemelham-se aos do grupo $C_{17}$, enquanto o grupo $C_{19}$ parece ser o motivo da subdivisão, pois é uma especialização do tópico sobre redes para representar a dinâmica do movimento humano.

O grupo $C_{20}$ não é o resultado de uma subdivisão do grupo $C_{15}$, apesar de desses grupos apresentarem tópicos similares. Apesar do grupo $C_{20}$ conter alguns artigos do grupo $C_{15}$ de 2010, a porcentagem de sobreposição não chega a 30\%. Essa porcentagem mínima de sobreposição para constituir um caso de subdivisão é determinada pelo parâmetro $\tau_{\text {split }}$, ao qual foi atribuído o valor de 0,3 para gerar este mapa dinâmico. Assim, o grupo $C_{20}$ foi detectado como um novo grupo que surgiu sobre redes metabólicas. No entanto, o tópico desse grupo foi dominado por dois documentos que utilizam muitos termos sobre a aglomeração de macromoléculas em células, que limitam a quantidade de solvente disponível para cada componente da célula, dificultando a medição de processos metabólicos. O grupo $C_{15}$ sobreviveu, preservando $61 \%$ de seu conteúdo. O tópico sobre o estudo de redes de metástase de câncer, que antes era o segundo tópico mais relevante, tornou-se o mais relevante.

Por último, a Figura 5.7c apresenta artigos publicados até $\mathbf{2 0 1 2}$ - toda a coleção. Todos os grupos sobreviveram sem grandes modificações, com exceção do grupo $C_{19}$ que teve alguns documentos removidos. O tópico (cell, system, call, data, phone, emergency), que no ano anterior era o segundo tópico mais relevante desse grupo, tornou-se o seu principal tópico. Inspecionando o resumo dos artigos do grupo $C_{19}$, percebe-se que esses também discutem sobre a dinâmica do movimento humano, porém com foco na localização de celulares (cell phones) para auxiliar serviços de emergência. A localização de celulares pode ser obtida, por exemplo, por meio das torres de celulares (cell towers) as quais um celular está conectado. 

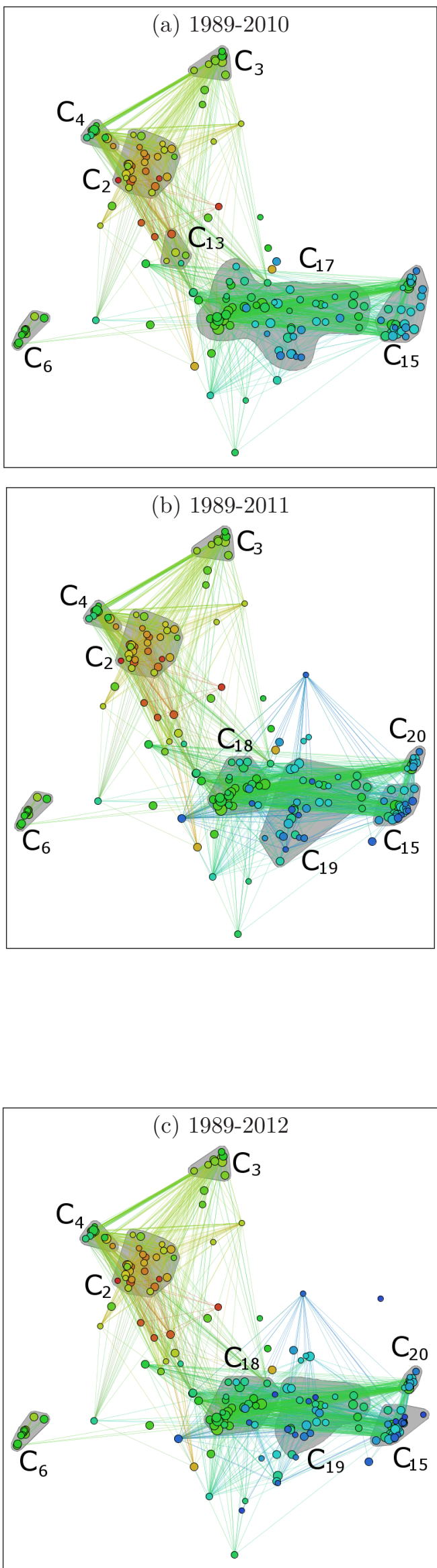

\begin{tabular}{|c|c|}
\hline Id (\# Docs) & Tópicos \\
\hline$C_{3}(10)$ & $\begin{array}{l}\text { (universality, depinning, transition, find, class, expo- } \\
\text { nent, alpha, scaling, beta, equation, phase) }[33,45] \text { (ag- } \\
\text { gregation, diffusion, deposition, model)[13,25] } \\
\text { (island, ripening, growth, equilibrium, heteroepita- } \\
\text { xial) }[21,48] \text { (sl, formation, miscut, superlattice, iii- } \\
\text { v) }[17,53]\end{array}$ \\
\hline$C_{4}(16)$ & $\begin{array}{l}\text { (surface, sputtering, ion, morphology, yield, rough- } \\
\text { ness) }[36,75]\end{array}$ \\
\hline$C_{6}(11)$ & , object) $[41,23]$ \\
\hline$C_{13}(5)$ & $\begin{array}{l}\text { (breathing, respiratory, wk, ibi, alpha, age, tonic, } \\
\text { oscillator, control, maturation, ...)[63,63] }\end{array}$ \\
\hline$C_{15}(34)$ & $\begin{array}{l}\text { (metabolic, growth, constraint) }[18,07] \text { (disease, human, } \\
\text { comorbidity, cancer)[11,99] (solvent, capacity, cons- } \\
\text { traint, limited, rate, disease, enzyme)[8,41] }\end{array}$ \\
\hline$C_{17}(58)$ & $\begin{array}{l}\text { (network, complex, scale-free, topology) }[15,68] \text { (network, } \\
\text { social, system)[11,22] (human, network, mobility) }[9,72]\end{array}$ \\
\hline Id (\# Dor & Śpicos \\
\hline$C_{2}(28)$ & $\begin{array}{l}\text { ion, find, class, expo- } \\
\text { on, phase)[33,45] (ag- } \\
\text { nodel) }[13,25]\end{array}$ \\
\hline$C_{3}(10)$ & $\begin{array}{l}\text { ripening, growth, equilibrium, heteroepita- } \\
\text { 48] (sl, formation, miscut, superlattice, iii- }\end{array}$ \\
\hline$C_{4}(16)$ & $\begin{array}{l}\text { sputtering, ion, morphology, yield, rough- } \\
75]\end{array}$ \\
\hline$C_{6}(11)$ & obiect) [41 22] \\
\hline & $\begin{array}{l}\text { (disease, human, medicine, care) }[20,57] \text { (network, di- } \\
\text { sease, ataxia, protein, functional)[11,63] (disease, hu- } \\
\text { man, interaction, network, interactome, evolutionary, } \\
\text { higher) }[10,43]\end{array}$ \\
\hline$C_{18}(29)$ & $\begin{array}{l}\text { erance, hierarchical, error, degree, scale- } \\
8,64] \text { (tolerance, error, robustness) }[16,32] \\
\text { ution, topology, complex) }[12,75]\end{array}$ \\
\hline$C_{19}(31)$ & $\begin{array}{l}\text { ity, based) }[22,27] \\
\text { ency) }[15,15]\end{array}$ \\
\hline$C_{20}(13)$ & $\begin{array}{l}\text { nited, metabolite, rate, } \\
\text { us, s., gene, multidrug- }\end{array}$ \\
\hline Id (\# Dor & $\mathrm{T}$ \\
\hline & $\begin{array}{l}\text { find, class, expo- } \\
\text { phase)[33,45] (ag- } \\
\text { lel) }[13,25]\end{array}$ \\
\hline$C_{3}(10$ & $\begin{array}{l}\text { and, ripening, growth, equilibrium, heteroepita- } \\
1)[21,48] \text { (sl, formation, miscut, superlattice, iii- } \\
17,53]\end{array}$ \\
\hline$C_{4}(16)$ & $\begin{array}{l}\text { fface, sputtering, ion, morphology, yield, rough- } \\
\text { s) }[36,75]\end{array}$ \\
\hline$C_{6}(11)$ & \\
\hline$C$ & $\begin{array}{l}\text { sease, human, cancer) }[19,18] \text { (network, disease, pro- } \\
\text { l, ataxia, functional) }[10,74] \text { (ataxia, cancer, metasta- } \\
\text { expression) }[10,09]\end{array}$ \\
\hline$C_{18}(31)$ & $\begin{array}{l}\text { x, tolerance, hierarchical, error, degree, scale- } \\
28] \text { (tolerance, error, robustness)[15,74] (hierar- } \\
\text { rganization, clustering) }[11,65]\end{array}$ \\
\hline$C_{19}(25$ & $\begin{array}{l}\text { (cell, system, call, data, phone, emergency) }[19,34] \\
\text { (network, topological, motif, transcriptional, regulatory, } \\
\text { complex) }[17,78]\end{array}$ \\
\hline$C$ & $\begin{array}{l}\text { vent, constraint, capacity, limited, metabolite, rate, } \\
\text { yme, glycolysis) }[25,81] \text { (aureus, s., gene, multidrug- } \\
\text { stant, single, essential) }[15,78]\end{array}$ \\
\hline
\end{tabular}

Figura 5.7: Subintervalo entre 2010-2012 do mapa dinâmico de artigos publicados por AlbertLászló Barabási. 


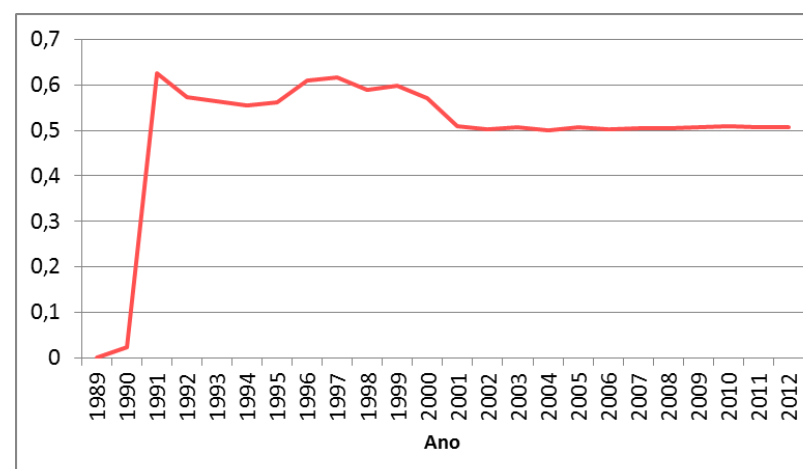

(a) Stress estático.

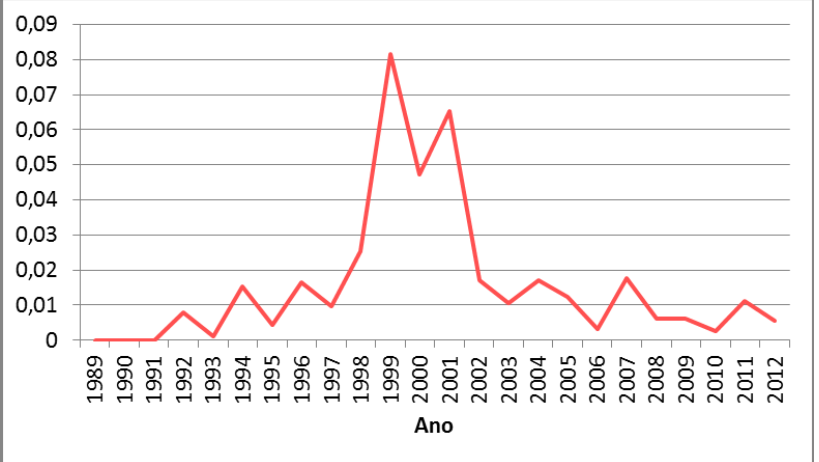

(b) Stress dinâmico.

Figura 5.8: Stress estático e stress dinâmico para a projeção dinâmica dos artigos publicados por László Barabási ,mostrada na Figura 5.5a.

A Figura 5.8a apresenta a série temporal que quantifica o stress estático (i.e., a acurácia local) dessa projeção dinâmica apresentada na Figura 5.5a. Já a Figura 5.8b apresenta a série temporal que quantifica o stress dinâmico (i.e., a coerência global) para a mesma sequência de projeções. Existem dois picos na Figura 5.8b, um no ano de 1999 e outro em 2000, o que coincide com o período da mudança do foco de pesquisa de Barabási, que descobriu as redes livres de escala e começou a publicar artigos relacionados a esse tema.

\subsubsection{Evolução de uma Área de Pesquisa: IEEE Transactions on Knowledge and Data Engineering}

O periódico científico IEEE Transactions on Knowledge and Data Engineering (TKDE) é publicado mensalmente pela IEEE Computer Society, cujos artigos abordam problemas relacionados ao atual cenário de armazenamento e análise de grandes conjuntos de dados. Os tópicos, segundo os editores, incluem, mas não estão limitados a: (a) técnicas de inteligência artificial, incluindo fala, voz, gráficos, imagens e documentos; (b) técnicas e ferramentas para engenharia de conhecimento e dados; (c) processamento paralelo e distribuído; (d) sistemas distribuídos em tempo real; (e) arquitetura, integração e modelagem de sistemas; (f) projeto, modelagem e gerenciamento de banco de dados; (g) modelagem de consultas e implementação de linguagens de consulta; (h) controle de bancos de dados distribuídos; (j) algoritmos para gerenciamento de dados e de conhecimento; (k) avaliação de desempenho de algoritmos e sistemas; (l) aspectos de comunicação de dados; (m) aplicações de sistemas; (n) sistemas baseados em conhecimento e especialistas; e (o) integridade, segurança e tolerância a falhas. Este periódico teve sua primeira edição em Dezembro de 1989 e o seu atual Qualis, segundo a CAPES é A1, ou seja, é considerado de excelência.

Para analisar a evolução das áreas de pesquisa representadas nesse veículo de publicação, foram recuperados no portal Web of Science 2.026 artigos publicados entre 1992 e 2012 . Apesar de esse periódico ter começado a ser publicado em 1989, o portal Web of Science só 


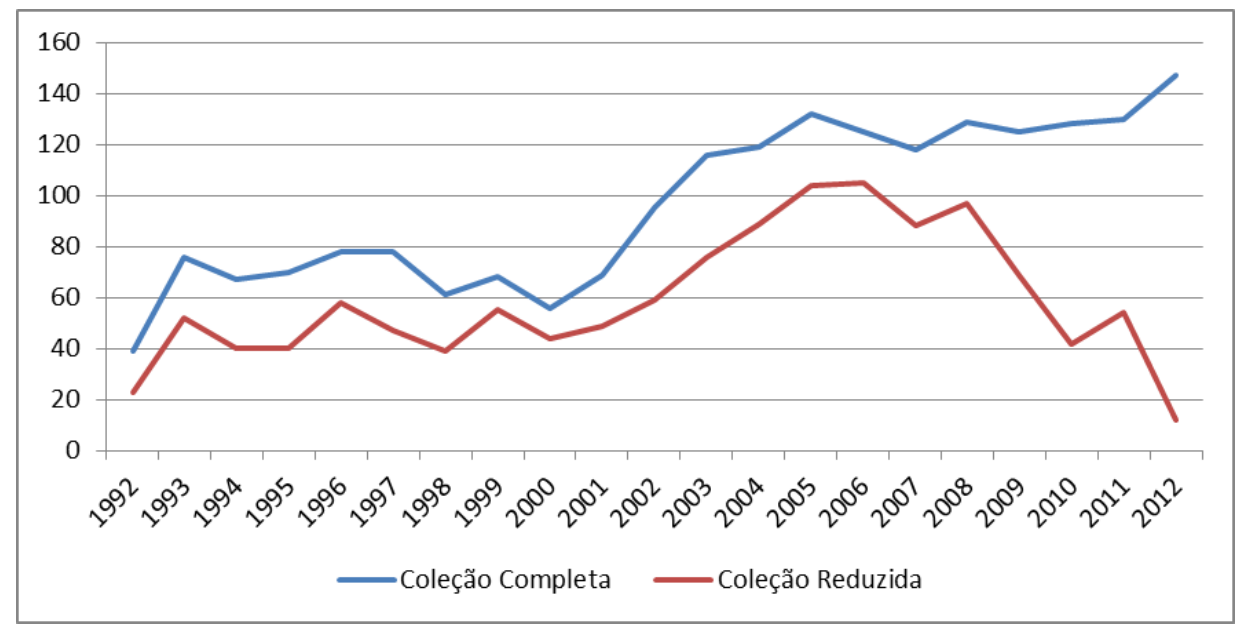

Figura 5.9: Número de artigos publicados pelo periódico TKDE.

começou a indexá-lo em 1992. Para limitar a análise somente aos artigos mais significativos, foram descartados todos os artigos publicados até 2005 com citação global - número de citações segundo o portal Thomson Reuters Web of Science - inferior ou igual a 5, os publicados entre 2006 e 2010 com citação inferior a 2 e os publicados após 2010 com citação inferior a 1. Essa ação reduziu o número de artigos de 2.026 para 1.242. A Figura 5.9 mostra o número de artigos publicados por ano para essa coleção, antes e depois da remoção dos artigos com base em sua citação. A coleção completa de artigos pulicados na TKDE encontra-se disponível em http://vicg.icmc.usp.br/ aretha/tlsp/datasets/TKDEDataset.isi.

A sequência de projeções obtida aplicando a técnica T-LSP à coleção é mostrada na Figura 5.10. A cor de cada círculo indica o ano de publicação do artigo correspondente, de acordo com a escala mostrada na Figura 5.10b. O tamanho de cada círculo é proporcional à citação global do artigo, em uma escala logarítmica. Um vídeo mostrando o mapa dinâmico completo encontra-se disponível em http://vicg.icmc.usp.br/ aretha/tlsp/examples/ TKDEDynamicMap.avi.

Por se tratar de uma coleção grande, o vocabulário associado também é proporcionalmente grande, 14.423 termos, o que tornou necessário técnicas mais complexas para extração e limpeza dos termos. Para eliminação de stopwords, utilizou-se um algoritmo de etiquetagem morfossintática (part-of-speech tagging) da biblioteca OpenNLP ${ }^{6}$, que marcou os termos com sua classe gramatical de acordo com o próprio termo e o contexto no qual ele está inserido, eliminando todos aqueles que não foram marcados como substantivo ou adjetivo. Mesmo após a remoção de stopwords pelo algoritmo de etiquetagem, ainda podem existir substantivos e adjetivos muito genéricos para a área de pesquisa representada por essa coleção como, por exemplo, 'artificial' e 'intelligence'. Por isso, também foi construída e utilizada uma lista de stopwords específica para essa coleção que contém substantivos e adjetivos que devem ser consideradas como stopwords a serem removidas. Essa lista pode ser editada pelo usuário, permitindo que ele insira seu conhecimento sobre a área. Também se empregou o stemming

${ }^{6}$ http://opennlp.apache.org 


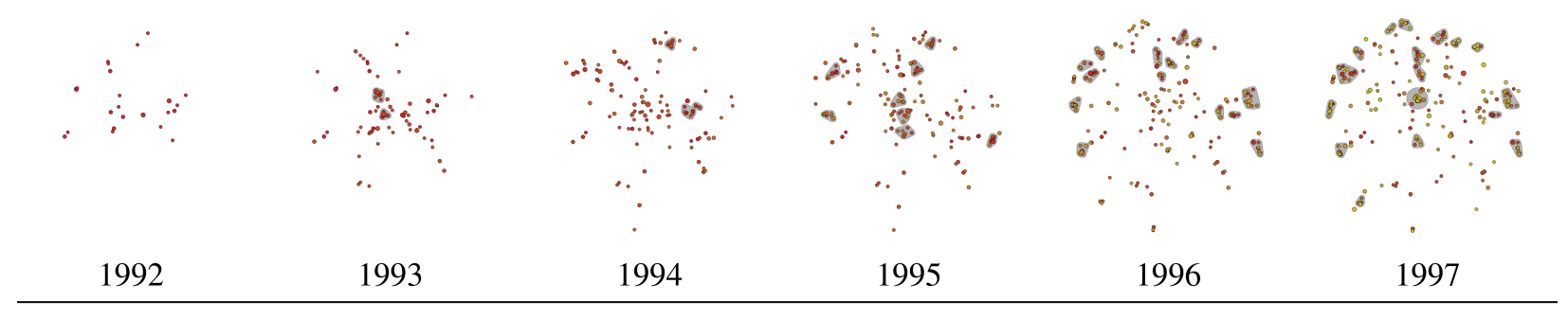
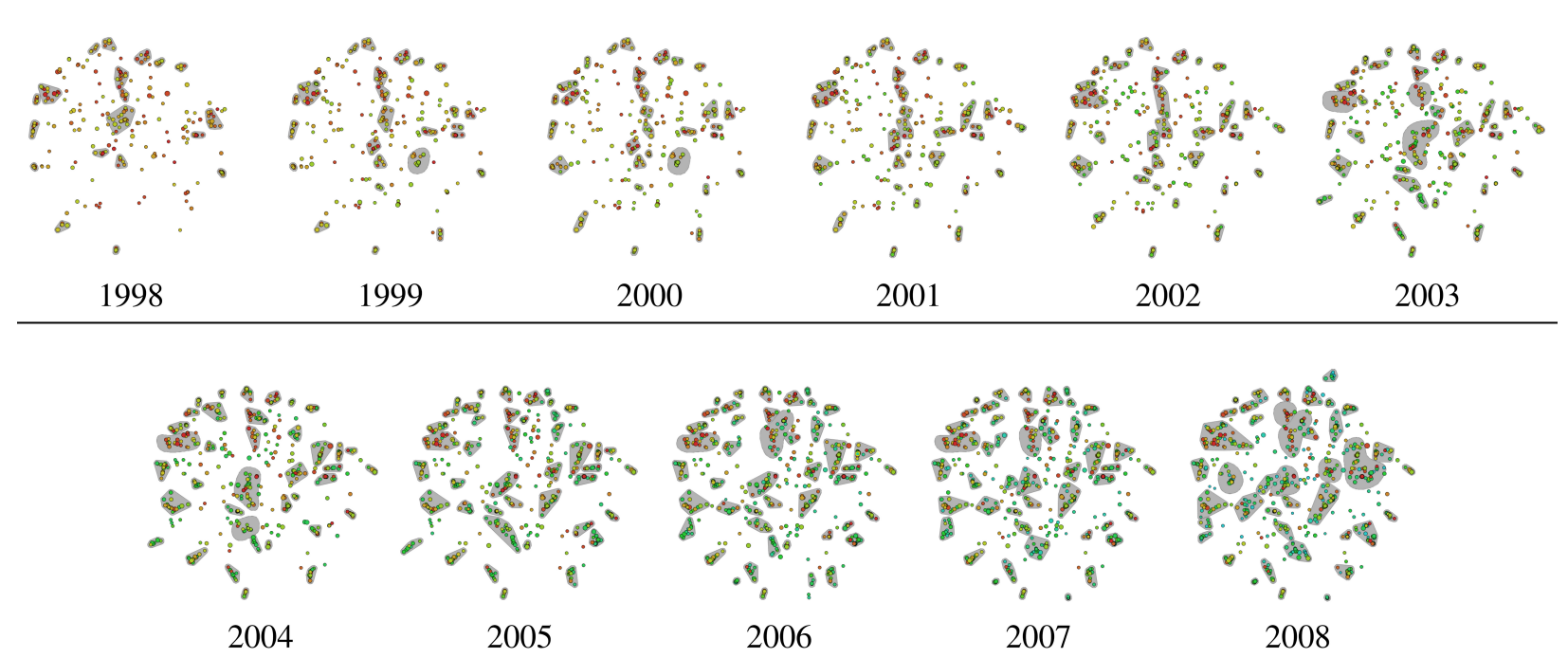

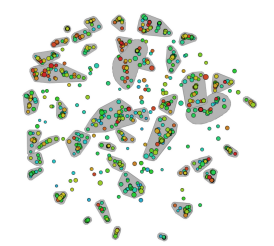

2009

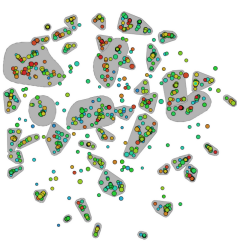

2010

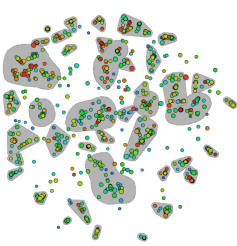

2011

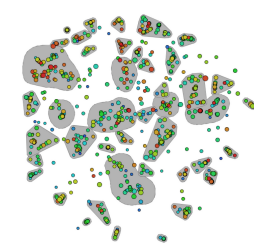

2012

(a) Sequência de projeções.

1992

(b) Legenda de cor.

Figura 5.10: Sequência de projeções obtida com a técnica T-LSP para a coleção de artigos publicados no periódico IEEE Transactions on Knowledge and Data Engineering (TKDE). Grupos identificados em cada projeção da sequência também são exibidos (áreas em cinza).

dos termos e removeram-se todos os termos com frequência inferior a 50, aplicando-se esse valor ao corte de Luhn inferior. Após essas operações, o tamanho do vocabulário foi reduzido a aproximadamente 500 termos.

Para obtenção dessa projeção dinâmica, utilizou-se o modelo probabilístico LDA, que é mais indicado para coleções grandes do que o modelo vetorial com tf-idf, com os parâmetros $T=250, \alpha=0,2, \beta=0,01$ e 2.500 iterações. Também foi aplicado um limiar ao modelo, que removeu todos os tópicos com probabilidade geral menor do que 0,012. A medida de similaridade do cosseno foi utilizada para quantificar a similaridade entre os artigos. Foram utilizados $n c=124$ pontos de controle e $k=10$ vizinhos para cada artigo nas relações de vizinhança para obter a última projeção da sequência (ano de 2012), a partir da qual é 
realizado o esquema retroativo da T-LSP. Para rastrear as transições temporais entre os grupos, empregou-se o algoritmo DBSCAN com parâmetros $\epsilon=0,033$ e MinPts $=5$ e o algoritmo $M O N I C$ com parâmetros $\tau=0,5$ e $\tau_{\text {split }}=0,3$. Utilizou-se também a técnica baseada em LDA para extração dos tópicos desses grupos, com parâmetros min_topics $=0,5$ e min_terms $=0,6$. Como o modelo LDA utilizado para gerar o mapa foi reaproveitado na extração dos tópicos, os termos dos tópicos foram reduzidos ao seu lema (stemming). Por questões de legibilidade e espaço, tópicos não são mostrados visualmente sobre os mapas na sequência de projeções, somente seus grupos.

Ao contrário da projeção dos artigos publicados por László Barabási (ver Figura 5.5), na projeção dinâmica dos artigos do periódico TKDE (ver Figura 5.10) não se percebe grandes grupos e sim vários grupos menores espaçados igualmente. Essa coleção representa uma única área de pesquisa e, portanto, existem alguns termos genéricos dessa área que aproximam os artigos de diferentes subáreas na projeção. Ao mesmo tempo, acontece uma sobreposição maior entre os artigos no layout, dando a impressão de que não existem 1.242 artigos na projeção final da sequência. Essa sobreposição maior é um efeito do modelo LDA, que inferiu uma distribuição probabilística de tópicos muito similar para os artigos sobrepostos. Interações na ferramenta Science View permitem que o usuário obtenha, por exemplo, a quantidade e uma lista de todos os artigos que compõem um grupo, auxiliando a minimizar o efeito dos problemas de sobreposição.

Novamente, analisaremos somente alguns subintervalos da sequência por restrições de espaço. O mapas referentes ao subintervalo entre 1998 e 1999 são mostrados na Figura 5.11, enquanto as transições temporais entre os grupos são mostradas na Tabela 5.3, juntamente com a taxa de sobreposição entre os grupos envolvidos em uma transição. Devido a grande quantidade de grupos e tópicos associados, somente analisaremos aqueles mais relevantes e com um número maior de artigos.

O mapa mostrado na Figura 5.11a mostra os artigos publicados até 1998. Diversos tópicos são abordados: no grupo $C_{5}$, controle de transações concorrentes em bancos de dados; no grupo $C_{9}$, programação lógica em bancos de dados dedutivos, capazes de deduzir informações adicionais a partir dos fatos e das regras de raciocínio armazenados; no grupo $C_{17}$, sistemas baseados em regras, também chamados sistemas especialistas; no $C_{18}$, processamento paralelo; no grupo $C_{19}$, integração de esquemas de bancos de dados; no grupo $C_{20}$, dois temas diferentes - redes neurais e relações de dependência em bancos de dados (funcional e entre transações); em $C_{22}$, uso de álgebra relacional em bancos de dados; em $C_{29}$, recuperação de imagens baseada em conteúdo; em $C_{24}$, bancos de dados relacionais; em $C_{26}$, sistemas de gerenciamento de bancos de dados orientados a objetos; e em $C_{30}$, otimização de consultas em bancos de dados.

No entanto, no mapa da Figura 5.11a alguns poucos grupos não possuem tópicos coerentes. O grupo $C_{27}$, por exemplo, contém 22 artigos, mas não possui nenhum tópico associado que se sobressaia. Esse grupo parece ser formado por artigos que não se encaixaram fortemente 
Tabela 5.3: Transições entre grupos para o subintervalo entre 1998-1999 do mapa dinâmico de artigos publicados no periódico TKDE.

\begin{tabular}{|ll|ll|}
\hline \multicolumn{5}{|c|}{ Transições 1998 $\rightarrow \mathbf{1 9 9 9}$} \\
\hline \hline$C_{5} \rightarrow C_{5}$ & $S\left(C_{5}, C_{5}\right)=1.0$ & $C_{25} \rightarrow C_{25}$ & $S\left(C_{25}, C_{25}\right)=1.0$ \\
\hline$C_{9} \rightarrow C_{9}$ & $S\left(C_{9}, C_{9}\right)=1.0$ & $C_{26} \rightarrow C_{26}$ & $S\left(C_{26}, C_{26}\right)=0.94$ \\
\hline$C_{15} \rightarrow C_{15}$ & $S\left(C_{15}, C_{15}\right)=1.0$ & $C_{27} \rightarrow C_{27}$ & $S\left(C_{27}, C_{27}\right)=0.59$ \\
\hline$C_{16} \rightarrow C_{16}$ & $S\left(C_{16}, C_{16}\right)=1.0$ & $C_{28} \rightarrow C_{28}$ & $S\left(C_{28}, C_{28}\right)=1.0$ \\
\hline$C_{17} \rightarrow C_{17}$ & $S\left(C_{17}, C_{17}\right)=1.0$ & $C_{29} \rightarrow C_{29}$ & $S\left(C_{29}, C_{29}\right)=1.0$ \\
\hline$C_{18} \rightarrow C_{18}$ & $S\left(C_{18}, C_{18}\right)=1.0$ & $C_{30} \rightarrow C_{30}$ & $S\left(C_{30}, C_{30}\right)=1.0$ \\
\hline$C_{19} \rightarrow C_{19}$ & $S\left(C_{19}, C_{19}\right)=1.0$ & $C_{31} \rightarrow C_{31}$ & $S\left(C_{31}, C_{31}\right)=1.0$ \\
\hline$C_{20} \rightarrow\left\{C_{32}, C_{33}\right\}$ & $S\left(C_{20}, C_{32}\right)=0.41$ & $\odot \rightarrow C_{34}$ & \\
& $S\left(C_{20}, C_{33}\right)=0.33$ & $\odot \rightarrow C_{35}$ & \\
\hline$C_{21} \rightarrow C_{21}$ & $S\left(C_{21}, C_{21}\right)=1.0$ & $\odot \rightarrow C_{36}$ \\
\hline$C_{22} \rightarrow C_{22}$ & $S\left(C_{22}, C_{22}\right)=1.0$ & $\odot \rightarrow C_{37}$ \\
\hline$C_{23} \rightarrow C_{23}$ & $S\left(C_{23}, C_{23}\right)=1.0$ & $\odot \rightarrow C_{38}$ \\
\hline$C_{24} \rightarrow C_{24}$ & $S\left(C_{24}, C_{24}\right)=1.0$ & $\odot \rightarrow C_{39}$ \\
\hline
\end{tabular}

em nenhum dos tópicos abordados pelos demais.

A Figura 5.11b inclui os artigos publicados até 1999. A maioria dos grupos sobreviveu sem grandes modificações e muitos persistiram nas mesmas posições relativas, com tópicos similares aos extraídos anteriormente. Uma exceção é o grupo $C_{20}$, que se subdividiu dando origem aos grupos $C_{32}$ e $C_{33}$. O grupo $C_{20}$ em 1998 uniu erroneamente dois temas diferentes, o que foi corrigido em 1999 por essa subdivisão. Neste ano, também surgiram 6 novos grupos, $C_{34}$ a $C_{39}$. Dois desses, $C_{34}$ e $C_{36}$, chamam a atenção por estarem relacionados a popularização da Internet nessa época. O grupo $C_{34}$ é sobre o uso de servidores para, por exemplo, recuperação de conteúdo em servidores multimídias, enquanto o grupo $C_{36}$ refere-se a aplicações relacionadas a Internet em geral, por exemplo, o fornecimento de feedback por parte do usuário sobre a relevância do conteúdo em cenários de recuperação de informações na Internet. Tópicos sobre armazenamento e mineração de dados espaciais (grupo $C_{35}$ ), sobre o gerenciamento de bancos de dados (grupo $C_{38}$ ) e sobre a mineração de textos (grupo $C_{39}$ ) também ganharam destaque em 1999. O grupo $C_{27}$, que não possuía tópicos significativos, sobreviveu, mas teve seu tamanho reduzido a 14 artigos. Parte dos artigos do grupo $C_{27}$ em 1998 foram realocados a outros grupos surgidos em 1999, $C_{35}, C_{36}$ e $C_{38}$, que representam melhor o seu conteúdo.

Os mapas do subintervalo entre 2002 e 2003 são mostrados na Figura 5.12, e as transições temporais entre os grupos desse subintervalo são mostradas na Tabela 5.4. Os artigos publicados até 2002 são apresentados na Figura 5.12a.

Uma característica interessante dessa coleção é que, mesmo passados alguns anos entre 1999 e 2002 e com 152 artigos adicionados nesse intervalo, a maioria dos grupos e seus tópicos que existiam em 1999 sobreviveram até 2002 - grupos que sobrevivem ao longo do tempo mantém o mesmo identificador. Esses tópicos sobreviveram, pois são tópicos consolidados e 


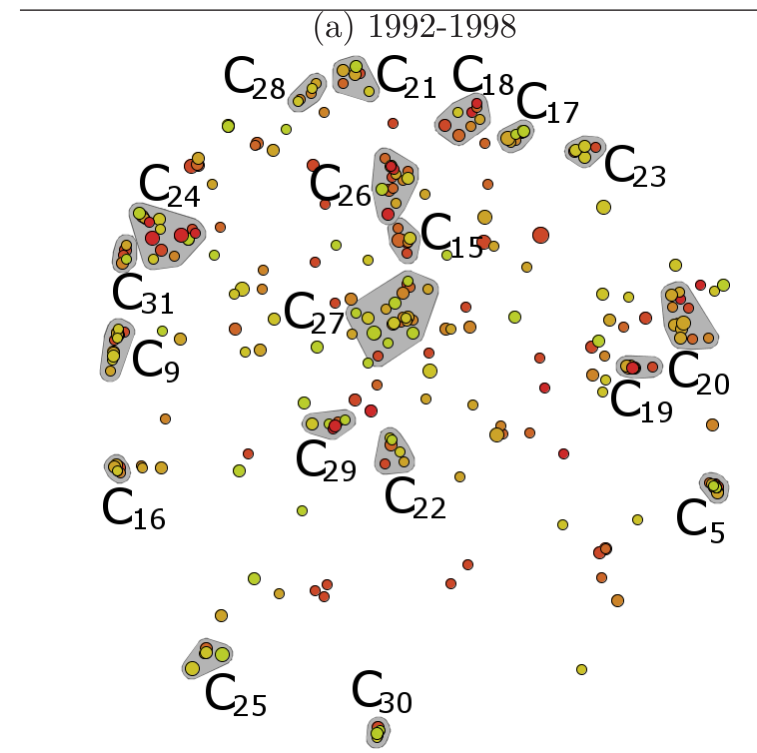

$C_{27}(22) \quad$ (local, global, distribut, processor) $[0,11]$ (spatial, queri, region, access) $[0,11]$ (tempor, event, period, interv) $[0,11]$ (manag, oper, integr, advanc)[0,09] (object-ori, complex, languag, schema) $[0,06]$ (queri, sql, relat, dbm) $[0,06]$

$C_{28}(5) \quad$ (graph, node, subgraph, match) $[0,64]$

$C_{29}$ (6) (imag, retriev, similar, contentbas) $[0,42]$ (index, search, organ, file) $[0,1]$

$C_{30}(7) \quad$ (queri, optim, semant, closur) $[0,59]$

$C_{31}(5) \quad$ (languag, queri, power, compon) $[0,59]$

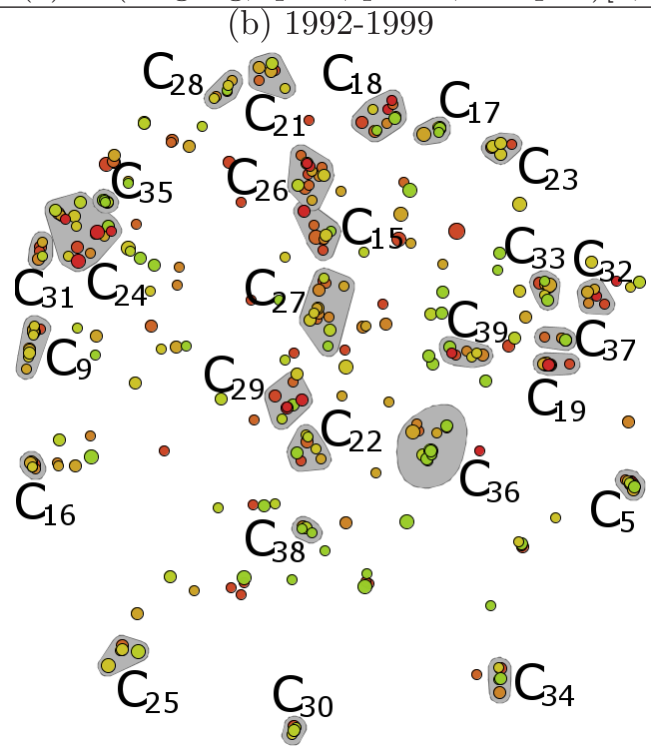

$C_{30}(7) \quad$ (queri, optim, semant, closur) $[0,59]$

$C_{31}(5) \quad$ (languag, queri, power, compon) $[0,59]$

$C_{32}(5) \quad$ (depend, function, relat, integr) $[0,49]$ (classif, term, iter, hybrid) $[0,1]$

$C_{33}(8) \quad$ (network, neural, unit, explicit) $[0,62]$

$C_{34}(5)$ (server, request, client, bandwidth) $[0,55]$

$C_{35}(7) \quad$ (spatial, queri, region, access) $[0,67]$

$C_{36}(13)$ (web, wide, world, access) $[0,48]$ (class, term, distribut, probabl) $[0,08]$

$C_{37}(5)$ (semant, concept, abstract, conceptu) $[0,57]$

$C_{38}(5) \quad$ (manag, oper, integr, advanc) $[0,53]$

$C_{39}(7) \quad$ (text, categor, document, word) $[0,54]$ \begin{tabular}{cll} 
Id (\# Docs) & Tópicos & \\
\hline$C_{5}(17)$ & (concurr, control, transact, proto-
\end{tabular} col) $[0,73]$

$C_{9}(16) \quad$ (logic, semant, reason, program) $[0,58]$

$C_{15}(7) \quad$ (queri, sql, relat, dbm) $[0,56]$

$C_{16}(6) \quad$ (queri, multipl, oper, fragment) $[0,7]$

$C_{17}(10) \quad$ (rule, rule-bas, reason, base) $[0,46]$ (parallel, processor, memori, partit) $[0,09]$

$C_{18}(8)$ (parallel, processor, memori, partit) $[0,47]$ (architectur, softwar, scalabl, integr) $[0,11]$

$C_{19}(11) \quad$ (integr, schema, activ, logic) $[0,5]$ (manag, oper, integr, advanc) [0,05]

$C_{20}(12) \quad$ (network, neural, unit, explicit) $[0,31]$ (depend, function, relat, integr) $[0,16]$ (semant, concept, abstract, conceptu) $[0,13]$

$C_{21}(6) \quad$ (rule, central, order, transit) $[0,55]$

$C_{22}(6) \quad$ (relat, algebra, oper, tupl) $[0,69]$

$C_{23}(5) \quad$ (statist, control, entiti, protect) $[0,32]$ (multidimension, space, formula, point) $[0,23]$

$C_{24}(19) \quad$ (relat, tupl, attribut, complex) $[0,34]$ (languag, queri, power, compon) $[0,11]$ (human, expert, autom, natur) [0,08]

$C_{25}(7) \quad$ (search, similar, index, distanc) $[0,55]$

$C_{26}$ (18) (object-ori, complex, languag, schema) $[0,42]$ (oper, relat, semant, support) $[0,1]$

\section{\begin{tabular}{cl} 
Id (\# Docs) & Tópicos \\
\hline$C_{5}(18)$ & (concurr, control, transact, proto-
\end{tabular} col) $[0,73]$ \\ $C_{9}(16) \quad$ (logic, semant, reason, program) $[0,58]$ \\ $C_{15}(9) \quad$ (queri, sql, relat, dbm)[0,49] (languag, queri, power, compon) $[0,19]$ \\ $C_{16}(6) \quad$ (queri, multipl, oper, fragment) $[0,7]$ \\ $C_{17}(13) \quad$ (rule, rule-bas, reason, base) $[0,47]$ (pa- rallel, processor, memori, partit) $[0,08]$ \\ $C_{18}(10)$ (parallel, processor, memori, par- tit) $[0,43]$ (architectur, softwar, scalabl, integr) $[0,17]$ \\ $C_{19}(12) \quad$ (integr, schema, activ, logic) $[0,51]$ \\ $C_{21}(6) \quad$ (rule, central, order, transit) $[0,55]$ \\ $C_{22}(7) \quad$ (relat, algebra, oper, tupl) $[0,66]$ \\ $C_{23}(5) \quad$ (statist, control, entiti, protect) $[0,32]$ (multidimension, space, formula, point) $[0,23]$}

$C_{24}(20) \quad$ (relat, tupl, attribut, complex) $[0,33]$ (human, expert, autom, natur) $[0,12]$ (languag, queri, power, compon) $[0,11]$

$C_{25}(7) \quad$ (search, similar, index, distanc) $[0,55]$

$C_{26}$ (17) (object-ori, complex, languag, schema) $[0,43]$ (oper, relat, semant, support) $[0,1]$

$C_{27}$ (14) (tempor, event, period, interv) [0,19] (index, search, organ, file) [0,1] (queri, sql, relat, dbm)[0,09] (object-ori, complex, languag, schema) $[0,07]$ (local, global, distribut, processor) $[0,07]$

$C_{28}(7) \quad$ (graph, node, subgraph, match) $[0,61]$

$C_{29}(8)$ (imag, retriev, similar, contentbas) $[0,46]$ (local, global, distribut, processor $)[0,08]$ 
em alguns casos ainda continuam a atrair o interesse dos pesquisadores. Ao mesmo tempo outros tópicos novos surgem, pois representam linhas de pesquisa que estão começando a atrair interesse. Este padrão também é perceptível nas transições de grupos entre 1998 e 1999, explicitadas na Tabela 5.3. Tal cenário é um indicativo da estabilidade dos tópicos abordados pelos artigos dessa coleção.

Comparando os tópicos entre 1999 e 2002, nota-se que os seguintes grupos que surgiram durante esse intervalo: o grupo $C_{43}$, discute sobre indexação de dados; o grupo $C_{47}$ aborda regras de associação, que, apesar de não ser um conceito muito recente, foi um assunto que começou a ser revisitado pelos autores dessa coleção; o grupo $C_{50}$ discute sobre serviços de busca na Internet; e o grupo $C_{53}$ engloba pesquisas sobre extensões para a linguagem de consulta SQL ou sobre o desenvolvimento de novas linguagens de consulta. O grupo $C_{27}$, que em 1999 não apresentava tópicos coerentes, desapareceu. Em contrapartida, um novo grupo, $C_{41}$, surgiu e que também não apresenta tópicos coerentes. Esta é uma coleção grande cujo vocabulário foi reduzido por meio de heurísticas, o que é sempre um processo imperfeito. Em geral, obter um modelo que represente precisamente todos os documentos de uma coleção é um problema muito difícil, e alguns documentos acabam não sendo bem representados.

Já a Figura 5.12b inclui os artigos publicados até 2003. Novamente, a maioria dos grupos sobreviveu sem grandes transformações e manteve as mesmas posições relativas. Os grupos $C_{22}, C_{29}$ e $C_{42}$ uniram-se para formar o grupo $C_{58}$, tornando este grupo o maior em número de artigos em 2003. Os tópicos do grupo $C_{58}$ são um combinação dos tópicos dos grupos envolvidos em sua formação. Os grupos $C_{38}$ e $C_{49}$ também sofreram uma junção que resultou no grupo $C_{59}$. Os grupos $C_{38}$ e $C_{49}$ possuíam tópicos similares e residiam próximos no layout do mapa em 2002, o que explica a sua junção. Também surgiram novos grupos, entre eles o grupo $C_{55}$ sobre análise de dados streaming e o grupo $C_{57}$ sobre ontologias e web semântica.

Por fim, a Tabela 5.5 mostra o estado final do mapa de documentos dinâmico para a coleção TKDE em 2012. Essa figura também apresenta os grupos identificados, o número de artigos em cada grupo, o ano médio de publicação dos artigos em um grupo e os tópicos extraídos. No layout do mapa, também são mostradas arestas baseadas em citações locais. A existência de um número relativamente grande dessas citações reflete uma prática comum de se citar artigos relacionados já publicados no veículo de publicação ao se escrever um artigo para o mesmo. Essas citações também não se restringem necessariamente aos grupos identificados - artigos de um grupo citam artigos de outros grupos.

O grupo $C_{26}$ é o mais antigo dentre os grupos, com seus artigos sendo publicados em média em 1997. Esse grupo aborda sistemas de gerenciamento de bancos de dados orientados a objetos. O grupo $C_{55}$, sobre a análise de dados streaming, é o mais novo com ano de publicação médio 2006 para os seus 15 artigos. Já os seguintes grupos destacam-se em tamanho: grupo $C_{95}, 52$ artigos, sobre recuperação de imagens baseada em conteúdo; grupo $C_{102}, 59$ artigos, sobre ontologias, web semântica e redes de comunicação; grupo $C_{71}, 61$ artigos, sobre aplicações relacionadas à Internet; grupo $C_{97}, 73$ artigos, sobre sistemas baseados em 


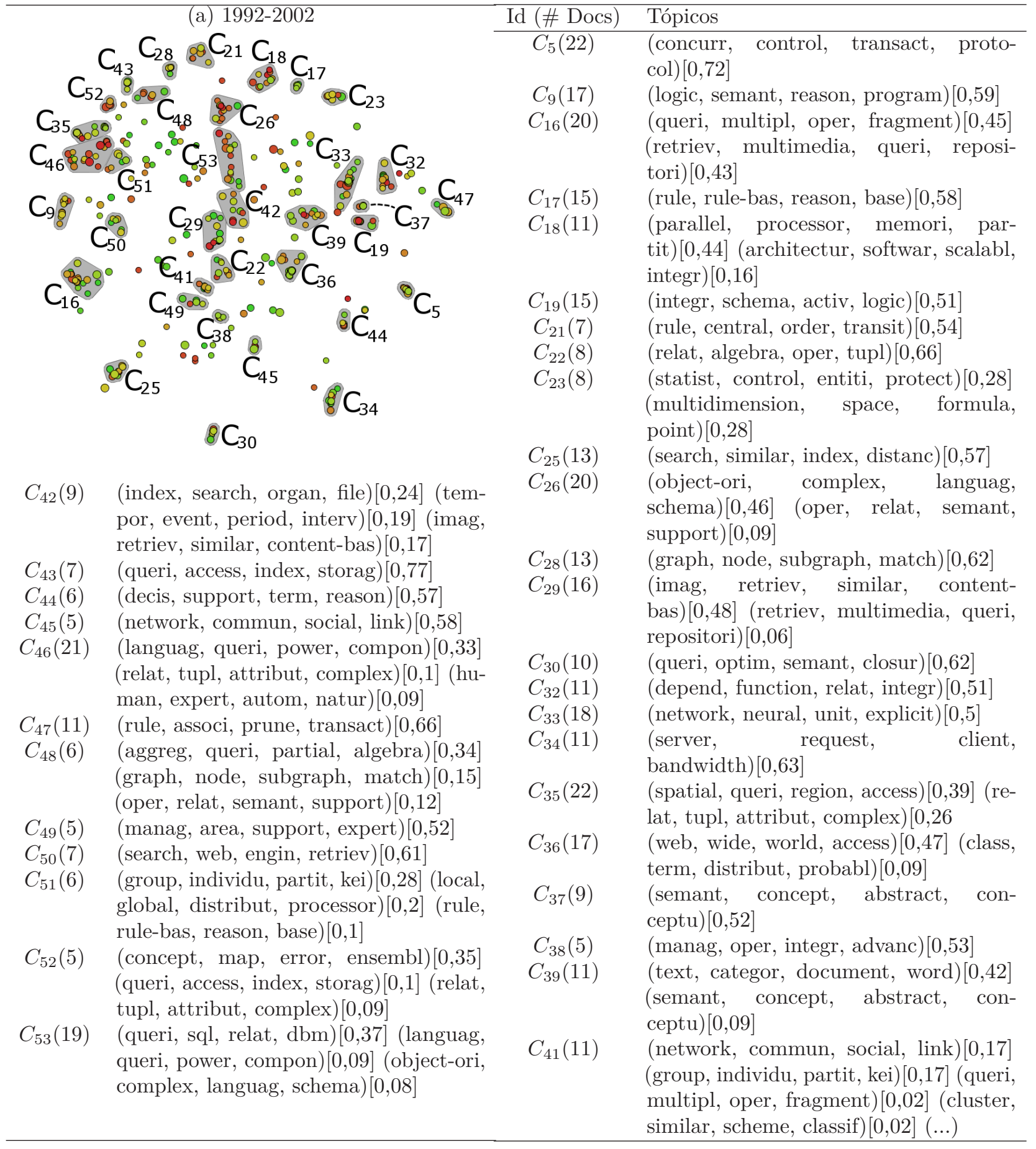

Figura 5.12: Subintervalo entre 2002-2003 do mapa dinâmico de artigos publicados no periódico TKDE.

regras e processamento paralelo; e grupo $C_{99}, 93$ artigos, sobre bases de dados e consultas espaciais e outros assuntos genéricos sobre bancos de dados relacionais.

A Figura 5.14a apresenta a série temporal que representa o stress estático para a projeção dinâmica de artigos publicados no periódico TKDE apresentada na Figura 5.10a. Apesar do stress estático estar um pouco alto nos primeiros anos, ele reduz depois de 1996, o que indica que a projeção dinâmica está se acomodando para melhor representar os dados. No 


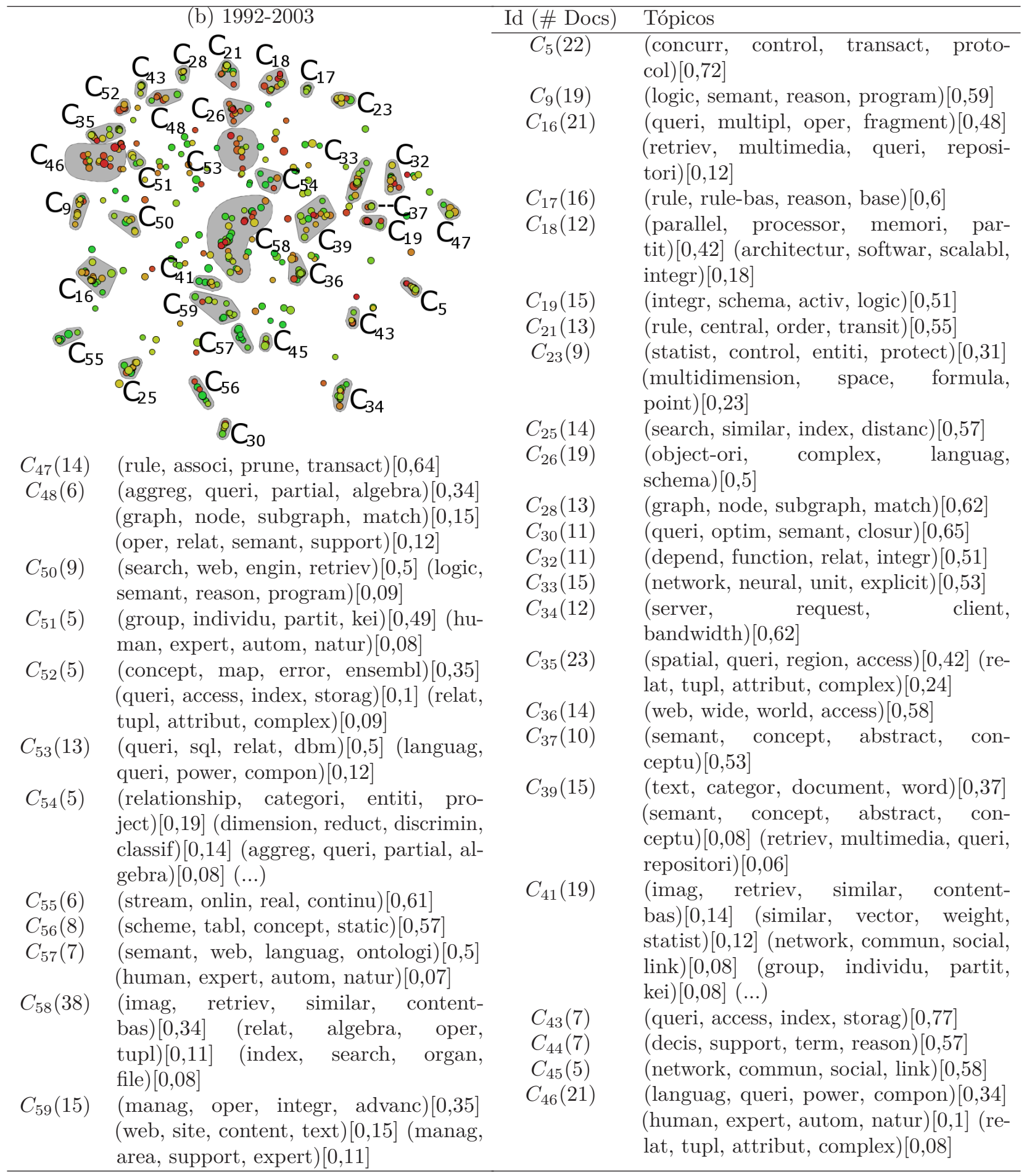

Figura 5.13: Subintervalo entre 2002-2003 do mapa dinâmico de artigos publicados no periódico TKDE (cont.).

final da série, o stress estático atinge o patamar de 0,56. Esse não é um valor muito alto, considerando o tamanho da coleção, e também não é muito distante do valor do stress estático atingido no final pela projeção dos artigos publicados por Barabási (ver Figura 5.8). Enquanto isso, a Figura 5.14b apresenta a série temporal que quantifica o stress dinâmico para a mesma sequência de projeções. Essa série apresenta alguns picos antes de 1996, que 
estão relacionados a um valor mais alto do stress estático para essa época também. Já após 1996, o stress dinâmico diminuiu consideravelmente, o que confirma uma maior estabilidade dos grupos dessa coleção, como mencionado anteriormente.

Tabela 5.4: Transições entre grupos para o subintervalo entre 2002-2003 do mapa dinâmico de artigos publicados no periódico TKDE.

\begin{tabular}{|c|c|c|c|}
\hline \multicolumn{4}{|c|}{ Transições $2002 \rightarrow 2003$} \\
\hline$C_{5} \rightarrow C_{5}$ & $S\left(C_{5}, C_{5}\right)=0.95$ & $C_{37} \rightarrow C_{37}$ & $S\left(C_{37}, C_{37}\right)=1.0$ \\
\hline$C_{9} \rightarrow C_{9}$ & $S\left(C_{9}, C_{9}\right)=1.0$ & \multirow[t]{2}{*}{$C_{38}, C_{49}$}$\stackrel{\subseteq}{\rightarrow} C_{59}$ & $S\left(C_{38}, C_{59}\right)=1.0$ \\
\hline$C_{16} \rightarrow C_{16}$ & $S\left(C_{16}, C_{16}\right)=0.95$ & & $S\left(C_{49}, C_{59}\right)=1.0$ \\
\hline$C_{17} \rightarrow C_{17}$ & $S\left(C_{17}, C_{17}\right)=1.0$ & $C_{39} \rightarrow C_{39}$ & $S\left(C_{39}, C_{39}\right)=1.0$ \\
\hline$C_{18} \rightarrow C_{18}$ & $S\left(C_{18}, C_{18}\right)=1.0$ & $C_{41} \rightarrow C_{41}$ & $S\left(C_{41}, C_{41}\right)=1.0$ \\
\hline$C_{19} \rightarrow C_{19}$ & $S\left(C_{19}, C_{19}\right)=1.0$ & $C_{43} \rightarrow C_{43}$ & $S\left(C_{43}, C_{43}\right)=1.0$ \\
\hline$C_{21} \rightarrow C_{21}$ & $S\left(C_{21}, C_{21}\right)=1.0$ & $C_{44} \rightarrow C_{44}$ & $S\left(C_{44}, C_{44}\right)=1.0$ \\
\hline$\left\{C_{22}, C_{29}, C_{42}\right\} \stackrel{S}{\rightarrow} C_{58}$ & $S\left(C_{22}, C_{58}\right)=0.93$ & $C_{45} \rightarrow C_{45}$ & $S\left(C_{45}, C_{45}\right)=1.0$ \\
\hline & $S\left(C_{29}, C_{58}\right)=0.88$ & $C_{46} \rightarrow C_{46}$ & $S\left(C_{46}, C_{46}\right)=0.95$ \\
\hline & $S\left(C_{42}, C_{58}\right)=0.87$ & $C_{47} \rightarrow C_{47}$ & $S\left(C_{47}, C_{47}\right)=1.0$ \\
\hline$C_{23} \rightarrow C_{23}$ & $S\left(C_{23}, C_{23}\right)=1.0$ & $C_{48} \rightarrow C_{48}$ & $S\left(C_{48}, C_{48}\right)=1.0$ \\
\hline$C_{25} \rightarrow C_{25}$ & $S\left(C_{25}, C_{25}\right)=1.0$ & $C_{50} \rightarrow C_{50}$ & $S\left(C_{50}, C_{50}\right)=1.0$ \\
\hline$C_{26} \rightarrow C_{26}$ & $S\left(C_{26}, C_{26}\right)=0.9$ & $C_{51} \rightarrow C_{51}$ & $S\left(C_{51}, C_{51}\right)=0.83$ \\
\hline$C_{28} \rightarrow C_{28}$ & $S\left(C_{28}, C_{28}\right)=1.0$ & $C_{52} \rightarrow C_{52}$ & $S\left(C_{52}, C_{52}\right)=1.0$ \\
\hline$C_{30} \rightarrow C_{30}$ & $S\left(C_{30}, C_{30}\right)=1.0$ & $C_{53} \rightarrow C_{53}$ & $S\left(C_{53}, C_{53}\right)=0.68$ \\
\hline$C_{32} \rightarrow C_{32}$ & $S\left(C_{32}, C_{32}\right)=1.0$ & $\odot \rightarrow C_{54}$ & \\
\hline$C_{33} \rightarrow C_{33}$ & $S\left(C_{33}, C_{33}\right)=0.83$ & $\odot \rightarrow C_{55}$ & \\
\hline$C_{34} \rightarrow C_{34}$ & $S\left(C_{34}, C_{34}\right)=1.0$ & $\odot \rightarrow C_{56}$ & \\
\hline$C_{35} \rightarrow C_{35}$ & $S\left(C_{35}, C_{35}\right)=1.0$ & $\odot \rightarrow C_{57}$ & \\
\hline$C_{36} \rightarrow C_{36}$ & $S\left(C_{36}, C_{36}\right)=0.70$ & & \\
\hline
\end{tabular}

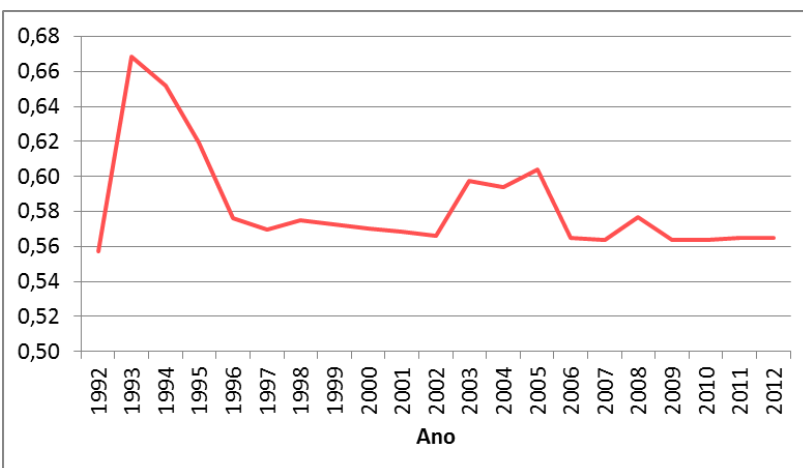

(a) Stress estático.

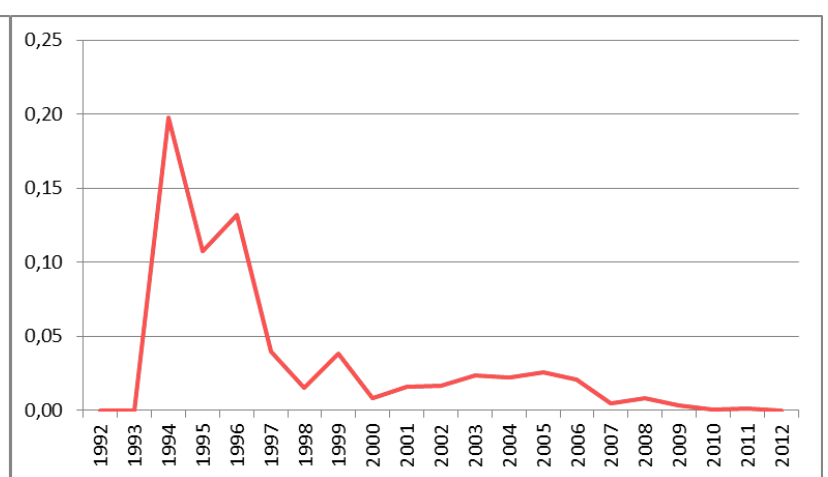

(b) Stress dinâmico.

Figura 5.14: Stress estático e stress dinâmico para a projeção dinâmica da coleção de artigos publicados no periódico TKDE mostrada na Figura 5.10a. 
Tabela 5.5: Estado final do mapa de documentos dinâmico para artigos publicados no periódico TKDE até 2012 .

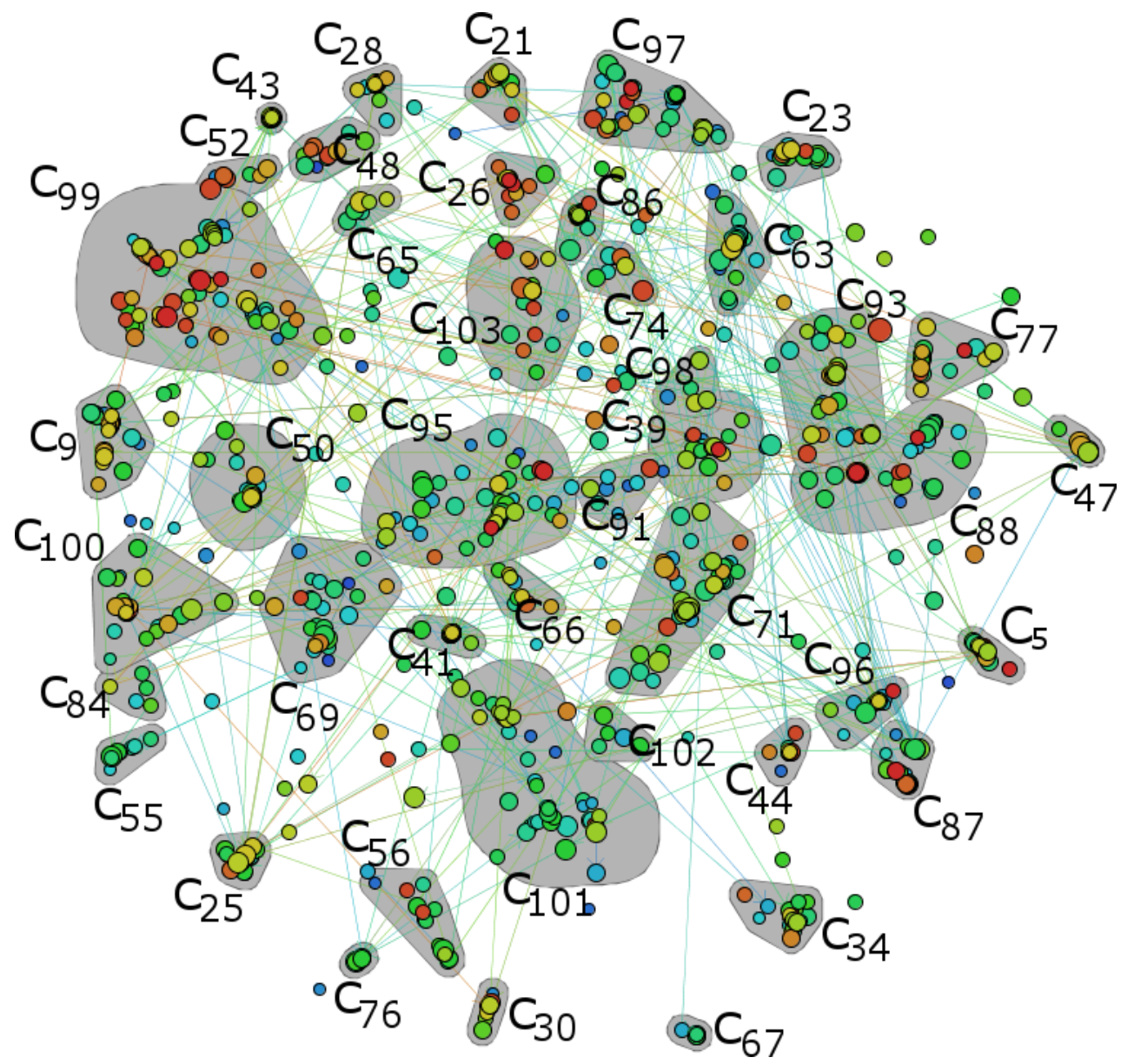

\begin{tabular}{|c|c|c|}
\hline Id (\# Docs) & $\begin{array}{l}\text { Média do ano } \\
\text { de publicação }\end{array}$ & Tópicos \\
\hline$C_{5}(28)$ & 1998 & (concurr, control, transact, protocol) $[0,71]$ \\
\hline$C_{9}(35)$ & 2001 & $\begin{array}{l}\text { (logic, semant, reason, program) }[0,41] \text { (dimens, dimension, high- } \\
\text { dimension, reduct) }[0,16]\end{array}$ \\
\hline$C_{21}(15)$ & 2000 & (rule, central, order, transit) $[0,54]$ \\
\hline$C_{23}(17)$ & 2003 & $\begin{array}{l}\text { (statist, control, entiti, protect) }[0,31] \text { (multidimension, space, formula, } \\
\text { point) }[0,29]\end{array}$ \\
\hline$C_{25}(33)$ & 2003 & (search, similar, index, distanc) $[0,58]$ \\
\hline$C_{26}(20)$ & 1997 & (object-ori, complex, languag, schema) $[0,5]$ \\
\hline$C_{28}(25)$ & 2003 & (graph, node, subgraph, match) $[0,63]$ \\
\hline$C_{30}(14)$ & 2000 & (queri, optim, semant, closur) $[0,64]$ \\
\hline$C_{34}(22)$ & 2002 & (server, request, client, bandwidth) $[0,54]$ \\
\hline$C_{39}(31)$ & 2003 & $\begin{array}{l}\text { (text, categor, document, word) }[0,45] \text { (semant, concept, abstract, } \\
\text { conceptu) }[0,05]\end{array}$ \\
\hline$C_{41}(38)$ & 2003 & $\begin{array}{l}\text { (imag, retriev, similar, content-bas) }[0,12] \text { (network, commun, social, } \\
\text { link) }[0,07] \text { (group, individu, partit, kei) }[0,07] \text { (search, similar, index, } \\
\text { distanc) }[0,05] \text { (classif, classifi, class, benchmark) }[0,04] \text { (queri, multipl, } \\
\text { oper, fragment) }[0,02] \text { (updat, oper, mainten, view) }[0,02] \text { (...) }\end{array}$ \\
\hline$C_{43}(13)$ & 2002 & (queri, access, index, storag) $[0,68]$ \\
\hline$C_{44}(17)$ & 2002 & (decis, support, term, reason) $[0,5]$ (tree, hierarch, match, node) $[0,06]$ \\
\hline$C_{47}(26)$ & 2003 & (rule, associ, prune, transact) $[0,67]$ \\
\hline
\end{tabular}


Tabela 5.5: Estado final do mapa de documentos dinâmico para artigos publicados no periódico TKDE até 2012 (cont.).

\begin{tabular}{|c|c|c|}
\hline Id (\# Docs) & $\begin{array}{l}\text { Média do ano } \\
\text { de publicação }\end{array}$ & Tópicos \\
\hline$C_{48}(12)$ & 2002 & $\begin{array}{l}\text { (aggreg, queri, partial, algebra) }[0,42] \text { (graph, node, subgraph, } \\
\text { match) }[0,1]\end{array}$ \\
\hline$C_{50}(24)$ & 2004 & (search, web, engin, retriev) $[0,64]$ \\
\hline$C_{52}(8)$ & 1999 & $\begin{array}{l}\text { (concept, map, error, ensembl) }[0,37] \text { (queri, access, index, storag) }[0,12] \\
\text { (spatial, queri, region, access) }[0,06]\end{array}$ \\
\hline$C_{55}(15)$ & 2006 & (stream, onlin, real, continu) $[0,58]$ \\
\hline$C_{56}(19)$ & 2004 & (scheme, tabl, concept, static) $[0,51]$ \\
\hline$C_{63}(31)$ & 2005 & (classif, classifi, class, benchmark) $[0,51]$ \\
\hline$C_{65}(20)$ & 2003 & (index, search, organ, file) $[0,53]$ \\
\hline$C_{66}(10)$ & 2001 & (relat, algebra, oper, tupl) $[0,6]$ \\
\hline$C_{67}(11)$ & 2005 & (cluster, subspac, high-dimension, real) $[0,68]$ \\
\hline$C_{69}(32)$ & 2005 & $\begin{array}{l}\text { (cluster, similar, scheme, classif) }[0,41] \text { (partit, loss, candid, heu- } \\
\text { rist) }[0,04] \text { (semant, web, languag, ontologi) }[0,04] \text { (imag, retriev, similar, } \\
\text { content-bas) }[0,03]\end{array}$ \\
\hline$C_{71}(61)$ & 2003 & $\begin{array}{l}\text { (web, wide, world, access) }[0,26] \text { (tempor, event, period, interv) }[0,16] \\
\text { (class, term, distribut, probabl) }[0,06] \text { (complex, multipl, large-scal, } \\
\text { real) }[0,04]\end{array}$ \\
\hline$C_{74}(7)$ & 2002 & (oper, relat, semant, support) $[0,53]$ \\
\hline$C_{76}(12)$ & 2005 & (web, site, content, text) $[0,64]$ \\
\hline$C_{77}(23)$ & 2002 & $\begin{array}{l}\text { (depend, function, relat, integr) }[0,38] \text { (updat, oper, mainten, } \\
\text { view) }[0,15]\end{array}$ \\
\hline$C_{84}(5)$ & 2002 & $\begin{array}{l}\text { (queri, multipl, oper, fragment) }[0,35] \text { (search, similar, index, dis- } \\
\text { tanc) }[0,17]\end{array}$ \\
\hline$C_{86}(28)$ & 2005 & (decis, tree, classif, induct) $[0,63]$ \\
\hline$C_{87}(47)$ & 2005 & $\begin{array}{l}\text { (classif, class, label, predict, classifi) }[0,38] \text { (tree, hierarch, match, } \\
\text { node) }[0,21]\end{array}$ \\
\hline$C_{88}(44)$ & 2002 & $\begin{array}{l}\text { (integr, schema, activ, logic) }[0,28] \text { (network, peer-to-p, peer, com- } \\
\text { mun) }[0,22] \text { (classif, term, iter, hybrid) }[0,07]\end{array}$ \\
\hline$C_{91}(8)$ & 2003 & $\begin{array}{l}\text { (text, categor, document, word) }[0,34] \text { (cluster, similar, scheme, } \\
\text { classif) }[0,17]\end{array}$ \\
\hline$C_{93}(35)$ & 2000 & $\begin{array}{l}\text { (network, neural, unit, explicit) }[0,31] \text { (semant, concept, abstract, } \\
\text { conceptu) }[0,15] \text { (rule, central, order, transit) }[0,05]\end{array}$ \\
\hline$C_{95}(52)$ & 2003 & $\begin{array}{l}\text { (imag, retriev, similar, content-bas) }[0,44] \text { (similar, vector, weight, } \\
\text { statist) }[0,09]\end{array}$ \\
\hline$C_{96}(17)$ & 2004 & $\begin{array}{l}\text { (dynam, program, optim, seri) }[0,43] \text { (manag, area, support, ex- } \\
\text { pert) }[0,06] \text { (server, request, client, bandwidth) }[0,05]\end{array}$ \\
\hline$C_{97}(73)$ & 2003 & $\begin{array}{l}\text { (rule, rule-bas, reason, base) }[0,17] \text { (dimension, reduct, discrimin, } \\
\text { classif) }[0,17] \text { (sequenti, sequenc, frequent, variant) }[0,14] \text { (parallel, } \\
\text { processor, memori, partit) }[0,09]\end{array}$ \\
\hline$C_{98}(5)$ & 2002 & $\begin{array}{l}\text { (relationship, categori, entiti, project) }[0,32] \text { (semant, concept, abstract, } \\
\text { conceptu) }[0,11] \text { (oper, relat, semant, support) }[0,1]\end{array}$ \\
\hline$C_{99}(93)$ & 2001 & $\begin{array}{l}\text { (spatial, queri, region, access) }[0,2] \text { (relat, tupl, attribut, complex) }[0,14] \\
\text { (languag, queri, power, compon) }[0,11] \text { (human, expert, autom, na- } \\
\text { tur) }[0,06]\end{array}$ \\
\hline
\end{tabular}


Tabela 5.5: Estado final do mapa de documentos dinâmico para artigos publicados no periódico TKDE até 2012 (cont.).

\begin{tabular}{ccl}
\hline Id (\# Docs) & $\begin{array}{c}\text { Média do ano } \\
\text { de publicação }\end{array}$ & Tópicos \\
\hline$C_{100}(39)$ & 2002 & $\begin{array}{l}\text { (queri, multipl, oper, fragment) }[0,43] \text { (retriev, multimedia, queri, } \\
\text { repositori) }[0,15]\end{array}$ \\
\hline$C_{101}(59)$ & 2004 & $\begin{array}{l}\text { (semant, web, languag, ontologi) }[0,27] \text { (network, commun, social, } \\
\text { link) }[0,13] \text { (manag, oper, integr, advanc) }[0,13]\end{array}$ \\
\hline$C_{102}(5)$ & 2004 & $\begin{array}{l}\text { (web, wide, world, access) [0,16] (web, site, content, text)[0,14] (text, } \\
\text { categor, document, word) }[0,1] \text { (network, commun, social, link) }[0,1]\end{array}$ \\
\hline$C_{103}(21)$ & 1999 & $\begin{array}{l}\text { (queri, sql, relat, dbm) }[0,42] \text { (languag, queri, power, compon) }[0,08] \\
\text { (partit, loss, candid, heurist) }[0,06]\end{array}$ \\
\hline
\end{tabular}

\subsubsection{Evolução de uma Área de Pesquisa: Layer-by-layer (LbL)}

O método Layer-by-layer (LbL) (Decher, 1997) é uma das principais escolhas para a fabricação de filmes ultrafinos (nanômetros de espessura) por ser simples e de baixo custo. Esse método pode ser aplicado uma grande diversidade de materiais como metais, cerâmicas, nanopartículas e moléculas biológicas. Essas características motivaram pesquisadores a empregá-lo em várias aplicações como eletrocromismo, catálise, eletroquímica de sensoriamento e biosensoriamento. Com o objetivo de analisar a área de pesquisa formada por estudos, métodos relacionados e aplicações do método LbL, uma coleção com 6.159 artigos relacionados a esse método, publicados entre 1991 e 2010, foi criada pelo criador desta técnica, o Prof. Gero Decher, professor de química na Universidade Louis Pasteur em Strasbourg, França, e pelo seu grupo de pesquisa. Essa coleção está no formato Endnote Export Format, que é suportado pela ferramenta Science View, e foi cedida pelo Prof. Decher para este trabalho.

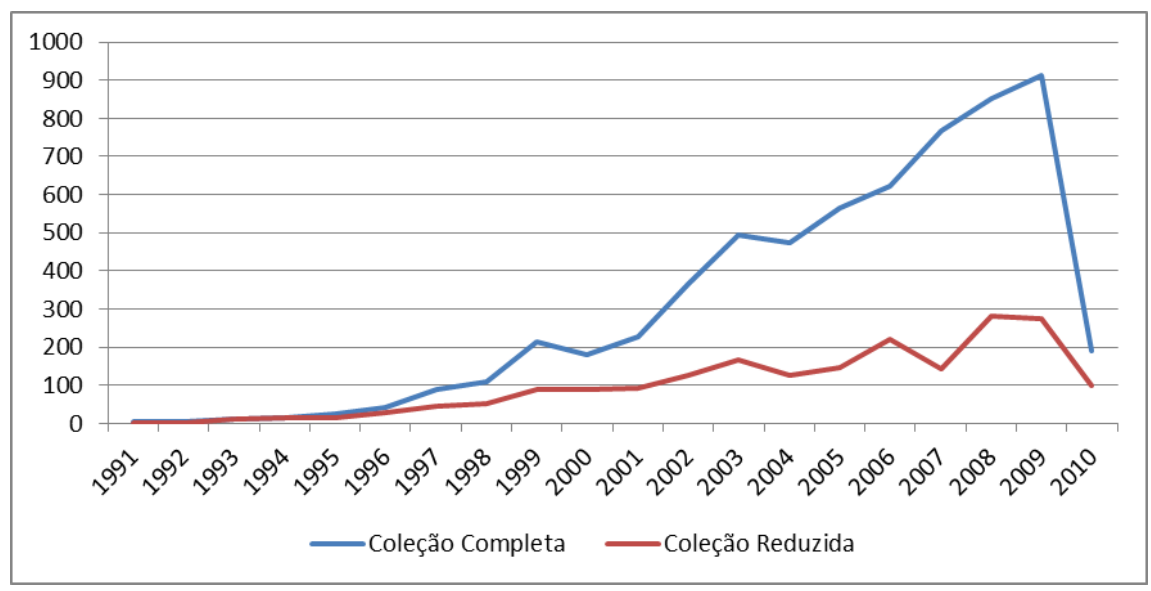

Figura 5.15: Número de artigos publicados para a coleção LbL.

Para limitar a análise somente aos artigos mais significativos, foram descartados todos os artigos publicados até 2005 com citação global inferior ou igual a 30, os publicados entre 2006 e 2007 com citação inferior ou igual a 15, os publicados em 2008 com citação 
inferior ou igual a 5 e os publicados em 2009 com citação inferior ou igual a 1. Para os artigos publicados em 2010, todos com citação global igual a zero, foram mantidos 100 artigos escolhidos aleatoriamente. Essa ação reduziu o número de artigos de 6.159 para 2.019. A Figura 5.15 mostra o número de artigos publicados por ano para essa coleção, antes e depois da remoção dos artigos. A coleção LbL completa encontra-se disponível em http://vicg.icmc. usp.br/ aretha/tlsp/datasets/LbLDataset .enw.

A sequência de projeções obtida aplicando a técnica T-LSP a esta coleção de artigos é mostrada na Figura 5.16. A cor de cada círculo indica o ano de publicação do artigo correspondente, de acordo com a escala mostrada na Figura 5.16b. Um vídeo mostrando o mapa dinâmico completo para essa coleção encontra-se disponível em http: //vicg.icmc.usp.br/ aretha/tlsp/examples/LbLDynamicMap.avi.

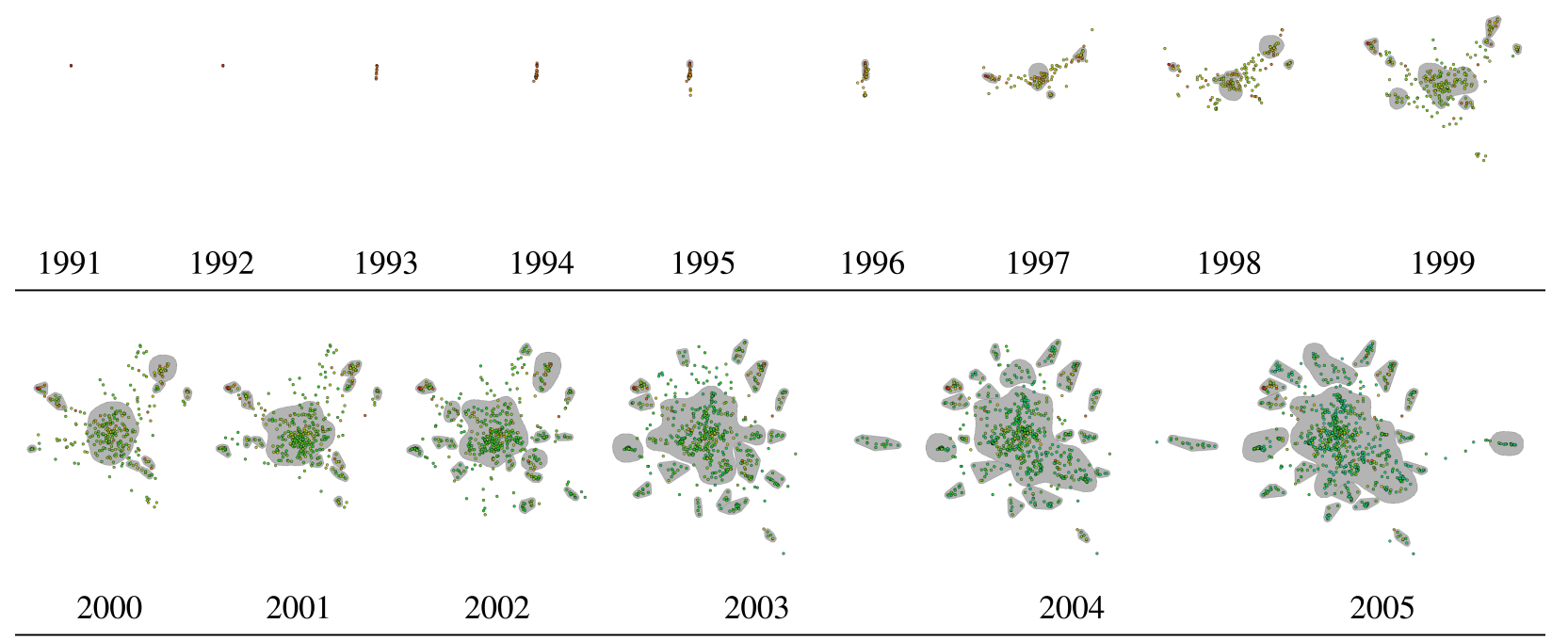

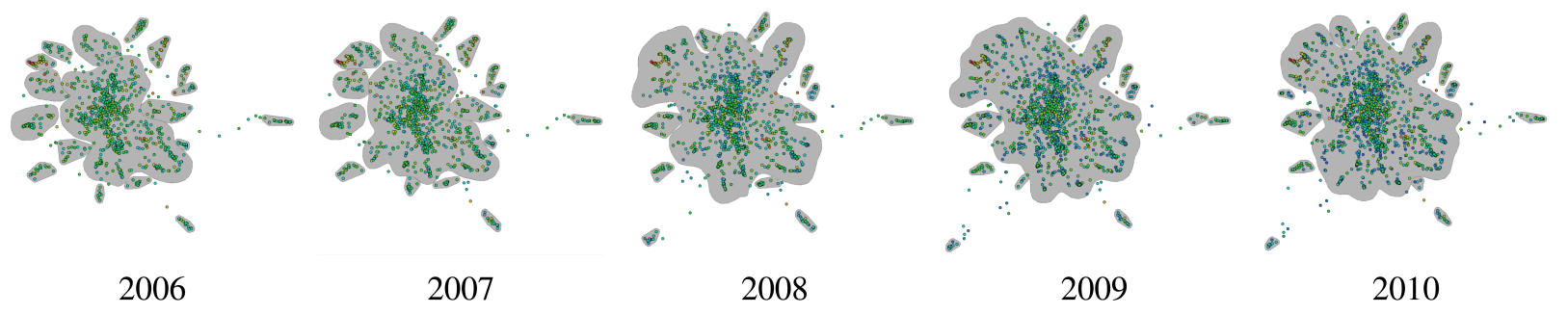

(a) Sequência de projeções.

1992

(b) Legenda de cor.

Figura 5.16: Sequência de projeções obtida com a técnica T-LSP para a coleção Layer-bylayer (LbL). Grupos encontrados para cada projeção da sequência também são exibidos.

Para eliminação de stopwords utilizou-se um algoritmo de etiquetagem morfossintática, eliminando-se todos aqueles que não foram marcados como substantivo ou adjetivo. Também se empregou o stemming dos termos e todos os termos com frequência inferior a 50 ou superior a 2.000 foram removidos. Assim como na coleção TKDE, também foi construída e utilizada uma lista de stopwords específica para a coleção LbL, que é aplicada após a 
remoção de stopwords pelo algoritmo de etiquetagem. O tamanho do vocabulário foi reduzido a aproximadamente 1.400 termos com essas operações. Após a definição do vocabulário, empregou-se o modelo probabilístico LDA com os parâmetros $T=350, \alpha=0,16, \beta=0,01 \mathrm{e}$ 3.000 iterações. Também foi aplicado um limiar nesse modelo probabilístico, que removeu do modelo todos os tópicos com probabilidade geral menor que 0,01, e a medida de similaridade do cosseno foi utilizada para quantificar a similaridade. Foram utilizados $n c=50$ pontos de controle e $k=15$ vizinhos para cada artigo nas relações de vizinhança para obter a última projeção da sequência (ano de 2010). Para rastrear as transições temporais entre os grupos, empregou-se o algoritmo DBSCAN com parâmetros $\epsilon=0,035$ e MinPts $=5$ e o algoritmo MONIC com parâmetros $\tau=0,5$ e $\tau_{\text {split }}=0,3$. Utilizou-se também a técnica baseada em LDA para extração dos tópicos desses grupos, com parâmetros min_topics $=0,5$ e min_terms $=0,6$.

A Tabela 5.6 mostra o mapa de documentos dinâmico final para a coleção LbL em 2010. Essa figura também apresenta os grupos identificados no mapa, o número de artigos em cada grupo, o ano médio de publicação desses artigos e os tópicos extraídos e seus pesos. Como é possível observar, o mapa dinâmico é formado por um grande grupo de artigos no centro cercado por grupos menores na borda - um padrão que se repete em todos os instantes do mapa. Os tópicos extraídos também não são muito coesos, principalmente os tópicos do grupo $C_{67}$ que é composto por 1.670 artigos. Essa coleção é muito focada, pois é formada por documentos de uma subárea de pesquisa muito específica, o que em parte explica esse comportamento do mapa dinâmico.

A qualidade da projeção T-LSP devido ao seu esquema retroativo é suscetível a qualidade da última projeção da sequência, que contém todos os documentos da coleção e essa última projeção é simplesmente a projeção LSP aplicada em sua forma pura. Se não se formarem grupos de documentos similares nessa última projeção, também não existirão grupos nas projeções anteriores. Isto impossibilita o rastreamento das transições temporais entre os grupos, o que implica na ausência de eventos claros de transição. Dessa forma, também podemos ter um cenário no qual a LSP não conseguiu diferenciar os artigos de modo a exibir grupos bem identificáveis. A escolha da LSP para servir de base para a T-LSP foi motivada principalmente pela LSP obter geralmente bons resultados quando aplicada a coleções de documentos e buscar preservar as vizinhanças locais (favorecer a formação de grupos), o que não significa que a LSP é sempre a técnica adequada para todos os casos. A questão é que não existe uma projeção que será a ideal em absolutamente todos os casos, sempre existirão exceções.

Outro fator que pode ter contribuído é o modelo de representação não ter conseguido representar adequadamente a coleção, o que influencia diretamente na qualidade da projeção. Nem sempre é trivial obter representações para coleções de documentos e definir quais termos são relevantes, especialmente em coleções com mais de 1.000 documentos que possuem um vasto vocabulário. Mesmo modelos mais complexos, como o modelo probabilístico LDA, são 
limitados em cenários como esse. Esta é uma dificuldade que ocorre não somente nos mapas dinâmicos apresentados neste trabalho, mas em mapas de documentos em geral, sejam eles gerados por projeções multidimensionais ou não.

Tabela 5.6: Estado final do mapa de documentos dinâmico para artigos da coleção LbL até 2010 .

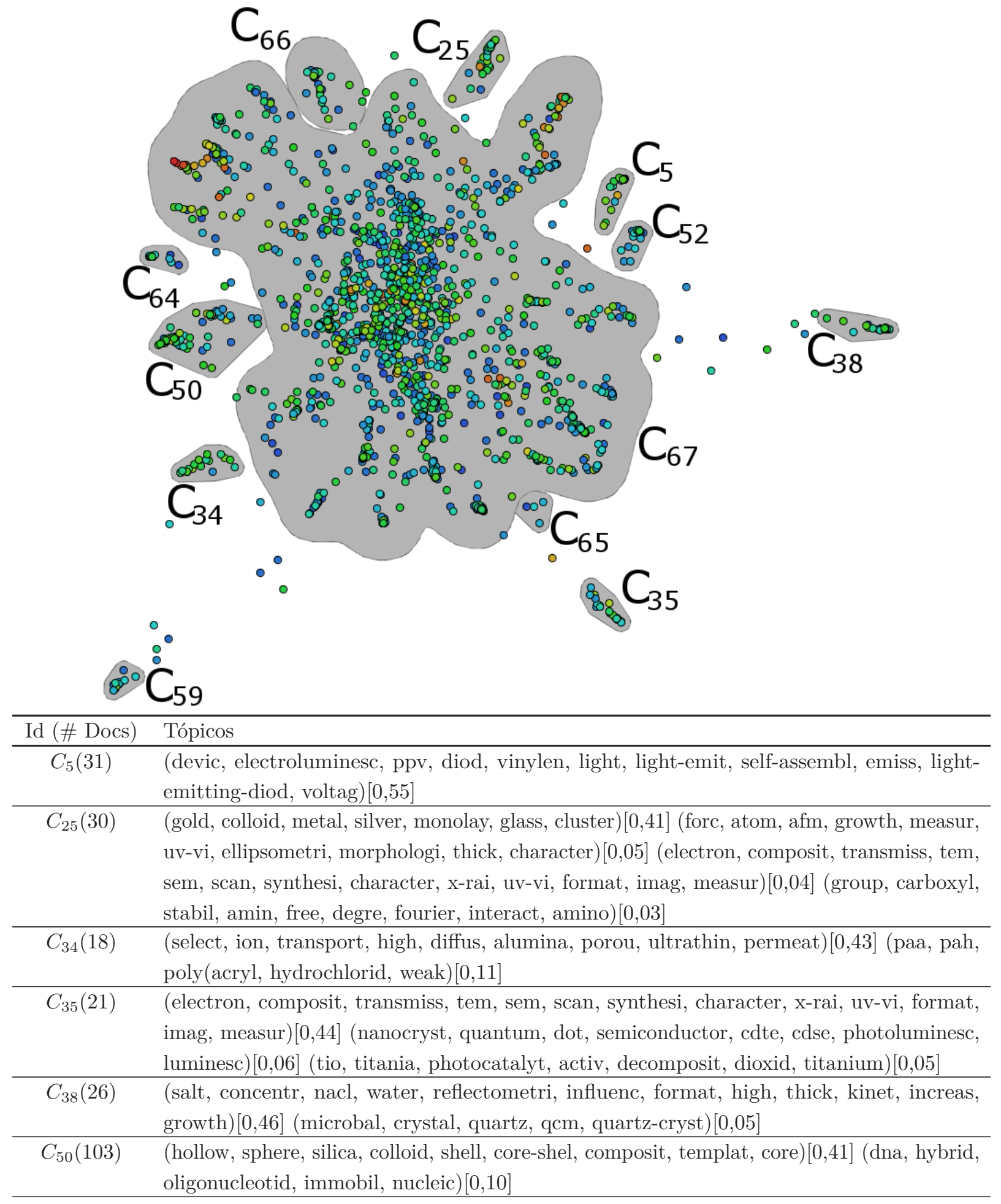


Tabela 5.6: Estado final do mapa de documentos dinâmico para artigos da coleção LbL até 2010 (cont.).

\begin{tabular}{cl}
\hline Id (\# Docs) & Tópicos \\
\hline$C_{52}(22)$ & (direct, transfer, electron, protein, hemoglobin, cytochrom, gold, electrochemistri, electron- \\
& transf, rate)[0,45] (electrocatalyt, reduct, carbon, hydrogen, cyclic, activ, electrochem, \\
& peroxid, voltammetri, glassi, oxid, monolay)[0,08] \\
\hline$C_{59}(12)$ & (reduct, platinum, oxygen, oxid, catalyt, activ, gold, catalyst, electron, aunp) [0,05] \\
\hline$C_{64}(22)$ & (growth, diffus, exponenti, step, thick, construct, linear, chain, mechan, increas) [0,46] \\
& (microbal, crystal, quartz, qcm, quartz-cryst)[0,05] \\
\hline$C_{65}(5)$ & (electron, composit, transmiss, tem, sem, scan, synthesi, character, x-rai, uv-vi, format, \\
& imag, measur)[0,33] (glass, treatment, respons, compound, fast, attract, pack, slide)[0,11] \\
& (scan, confoc, microcapsul, laser, forc, hollow, electron, permeabl, shell, clsm)[0,09] \\
\hline$C_{66}(26)$ & (photocurr, photovolta, electron, photoelectrochem, charg, convers, devic, gener, energi, \\
& separ, transfer, solar-cel, hybrid, photoinduc, electron-transf, fulleren, acceptor)[0,41] \\
& (forc, atom, afm, growth, measur, uv-vi, ellipsometri, morphologi, thick, character)[0,05] \\
& (nanotub, carbon, swnt, single-wal) [0,04] (altern, polyc, ultrathin, linear, polyanion, \\
& polyion, cation, growth, molecular, poly(allylamin, anion, assembli, complex)[0,03] \\
\hline & (system, potenti, rang, biomed, control, design, function, chemic, biolog, drug, wide, year, \\
& mechan, chemistri, featur, interfac, area, devic, format, interest, direct, futur, scienc, \\
& articl, strategi, field, polymer, type, larg, signific, kei, synthet, combin, physic, characterist, \\
& prepar, by-lay, character, versatil)[0,06] (biosensor, detect, amperometr, electrochem, \\
& respons, sensit, limit, gold, linear, immobil, rang, sensor, enzym, potenti, stabil) [0,03](...) \\
\hline$C_{67}(1.670$
\end{tabular}

A Figura 5.17a apresenta o stress estático para a projeção dinâmica da coleção LbL mostrada na Figura 5.16. O stress estático para essa coleção é o mais alto quando comparado ao stress estático das outras coleções apresentadas anteriormente. No entanto, como os valores do stress estático não se situam extremamente perto do valor 1, o mapa dinâmico aparentemente capturou de fato alguns dos padrões presentes nos dados. Por sua vez, a Figura 5.17b apresenta a série temporal que quantifica o stress dinâmico para a mesma sequência de projeções. O pico mais alto dessa série situa-se perto de 1997, que é data da

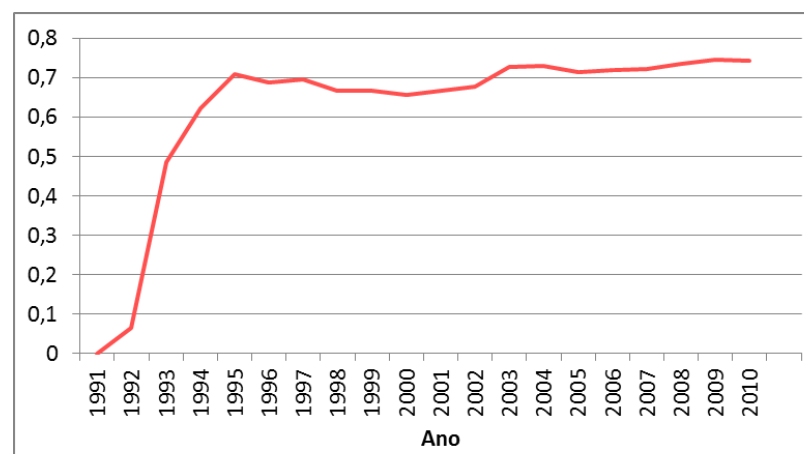

(a) Stress estático.

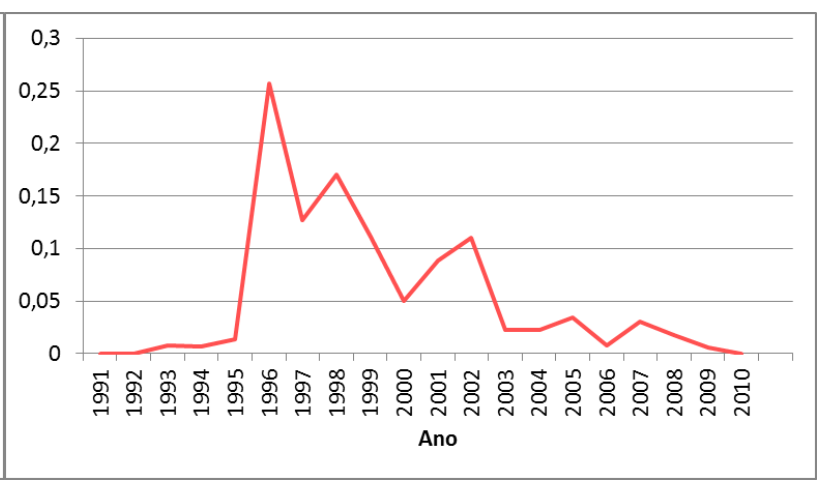

(b) Stress dinâmico.

Figura 5.17: Stress estático e stress dinâmico para a projeção dinâmica da coleção de artigos Layer-by-layer (LbL) mostrada na Figura 5.16. 
primeira publicação do método LbL por seu autor em Decher (1997), e quando um número maior de artigos passa a ser adicionado a projeção a cada ano.

\subsection{Tempos de Processamento}

A Tabela 5.7 mostra os tempos de processamento para gerar os mapas de documentos dinâmicos apresentados neste capítulo, para cada uma das etapas envolvidas. Esses tempos de execução foram calculados em um computador com processador Intel Core i† de $3.4 \mathrm{G} . \mathrm{Hz}$ e com 16 GB de memória RAM.

Como mencionado, o carregamento da coleção de banco de dados é uma das etapas mais demoradas do processo, pois são realizadas operações de unificação de autores e referências. O tempo mostrado para essa etapa é o tempo para carregar a coleção original, pois a seleção de artigos com base em suas citações globais só é executada após o carregamento da coleção inteira. A vantagem é que essa etapa só precisa ser executada uma vez, caso se deseje gerar múltiplos mapas dinâmicos com parâmetros diferentes para uma mesma coleção.

A detecção da evolução temporal de grupos também pode ser demorada, pois o tempo nesse caso inclui a geração das representações visuais para as transições temporais. Se o cálculo das representações visuais incluir o cálculo de contornos implícitos para grupos com muitos círculos, esse processo torna-se ainda mais demorado.

A extração de tópicos para as coleções TKDE e LbL utilizou a técnica de extração baseada em LDA, reaproveitando o mesmo modelo inferido durante o pré-processamento, o que diminuiu o tempo de execução.

Tabela 5.7: Tempos de processamento.

\begin{tabular}{|l||l|l|l|}
\hline & $\begin{array}{l}\text { Coleção Albert- } \\
\text { László Barabási }\end{array}$ & Coleção TKDE & Coleção LbL \\
\hline \hline $\begin{array}{l}\text { Carregamento da coleção } \\
\text { no banco de dados }\end{array}$ & $17 \mathrm{~s} 1 \mathrm{~ms}$ & $31 \mathrm{~min} 7 \mathrm{~s} \mathrm{6ms}$ & $8 \mathrm{~h} 32 \mathrm{~min} 536 \mathrm{~ms}$ \\
\hline $\begin{array}{l}\text { Pré-processamento e cons- } \\
\text { trução do modelo de repre- } \\
\text { sentação }\end{array}$ & $753 \mathrm{~ms}$ & $1 \mathrm{~min} 20 \mathrm{~s}$ & $2 \mathrm{~min} 45 \mathrm{~s}$ \\
\hline $\begin{array}{l}\text { Projeção dinâmica } \\
\text { (T-LSP) }\end{array}$ & $9 \mathrm{~s} 914 \mathrm{~ms}$ & $14 \mathrm{~min} 28 \mathrm{~s} 652 \mathrm{~ms}$ & $23 \mathrm{~min} 26 \mathrm{~s} 173 \mathrm{~ms}$ \\
\hline $\begin{array}{l}\text { Detecção da Evolução Tem- } \\
\text { poral de Grupos (DBSCAN } \\
+ \text { MONIC) }\end{array}$ & $404 \mathrm{~ms}$ & $11 \mathrm{~min} 58 \mathrm{~s} 763 \mathrm{~ms}$ & $43 \mathrm{~min} 12 \mathrm{~s} 765 \mathrm{~ms}$ \\
\hline Extração de Tópicos & 3s $672 \mathrm{~ms}$ & $80 \mathrm{~ms}$ & 2s $511 \mathrm{~ms}$ \\
\hline
\end{tabular}




\subsection{Estudo comparativo entre técnicas para constru- ção de mapas de documentos dinâmicos baseados em projeções multidimensionais dinâmicas}

A Seção 3.1.3 do Capítulo 3 apresentou um conjunto técnicas e ferramentas para projeções multidimensionais dinâmicas aplicáveis a coleções de documentos encontradas na literatura - ferramentas Streamit, TextPool, Visone e incBoard. Como a abordagem adotada neste trabalho têm como base a projeção multidimensional dinâmica T-LSP, esta seção apresenta um comparativo entre o mapa dinâmico baseado na T-LSP e as projeções dinâmicas da Seção 3.1.3, segundo uma série de quesitos descritos a seguir. A Tabela 5.8 apresenta um resumo geral das técnicas de projeção multidimensional dinâmica selecionadas, de acordo com as propriedades consideradas.

Primeiramente, a tabela apresenta as referências originais para as técnicas selecionadas. Em seguida, o quesito entrada descreve que tipo de documento (documentos em geral, artigos científicos ou notícias) essas técnicas recebem como entrada. O fato de uma técnica ter sido desenvolvida para certo tipo de documento não significa necessariamente que ela não seja aplicável à outros tipos de documentos ou dados. Esse quesito apenas indica o intuito original dos autores e em que tipo de cenário elas foram testadas. Por exemplo, a T-LSP é aplicável a qualquer tipo de coleção de dados indexada temporalmente, que possa ser representada em um espaço multidimensional ou para a qual relações de similaridade possam ser definidas.

O tipo de instâncias representadas refere-se ao elemento representado no layout da representação visual e no modelo de representação. Geralmente, técnicas de projeção multidimensional, quando aplicadas a coleções de documentos, buscam representar os próprios documentos, gerando mapas de documentos. Nesse aspecto, a técnica Visone destaca-se por ser multimodal e representar ao mesmo tempo termos dos títulos, jornais e autores dos artigos, enquanto a TextPool representa termos, ao invés de documentos.

Já o quesito modelo de representação indica quais tipos de modelos foram utilizados pelos autores em suas técnicas. A T-LSP foi testada com o modelo vetorial, o modelo vetorial estendido e o modelo probabilístico LDA, apresentados respectivamente nas Seções 2.2.1, 4.1.1 e 2.2.2. A técnica Streamit também utiliza o modelo probabilístico LDA, o qual é na verdade aplicado a uma outra coleção de documentos auxiliar que deve ser muito similar à original. Essa abordagem é adotada para permitir que técnica seja incremental. Cada documento novo a ser adicionado à representação visual deve então ser comparado aos tópicos extraídos desta coleção auxiliar, de forma a determinar os tópicos que melhor o representam. No entanto, para obter uma coleção de documentos tão similar a original, sem um custo adicional de criar tal coleção, geralmente é necessário dividir a coleção original em duas. Nessa divisão é necessário tomar certos cuidados para que, por exemplo, a coleção auxiliar cubra todo o 
período da coleção original. Já a técnica Visone utiliza uma matriz de coocorrências entre as instâncias representadas, enquanto a TextPool também utiliza o modelo vetorial. Por fim, a incBoard utiliza um modelo vetorial incremental descrito em maiores detalhes em Salazar (2012), que é uma versão incremental do modelo vetorial também inicializado com uma coleção auxiliar e atualizado a cada novo documento.

Uma estratégia para criar novas técnicas de projeção multidimensional dinâmicas é adaptar as técnicas existentes para tratar a componente temporal explicitamente. O quesito projeção base busca identificar quais técnicas pré-existentes foram utilizadas como base em cada uma das técnicas comparadas. Como mencionado anteriormente, a T-LSP utiliza como base a LSP com modificações que buscam assegurar a coerência espacial global. A Streamit utiliza como base uma projeção do tipo FDP em sua forma pura, cujo processo iterativo proporciona um comportamento dinâmico e incremental à ferramenta. Novos documentos são incluídos na vizinhança de documentos similares ao novo documento, de forma a exigir menos iterações para estabilizar o sistema FDP. A TextPool também utiliza uma projeção do tipo FDP como base, incluindo novos documentos na borda da projeção. Já a Visone utiliza como base uma projeção do tipo MDS, também iterativa, adaptando sua função de stress para também assegurar a coerência global. Em contrapartida, a incBoard adota uma abordagem de MDS não métrico em um tabuleiro incremental.

O quesito layout identifica o tipo de layout da representação visual das técnicas selecionadas. A representação visual de uma projeção multidimensional é geralmente bidimensional e a mesma suposição é válida para projeções dinâmicas. Todas as técnicas selecionadas adotam um layout bidimensional, com exceção da incBoard que adota um tabuleiro como layout padrão e um bidimensional como alternativa.

Quanto às técnicas de extração de tópicos para grupos de documentos, somente a T-LSP e a Streamit incorporam técnicas para tal. O mapa dinâmico gerado pela T-LSP conta com técnicas de extração de tópicos baseadas em PCA, LDA e covariância, como apresentado na Seção 4.2. Já a técnica Streamit adota uma abordagem diferente ao listar os tópicos do modelo de representação LDA utilizados para construir a projeção e permitir que o usuário identifique por meio de iterações que documentos abordam um certo tópico. Neste caso, é permitido que um documento seja associado a mais de um tópico. O conceito de extração de tópicos não é aplicável às técnicas Visone e TextPool, pois as instâncias representadas no layout não são documentos. A incBoard representa documentos em seu layout, mas não implementa técnicas para extração de tópicos.

Novamente, somente os mapas dinâmicos gerados pelas técnicas T-LSP e Streamit possuem métodos para detecção da evolução temporal dos grupos. O mapa dinâmico baseado na T-LSP utiliza a abordagem apresentada na Seção 4.3, que consiste na aplicação em conjunto do algoritmo de agrupamento DBSCAN com o algoritmo de rastreamento das transições temporais entre grupos MONIC. Na técnica Streamit, essa detecção é realizada em três etapas: aplicação da triangulação de Delaunay sobre as posições das instâncias na 
projeção; remoção de todas as arestas com tamanho maior que um parâmetro $\varsigma$, formando componentes conectados (grupos); e, por último, o rastreamento das transições temporais entre grupos é realizado por meio da sobreposição entre os grupos identificando a sobrevivência e o surgimento de novos grupos.

Uma técnica é considerada incremental se ela constrói sua representação visual a medida que novas instâncias chegam, sem utilizar informação sobre as instâncias que chegarão no futuro. Essa nem sempre é uma tarefa fácil, pois pode ser necessário recalcular toda a projeção novamente. Também é mais difícil manter a coerência espacial global de uma projeção dinâmica em técnicas incrementais. Em um cenário, por exemplo, em que os grupos de instâncias atuais estão distribuídos uniformemente e ocupando boa parte do espaço disponível no layout da projeção, se um grupo novo surgir será necessário rearranjar todos os grupos existentes de forma a abrir espaço para esse novo.

A T-LSP não é incremental, pois ela prioriza a coerência espacial global. Neste trabalho, a T-LSP foi aplicada a coleções de artigos científicos, que não evoluem em questões de minutos como coleções de notícias. Portanto, apesar de desejável, não há absoluta necessidade de uma técnica incremental. A técnica da ferramenta Streamit é incremental, pois se vale do processo iterativo de uma projeção do tipo FDP. A técnica TextPool é incremental, pois também se vale do processo iterativo de uma projeção do tipo FDP. A incBoard também se vale do processo iterativo de sua projeção base do tipo MDS não-métrico, e, portanto, também é incremental. Apesar da técnica da ferramenta Visone ser baseada em uma projeção do tipo MDS (processo iterativo), ela não é incremental, priorizando também a coerência espacial global.

O quesito coerência espacial global está ligado à capacidade da projeção dinâmica de posicionar instâncias com conteúdo similar e posicionadas em uma certa região da projeção no instante de tempo $t$, aproximadamente na mesma região da projeção no instante de tempo subsequente $t+1$. Apesar das modificações, é importante que os layouts mantenham-se consistentes ao longo da sequência de mapas de forma a evitar confusão do usuário. Esse quesito busca identificar como as técnicas selecionadas buscam garantir essa propriedade.

Na técnica T-LSP, essa coerência é direcionada pelos dados, mais especificamente pelo esquema retroativo que usa como pontos de controle posições de certas instâncias no instante $t+1$ para determinar a projeção do instante $t$. Na técnica Streamit, o único esforço nesse sentido é posicionar novas instâncias na vizinhança de documentos similares ao novo documento. Dessa forma, o sistema FDP converge mais rápido e menos iterações são necessárias. Como é possível ver no vídeo da técnica, esse esforço nem sempre é o suficiente. Na técnica Visone, a coerência é direcionada por um parâmetro na função de stress que penaliza movimentos drásticos da posição de uma instância do instante $t$ para sua próxima posição no instante $t+1$. No entanto, se um novo grupo diferente de todos os demais estiver surgindo, esse parâmetro na função de stress pode eventualmente dificultar a sua formação ao não identificar esse padrão nos dados. Na técnica incBoard, a estabilidade também é direcionada pelos dados, 
mais especificamente em um esquema que adiciona uma nova instância na célula que contém a instância mais similar a ela, e depois realiza movimentações na vizinhança dessa célula para tornar o tabuleiro estável (com nenhuma célula contendo duas instâncias) novamente. Em contrapartida a todas essas técnicas, a TextPool não oferece nenhuma garantia de coerência além daquelas oferecidas pela sua projeção base

Uma técnica de visualização é cumulativa quando instâncias são somente adicionadas a representação visual, nunca sendo removidas após um certo período de tempo. A T-LSP é cumulativa, ao contrário das técnicas Streamit, Visone e TextPool, que utilizam janelas temporais deslizantes que removem documentos não incluídos pela janela temporal. Já a incBoard possui a opção de utilizar uma janela temporal ou não.

Já o quesito complexidade computacional diz respeito aos recursos computacionais - espaço de memória e tempo de execução - requeridos para solucionar um problema. A complexidade da T-LSP conforme explicado na Seção 4.1 .4 é de $O(\max \{n \sqrt{n}, n \sqrt{k}\} \times T-1)$, onde $T$ é o número de intervalos de tempo e $n$ é o número de instâncias a cada intervalo. $\mathrm{O}$ valor de $n$ diminui a cada intervalo, devido ao esquema retroativo da T-LSP. Já as técnicas Streamit, Visone e TextPool são todas $O\left(n^{2} \times T\right)$. A complexidade da técnica incBoard depende muito do número de movimentações necessárias a cada inclusão, i.e., a complexidade está relacionada aos dados. No entanto, segundo Pinho (2009) a complexidade da técnica incBoard no caso médio é de $O\left(n^{\frac{3}{2}}\right)$.

O quesito exemplo em vídeo indica links onde é possível obter exemplos em vídeo da execução das ferramentas, como o objetivo de melhor observar suas propriedades. Por fim, o quesito disponibilidade refere-se a possibilidade de se obter o executável da ferramenta ou técnica por usuários interessados. A ferramenta Science View que implementa a técnica T-LSP encontra-se disponível no link indicado. Já a ferramenta Streamit é desenvolvida por um grupo de pesquisa da Microsoft e não se encontra disponível. Apesar da ferramenta Visone encontrar-se disponível no link fornecido, seu uso não é intuitivo. Essa ferramenta é segmentada, no sentido de que é necessário executar programas separados em sequência para poder utilizar a ferramenta. Alguns desses programas, na etapa de pré-processamento, por exemplo, são apenas executáveis em MS-DOS e quando um erro acontece é somente fornecido um número que identifica o erro. A ferramenta TextPool também não se encontra disponível.

\subsection{Considerações Finais}

Neste capítulo, foram apresentados e discutidos estudos de caso aplicando a abordagem proposta no Capítulo 4 - um mapa dinâmico de documentos baseado na técnica T-LSP. Primeiramente, foi realizada uma análise da trajetória acadêmica do pesquisador AlbertLászló Barabási por meio da sua produção científica entre 1989 e 2012, com base no mapa dinâmico obtido para essa coleção. Em seguida, foi apresentada uma análise da evolução da área de pesquisa representada por artigos publicados no periódico IEEE Transactions 
on Knowledge and Data Engineering (TKDE) entre 1992 e 2012. Estes estudos de casos ilustram a aplicabilidade da abordagem proposta para capturar e apoiar a análise da evolução temporal dos tópicos para coleções de documentos de diferentes tamanhos e de diferentes enfoques. Um terceiro estudo de caso fornece um "contra-exemplo" no qual o mapa dinâmico de documentos obtido para uma coleção de artigos relacionados ao método LbL, método para fabricação de filmes ultrafinos com nanômetros de espessura, mostrou-se pouco informativo. Nesse último estudo de caso, também são apresentada hipóteses que buscam explicar por que a abordagem proposta não proveu bons resultados para essa coleção.

Os textos associados aos estudos de caso podem ser considerados longos. No entanto, deve-se ter em mente que eles são a análise e descrição de uma visualização dinâmica e são baseados em um conjunto de informações e funcionalidades providas pela ferramenta Science View - projeção dinâmica, transições temporais entre grupos, tópicos, interações com o mapa dinâmico e estatísticas diversas.

Quanto a construção do mapa dinâmico, uma questão importante é a escolha dos parâmetros. Apesar de valores padrões serem fornecidos, para grandes coleções de documentos pode ser necessário testar diferentes configurações para os valores dos parâmetros, observando como diferentes valores para cada parâmetro afetam o mapa dinâmico. Também pode ser necessário que o usuário insira parte do seu conhecimento sobre as áreas de pesquisa representadas pela coleção sendo analisada, inserindo termos genéricos para aquelas áreas na lista de stopwords. Caso o usuário não tenha nenhum conhecimento sobre a coleção, uma possibilidade é observar os principais termos utilizados no modelo de representação e buscar detectar esses termos genéricos com base no contexto em que eles aparecem nos documentos.

Também foi apresentada a ferramenta Science View, desenvolvida como um arcabouço visual para aplicar e testar as técnicas desenvolvidas. Ao final deste capítulo é incluso um comparativo entre técnicas para construção de mapas de documentos dinâmicos baseados em projeções multidimensionais dinâmicas, que traz uma análise crítica dessas técnicas segundo uma série de quesitos. No próximo capítulo são apresentadas conclusões sobre as contribuições, limitações e sobre possíveis trabalhos futuros sobre o trabalho apresentado. 


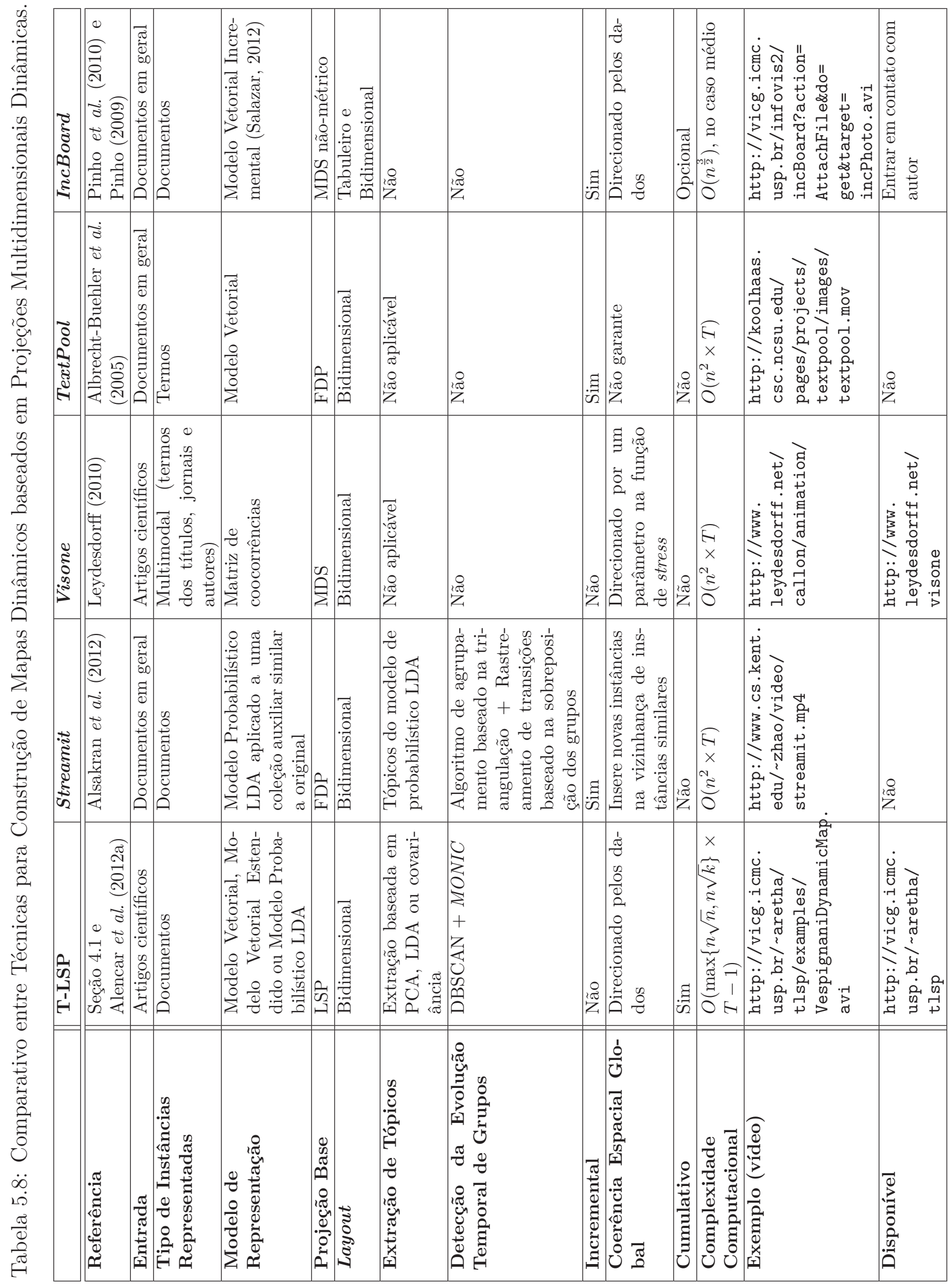




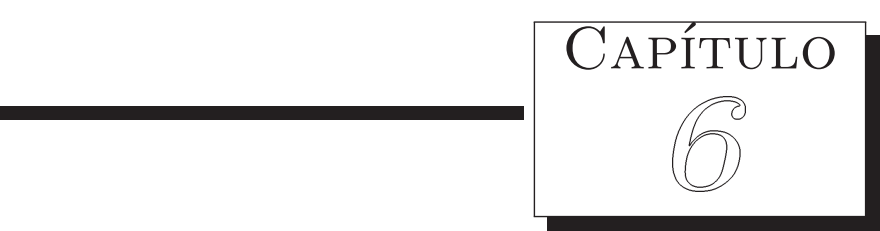

\section{Conclusões}

Nesta tese foi apresentado um conjunto de técnicas desenvolvidas e outras integradas visando auxiliar a análise exploratória da evolução temporal em coleções de artigos científicos e seus tópicos. Neste capítulo serão apresentadas as principais contribuições desta tese para a área de visualização e análise visual da evolução temporal de coleções de artigos científicos. Também são apresentados desenvolvimentos futuros que podem dar continuidade à abordagem proposta, superando algumas limitações e gerando outras contribuições.

\subsection{Contribuições}

A principal contribuição foi o desenvolvimento da técnica de projeção multidimensional dinâmica Time-based Least Square Projection (T-LSP), incorporando explicitamente a componente temporal no processo de obtenção da projeção Least Square Projection (LSP) (Paulovich et al., 2008), de modo a transmitir as mudanças nas relações de similaridade em um conjunto de dados multidimensional ao longo do tempo. A LSP é especialmente indicada para coleções de documentos (espaços esparso) e oferece um bom equilíbrio entre a preservação da informação global e das relações de vizinhança locais, o que favorece a formação de grupos. No entanto, a LSP em sua forma convencional não incorpora a componente temporal em seu processo, cuja análise é crucial quando o objetivo é analisar a evolução de uma coleção de documentos ao longo do tempo. Tal cenário motivou o desenvolvimento da 
T-LSP, que obteve um bom balanço entre a acurácia local e a coerência espacial global. A T-LSP possui uma complexidade computacional igual a $O(\max \{n \sqrt{n}, n \sqrt{k}\} \times T-1)$, inferior em relação ao obtido por outras técnicas de projeção dinâmica baseadas em projeções do tipo FDP ou MDS.

Com o intuito de melhorar a qualidade do mapa de documentos dinâmico para coleções de artigos, foi proposto um modelo vetorial estendido que incorpora as referências de uma coleção como atributos em sua representação. Artigos científicos incluem citações para reconhecer trabalhos relacionados e fontes de informação. Dessa forma, referências em comum também denotam similaridade semântica entre dois artigos. A citação de artigos é uma propriedade de artigos científicos, que se mostrou valiosa para melhorar a qualidade de mapas com artigos de um único pesquisador. Um pesquisador em particular tende a ser mais uniforme nas citações que faz ao longo do tempo do que múltiplos autores de artigos de um periódico ou de área de pesquisa.

Mudanças nas relações de similaridade entre artigos ao longo do tempo, evidenciadas pela T-LSP, são um bom indicativo da evolução dos tópicos na coleção, dado que um tópico deve estar associado a um conjunto de artigos similares. A detecção da evolução dos tópicos é realizada utilizando técnicas encontradas na literatura em conjunto com técnicas de extração de tópicos elaboradas no contexto desta tese. Primeiramente, o algoritmo Density Based Spatial Clustering of Applications with Noise (DBSCAN) proposto por Sander et al. (1998) identifica os grupos para cada instante de tempo na sequência de projeções, que não requer que seja definido o número de grupos e é capaz de identificar grupos de formatos arbitrários. Em seguida, o algoritmo MONIC proposto por Spiliopoulou et al. (2006) rastreia as transições temporais entre esses grupos, sendo capaz de detectar o surgimento, a sobrevivência, a subdivisão, a junção e o desparecimento dos grupos por meio da sobreposição de elementos entre eles. Por fim, são extraídos tópicos desses grupos em cada instante de tempo, utilizando a técnica baseada em PCA, ou a técnica baseada LDA, propostas neste trabalho.

Essas informações sobre a evolução dos tópicos são adicionadas ao mapa de documentos dinâmicos por meio de elementos visuais, como as Topic Clouds, que mostram os tópicos utilizando tag clouds para tornar a exibição mais intuitiva e atrativa; e animação dos polígonos, que delimita os grupos por polígonos definidos pelo fecho convexo ou pelo contorno explícito dos elementos contidos e os anima para representar as diferentes transições entre grupos.

Para comprovar a validade da abordagem proposta, foram conduzidos três estudos de caso: (a) para analisar a trajetória de pesquisa de Albert-László Barabási com base em seus 2008 artigos publicados entre 1989 e 2012; (b) para analisar a evolução da área de pesquisa representada por 1.242 artigos publicados no periódico IEEE Transactions on Knowledge and Data Engineering (TKDE) entre 1992 e 2012; (c) um contraexemplo baseado em uma coleção de artigos coletados sobre o método Layer-by-layer (LbL) com data de publicação entre 1991 e 2010, que fornece evidências de cenários em que a abordagem pode não obter bons resultados. 
Além disso, também foi realizado um estudo comparativo entre técnicas para construção de mapas de documentos dinâmicos baseados em projeções multidimensionais, que apresenta uma análise mais crítica das técnicas segundo uma série de quesitos, contextualizando a contribuição deste trabalho em relação ao estado da arte.

Para testar e aplicar as técnicas desenvolvidas e conduzir os estudos de caso apresentados, bem como para dar maior suporte ao processo de mineração visual de coleções de artigos com base na projeção multidimensional dinâmica T-LSP, foi criada a ferramenta Science View ${ }^{1}$. Essa ferramenta aceita como entrada coleções nos formatos ISI, Endnote Export Format ou BibTeX, formatos com larga utilização no meio acadêmico. Um assistente de projeção guia o usuário na escolha dos parâmetros para obter uma projeção dinâmica para a coleção de artigos científicos fornecida. Após finalização do assistente, é possível enriquecer esse mapa de documentos dinâmico com informações relacionadas a evolução temporal dos tópicos dessa coleção. O usuário pode escolher parâmetros para identificação dos grupos em cada instante na sequência de projeções e para rastrear as transições temporais entre esses grupos. Uma vez identificados os grupos, o usuário pode escolher entre duas diferentes técnicas para extração dos tópicos - a técnica baseada em PCA ou a baseada em LDA. A técnica baseada em PCA tende a ser mais concisa do que a baseada em LDA, apresentando também um tempo de execução menor. No entanto, a técnica LDA funciona melhor em cenários mais complexos, e.g., coleções grandes com vasto vocabulário. Outras funcionalidades também se encontram disponíveis, desde as mais básicas como aplicar um zoom na projeção em um certo instante a outras não tão triviais, como representar citações locais por meio de arestas direcionadas. Também é possível avaliar numericamente a qualidade das projeções dinâmicas obtidas por meio do stress estático, que avalia a acurácia global, e do stress dinâmico, que avalia a coerência espacial global.

De forma geral, além das técnicas e ferramenta desenvolvidas, este trabalho de doutorado contribui para um melhor entendimento das características desejáveis de técnicas de projeção multidimensional dinâmicas, principalmente as específicas para coleções de artigos científicos, e dificuldades associadas ao seu uso nesse contexto, como as discutidas a seguir.

\subsection{Limitações}

Embora os resultados apresentados sejam promissores, algumas limitações devem ser observadas:

- A técnica T-LSP é suscetível à qualidade da última projeção da sequência, que contém todos os documentos da coleção, devido ao seu esquema retroativo. Se não se formarem grupos de documentos similares nessa última projeção, também não existirão grupos nas projeções anteriores. Isto impossibilitará o rastreamento das transições temporais

\footnotetext{
$\overline{{ }^{1} \text { http://vicg.icmc.usp.br/ aretha/tl sp }}$
} 
entre os grupos, o que implica na ausência de eventos claros de transição como a junção de dois tópicos em um único.

- A qualidade do mapa dinâmico para uma coleção de documentos está diretamente ligada à qualidade do modelo de representação obtido para a coleção. No entanto, nem sempre é trivial obter representações para coleções de documentos e definir quais termos são os mais relevantes. Especialmente em coleções relativamente grandes com mais de 1.000 documentos, nas quais o vocabulário associado é igualmente grande. Mesmo modelos mais complexos, como o modelo probabilístico LDA, são afetados em cenários como esse. Esta é uma dificuldade que ocorre não somente no mapa dinâmico apresentado neste trabalho, mas em mapas de documentos em geral, sejam eles gerados por projeções multidimensionais ou não.

- Polígonos são utilizados para indicar visualmente grupos detectados pelo algoritmo DBSCAN, o que promove uma sumarização visual. No entanto, ainda pode ocorrer um certo nível de oclusão visual quando a coleção de documentos é grande, pois a escalabilidade visual do mapa de documentos dinâmico é afetada pela metáfora empregada (um círculo para cada documento).

- Atualmente, não é permitido ao usuário definir a resolução dos intervalos de tempo que serão utilizadas para a criação do mapa dinâmico. Adotam-se sempre intervalos de um ano. No entanto, os padrões a serem detectados podem variar de acordo com a resolução temporal considerada.

- O emprego efetivo da ferramenta Science View para gerar um mapa dinâmico de documentos, requer certo conhecimento prévio sobre os parâmetros da T-LSP, modelos de representação, medidas de dissimilaridade e outras configurações disponíveis. No entanto, busca-se facilitar esse processo pelo uso de um assistente de projeção com valores default para opções de configuração e parâmetros.

\subsection{Trabalhos Futuros}

Os passos para dar continuidade a esse trabalho estão relacionados às limitações identificadas e a investigação e incorporação de algumas ideias que surgiram no decorrer na pesquisa, mas que não foram incluídas nesse trabalho. A seguir, alguns desses passos são brevemente discutidos:

- Permitir um esquema de criação semi-supervisionado do mapa dinâmico, no qual o usuário fornece dicas sobre quais tópicos ele deseja evidenciar. Eventuais falhas, como, por exemplo, um tópico pouco representativo que foi incluído no mapa, também poderiam ser corrigidas por meio de intervenções do usuário.

- Tipicamente, a medida $f r e q i j$ utilizada no modelo vetorial para definir a influência do termo $t_{j}$ no documento $t_{i}$ é constante, e calculada por uma fórmula pré-definida. No entanto, um termo pode aparecer constantemente ao longo do tempo e depois 
desaparecer, enquanto outro termo pode sofrer momentos de pico ao longo do tempo. Dessa forma, seria interessante propor um peso que aumente ou diminua dinamicamente a importância de um termo ao longo do tempo com base nas suas variações de frequência.

- Alguns usuários podem ter dificuldade em acompanhar a evolução dos tópicos por meio de efeitos de animação. Portanto, é interessante desenvolver uma visualização estática focada somente nas informações referentes à evolução dos tópicos. Entre as informações que poderiam ser apresentadas estão: as transições entre os grupos de documentos associados, termos que aparecem e desaparecem dos tópicos de um grupo de um instante de tempo para o próximo, entre outras. Esta versão estática da evolução dos tópicos estaria coordenada com o mapa dinâmico em seu formato atual.

- Permitir que o usuário tenha a opção de definir manualmente a resolução dos intervalos de tempo a serem utilizados para criação do mapa dinâmico.

- Quando se têm grupos de documentos muitos similares, pode ocorrer um certo nível de sobreposição desses grupos no layout da projeção. Poderia ser interessante "perturbar" um pouco a posição desses documentos no layout para desfazer essa sobreposição. Isso poderia ser feito, por exemplo, aplicando uma técnica do tipo FDP de forma limitada à área dos documentos sobrepostos.

- Investigar mais a fundo o efeito das parametrizações nos resultados obtidos e criar um manual do usuário para facilitar o uso da ferramenta.

\subsection{Artigos Publicados}

Os seguintes artigos foram publicados até o momento reportando os resultados do trabalho realizado nesta tese:

- Alencar, Aretha B.; Börner, Katy; Paulovich, Fernando V.; Oliveira, Maria Cristina F. Time-aware visualization of document collections. In: 27th Annual ACM Symposium on Applied Computing. New York, NY, EUA: ACM, 2012. p. 997-1004. ISBN 978-1-4503-0857-1.

- Alencar, Aretha B.; Oliveira, Maria Cristina F.; Paulovich, Fernando V. Seeing beyond reading: a survey on visual text analytics. Wiley Interdisciplinary Reviews: Data Mining and Knowledge Discovery, John Wiley \& Sons, Malden, MA, EUA, v. 2, n. 6, p. 476-492, nov-dez. 2012. ISSN 1942-4795. 


\section{Referências}

AGGARWAL, C. C. (Ed.). Data Streams: Models and Algorithms. 1. ed. EUA: Springer, 2007. 358 p. (Advances in Database Systems, 84 illus). ISBN 978-0-387-28759-1. Disponível em: http://charuaggarwal.net/streambook.pdf.

AGGARWAL, C. C. et al. A framework for clustering evolving data streams. In: 29th International Conference on Very Large Data Bases, 2003. p. 81-92. ISBN 0-12-722442-4. ISSN 0730-9317.

AGGARWAL, C. C.; YU, P. S. On clustering massive text and categorical data streams. Knowledge and Information Systems, Springer-Verlag, New York, NY, EUA, v. 24, n. 2, p. 171-196, ago. 2010. ISSN 0219-1377.

AGGARWAL, C. C.; ZHAI, C. X. (Ed.). Mining Text Data. New York, NY, EUA: Springer, 2012. 522 p. ISBN 978-1-4614-3222-7.

ALBRECHT-BUEHLER, C.; WATSON, B.; SHAMMA, D. A. Visualizing live text streams using motion and temporal pooling. IEEE Computer Graphics and Applications, IEEE Computer Society, Los Alamitos, CA, EUA, v. 25, n. 3, p. 52-59, maio 2005. ISSN 0272-1716.

ALENCAR, A. B. et al. Time-aware visualization of document collections. In: 27th Annual ACM Symposium on Applied Computing, 2012. p. 997-1004. ISBN 978-1-4503-0857-1.

ALENCAR, A. B.; OLIVEIRA, M. C. F.; PAULOVICH, F. V. Seeing beyond reading: a survey on visual text analytics. Wiley Interdisciplinary Reviews: Data Mining and Knowledge Discovery, John Wiley \& Sons, Malden, MA, EUA, v. 2, n. 6, p. 476-492, nov.-dez. 2012. ISSN 1942-4795.

ALLAN, J.; LAVRENKO, V.; JIN, H. First story detection in TDT is hard. In: 9th International Conference on Information and Knowledge Management, 2000. p. 374-381. ISBN 1-58113-320-0. 
ALLAN, J.; PAPKA, R.; LAVRENKO, V. On-line new event detection and tracking. In: 21st Annual International ACM SIGIR Conference on Research \& Development on Information Retrieval, 1998. p. 37-45. ISBN 1-58113-015-5.

ALSAKRAN, J. et al. Real-time visualization of streaming text with a force-based dynamic system. IEEE Computer Graphics and Applications, IEEE Computer Society, Los Alamitos, CA, EUA, v. 32, n. 1, p. 34-45, jan. 2012. ISSN 0272-1716.

ANDREWS, K. et al. The InfoSky visual explorer: exploiting hierarchical structure and document similarities. Information Visualization, SAGE, EUA, v. 1, n. 3/4, p. 166-181, dez. 2002. ISSN 1473-8716.

BACHMAIER, C.; BRANDES, U.; SCHLIEPER, B. Drawing phylogenetic trees. In: 16th International Conference on Algorithms and Computation, 2005. (Lecture Notes in Computer Science, 3827), p. 1110-1121. ISBN 3-540-30935-7.

BAEZA-YATES, R.; RIBEIRO-NETO, B. Modern information retrieval. 1. ed. Reino Unido: Addison Wesley, 1999. 513 p. ISBN 020139829X.

BECKS, A.; SEELING, C.; MINKENBERG, R. Benefits of document maps for text access in knowledge management: a comparative study. In: 2002 ACM Symposium on Applied Computing, 2002. p. 621-626. ISBN 1-58113-445-2.

BEKKERMAN, R.; ALlAN, J. Using Bigrams in Text Categorization. EUA, dez. 2003. Disponível em: http://www.cs .umass.edu/ ronb/papers/bigrams.pdf.

BENTLEY, J. L. Multidimensional binary search trees used for associative searching. Communications of the ACM, ACM, New York, NY, EUA, v. 18, n. 9, p. 509-517, set. 1975. ISSN 0001-0782.

BLEI, D.; LAFFERTY, J. Topic models. In: SRIVASTAVA, A.; SAHAMI, M. (Ed.). Text Mining: Classification, Clustering, and Applications. 1. ed. EUA: Chapman \& Hall/CRC, 2009, (Data Mining and Knowledge Discovery Series). cap. 4, p. 71-93. ISBN 978-1420059403.

BLEI, D. M. Probabilistic topic models. Communications of the ACM, ACM, New York, NY, EUA, v. 55, n. 4, p. 77-84, abr. 2012. ISSN 0001-0782.

BLEI, D. M.; LAFFERTY, J. D. Dynamic topic models. In: 23rd International Conference on Machine Learning, 2006. p. 113-120. ISBN 1-59593-383-2.

BLEI, D. M.; LAFFERTY, J. D. A correlated topic model of science. Annals of Applied Statistics, Institute of Mathematical Statistics, Beachwood, OH, EUA, v. 1, n. 1, p. 17-35, 2007. ISSN 1932-6157. 
BLEI, D. M.; NG, A. Y.; JORDAN, M. I. Latent dirichlet allocation. Journal of Machine Learning Research, MIT, EUA, v. 3, p. 993-1022, jan. 2003. ISSN 1533-7928.

BöRNER, K. Atlas of Science: Visualizaing What We Know. Cambridge, Massachusetts, EUA: The MIT Press, 2010. 272 p. ISBN 978-0262014458.

BUNTINE, W. Estimating likelihoods for topic models. In: 1st Asian Conference on Machine Learning: Advances in Machine Learning, 2009. (Lecture Notes in Computer Science, v. 5828), p. 51-64. ISBN 978-3-642-05223-1.

CARD, S. K.; MACKINLAY, J. D.; SHNEIDERMAN, B. (Ed.). Readings in information visualization: using vision to think. San Francisco, CA, EUA: Morgan Kaufmann, 1999. 712 p. ISBN 1-55860-533-9.

CARMI, A.; SEPTIER, F.; GODSILL, S.J. The gaussian mixture MCMC particle algorithm for dynamic cluster tracking. In: 12th International Conference on Information Fusion, 2009. p. 1179-1186. ISBN 978-0-9824-4380-4.

CHAKRABARTI, D.; KUMAR, R.; TOMKINS, A. Evolutionary clustering. In: 12th International Conference on Knowledge Discovery and Data Mining, 2006. p. 554-560. ISBN 1-59593-339-5.

CHALMERS, M. A linear iteration time layout algorithm for visualising high-dimensional data. In: 7th Conference on Visualization, 1996. p. 127-131. ISBN 0-89791-864-9.

CHARIKAR, M. et al. Incremental clustering and dynamic information retrieval. In: 29th Annual Symposium on Theory of Computing, 1997. p. 626-635. ISBN 0-89791-888-6.

CHEN, C. CiteSpace II: Detecting and visualizing emerging trends and transient patterns in scientific literature. Journal of the American Society for Information Science and Technology, John Wiley \& Sons, New York, NY, EUA, v. 57, n. 3, p. 359-377, fev. 2006. ISSN 0002-8231.

CHEN, C. Information Visualization: Beyond the Horizon. Secaucus, NJ, EUA: SpringerVerlag, 2006. ISBN 184628340X.

COLlinS, C.; PENN, G.; CARPENDALE, S. Bubble Sets: Revealing set relations with isocontours over existing visualizations. IEEE Transactions on Visualization and Computer Graphics, IEEE Computer Society, Los Alamitos, CA, EUA, v. 15, n. 6, p. 1009-1016, nov. 2009. ISSN 1077-2626.

CUADROS, A. M. et al. Point placement by phylogenetic trees and its application to visual analysis of document collections. In: 2007 IEEE Symposium on Visual Analytics Science and Technology, 2007. p. 99-106. ISBN 978-1-4244-1659-2. 
CUI, W. et al. TextFlow: Towards better understanding of evolving topics in text. IEEE Transactions on Visualization and Computer Graphics, IEEE Computer Society, Los Alamitos, CA, EUA, v. 17, n. 12, p. 2412-2421, dez. 2011. ISSN 1077-2626.

CUI, W. et al. Context-preserving, dynamic word cloud visualization. IEEE Computer Graphics and Applications, IEEE Computer Society, Los Alamitos, CA, EUA, v. 30, n. 6, p. 42-53, nov.-dez. 2010. ISSN 0272-1716.

DAVIS, T. A. Direct Methods for Sparse Linear Systems (Fundamentals of Algorithms). 1. ed. Philadelphia, PA, EUA: Society for Industrial and Applied Mathematic, 2006. 217 p. ISBN 0898716136.

DECHER, G. Fuzzy nanoassemblies: Toward layered polymeric multicomposites. Science, AAAS, Washington, DC, EUA, v. 277, n. 5330, p. 1232-1237, ago. 1997. ISSN 0036-8075.

DEMPSTER, A. P.; LAIRD, N. M.; RUBIN, D. B. Maximum likelihood from incomplete data via the EM algorithm. Journal of the Royal Statistical Society. Series B (Methodological), Wiley-Blackwell, London, Reino Unido, v. 39, n. 1, p. 1-38, 1977. ISSN 0035-9246. Disponível em: http://www. jstor.org/stable/2984875.

DIEHL, S.; GöRG, C. Graphs, they are changing - dynamic graph drawing for a sequence of graphs. In: 10th International Symposium on Graph Drawing, 2002. (Lecture Notes in Computer Science, v. 2528), p. 23-31. ISBN 3-540-00158-1.

FALKOWSKI, T.; BARTELHEIMER, J.; SPILIOPOULOU, M. Mining and visualizing the evolution of subgroups in social networks. In: IEEE/WIC/ACM International Conference on Web Intelligence, 2006. p. 52-58. ISBN 0-7695-2747-7.

FALOUTSOS, C.; LIN, K-L. FastMap: a fast algorithm for indexing, data-mining and visualization of traditional and multimedia datasets. In: ACM SIGMOD International Conference on Management of Data, 1995. p. 163-174. ISBN 0-89791-731-6.

FAYYAD, U.; PIATETSKY-SHAPIRO, G.; SMYTH, P. From data mining to knowledge discovery in databases. AI Magazine, Association for the Advancement of Artificial Intelligence (AAAI), Palo Alto, CA, EUA, v. 17, n. 3, p. 37-54, set.-dez. 1996. ISSN 0738-4602.

FODOR, I. K. A survey of dimension reduction techniques. Livermore, CA, EUA, maio 2002. Disponível em: http://www.llnl.gov/casc/sapphire/pubs/148494.pdf.

FRISHMAN, Y.; TAL, A. Online dynamic graph drawing. IEEE Transactions on Visualization and Computer Graphics, IEEE Computer Society, Los Alamitos, CA, EUA, v. 14, n. 4, p. 727-740, jul. 2008. ISSN 1077-2626. 
FRUCHTERMAN, T. M. J.; REINGOLD, E. M. Graph drawing by force-directed placement. Software: Practice and Experience, John Wiley \& Sons, New York, NY, EUA, v. 21, n. 11, p. 1129-1164, nov. 1991. ISSN 0038-0644.

GALASSO, F. et al. Spatio-temporal clustering of probabilistic region trajectories. In: 13th International Conference on Computer Vision, 2011. p. 1738-1745. ISBN 9781457711008. ISSN 1550-5499.

GAO, Z. J. et al. Tracking and connecting topics via incremental hierarchical dirichlet processes. In: 11th International Conference on Data Mining, 2011. p. 1056-1061. ISBN 978-0-7695-4408-3. ISSN 1550-4786.

GONG, L.; ZENG, J.; ZHANG, S. Text stream clustering algorithm based on adaptive feature selection. Expert Systems with Applications, Elsevier, Tarrytown, NY, EUA, v. 38, n. 3, p. 1393-1399, mar. 2011. ISSN 0957-4174.

GOVE, R. et al. Evaluating visual and statistical exploration of scientific literature networks. In: IEEE Symposium on Visual Languages and Human-Centric Computing 2011, 2011. p. 217-224. ISBN 978-1-4577-1246-3. ISSN 1943-6092.

GRAHAM, Ronald L. An efficient algorithm for determining the convex hull of a finite planar set. Information Processing Letters, Elsevier, Holanda, v. 1, n. 4, p. 132-133, jun. 1972. ISSN 0020-0190.

GRIFFITHS, T. L.; STEYVERS, M. A probabilistic approach to semantic representation. In: GRAY, W. D.; SCHUNN, C. (Ed.). 24th Annual Conference of the Cognitive Science Society, 2002. p. 381-386. ISBN 0-8058-4581-X, 0-8058-4583-6. ISSN 1047-1316.

GRIFFITHS, T. L.; STEYVERS, M. Finding scientific topics. Proceedings of the National Academy of Sciences, National Academy of Sciences, Washington, DC, EUA, v. 101, n. Suppl 1, p. 5228-5235, abr. 2004. ISSN 1091-6490.

GUPTA, C.; GROSSMAN, R. L. GenIc: A single-pass generalized incremental algorithm for clustering. In: BERRY, M. W. et al. (Ed.). 4th SIAM International Conference on Data Mining, 2004. p. 1-7. ISBN 0-89871-568-7. Disponível em: https://www.siam.org/ proceedings/datamining/2004/dm04_014guptac.pdf.

HAM, F. van; WATTENBERG, M.; VIEGAS, F. B. Mapping text with phrase nets. IEEE Transactions on Visualization and Computer Graphics, IEEE Computer Society, Los Alamitos, CA, EUA, v. 15, n. 6, p. 1169-1176, nov. 2009. ISSN 1077-2626.

HAVRE, S. et al. ThemeRiver: Visualizing thematic changes in large document collections. IEEE Transactions on Visualization and Computer Graphics, IEEE Computer Society, Los Alamitos, CA, EUA, v. 8, n. 1, p. 9-20, jan.-mar. 2002. ISSN 1077-2626. 
Herr II, B. W. et al. 113 years of physical review: Using flow maps to show temporal and topical citation patterns. In: 12th International Conference Information Visualisation, 2008. p. 421-426. ISBN 978-0-7695-3268-4. ISSN 1550-6037.

HOFMANN, T. Probabilistic latent semantic indexing. In: 22nd Annual International ACM SIGIR Conference on Research and Development in Information Retrieval, 1999. p. 50-57. ISBN 1-58113-096-1.

HOFMANN, T. Unsupervised learning by probabilistic latent semantic analysis. Artificial Intelligence, Elsevier, Holanda, v. 42, n. 1-2, p. 177-196, jan.-fev. 2001. ISSN 0004-3702.

HOUAISS, Instituto Antônio. Dicionário Houaiss Eletrônico. Rio de Janeiro, RJ, Brasil: Houaiss, 2009.

JACKSON, J. Edward. A User's Guide to Principal Components. 1. ed. New York, NY, EUA: John Wiley \& Sons, 1991. 592 p. (Wiley Series in Probability and Statistics). ISBN 9780471622673 .

JOIA, P. et al. Local affine multidimensional projection. IEEE Transactions on Visualization and Computer Graphics, IEEE Computer Society, Los Alamitos, CA, EUA, v. 17, n. 12, p. 2563-2571, set. 2011. ISSN 1077-2626.

JOLliffe, I. T. Principal Component Analysis. 2. ed. New York, NY, EUA: Springer, 2002. 487 p. (Springer Series in Statistics, 502). ISBN 978-0-387-95442-4.

JONES, K. S. Document retrieval systems. In: WILLETT, Peter (Ed.). London, UK, Reino Unido: Taylor Graham Publishing, 1988. cap. A statistical interpretation of term specificity and its application in retrieval, p. 132-142. ISBN 0-947568-21-2.

KALNIS, P.; MAMOULIS, N.; BAKIRAS, S. On discovering moving clusters in spatiotemporal data. In: MEDEIROS, C. Bauzer; EGENHOFER, M.; BERTINO, E. (Ed.). 9th International Conference on Advances in Spatial and Temporal Databases, 2005. (Lecture Notes in Computer Science, v. 3633), p. 364-381. ISBN 978-3-540-28127-6.

KAMADA, T.; KAWAI, S. An algorithm for drawing general undirected graphs. Information Processing Letters, Elsevier, Holanda, v. 31, n. 1, p. 7-15, abr. 1989. ISSN 0020-0190.

KEIM, Daniel A. Information visualization and visual data mining. IEEE Transactions on Visualization and Computer Graphics, IEEE Educational Activities Department, Piscataway, NJ, EUA, v. 8, n. 1, p. 1-8, jan. 2002. ISSN 1077-2626.

KEIM, D. A. et al. Visual data mining. In: SIMOFF, S. J.; BöHLEN, M. H.; MAZEIKA, A. (Ed.). Berlin, Heidelberg, Alemanha: Springer-Verlag, 2008. cap. Visual Analytics: Scope and Challenges, p. 76-90. ISBN 978-3-540-71079-0. 
KLEINBERG, J. Bursty and hierarchical structure in streams. In: 8th International Conference on Knowledge Discovery and Data Mining, 2002. p. 91-101. ISBN 1-58113-567-X.

KOH, K. et al. ManiWordle: Providing flexible control over Wordle. IEEE Transactions on Visualization and Computer Graphics, IEEE Computer Society, Los Alamitos, CA, EUA, v. 16, n. 6, p. 1190-1197, nov. 2010. ISSN 1077-2626.

KOLMOGOROV, A. N. Three approaches to the quantitative "definition of information". Problemy Peredachi Informatsii, Russian Academy of Sciences, Rússia, v. 1, n. 1, p. 3-11, 1965. ISSN 0555-2923.

KRUSKAL, J. B. Nonmetric multidimensional scaling: a numerical method. Psychometrika, Springer, New York, NY, EUA, v. 29, n. 2, p. 115-129, jun. 1964. ISSN 0033-3123.

KRUSKAL, J. B.; WISH, M. Multidimensional Scaling. Newbury Park, CA, EUA: SAGE, 1978. 96 p. (Quantitative Applications in the Social Sciences). ISBN 0-8039-0940-3.

LEE, B. et al. SparkClouds: Visualizing trends in tag clouds. IEEE Transactions on Visualization and Computer Graphics, IEEE Computer Society, Los Alamitos, CA, EUA, v. 16, n. 6, p. 1182-1189, nov. 2010. ISSN 1077-2626.

LEWIS, D. D. An evaluation of phrasal and clustered representations on a text categorization task. In: 15th Annual International ACM SIGIR Conference on Research and Development in Information Retrieval, 1992. p. 37-50. ISBN 0-89791-523-2.

LEYDESDORFF, L. What can heterogeneity add to the scientometric map? Steps towards algorithmic historiography. In: AKRICH, Madeleine et al. (Ed.). Débordements: Mélanges offerts à Michel Callon. 1. ed. Paris, França: Presses des Mines, 2010, (Collection Science Sociales, abs/1002.0532). p. 283-289. ISBN 9782911256387.

LEYDESDORFF, L.; SCHANK, T. Dynamic animations of journal maps: Indicators of structural changes and interdisciplinary developments. Journal of the American Society for Information Science and Technology, John Wiley \& Sons, New York, NY, EUA, v. 59, n. 11, p. 1810-1818, set. 2008. ISSN 0002-8231.

LI, M. et al. Clustering by compression. In: International Symposium on Information Theory 2003, 2003. p. 261-261. ISBN 0-7803-7728-1.

LIN, J. Divergence measures based on the Shannon entropy. IEEE Transactions on Information Theory, IEEE Information Theory Society, Los Alamitos, CA, EUA, v. 37, n. 1, p. 145-151, jan. 1991. ISSN 0018-9448.

LIU, S. et al. TIARA: Interactive, topic-based visual text summarization and analysis. ACM Transactions on Intelligent Systems and Technology, ACM, New York, NY, EUA, v. 3, n. 2, p. 25:1-25:28, fev. 2012. ISSN 2157-6904. 
LOPES, A. A. et al. Visual text mining using association rules. Computer Graphics, Elsevier, Elmsford, NY, EUA, v. 31, n. 3, p. 316-326, jun. 2007. ISSN 0097-8493.

LORENSEN, W. E.; CLINE, H. E. Marching cubes: A high resolution 3D surface construction algorithm. In: 14st Annual Conference on Computer Graphics and Interactive Techniques (SIGGRAPH), 1987. p. 163-169. ISBN 0-89791-227-6. ISSN 0097-8930.

LUHN, H. P. The automatic creation of literature abstracts. IBM Journal of Research and Development, IBM, Riverton, NJ, EUA, v. 2, n. 2, p. 159-165, abr. 1958. ISSN 0018-8646.

MAO, Y.; DILLON, J. V.; LEBANON, G. Sequential document visualization. IEEE Transactions on Visualization and Computer Graphics, IEEE Computer Society, Los Alamitos, CA, EUA, v. 13, n. 6, p. 1208-1215, nov.-dez. 2007. ISSN 1077-2626.

MatsubarA, E. T.; MARTINS, C. A.; MONARD, M. C. PreTexT: uma ferramenta para pré-processamento de textos utilizando a abordagem bag-of-words. São Carlos, SP, Brasil, ago. 2003. Disponível em: http://www.icmc.usp.br/ biblio/BIBLIOTECA/rel_tec/RT_ 209.pdf.

MCCALLUM, Andrew Kachites. MALLET: A Machine Learning for Language Toolkit. 2002. Programa de computador. Acessado em: 15/06/2012. Disponível em: http://mallet.cs . umass . edu.

MOURA, M. F.; REZENDE, S. O. A simple method for labeling hierarchical document clusters. In: , 2010. p. 363-371.

O'CALLAGHAN, L. et al. Streaming-data algorithms for high-quality clustering. In: 18th International Conference on Data Engineering, 2002. p. 685-694. ISBN 0-7695-1531-2. ISSN 1063-6382.

OLIVEIRA, M. C. F.; LEVKOWITZ, H. From visual data exploration to visual data mining: a survey. IEEE Transactions on Visualization and Computer Graphics, IEEE Computer Society, Los Alamitos, CA, EUA, v. 9, n. 3, p. 378-394, jul.-set. 2003. ISSN 1077-2626.

PAULOVICH, F. V. Mapeamento de dados multi-dimensionais integrando mineração e visualização. 120 p. Tese (Doutorado) - Instituto de Ciências Matemáticas e de Computação, Universidade de São Paulo, São Carlos, SP, Brasil, 2008.

PAULOVICH, F. V.; MINGHIM, R. HiPP: A novel hierarchical point placement strategy and its application to the exploration of document collections. IEEE Transactions on Visualization and Computer Graphics, IEEE Computer Society, Los Alamitos, CA, EUA, v. 14, n. 6, p. 1229-1236, nov. 2008. ISSN 1077-2626. 
PAULOVICH, F. V. et al. Least Square Projection: A fast high-precision multidimensional projection technique and its application to document mapping. IEEE Transactions on Visualization and Computer Graphics, IEEE Computer Society, Los Alamitos, CA, EUA, v. 14, n. 3, p. 564-575, maio-jun. 2008. ISSN 1077-2626.

PAUlOVICH, F. V.; SILVA, C. T.; NONATO, L. G. Two-phase mapping for projecting massive data sets. IEEE Transactions on Visualization and Computer Graphics, IEEE Computer Society, Los Alamitos, CA, EUA, v. 16, n. 6, p. 1281-1290, jan.-fev. 2010. ISSN $1077-2626$.

PAULOVICH, F. V. et al. Semantic wordification of document collections. Computer Graphics Forum, John Wiley \& Sons, New York, NY, EUA, v. 31, n. 3pt3, p. 1145-1153, jun. 2012. ISSN 0167-7055.

PEARSON, K. On lines and planes of closest fit to systems of points in space. Philosophical Magazine, Taylor \& Francis, Reino Unido, v. 2, n. 11, p. 559-572, 1901. ISSN 1478-6435.

PEKALSKA, E. et al. A new method of generalizing Sammon mapping with application to algorithm speed-up. In: BOASSON, M. et al. (Ed.). 5th Annual Conference of the Advanced School for Computing and Imaging, 1999. p. 221-228.

PINHO, R. D. Espaço incremental para a mineração visual de conjuntos dinâmicos de documentos. Tese (Doutorado) — Instituto de Ciências Matemáicas e de Computação, Universidade de São Paulo, São Carlos, SP, Brasil, jun. 2009.

PINHO, R. D.; OLIVEIRA, M. C.; LOPES, A. A. An incremental space to visualize dynamic data sets. Multimedia Tools and Applications, Springer, Hingham, MA, EUA, v. 50, n. 3, p. 533-562, dez. 2010. ISSN 1380-7501.

PNNL. IN-SPIRE ${ }^{T M}$ Visual Document Analysis. 2008. Programa de computador. Acessado em: 30/09/2012. Disponível em: http://in-spire.pnl.gov.

PONS-PORRATA, A.; BERLANGA-LLAVORI, R.; RUIZ-SHULCLOPER, J. Topic discovery based on text mining techniques. Information Processing $\&$ Management, Elsevier, Tarrytown, NY, EUA, v. 43, n. 3, p. 752-768, maio 2007. ISSN 0306-4573.

PORTER, M. F. An algorithm for suffix stripping. Program: electronic library and information systems, Emerald, Reino Unido, v. 14, n. 3, p. 130-137, 1980. ISSN 0033-0337.

ROSEN-ZVI, M. et al. The author-topic model for authors and documents. In: 20th Conference on Uncertainty in Artificial Intelligence, 2004. p. 487-494. ISBN 0-9749039-0-6.

SALAZAR, F. A. S. R. Um estudo sobre o papel de medidas de similaridade em visualização de coleções de documentos. 95 p. Dissertação (Mestrado) — Instituto de Ciências Matemáticas e de Computação - Universidade de São Paulo, São Carlos, SP, Brasil, set. 2012. 
SALAZAR, F. S. R. et al. A study on the role of similarity measures in visual text analytics. In: 4th International Conference on Information Visualization Theory and Applications, 2013. Submetido.

SALTON, G.; WONG, A.; YANG, C. S. A vector space model for automatic indexing. Communications of the ACM, ACM, New York, NY, EUA, v. 18, n. 11, p. 613-620, nov. 1975. ISSN 0001-0782.

SAMMON, J. W. A nonlinear mapping for data structure analysis. IEEE Transactions on Computers, IEEE Computer Society, Washington, DC, EUA, v. 18, n. 5, p. 401-409, maio 1969. ISSN 0018-9340.

SANDER, J. et al. Density-based clustering in spatial databases: The algorithm GDBSCAN and its applications. Data Mining and Knowledge Discovery, Springer, Hingham, MA, EUA, v. 2, n. 2, p. 169-194, jun. 1998. ISSN 1384-5810.

SCHVANEVELDT, R. W. (Ed.). Pathfinder associative networks: studies in knowledge organization. 1. ed. Norwood, NJ, EUA: Ablex, 1990. 240 p. ISBN 0-89391-624-2.

$\mathrm{SCI}^{2}$ TEAM. Science of Science (Sci $\left.{ }^{2}\right)$ Tool. Indiana University and SciTech Strategies. dez. 2009. Programa de computador. Acessado em: 10/06/2012. Disponível em: http: //sci2.cns.iu.edu.

SHEWCHUK, J. R. An introduction to the conjugate gradient method without the agonizing pain. Pittsburgh, PA, EUA, ago. 1994. 58 p. Disponível em: http://www.cs.cmu.edu/ quake-papers/painless-conjugate-gradient.pdf.

SKUPIN, A. A cartographic approach to visualizing conference abstracts. IEEE Computer Graphics and Applications, IEEE Computer Society, Los Alamitos, CA, EUA, v. 22, n. 1, p. 50-58, jan.-fev. 2002. ISSN 0272-1716.

SPENCE, R. Information Visualization:Design for Interaction. 2 ed.. ed. Harlow, Inglaterra: Prentice Hall, 2007. 304 p. ISBN 978-0132065504.

SPILIOPOULOU, M. et al. MONIC: modeling and monitoring cluster transitions. In: 12th International Conference on Knowledge Discovery and Data Mining, 2006. p. 706-711. ISBN 1-59593-339-5.

STEINBACH, M.; KARYPIS, G.; KUMAR, V. A comparison of document clustering techniques. In: KDD Workshop on Text Mining, 2000. p. 1-20.

STEYVERS, M.; GRIFFITHS, T. Probabilistic topic models. In: LANDAUER, T. K. et al. (Ed.). Handbook of Latent Semantic Analysis. 1. ed. Mahwah, NJ, EUA: Laurence Erlbaum, 2007. cap. 22, p. 427-448. ISBN 978-0-8058-5418-3. 
TAN, A-H. Text mining: The state of the art and the challenges. In: Pacific-Asia Workshop on Knowledge Discovery from Advanced Databases (KDAD 99), 1999. p. 65-70.

TAN, P-N.; STEINBACH, M.; KUMAR, V. Introduction to data mining. 1. ed. EUA: Addison Wesley, 2005. 769 p. ISBN 0321321367.

TANTIPATHANANANDH, C.; BERGER-WOLF, T.; KEMPE, D. A framework for community identification in dynamic social networks. In: 13th International Conference on Knowledge Discovery and Data Mining, 2007. p. 717-726. ISBN 978-1-59593-609-7.

TEH, Y. W. et al. Hierarchical dirichlet processes. Journal of the American Statistical Association, American Statistical Association, Alexandria, VA, EUA, v. 101, n. 476, p. 1566-1581, 2006. ISSN 0162-1459.

TEJADA, E.; MINGHIM, R.; NONATO, L. G. On improved projection techniques to support visual exploration of multidimensional data sets. Information Visualization, SAGE, EUA, v. 2, n. 4, p. 218-231, dez. 2003. ISSN 1473-8716.

TElleS, G. P.; Minghim, R.; PAUlOVICH, F. V. Visual analytics: Normalized compression distance for visual analysis of document collections. Computer Graphics, Elsevier, Elmsford, NY, EUA, v. 31, n. 3, p. 327-337, jun. 2007. ISSN 0097-8493.

THOMAS, J. J.; COOK, K. A. A visual analytics agenda. IEEE Computer Graphics and Applications, IEEE Computer Society Press, Los Alamitos, CA, EUA, v. 26, n. 1, p. 10-13, jan. 2006. ISSN 0272-1716.

VIEGAS, F. B.; WATTENBERG, M.; FEINBERG, J. Participatory visualization with Wordle. IEEE Transactions on Visualization and Computer Graphics, IEEE Computer Society, Los Alamitos, CA, EUA, v. 15, n. 6, p. 1137-1144, nov.-dez. 2009. ISSN 1077-2626.

WATTENBERG, M.; VIEGAS, F. B. The Word Tree, an interactive visual concordance. IEEE Transactions on Visualization and Computer Graphics, IEEE Computer Society, Los Alamitos, CA, EUA, v. 14, n. 6, p. 1221-1228, nov. 2008. ISSN 1077-2626.

WISE, J. A. The ecological approach to text visualization. Journal of the American Society for Information Science and Technology, John Wiley \& Sons, New York, NY, EUA, v. 50, n. 13, p. 1224-1233, nov. 1999. ISSN 0002-8231.

WONG, C. Explorando Conjuntos de Dados Volumétricos Multi-dimensionais Variantes no Tempo Usando Projeções. 107 p. Dissertação (Mestrado) — Instituto de Ciências Matemáticas e de Computação, Universidade de São Paulo, São Carlos, SP, Brasil, 2012.

YANG, Y.; PIERCE, T.; CARBONELL, J. A study of retrospective and on-line event detection. In: 21st Annual International ACM SIGIR Conference on Research 8 Development on Information Retrieval, 1998. p. 28-36. ISBN 1-58113-015-5. 
ZHANG, J.; GHAHRAMANI, Z.; YANG, Y. A probabilistic model for online document clustering with application to novelty detection. In: SAUL, Lawrence K.; WEISS, Yair; BOTTOU, Léon (Ed.). Advances in Neural Information Processing Letters. Cambridge, MA, EUA: MIT, 2005. v. 17, p. 1617-1624.

ZHONG, S. Efficient streaming text clustering. Neural Networks, Elsevier Science, Oxford, Reino Unido, v. 18, n. 5-6, p. 790-798, jul.-ago. 2005. ISSN 0893-6080.

ZIPF, G. K. Human Behaviour and the Principle of Least Effort: An Introduction to Human Ecology. Cambridge, MA, EUA: Addison-Wesley, 1949. 578 p. ISBN 978-1614273127. 


\section{APÊNDICE}

\section{Algoritmo MONIC}

Seja $t_{1}, \ldots, t_{T}$ uma sequência de instantes no tempo relativos a um conjunto de dados $D$, onde $D_{i}(i=1, \ldots, T)$ é um subconjunto de instâncias de dados de $D$ acumuladas de $t_{1}$ até $t_{i}$, com $D_{T}$ sendo igual ao conjunto total de dados, de forma que $D_{i} \cap D_{j} \neq \emptyset$ para $i \neq j$. Para cada um desses subconjuntos cumulativos dos dados $D_{i}$ no instante de tempo $t_{i}$, têm-se um agrupamento $\tau_{i}$. O algoritmo MONIC (Spiliopoulou et al., 2006) identifica transições temporais que descrevem a evolução desses agrupamentos $\left\{\zeta_{1}, \ldots, \zeta_{T}\right\}$, como, por exemplo, a subdivisão de um grupo em dois ou mais grupos.

O Algoritmo 1 apresenta o algoritmo MONIC. Segundo Spiliopoulou et al. (2006), o algoritmo faz algumas inicializações para cada grupo $X \in \zeta_{i}$ e depois computa a sobreposição de $X$ com cada grupo de $\zeta_{i+1}$ (linha 7). Na linha 9, o grupo com maior sobreposição em relação a $X$ é selecionado, i.e., o grupo equivalente a $X$ em $\zeta_{i+1}$. Se $X$ não tem nenhum, grupos com sobreposição maior que $\tau_{\text {split }}$ em $\zeta_{i+1}$ são encontrados (linhas 11-13). Se não existem grupos com sobreposição maior que $\tau_{\text {split }}$ em $\zeta_{i+1}$, então $X$ é desapareceu (linhas 14-15).

Detecção de subdivisões envolve a construção de uma lista de grupos candidatos a subdivisão (linha 12), cuja união dever forma um grupo equivalente a $X$ (linhas 13 e 17). Caso a união dos candidatos a subdivisão não sejam equivalentes a $X$, então $X$ desapareceu (linha 21).

Os casos de junção e sobrevivência são inicialmente tratados juntos: os grupos de $\zeta_{i}$ e seus candidatos a sobrevivência são adicionados a uma lista de junções e sobrevivências (linha 23). Quando todos os grupos de $\zeta_{i}$ forem processados, essa lista de junções e sobrevivências estará completa. Então para cada grupo $Y \in z_{\text {eta }} a_{i+1}$, o algoritmo extrai da lista de junções e sobrevivências todos os grupos de $\zeta_{i}$ para os quais $Y$ é um candidato a sobrevivência (linha 
25). Se forem encontrados mais de um grupo para os quais $Y$ é um candidato a sobrevivência, então esses grupos sofreram uma junção para formar $Y$ (linhas 29-33). Caso contrário, um único grupo $X$ tem como candidato a sobrevivência $Y$, e portanto sobreviveu (linhas 30-32).

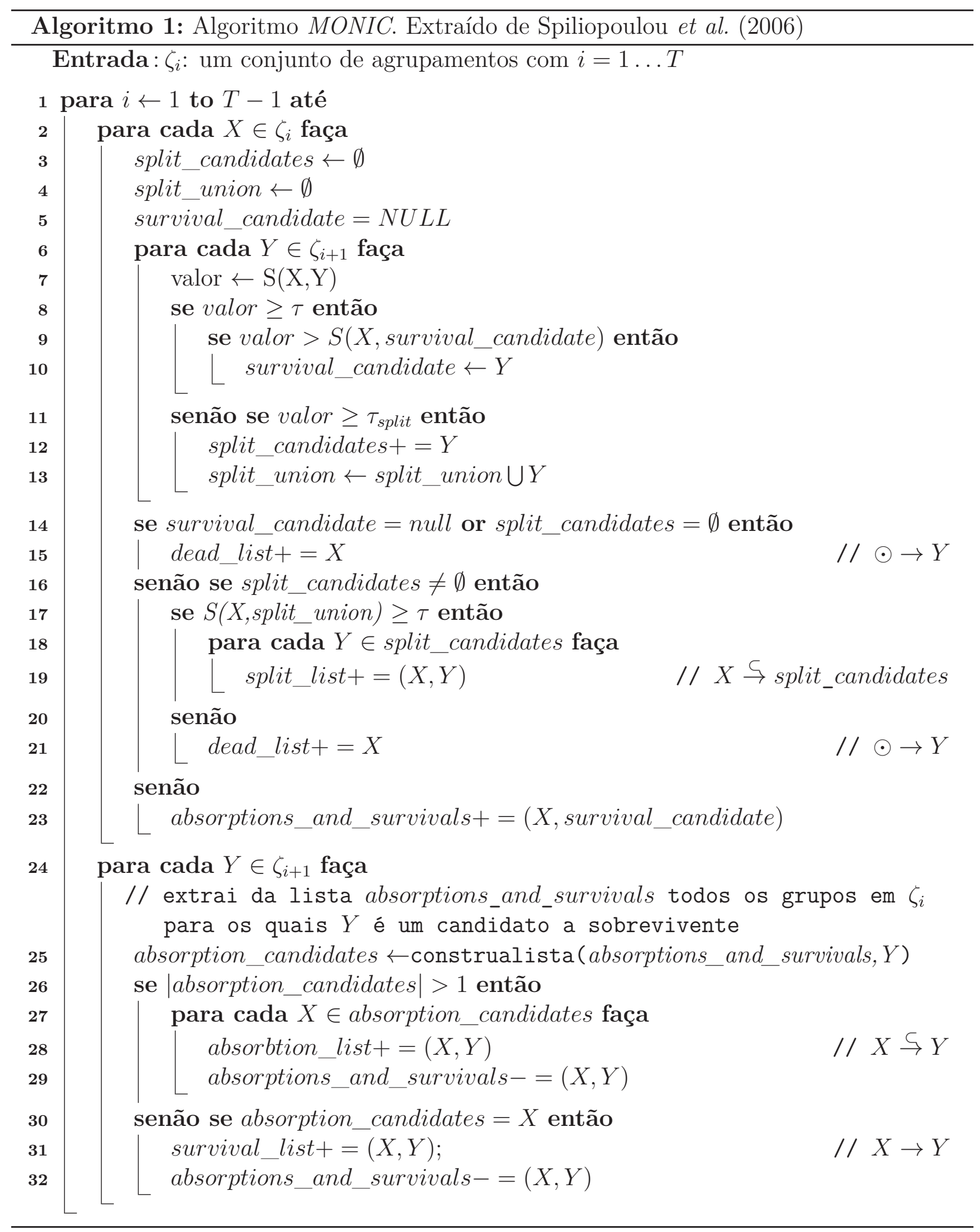




\section{APÊNDICE}

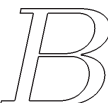

\section{Animação de Polígonos}

Supondo a sobrevivência de um grupo de docmentos $X$ que está presente no momento $t$ e seu equivalente $Y$ que está presente em $t+1$, é possível observar as seguintes modificações: alguns documentos foram removidos; alguns documentos foram adicionados; e a maior parte dos documentos que permaneceram, mas que podem ter tido sua posição alterada. Dados um polígono $\mathrm{Pol}_{t}$, que representa o grupo $X$ em $t$, e outro polígono $\mathrm{Pol}_{t+1}$, que representa o grupo $Y$ em $t+1$, a questão resume-se em como calcular a animação dada pela transformação do polígono $\mathrm{Pol}_{t}$ em $\mathrm{Pol}_{t+1}$ para os quadros intermediários da animação. Quando um documento a ser adicionado está se movendo em direção ao polígono ao qual deve ser adicionado e inicialmente sua posição de partida é fora deste polígono, o polígono deve lentamente se expandir na direção desse documento de forma a incluí-lo. Já quando um documento deve ser removido do polígono que representa seu grupo, o polígono deve lentamente se contrair na direção dos documentos que irão permanecer. Para a transição de sobrevivência e para outras transições devemos frequentemente calcular uma animação que transforma um polígono Pol $_{t}$ em outro Pol $_{t+1}$ pela adição e remoção de documentos.

A animação de um polígono $\operatorname{Pol}_{t}$ em outro $\operatorname{Pol}_{t+1}$ é dada por uma sequência de polígonos que contém um polígono para cada um dos $N$ quadros intermediários entre $t$ e $t+1$, a qual é calculada da seguinte forma:

\section{Entrada:}

- um grupo $X$ no momento de tempo $t$ que é equivalente ao grupo $Y$ em $t+1$;

- um conjunto de documentos adicionados $A=\left\{a_{i}, \ldots\right\}$ e um conjunto de documentos removidos $R=\left\{r_{i}, \ldots\right\}$ nessa transição; 
- um polígono $\mathrm{Pol}_{t}$, que representa $X$ em $t$ (ver Figura B.1a), e um polígono Pol $_{t+1}$, que representa $Y$ em $t+1$ (ver Figura B.1d);

- $N$ quadros intermediários entre $t$ e $t+1$;

- uma tabela hash que para cada documento adicionado ou removido define um índice, i.e., $f\left(x_{i}\right)=$ index, $\forall x_{i} \in A \cup R$. Essa tabela hash deve ser inicializada com 0 para todas as entradas, i.e., $f\left(x_{i}\right)=0, \forall x_{i} \in A \cup R$

- uma lista $P O L$ de polígonos, inicialmente vazia;

- uma lista $L$ de posições no espaço bidimensional, também inicialmente vazia.

2.Para cada frame intermediário com índice $k$ no intervalo [1..N]:

2.1.Adicione à lista $L$ a posição atual de todos os documentos que irão permanecer no grupo. Calcule um polígono auxiliar Pol $_{\text {aux }}$ com base nas posições em $L$. Polígonos auxiliares são representados por polígonos com borda amarela e pontilhada, como nas Figuras B.1b e B.1c.

2.2.Para cada documento $r_{i}$ que deve ser removido:

2.2.1.Se $r_{i}$ encontra-se fora da área definida por $P$ ol $l_{\text {aux }}$ :

2.2.1.1.Se $f\left(r_{i}\right)=0$, atualize para $f\left(r_{i}\right)=k$.

2.2.1.2. Calcule um segmento de reta que parte do ponto de $P_{a u x}$ mais próximo de $r_{i}$ até $r_{i}$. Calcule um vértice falso cuja posição é igual a coordenada correspondente a uma fração de $1-\frac{k-f\left(r_{i}\right)}{N-f\left(r_{i}\right)}$ do segmento de reta, adicionando a posição desse vértice falso a lista $L$. Ver Figura B.1b.

2.2.2.Se $r_{i}$ encontra-se dentro da área definida por $P o l_{\text {aux }}$, adicione sua posição atual a lista $L$.

2.3.Para cada documento $a_{i}$ que deve ser adicionado:

2.3.1.Se $a_{i}$ encontra-se dentro da área definida por $P o l_{\text {aux }}$, adicione sua posição atual a lista $L$.

2.3.2.Se $a_{i}$ encontra-se fora da área definida por $P_{0} l_{a u x}$ e se sua posição atual está a menos de 20 pixels de distância de $P_{\text {aux }}$ :

2.3.2.1.Se $f\left(a_{i}\right)=0$, atualize para $f\left(a_{i}\right)=k$.

2.3.2.2. Calcule um segmento de reta que parte de $a_{i}$ até o ponto de $P_{a u x}$ mais próximo de $a_{i}$. E calcule um vértice falso cuja posição é igual a coordenada correspondente a uma fração de $\frac{k-f\left(a_{i}\right)}{N-f\left(a_{i}\right)}$ do segmento de reta, adicionando a posição desse vértice falso a lista $L$. Ver Figura B.1c.

2.4. Calcule um polígono utilizando como base as posições presentes na lista $L$, e o adicione a lista $P O L$. Esvazie a lista $L$.

2.5.Saída: A sequência de polígonos dadas pela lista $P O L$.

Vértices falsos, polígonos auxiliares e segmentos de reta são utilizados somente para o cálculo da animação de um polígono, e não devem ser incluídos na representação visual. 


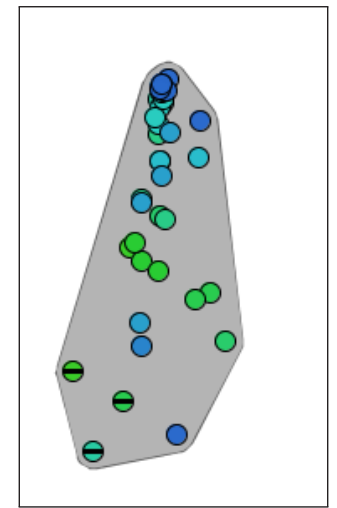

(a) Polt.

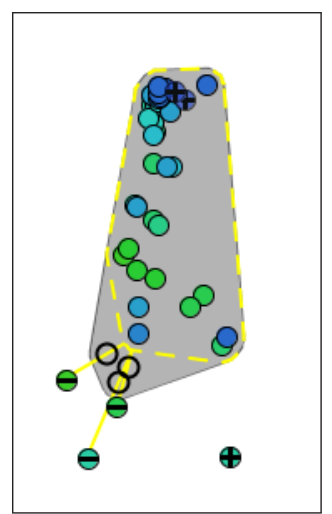

(b) Frame intermediário.

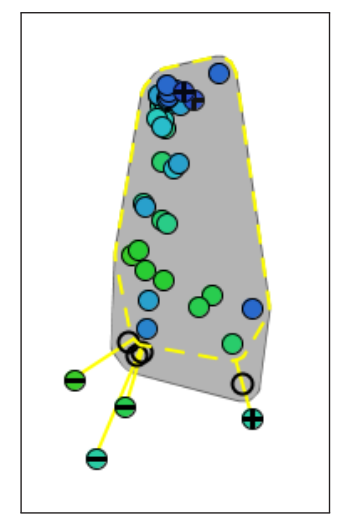

(c) Frame intermediário.

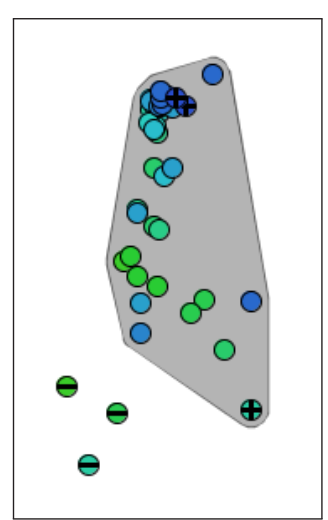

(d) Pol $_{t+1}$.

Figura B.1: Animação que transforma o polígono $\mathrm{Pol}_{t}$ em $\mathrm{Pol}_{t+1}$ para indicar a sobrevivência de um grupo. Documentos a serem removidos com sinal '-' em seu interior e documentos a serem adicionados com sinal ' + ' em seu interior. Vértices falsos representados por círculos pretos, polígonos auxiliares representados por polígonos com borda amarela e pontilhada, e segmentos de reta em amarelo. 